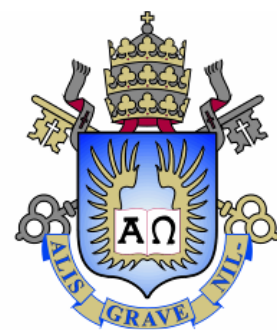

Julio Cesar Spadotto

\title{
Estudo Micro/Nanoanalítico das Transformações Descontínuas e Identificação de Fases na Liga 33 à base de $\mathrm{Cr}-\mathrm{Fe}-\mathrm{Ni}$
}

\section{Tese de Doutorado}

\begin{abstract}
Tese apresentada como requisito parcial para obtenção do grau de Doutor pelo Programa de Pós-graduação em Engenharia de Materiais e de Processos Químicos e Metalúrgicos do Departamento de Engenharia Química e de Materiais da PUC-Rio.
\end{abstract}

Orientador: Prof. Guillermo Solórzano-Naranjo Co-orientadora: Prof ${ }^{a}$. Grace Burke (University of Manchester-UK)

Rio de Janeiro Julho de 2019 


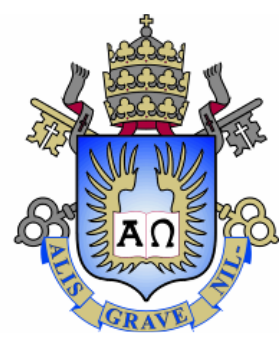

Julio Cesar Spadotto

\section{Estudo Micro/Nanoanalítico das Transformações Descontínuas e Identificação de Fases na Liga 33 à base de $\mathrm{Cr}-\mathrm{Fe}-\mathrm{Ni}$}

Tese apresentada como requisito parcial para obtenção do grau de Doutor pelo Programa de Pós-graduação em Engenharia de Materiais e de Processos Químicos e Metalúrgicos do Departamento de Engenharia de Materiais da PUC-Rio. Aprovada pela Comissão Examinadora abaixo.

\section{Prof. Guillermo Solórzano-Naranjo} Orientador

Departamento de Engenharia de Materiais - PUC-Rio

Prof. Grace Burke

Co-orientadora

School of Materials - University of Manchester - UK

Prof. Marcelo Henrique Prado da Silva Departamento de Engenharia de Materiais - IME/RJ

Prof. Bojan Marinkovic

Departamento de Engenharia de Materiais - PUC-Rio

Prof. Jean Dille

ULB-Bélgica

Dr. Bráulio Archanjo

Divisão de Metrologia de Materiais - INMETRO/RJ 
Todos os direitos reversados. É proibida a reprodução total ou parcial do trabalho sem autorização da universidade, do autor e do orientador.

\section{Julio Cesar Spadotto}

Graduado em Física pela Universidade Estadual de Londrina (UEL) em 2012. Mestre em Engenharia de Materiais e de Processos Químicos e Metalúrgicos (PUC-Rio) em 2015.

Ficha Catalográfica

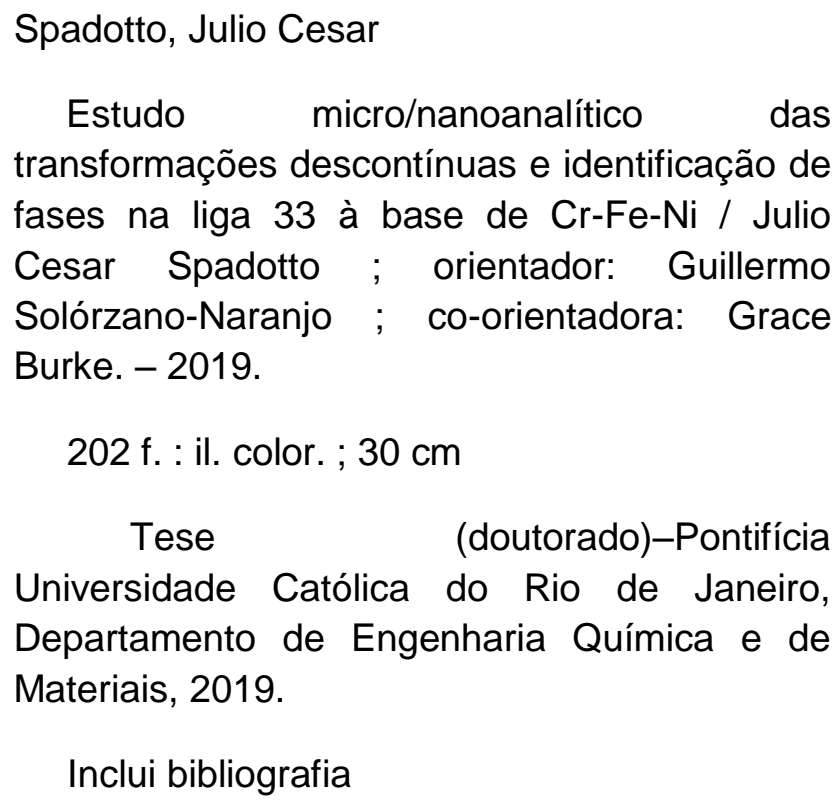

Inclui bibliografia

1. Engenharia Química e de Materiais Teses. 2. Liga 33. 3. Processos de precipitação. 4. Reação de precipitação descontínua. 5. DIGM. 6. Microscopia eletrônica de transmissão analítica. I. Solórzano, Guillermo. II. Burke, Grace. III. Pontifícia Universidade Católica do Rio de Janeiro. Departamento de Engenharia Química e de Materiais. IV. Título. 
Dedicado a meus avós, Plácido e Leonilda, Otávio (in memoriam) e Rosa, e para meus pais, Antonio e Marilisa pelo apoio e pela confiança. 


\section{Agradecimentos}

Ao meu orientador, Prof. Guillermo Solórzano pela sugestão do tema da tese, pelo apoio e confiança durante todo o doutorado e, principalmente pelos ensinamentos no microscópio eletrônico de transmissão.

À minha co-orientadora, Prof. Grace Burke pela receptividade e oportunidade concedida para a realização da pesquisa experimental na School of Materials da University of Manchester-UK.

Em especial, um agradecimento à minha companheira Naiara pelo carinho, amor e muita paciência durante esta trajetória.

Ao LabNano-CBPF, na figura do Prof. André Pinto (in memoriam) e do Prof. André Rossi, pela disponibilidade de acesso aos microscópios eletrônicos e equipamentos de preparação de amostras. Em especial à Dra. Cilene Labre pelos ensinamentos e treinamento nos microscópios, e principalmente pelo apoio e amizade.

Ao LaMAR-UFF, na figura do Prof. Yutao Xing, pela disponibilidade de acesso ao microscópio eletrônico de transmissão.

Ao Prof. Masashi Watanabe da Lehigh University-USA e ao Prof. Jean Dille da Coppe/UFRJ pelas análises de microscopia eletrônica de transmissão analítica e pela colaboração consolidada pela publicação de um artigo científico.

Novamente um agradecimento à minha família que mais do que ninguém sabem o quanto foi difícil essa conquista. Em especial à minha Mãe e meu Pai. Muito obrigado.

Aos Professores, funcionários e colegas da PUC pelo conhecimento transmitido e auxilio durante os quatro anos de doutorado. Aos técnicos Yuri Nascimento e Henrique Chayin, do Laboratório de Análise Térmica- LAT (PUCRio) e Asafe Bittencourt do LMTT, da PUC-Rio pelo auxilio prestado. Em especial à Dra. Liying Liu e ao Prof. Eduardo Amarante pela amizade e apoio durante todo o doutorado.

E sem esquecer do Prof. Pedro Henrique Arruda Aragão (UEL) e da Prof ${ }^{a}$. Célia Guadalupe (UEL) que acreditaram em mim num período que poucos acreditavam. Obrigado.

Ao grupo de pesquisa da Prof. Grace Burke, pela receptividade e apoio durante todo meu período de doutorado-sanduíche na Universidade de 
Manchester-UK, ao Dr. Octav Ciuca, Dra. Elisabeth Francis, Dr. Litao Chang e ao aluno de doutorado Liberato Volpe. Em especial à Matt Smith pelo treinamento nos microscópios eletrônicos de transmissão.

Às agências de fomento, CNPq e à PUC-Rio, pelos auxílios concedidos, sem os quais este trabalho não poderia ter sido realizado.

O presente trabalho foi realizado com apoio da Coordenação de Aperfeiçoamento de Pessoal de Nível Superior - Brasil (CAPES) - Código de Financiamento 001. 


\section{Resumo}

Spadotto, Julio Cesar; Solórzano-Naranjo, Guillermo (Orientador); Burke, Grace (Co-orientadora). Estudo Micro/Nanoanálitico das Transformações Descontínuas e Identificação de Fases na Liga 33 à base de Cr-Fe-Ni. Rio de janeiro, 2019. 202p. Tese de Doutorado Departamento de Engenharia Química e de Materiais, Pontifícia Universidade Católica do Rio de Janeiro.

A presente tese tem como objetivo estudar as reações descontínuas que ocorreram nos contornos de grão (CG) sob condições de envelhecimento a altas temperaturas e identificar as fases que precipitam em função do tempo em uma liga de alto teor de $\mathrm{Cr}$ e $\mathrm{Ni}$ - Liga 33, tendo em vista o efeito destas transformações nas potenciais aplicações em indústrias de alto desempenho. Amostras na condição como recebida foram submetidas a tratamentos isotérmicos de envelhecimento a $700{ }^{\circ} \mathrm{C}, 800{ }^{\circ} \mathrm{C}$ e $900{ }^{\circ} \mathrm{C}$. Ênfase foi dada ao estudo do envelhecimento a $800{ }^{\circ} \mathrm{C}$ em intervalos de tempo entre 10 minutos e 100 horas com o objetivo de promover fenômenos de precipitação nos modos convencional e descontínua. A caracterização microestrutural foi realizada por microscopia óptica (MO), microscopia eletrônica de varredura (MEV) analítica por espectroscopia por dispersão de energia de raios-X (XEDS), difração de elétrons retroespalhados (EBSD) e microscopia eletrônica de transmissão (MET) no modo convencional, utilizando contraste de difração, e no modo analítico (STEM/XEDS). Resultados obtidos por STEM/XEDS e difração de elétrons mostraram que a transformação descontínua, pela partição de solutos, gera colônias de precipitação descontínua (PD) concomitante à migração do CG e resulta na precipitação de cinco diferentes fases dentro de uma mesma colônia de PD: (1) carbeto- $\mathrm{M}_{23} \mathrm{C}_{6}$ rico em $\mathrm{Cr}$ com estrutura $\mathrm{CFC}$; (2) fase- $\eta$ enriquecida em Si com estrutura cúbica-diamante; (3) fase $\alpha$ rica em $\mathrm{Cr}$ com estrutura CCC; (4) fase intermetálica $\sigma$ com estrutura tetragonal e (5) nitreto- $\mathrm{M}_{2} \mathrm{~N}$ rico em $\mathrm{Cr}$ com estrutura hexagonal. Em geral, as colônias de PD na Liga 33 evoluem no envelhecimento seguindo a sequência, a saber: nos estágios iniciais do processo ocorre precipitação intergranular (carbeto- $\mathrm{M}_{23} \mathrm{C}_{6}$ e fase- $\eta$ ) no $\mathrm{CG}$ original; com o aumento no tempo de envelhecimento, os contornos migraram alimentados pela difusão de soluto num processo conhecido como DIGM ("diffusion-induced grain boundary migration"), enquanto precipitados da fase $\alpha$-Cr nuclearam adjacente ao CG e cresceram com morfologia lamelar acompanhando a migração do contorno. 
desenvolvendo, assim, as colônias de PD. Eventualmente, a fase- $\eta$ também precipita no interior da colônia e na frente de reação. Nos estágios finais do processo de crescimento das colônias de PD ocorre a formação da fase- $\sigma$ na frente de reação da $\mathrm{PD}$ e, posteriormente, a formação do nitreto- $\mathrm{M}_{2} \mathrm{~N}$ na frente de reação e dentro da colônia. Foi verificado que a reação de PD é controlada, primeiramente, pela difusão de $\mathrm{CG}$ do $\mathrm{Cr}$ e, com o tempo de reação pela difusão de volume do $\mathrm{Cr}$, o que resultou em um crescimento no estado não-estacionário da reação. Além da ocorrência de cinco fases precipitadas dentro da mesma colônia, outra característica marcante da reação de PD na Liga 33 refere-se à consistente evidência que a fase inicialmente precipitada nos $\mathrm{CG}$ (carbeto- $\mathrm{M}_{23} \mathrm{C}_{6}$ ) é diferente da fase precipitado com morfologia lamelar (fase $\alpha-\mathrm{Cr}$ ) dentro da colônia. Tal observação constitui a primeira evidência para o fenômeno de PD envolvendo colônias multi-fases em materiais multicomponentes estruturais.

\section{Palavras-chave}

Liga 33; processos de precipitação; reação de precipitação descontínua; DIGM; microscopia eletrônica de transmissão analítica. 


\section{Abstract}

Spadotto, Julio Cesar; Solórzano-Naranjo, Guillermo (Advisor); Burke, Grace (Co-advisor). Micro/Nanoanalytical Study of Discontinuous Transformations and Phases Identification in Alloy 33 based on $\mathrm{Cr}-\mathrm{Fe}-\mathrm{Ni}$. Rio de Janeiro, 2019. 202p. Tese de Doutorado - Departamento de Engenharia Química e de Materiais, Pontifícia Universidade Católica do Rio de Janeiro.

This thesis aims at study the discontinuous reactions taking place at grain boundaries (GB) under high-temperature aging conditions and to identify the precipitated phases as a function of the time in a $\mathrm{Cr}-\mathrm{Fe}-\mathrm{Ni}$ alloy - Alloy 33, in view of the deleterious effect of these transformations on potential applications of this alloy in high-performance industries. Samples in the as-received condition were submitted to isothermal aging treatments at $700{ }^{\circ} \mathrm{C}, 800{ }^{\circ} \mathrm{C}$ and $900{ }^{\circ} \mathrm{C}$. Emphasis was given to the study of aging at $800{ }^{\circ} \mathrm{C}$ in time intervals between 10 minutes and 100 hours in order to promote precipitation phenomena in the conventional and discontinuous modes. The microstructural characterization was carried out by light optical microscopy (LOM), analytical scanning electron microscopy (SEM) by X-ray energy dispersive spectroscopy (XEDS), electron backscatter diffraction (EBSD) and transmission electron microscopy (TEM) under conventional mode using diffraction contrast and analytical mode (STEM/XEDS). Results obtained by STEM/XEDS and electron diffraction revealed that the discontinuous transformation, by solutes partitioning, generates discontinuous precipitation (DP) colonies concomitant with GB migration and results in the precipitation of five different phases within a single DP colony: (1) Cr-rich $\mathrm{M}_{23} \mathrm{C}_{6}$-carbide with FCC structure, (2) Si-enriched $\eta$-phase with diamondcubic structure, (3) Cr-rich $\alpha$-phase with BCC structure, (4) intermetallic $\sigma$-phase with tetragonal structure, and (5) $\mathrm{Cr}$-rich $\mathrm{M}_{2} \mathrm{~N}$-nitride with hexagonal structure. In summary, DP colonies in Alloy 33 upon aging at $800{ }^{\circ} \mathrm{C}$ evolve according the following the sequence: in the initial stages of the process intergranular precipitation $\left(\mathrm{M}_{23} \mathrm{C}_{6}\right.$-carbide and n-phase) occurs at original $\mathrm{GB}$; with the increase in aging time, the boundaries migrated fed by solute atoms in a process known as diffusion-induced grain boundary migration (DIGM), whereas $\alpha-\mathrm{Cr}$ phase precipitates have nucleated adjacent to the GB and grew with lamellar morphology accompanying the migration of the boundary thereby developing the 
DP colonies. Eventually, the n-phase also precipitates both within the colony and at the DP reaction-front. Over the final stages of the DP colonies growth process occurs the nucleation and growth of the $\sigma$-phase at the GB reaction-front and, later, $\mathrm{M}_{2} \mathrm{~N}$-nitride precipitates also at the reaction-front and within the DP colony. It was verified that the DP reaction growth is controlled, initially by GB diffusion of $\mathrm{Cr}$ and, with the progress of reaction time by the volume diffusion of the $\mathrm{Cr}$, which resulted in a non-steady state growth process. In addition to the occurrence of five precipitated phases within the same colony, another striking feature of the DP reaction in Alloy 33 refers to the consistent evidence that the phase initially precipitated at original $\mathrm{GB}$ position $\left(\mathrm{M}_{23} \mathrm{C}_{6}\right.$-carbide $)$ is different from the precipitated phase with lamellar morphology ( $\alpha$-Cr phase) within the colony. This observation constitutes the first evidence for the DP phenomenon resulting in multi-phase DP colonies in multicomponent structural materials.

\section{Keywords}

Alloy 33; precipitation processes; discontinuous precipitation reaction; DIGM; analytical scanning/transmission electron microscopy. 


\section{Sumário}

1. Introdução

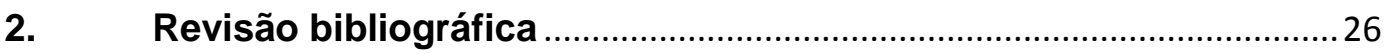

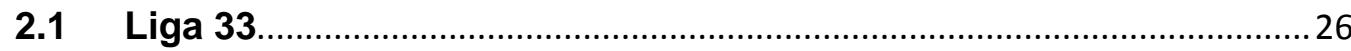

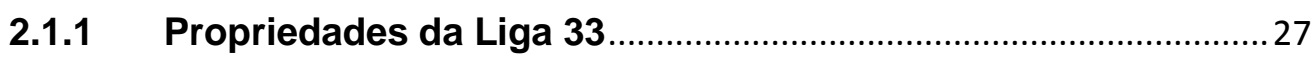

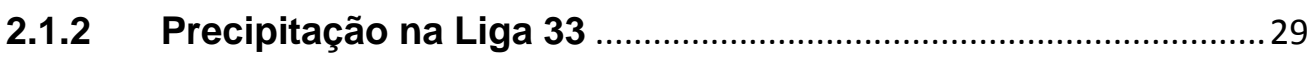

2.2 Processos de Precipitação em Sistemas Metálicos ………................. 30

2.2.1 Precipitação Convencional em Sistemas Multicomponentes .. 31

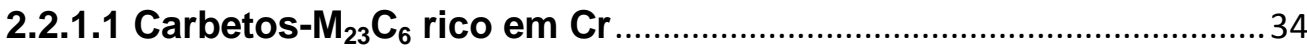

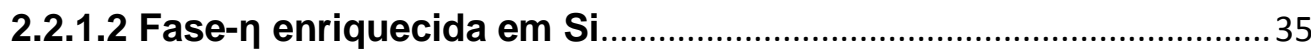

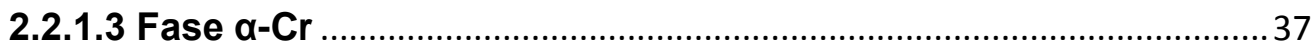

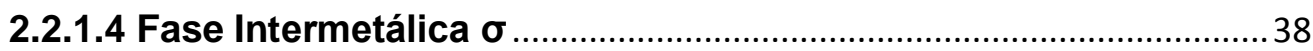

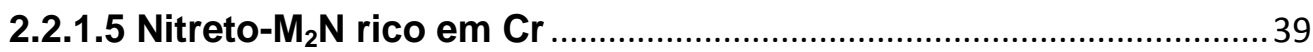

2.3 Fenômeno de Precipitação Descontínua .................................................. 40

2.3.1 Precipitação Descontínua em Sistemas Binários...............................4 42

2.3.2 Precipitação Descontínua em Sistemas Multicomponentes ..........50

2.3.2.1 Ligas contendo Solutos Substitucionais e Intersticiais ...............50

2.3.2.2 Precipitação Descontínua em Ligas à base de Ni com Matriz

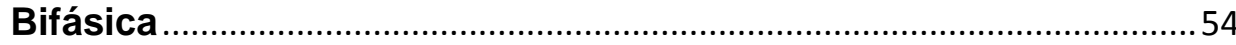

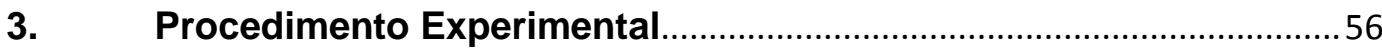

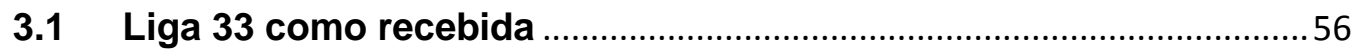

3.2 Tratamentos Térmicos de Envelhecimento ….............................................56

3.3 Técnicas de Caracterização Micro/NanoEstrutural e Analítica ..............56

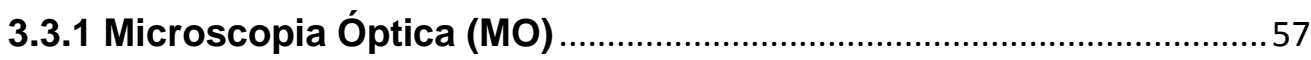

3.3.2 Microscopia Eletrônica de Varredura (MEV) …………......................58

3.3.2.1 Difração de Elétrons Retroespalhados (EBSD)................................60

3.3.3 Microscopia Eletrônica de Transmissão (MET) ………………….......63

3.3.3.1 Microscopia Eletrônica de Transmissão Convencional (CTEM, "Conventional Transmission Electron Microscopy") ..........................63

3.3.3.2 Microscopia Eletrônica de Transmissão e Varredura (STEM, "Scanning Transmission Electron Microscopy")..................................66

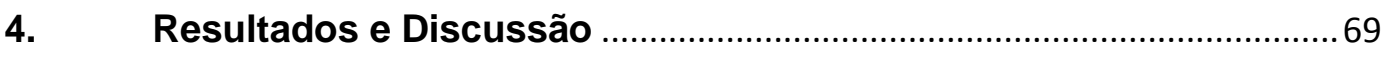

4.1 Microestrutura da Liga 33 na condição como recebida ......................69

4.2 Estágios Iniciais dos Fenômenos de Precipitação do CG na Liga 33 Envelhecida a $800^{\circ} \mathrm{C}$. 
4.3 Precipitação Descontínua no envelhecimento a $800{ }^{\circ} \mathrm{C}$ por $1 \mathrm{~h}$ até 100 h - Observações por MO e MEV.

4.4 Fenômenos de Precipitação no CG e Identificação das Fases na Liga 33 envelhecida a $800^{\circ} \mathrm{C}$ : Análise por MET/STEM

4.4.1 Precipitação no envelhecimento por $1 \mathrm{~h}$ até $10 \mathrm{~h}$. .115

4.4.2 Precipitação no envelhecimento por $20 \mathrm{~h}$

4.4.3 Precipitação no envelhecimento por $50 \mathrm{~h}$ e $100 \mathrm{~h}$ 154

4.5 Relação entre a Desorientação Angular no CG e a Ocorrência da Reação de PD na Liga 33 envelhecida a $800{ }^{\circ} \mathrm{C}$ (EBSD) ............................ 168

4.6 Características da Cinética de PD na Liga 33 envelhecida a $800{ }^{\circ} \mathrm{C} . .174$

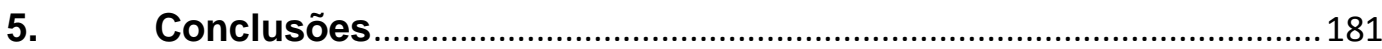

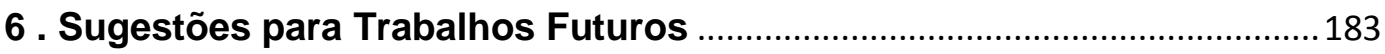

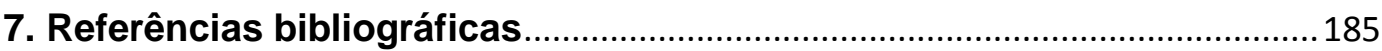

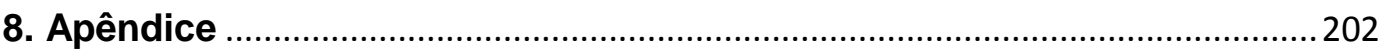

8.1 Publicações Geradas a partir da presente tese de doutorado .............202 


\section{Lista de Figuras}

Figura 2.1 - Comparação do limite de escoamento e resistência à tração da Liga 33 e outras ligas utilizadas em ambientes agressivos [26][46]. A seta indica as propriedades da Liga 33

Figura 2.2 - Variação de $\Delta G$ com o raio crítico para a nucleação homogênea. Existe uma barreira energética $\Delta G^{*}$ para que a transformação ocorra (adaptado de [62])........ 32 Figura 2.3 - Diagrama esquemático da precipitação descontínua ocorrendo no contorno de grão (CG). FR: frente de reação; $\alpha_{0}$ : matriz supersaturada em soluto; $\alpha$ : matriz empobrecida em soluto; $\beta$ : precipitados lamelares descontínuos (adaptado de [23]).

Figura 2.4 - Ilustração do mecanismo "pucker" de iniciação da PD proposto por Tu e Turnbull. $\alpha_{0} \rightarrow$ matriz supersaturada; $\alpha$ ' $\rightarrow$ matriz empobrecida em soluto; $\beta \rightarrow$ fase precipitada (adaptado de [23])

Figura 2.5 - llustração do mecanismo de Fournelle e Clark para a iniciação da reação de PD. $\alpha_{0}$ : matriz supersaturada; $\alpha$ : matriz empobrecida em soluto; $\beta$ : fase precipitada; CG: contorno de grão; $\rightarrow$ representa o CG em movimento; v: velocidade de propagação do CG (adaptado de [181]).

Figura 2.6 - llustração do mecanismo de iniciação da PD proposto por Solórzano e Lopes. $\alpha_{0}$ : matriz supersaturada; $\alpha$ ': matriz empobrecida em soluto; $\beta$ : precipitado; $\rightarrow$ representa o CG em movimento; v: velocidade de propagação do CG (adaptado de [179].

Figura 2.7 - Morfologias possíveis da frente de reação durante o crescimento de acordo com Hillert [190]. Em (a) o crescimento dos precipitados empurra o contorno e em (b) o contorno avançando conduz o crescimento das lamelas. $\alpha_{0}$ : matriz supersaturada em soluto; $\alpha$ ': matriz empobrecida em soluto (adaptado de [190]).

Figura 2.8 - llustração do mecanismo de crescimento em $S$ proposto por Fournelle. $C G \rightarrow$ contorno de grão (adaptado de [192]).

Figura 2.9 - Ilustração do crescimento em $S$ resultando na morfologia de dupla camada. CG $\rightarrow$ contorno de grão (adaptado de [24])

Figura 3.1 - Imagens obtidas no MO nos modos (a) campo claro e (b) campo escuro da Liga 33 envelhecida a $800{ }^{\circ} \mathrm{C}$ por 2 h. CG: contorno de grão; PD: precipitação descontínua.

Figura 3.2 - Sinais gerados na interação do feixe de elétrons com a amostra no MEV (adaptado de [220]).

Figura 3.3 - Volume de interação dos sinais emitidos pela amostra no MEV. As dimensões na figura são ilustrativas (adaptado de [257]).

Figura 3.4 - Imagens de MEV da Liga 33 envelhecida a $800{ }^{\circ} \mathrm{C}$ por $50 \mathrm{~h}$ obtidas com (a) elétrons secundários e (b) elétrons retroespalhados.

Figura 3.5 - Diagrama esquemático mostrando o conjunto experimental simplificado para observações por EBSD (adaptado de [224]).

Figura 3.6 - Sinais gerados na interação do feixe de elétrons com a amostra no MET (adaptado de [220])

Figura 3.7 - llustração do diagrama de raios mostrando o processo de obtenção de imagens em (a) BF, (b) DF e (c) CDF no modo contraste de difração (adaptado de [220])

Figura 3.8 - Par de imagens no modo (a) BF e (b) DF da Liga 33 envelhecida a 800 ${ }^{\circ} \mathrm{C}$ por $1 \mathrm{~h}$ mostrando um carbeto $\mathrm{M}_{23} \mathrm{C}_{6}$ com forma de "L" no $\mathrm{CG}$ e o respectivo padrão SAED obtido da interface precipitado/matriz (indicado pelo círculo).

Figura 3.9 - llustração do esquema de detectores no modo STEM (adaptado de [220]) 
Figura 4.1 - Imagem da Liga 33 na condição como recebida por (a) MO-BF e (b) MET-BF.

Figura 4.2 - Imagens de STEM-BF da Liga 33 na condição como recebida mostrando vários $C G$ e os correspondentes mapas elementares obtidos por $\mathrm{STEM} / \mathrm{XEDS}$ do $\mathrm{Cr}$, $\mathrm{Fe}$, and $\mathrm{Ni}$ em duas diferentes regiões da amostra.

Figura 4.3 - Imagens de MEV-SE da Liga 33 envelhecida a $800^{\circ} \mathrm{C}$ por (a) 10 min e (b) $30 \mathrm{~min}$.

Figura 4.4 - (a) e (b) Pares de imagens de MET-BF/CDF de um carbeto- $\mathrm{M}_{23} \mathrm{C}_{6}$ no CG formado durante o envelhecimento a $800{ }^{\circ} \mathrm{C}$ por 10 min e (c) padrão SAED obtido no eixo de zona [001] mostrando uma R.O. cubo-a-cubo, $001 \mathrm{M} 23 \mathrm{C} 6 / /$ $\left[\begin{array}{lll}0 & 0 & 1\end{array}\right]$ matriz $-C F C$. As setas em (b) indicam discordâncias na interface carbeto$\mathrm{M}_{23} \mathrm{C}_{6} /$ matriz $\mathrm{CFC}$. $\mathrm{O}$ quadrado vermelho é referente à matriz-CFC e o quadrado amarelo é referente ao carbeto- $\mathrm{M}_{23} \mathrm{C}_{6}$.

Figura 4.5 - (a) Imagem de STEM-BF de um ponto triplo na Liga 33 envelhecida a $800{ }^{\circ} \mathrm{C}$ por $10 \mathrm{~min}$; (b) imagem de STEM-BF obtida da região indicada pelo retângulo vermelho em (a); (c) imagens de MET-BF/CDF do carbeto- $\mathrm{M}_{23} \mathrm{C}_{6}$ no $C G$ e (d) padrão SAED mostrando uma relação cubo-a-cubo, [101]M23C6 // [101]matriz - CFC. O losango vermelho é referente à matriz-CFC e o losango amarelo é referente ao carbeto- $\mathrm{M}_{23} \mathrm{C}_{6}$.

Figura 4.6 - Imagem de STEM-BF da mesma região mostrada na Figura 4.5b e os correspondentes mapas elementares por STEM-XEDS do $\mathrm{Cr}$, Fe, Ni, Mo, Si, C, and N.

Figura 4.7 - Imagem de MET-BF mostrando precipitados no CG bem como a migração em algumas regiões deste contorno na Liga 33 envelhecida a $800{ }^{\circ} \mathrm{C}$ por 10 min. O quadrado vermelho indica a região mostrada na Figura 4.8.

Figura 4.8 - (a) e (b) Imagens de MET-BF/CDF mostrando a migração do CG na Liga 33 envelhecida a $800{ }^{\circ} \mathrm{C}$ por 10 min e padrões SAED obtidos da matriz CFC e da interface carbeto- $\mathrm{M}_{23} \mathrm{C}_{6} /$ matriz CFC, respectivamente; e (c) espectro pontual obtido por STEM/XEDS do carbeto mostrado em (a).

Figura 4.9 - Imagem de STEM-BF de um carbeto- $\mathrm{M}_{23} \mathrm{C}_{6}$ no $\mathrm{CG}$ na Liga 33 envelhecida a $800{ }^{\circ} \mathrm{C}$ por 10 min e o correspondente mapa elementar obtido por STEM/XEDS do $\mathrm{Cr}$. A seta indica o início da migração do CG.

Figura 4.10 - Imagem de STEM-BF de um carbeto- $\mathrm{M}_{23} \mathrm{C}_{6}$ na Liga 33 envelhecida a $800{ }^{\circ} \mathrm{C}$ por $10 \mathrm{~min}$ e os correspondentes mapas elementares obtidos por STEM/XEDS do $\mathrm{Cr}, \mathrm{Fe}, \mathrm{Ni}, \mathrm{Si}, \mathrm{Mo}, \mathrm{C}$, and $\mathrm{N}$. As setas indicam o início da migração do $C G$ em direções opostas.

Figura 4.11 - Imagens de MET-BF/CDF mostrando a migração do CG para ambos os lados do contorno na Liga 33 envelhecida a $800{ }^{\circ} \mathrm{C}$ por 30 min e um padrão SAED obtido a partir da região indicada pelo círculo. Os precipitados no CG foram identificados como carbetos $-\mathrm{M}_{23} \mathrm{C}_{6}$ com R.O. [112]M23C6 //[112]matriz - CFC com a matriz CFC. As setas indicam regiões facetadas do $C G$ avançando. $O$ retângulo vermelho é referente à matriz-CFC e o retângulo amarelo é referente ao carbeto- $\mathrm{M}_{23} \mathrm{C}_{6}$.

Figura 4.12 - Imagem de STEM-BF mostrando um CG decorados por precipitados na Liga 33 envelhecida a $800^{\circ} \mathrm{C}$ por 30 minutos.

Figura 4.13 - Imagens de STEM-BF/HAADF obtidas da região indicada pelo retângulo vermelho na Figura 4.12 e os correspondentes mapas elementares obtidos por STEM/XEDS do $\mathrm{Cr}, \mathrm{Fe}, \mathrm{Ni}, \mathrm{Si}, \mathrm{Mo}, \mathrm{C}$, and $\mathrm{N}$. O quadrado indica a região mostrada na Figura 4.14 e a seta indica a região onde ocorreu o enriquecimento em Si. 
Figura 4.14 - Imagens de STEM-BF/HAADF obtida da região indicada pelo quadrado vermelho na Figura 4.13 e os correspondentes mapas elementares obtidos por STEM/XEDS do $\mathrm{Cr}, \mathrm{Fe}, \mathrm{Ni}, \mathrm{Si}, \mathrm{Mo}, \mathrm{C}$, and $\mathrm{N}$.

Figura 4.15 - Imagens de STEM-BF/DF obtidas da região indicada pelo quadrado amarelo na Figura 4.12 e os correspondentes mapas elementares obtidos por STEM/XEDS do $\mathrm{Cr}, \mathrm{Fe}, \mathrm{Ni}, \mathrm{Si}, \mathrm{Mo}, \mathrm{C}$, and $\mathrm{N}$. O quadrado indica a região mostrada na Figura 4.16 e a seta indica a região onde ocorreu o enriquecimento em $\mathrm{Si}$.

Figura 4.16 - (a) Imagens de STEM-BF/DF obtidas a partir da região indicada pelo quadrado vermelho na Figura 4.15 e os correspondentes mapas elementares obtidos por STEM/XEDS do $\mathrm{Cr}, \mathrm{Fe}, \mathrm{Ni}, \mathrm{Si}, \mathrm{Mo}, \mathrm{C}$, and $\mathrm{N}$

Figura 4.17 - Imagens de STEM-BF/HAADF mostrando os estágios iniciais da reação de PD na Liga 33 envelhecida a $800{ }^{\circ} \mathrm{C}$ por 30 min e os correspondentes mapas elementares obtidos por STEM/XEDS do $\mathrm{Cr}, \mathrm{Fe}, \mathrm{Ni}, \mathrm{Si}, \mathrm{Mo}, \mathrm{C}$ e N. O quadrado indica a região mostrada na Figura 4.18.

Figura 4.18 - Imagens de STEM-BF/HAADF obtidas da região indicada pelo quadrado vermelho na Figura 4.17 e os correspondentes mapas elementares obtidos por STEM/XEDS do $\mathrm{Cr}, \mathrm{Fe}, \mathrm{Ni}, \mathrm{Si}, \mathrm{Mo}, \mathrm{C}$ e N.

Figura 4.19 - Imagem de STEM-BF mostrando um CG decorado por precipitados na Liga 33 envelhecida a $800{ }^{\circ} \mathrm{C}$ por 30 min e uma imagem de STEM-BF obtida da região indicada pelo retângulo vermelho em (a) e os correspondentes mapas

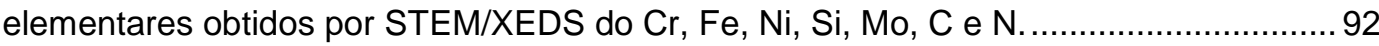
Figura 4.20 - Imagem de STEM-BF mostrada na Figura 4.19 e dois espectros pontuais obtidos por STEM/XEDS dos precipitados indicados pelos números 1 e 2 ........93 Figura 4.21 - Imagens de MO-BF da Liga 33 envelhecida a $800{ }^{\circ} \mathrm{C}$ por (a) $1 \mathrm{~h}$; (b) 2 h; (c) 5 h; (d) 10 h; (e) 20 h; (f) 50 h; e (g) 100 h. $O$ círculo em (c) indica precipitados intragranulares.

Figura 4.22 - Imagens de MEV-SE mostrando diferentes produtos e topologias da precipitação nos CG na Liga 33 envelhecida a $800^{\circ} \mathrm{C}$ por $1 \mathrm{~h}$. As setas vermelhas indicam segmentos do $C G$ que migrou juntamente com o crescimento do precipitado e as setas amarelas indicam segmentos do CG que migrou sem conexão com precipitado no CG.

Figura 4.23 - Imagens de MEV-SE de colônias de PD na Liga 33 envelhecida a 800 ${ }^{\circ} \mathrm{C}$ por $2 \mathrm{~h}$

Figura 4.24 - Imagens de MEV-SE da Liga 33 envelhecida a $800{ }^{\circ} \mathrm{C}$ por 5 h. (a) Imagem em baixo aumento e (b) colônia de PD bem desenvolvida obtida da região indicada pelo retângulo em (a). Os círculos e quadrados em (b) indicam precipitados com morfologia lamelar e nodular, respectivamente.

Figura 4.25 - Imagem de MEV (a) SE and (b) BSE da Liga 33 mostrando uma colônia de PD bem desenvolvida com precipitados com diferentes morfologias resultante do envelhecimento a $800{ }^{\circ} \mathrm{C}$ por $5 \mathrm{~h}$. As setas indicam uma fase precipitada com contraste mais claro em relação às outras fases precipitadas dentro da colônia de PD.

Figura 4.26 - Imagem de MEV-SE da Liga 33 envelhecida a $800{ }^{\circ} \mathrm{C}$ por $10 \mathrm{~h}$ mostrando uma colônia de PD, além de precipitados convencionais e os correspondentes mapas elementares obtidos por MEV/XEDS de $\mathrm{Cr}$, Fe, Ni, Mo e Si. . 103 Figura 4.27 - Imagens de MEV-SE da Liga 33 envelhecida a $800{ }^{\circ} \mathrm{C}$ por $10 \mathrm{~h}$ obtida da região indicada pelo (a) retângulo vermelho e (b) retângulo amarelo na Figura 4.26 e os correspondentes mapas elementares obtidos por MEV/XEDS do $\mathrm{Cr}, \mathrm{Fe}$, $\mathrm{Ni}$, Mo e Si.

Figura 4.28 - Imagem de MEV-SE da Liga 33 envelhecida a $800{ }^{\circ} \mathrm{C}$ por $10 \mathrm{~h}$ mostrando uma colônia de PD com morfologia "double seam" e os correspondentes mapas elementares obtidos por MEV/XEDS do $\mathrm{Cr}$, Fe, Ni, Mo e Si. As setas vermelhas indicam precipitados enriquecidos em Si formados na frente de reação 
da PD e as setas amarelas indicam precipitados enriquecidos em Si na posição original do CG. O retângulo vermelho indica a região mostrada na Figura 4.29.

Figura 4.29 - Imagem de MEV-SE da Liga 33 envelhecida a $800{ }^{\circ} \mathrm{C}$ por $10 \mathrm{~h}$ obtida da região indicada pelo retângulo vermelho na Figura 4.28 e os correspondentes mapas elementares obtidos por MEV/XEDS do $\mathrm{Cr}, \mathrm{Fe}, \mathrm{Ni}$, Mo e Si. Precipitado ${ }^{\circ} 1$ : rico em $\mathrm{Cr}$; precipitado $\mathrm{n}^{\circ}$ 2: enriquecido em $\mathrm{Cr}$ e Mo; precipitado $\mathrm{n}^{\circ}$ 3: enriquecido em Si e Mo.

Figura 4.30 - Imagens de MEV-SE da Liga 33 envelhecida a $800^{\circ} \mathrm{C}$ por (a) $20 \mathrm{~h}$;

(b) $50 \mathrm{~h}$; e (c) $100 \mathrm{~h}$

Figura 4.31 - Imagens de MEV-BSE da Liga 33 envelhecida a $800{ }^{\circ} \mathrm{C}$ por 20 horas (a) imagem em baixa magnificação mostrando a microestrutura geral e (b) colônia de PD obtida da região indicada pelo retângulo vermelho em (a) mostrando uma morfologia "double seam".

Figura 4.32 - Imagem de MEV-BSE de uma colônia de PD bem desenvolvida na Liga 33 envelhecida a $800^{\circ} \mathrm{C}$ por $20 \mathrm{~h}$ contendo tanto precipitados lamelares como nodulares na região varrida pela irregular frente de reação da PD. As setas vermelhas indicam precipitados, com contraste mais claro, formados na frente de reação da PD e a seta amarela indica uma mudança abrupta na direção cristalográfica de crescimento das lamelas precipitadas dentro da colônia de PD. ....... 109 Figura 4.33 - Imagem de MEV-BSE da Liga 33 envelhecida a $800{ }^{\circ} \mathrm{C}$ por $20 \mathrm{~h}$ e os correspondentes mapas elementares por XEDS do $\mathrm{Cr}, \mathrm{Fe}, \mathrm{Ni}, \mathrm{Si}$ e $\mathrm{Mo}$ obtidos da região indicada pelo quadrado vermelho.

Figura 4.34 - Imagem de MEV-BSE da Liga 33 envelhecida a $800{ }^{\circ} \mathrm{C}$ por $20 \mathrm{~h}$ mostrando colônias de PD e os correspondentes mapeamentos de XEDS do $\mathrm{Cr}, \mathrm{Fe}$, $\mathrm{Ni}$, Si e Mo.

Figura 4.35 - Imagem de MEV (a) SE e (b) BSE da Liga 33 envelhecida a $800{ }^{\circ} \mathrm{C}$ por 100 h. O quadrado indica a região mostrada nas Figuras 4.36 e 4.37.

Figura 4.36 - Imagem de MEV-BSE da Liga 33 envelhecida a $800{ }^{\circ} \mathrm{C}$ por $100 \mathrm{~h}$ obtida da região indicada pelo quadrado na Figura 4.37b e os correspondentes mapas elementares do $\mathrm{Cr}$, $\mathrm{Fe}, \mathrm{Ni}, \mathrm{Si}$, Mo e $\mathrm{N}$.

Figura 4.37 - Imagem de MEV-BSE da Liga 33 envelhecida a $800{ }^{\circ} \mathrm{C}$ por $100 \mathrm{~h}$ mostrando a mesma região mostrada na Figura 4.35 e os espectros pontuais por XEDS dos precipitados indicados pelos números 1, 2, 3 e 4 .

Figura 4.38 - (a) Imagem de STEM-BF de uma colônia de PD nos estágios iniciais do processo de crescimento e os correspondentes mapas elementares obtidos por $\mathrm{STEM} / \mathrm{XEDS}$ do $\mathrm{Cr}, \mathrm{Fe}, \mathrm{Ni}, \mathrm{Mo}, \mathrm{Si}, \mathrm{N}$ e C

Figura 4.39 - (a) Imagem de STEM-BF mostrando carbetos- $\mathrm{M}_{23} \mathrm{C}_{6}$ em um contorno ondulado na Liga 33 envelhecida a $800{ }^{\circ} \mathrm{C}$ por $1 \mathrm{~h}$ e os correspondentes mapas elementares obtidos por STEM/XEDS do $\mathrm{Cr}$, Fe, Ni, Mo, Si, C e N. As setas indicam a região onde ocorreu o enriquecimento em Si concomitante ao empobrecimento em $\mathrm{Cr}$

Figura 4.40 - Imagens de STEM-BF e os correspondentes mapas elementares obtidos por STEM/XEDS do $\mathrm{Cr}$ e Si de três diferentes $\mathrm{CG}$ decorados com carbetos$\mathrm{M}_{23} \mathrm{C}_{6}$ na Liga 33 envelhecida a $800{ }^{\circ} \mathrm{C}$ por $1 \mathrm{~h}$ mostrando o enriquecimento em Si ao redor dos carbetos.

Figura 4.41 - Imagens de STEM-BF da Liga 33 envelhecida a $800{ }^{\circ} \mathrm{C}$ por $1 \mathrm{~h}$ mostrando um CG decorado com carbetos-M23C6 e os correspondentes mapas elementares obtidos por STEM/XEDS do $\mathrm{Cr}$, Fe, Ni, Si, Mo, C e N. A formação de uma fase enriquecida em $\mathrm{Si}, \mathrm{Ni}$ e $\mathrm{N}$ foi observada, a qual está indicada pela seta branca.

Figura 4.42 - (a) Imagem de MET-BF de um contorno curvado na Liga 33 envelhecida a $800{ }^{\circ} \mathrm{C}$ por $1 \mathrm{~h}$; (b) respectiva imagem de MET-CDF e o correspondente padrão SAED obtido do grão de cima na imagem em (a); e (c) 
imagem de MET-CDF revelando carbetos- $\mathrm{M}_{23} \mathrm{C}_{6}$ no $\mathrm{CG}$ e o padrão SAED obtido da interface carbeto/matriz mostrando a R.O. [101]M23C6 \|[101]matriz-CFC. O losango vermelho é referente à matriz-CFC e o losango amarelo é referente ao carbeto- $\mathrm{M}_{23} \mathrm{C}_{6}$.....

Figura 4.43 - Imagens de MET-CDF mostrando os carbetos- $\mathrm{M}_{23} \mathrm{C}_{6}$ indicados pelas setas vermelhas na Figura 4.42. Inserção: padrão SAED obtido da interface carbeto/matriz mostrando a R.O. [ [ 101$]$ M23C6 // [ [ $\left.\begin{array}{lll}1 & 0 & 1\end{array}\right]$ matriz - CFC

Figura 4.44 - Imagens de MET-BF/CDF obtida da região indicada pelo quadrado vermelho na Figura 4.42 mostrando o precipitado lamelar, o qual foi identificado como a fase $\alpha-\mathrm{Cr}$ com estrutura CCC. A R.O. K-S foi verificada, $(-110)_{\alpha-C r} \|(-$ 111) matriz-CFC, $\quad[111]_{\alpha-C r} \|[101]_{\text {matriz-CFC. }}$ O losango vermelho é referente à matriz-CFC e o losango azul é referente à fase $\alpha-C r$.

Figura 4.45 - Imagem de STEM-BF de um CG decorado por precipitados, o qual representa os estágios iniciais da reação de PD na Liga 33. O retângulo amarelo indica a região onde foi obtido o mapeamento elementar por STEM/XEDS mostrado na Figura 4.46. Seta vermelha: migração do contorno conectado com o precipitado; seta amarela: migração do contorno sem conexão com o precipitado

Figura 4.46 - Imagem de STEM-BF obtida da região indicada pelo retângulo amarelo na Figura 4.45 e os correspondentes mapas elementares obtido por STEM/XEDS do $\mathrm{Cr}, \mathrm{Fe}, \mathrm{Ni}, \mathrm{Mo}, \mathrm{Si}, \mathrm{C}$ e $\mathrm{N}$. O resultado da análise de XEDS em linha, obtida na região indicada pela seta, mostra uma acentuada descontinuidade na composição do $\mathrm{Cr}$ através da frente de reação da PD.

Figura 4.47 - Imagem de STEM-BF da Liga 33 envelhecida a $800^{\circ} \mathrm{C}$ por 5 horas mostrando a precipitação concomitante com a migração no $\mathrm{CG}$. O retângulo vermelho indica a região mostrada na Figura 4.48.

Figura 4.48 - Imagem de STEM-HAADF obtida da região indicada pelo retângulo vermelho na Figura 4.47 e os correspondentes mapas elementares obtidos por STEM/XEDS do $\mathrm{Cr}$, Fe, Ni, Mo, Si, N e C. CG: contorno de grão. Precipitado $\mathrm{n}^{\circ}$ 1: fase $\alpha$-Cr; precipitado $n^{\circ}$ 2: carbeto- $\mathrm{M}_{23} \mathrm{C}_{6}$; precipitado 3: enriquecido em Si, N e Ni.... 124 Figura 4.49 - Imagem de STEM-HAADF obtida da imagem mostrada na Figura 4.47 e os correspondentes mapas elementares obtidos por STEM/XEDS do $\mathrm{Cr}, \mathrm{Fe}, \mathrm{Ni}$, $\mathrm{Mo}, \mathrm{Si}, \mathrm{N}$ e C.

Figura 4.50 - Imagem de MET-CDF da fase intermetálica $\sigma$ com estrutura tetragonal formada na frente de reação da PD e o respectivo padrão SAED no eixo de zona [1 $13]$

Figura 4.51 - (a) Imagem de STEM-BF da colônia de PD mostrada na Figura 4.47 e (b) espectros pontuais obtidos por STEM/XEDS dos precipitados indicados pelos números 1, 2, 3 e 4 em (a). (1) fase $\alpha-C r$ (estrutura $C C C$ ); (2) carbeto- $\mathrm{M}_{23} \mathrm{C}_{6}$ (estrutura $\mathrm{CCC}$ ); (3) fase precipitada enriquecida em Si; (4) fase intermetálica $\sigma$ (estrutura tetragonal)

Figura 4.52 - Imagem de STEM-HAADF de uma colônia de PD na Liga 33 envelhecida a $800{ }^{\circ} \mathrm{C}$ por $10 \mathrm{~h}$ e os correspondentes mapas elementares obtidos por STEM/XEDS do $\mathrm{Cr}, \mathrm{Fe}, \mathrm{Ni}$, Mo e Si. O quadrado indica a região mostrada na Figura 4.53

Figura 4.53 - (a) Imagem de STEM-HAADF da Liga 33 envelhecida a $800^{\circ} \mathrm{C}$ por 10 $\mathrm{h}$ obtida da região indicada pelo quadrado vermelho na Figura 4.52 e os padrões SAED obtidos no eixo de zona [001] da matriz CFC, carbeto- $\mathrm{M}_{23} \mathrm{C}_{6}$ e fase- $\eta$, respectivamente. $\mathrm{O}$ quadrado vermelho é referente à matriz-CFC, o quadrado amarelo é referente ao carbeto- $\mathrm{M}_{23} \mathrm{C}_{6}$ e o quadrado verde é referente à fase-n. 131 Figura 4.54 - (a) Imagem de MEV-BSE de uma amostra "thin-foil" de MET da Liga 33 envelhecida a $800^{\circ} \mathrm{C}$ por $20 \mathrm{~h}$; (b) Imagem de STEM-BF mostrando uma colônia de PD obtida da região indicada pelo retângulo vermelho em (a); e (c) Imagem de STEM-BF obtida da região indicada pelo retângulo vermelho em (b) e os 
correspondentes mapas elementares obtidos por STEM/XEDS do $\mathrm{Cr}, \mathrm{Fe}, \mathrm{Ni}, \mathrm{Si}, \mathrm{Mo}$, $\mathrm{N}, \mathrm{C}$ e V. Precipitado $\mathrm{n}^{\circ}$ 1: carbeto- $\mathrm{M}_{23} \mathrm{C}_{6}$; precipitado $\mathrm{n}^{\circ} 2$ : fase $\alpha-C r$; precipitado $\mathrm{n}^{\circ}$ 3: fase- $\eta$......

Figura 4.55 - (a) Imagem de MET-BF obtida da mesma região mostrada na Figura 4.54c e (b) imagem de MET-BF obtida da região indicada pelo retângulo vermelho em (a) e o padrão SAED obtido da região indicada pelo círculo em (b) mostrando uma R.O. cubo-a-cubo, [001]M23C6//[001] matriz - CFC entre o carbeto e a matriz CFC. A seta vermelha indica precipitados mostrados na Figura 4.56 e 4.57...... 136 Figura 4.56 - (a) Imagem de MEV-BSE mostrando a mesma colônia de PD da Figura 4.54; (b) imagem de MET-BF obtida da região indicada pelo quadrado vermelho em (a); e (c) padrões SAED obtidos das regiões indicadas pelos números 1,2 e 3 em (b). A seta indica os precipitados mostrada na Figura 4.58. Nos padrões SAED: o quadrado vermelho é referente à matriz-CFC, o quadrado amarelo é referente ao carbeto- $\mathrm{M}_{23} \mathrm{C}_{6}$ e o paralelogramo verde é referente à fase- $\eta$.

Figura 4.57 - (a) Imagem de MET-BF do carbeto- $\mathrm{M}_{23} \mathrm{C}_{6}$ e da fase- $\eta$, o padrão SAED mostrando a R.O. [001]M23C6//[001]matriz-CFC obtido da interface carbeto/matriz e a imagem de MET-CDF revelando o carbeto; (b) Imagem de MET$\mathrm{BF}$ do carbeto- $\mathrm{M}_{23} \mathrm{C}_{6}$ e da fase- $\eta$, o padrão SAED mostrando a R.O. [122] $\eta / /$ [001] matriz - CFC entre a fase- $\eta$ e a matriz CFC e a imagem de MET-CDF revelando a fase- $\eta$; (c) Imagens de MET-BF/DF da fase- $\eta$, o padrão SAED mostrando R.O. [122] $\eta / /[001]$ matriz $-C F C$ entre a fase- $\eta$ e a matriz CFC e a imagem de MET-CDF revelando a fase-n.

Figura 4.58 - Imagens de MET-BF/CDF dos precipitados lamelares da fase $\alpha-\mathrm{Cr}$ indicados pela seta na Figura 4.57a e o respectivo padrão SAED no eixo de zona [001].

Figura 4.59 - (a) Imagem de MEV-BSE de uma amostra "thin-foil" de MET da Liga 33 envelhecida a $800^{\circ} \mathrm{C}$ por $20 \mathrm{~h}$; (b) Imagem de MEV-BSE mostrando uma colônia de PD obtida da região indicada pelo retângulo vermelho em (a); e (c) Imagem de STEM-BF obtida da região indicada pelo retângulo vermelho em (b) e os correspondentes mapas elementares obtidos por STEM/XEDS do $\mathrm{Cr}, \mathrm{Fe}, \mathrm{Ni}, \mathrm{Si}, \mathrm{Mo}$, $\mathrm{N}, \mathrm{C}$ e V. O retângulo vermelho em (c) indica a região mostrada na Figura 4.61.

Figura 4.60 - (a) Imagem de MEV-BSE da mesma colônia de PD mostrada na Figura 4.59 e padrões SAED em dois diferentes eixos de zona, [140] e [110], obtidos da fase- $\sigma$ na frente de reação da PD indicada pelo círculo vermelho.

Figura 4.61 - (a) Imagem de MET-BF obtido da região indicada pelo quadrado vermelho na Figura $4.59 \mathrm{c}$ e o respectivo padrão SAED mostrando a R.O. K-S, (110) $\alpha / /(111)$ matriz $-C F C ;[111] \alpha / /[101]$ matriz $-C F C$ entre a fase $\alpha-C r$ e a matriz CFC.

Figura 4.62 - Pares de imagens de MET-BF/CDF mostrando precipitados homogêneos na Liga 33 envelhecida a $800^{\circ} \mathrm{C}$ por $20 \mathrm{~h}$.

Figura 4.63 - Imagens de STEM-BF/HAADF de uma colônia de PD com morfologia clássica na Liga 33 envelhecida a $800{ }^{\circ} \mathrm{C}$ por $20 \mathrm{~h}$ e os correspondentes mapas elementares obtidos por STEM/XEDS do $\mathrm{Cr}, \mathrm{Fe}, \mathrm{Ni}, \mathrm{Si}, \mathrm{Mo}, \mathrm{N}$ e C. O retângulo vermelho indica a região mostrada na Figura 4.64.

Figura 4.64 - Imagem de STEM-BF obtido da região indicada pelo quadrado vermelho na Figura 4.63 e os correspondentes mapas elementares obtidos por $\mathrm{STEM} / \mathrm{XEDS}$ do $\mathrm{Cr}$, Fe, Ni, Si, Mo, C, N e V.

Figura 4.65 - Espectros pontuais obtidos por STEM/XEDS dos precipitados indicados pelos números 1, 2, e 3 na Figura 4.64. Espectro 1: Fase-n; Espectro 2: Fase $\alpha-C r$; Espectro 3: carbeto- $\mathrm{M}_{23} \mathrm{C}_{6}$. 147

Figura 4.66 - (a) Imagem de STEM-BF obtida da mesma colônia de PD mostrada na Figura 4.63 e os correspondentes mapas elementares de STEM/XEDS do $\mathrm{Cr}$, 
$\mathrm{Fe}, \mathrm{Ni}, \mathrm{Si}, \mathrm{Mo}, \mathrm{C}, \mathrm{N}$ e $\mathrm{V}$ e (b) Espectros pontuais obtidos por STEM/XEDS dos precipitados indicados pelos números 1 e 2 em (a). As setas indicam nitretos ricos em Cr formados dentro da colônia de PD.

Figura 4.67 - (a) Imagem de MET-BF da fase intermetálica $\sigma$ na Liga 33 envelhecida a $800{ }^{\circ} \mathrm{C}$ por $20 \mathrm{~h}$ e (b) padrões SAED obtidos, respectivamente, da matriz CFC, fase- $\sigma$ com estrutura tetragonal e da interface matriz CFC/fase- $\sigma$ mostrando a R.O. [101] $/ /[110]_{\sigma}$. O losango vermelho é referente à matriz-CFC e o retângulo amarelo é referente à fase- $\sigma$.

Figura 4.68 - (a) Imagem de STEM-BF mostrando precipitados com morfologia de plaquetas nos contornos incoerentes de macla na Liga 33 envelhecida a $800{ }^{\circ} \mathrm{C}$ por $20 \mathrm{~h}$; (b) imagem de STEM-HAADF obtida da região indicada pelo quadrado em (a) e os correspondentes mapeamentos elementares do $\mathrm{Cr}, \mathrm{Fe}, \mathrm{Ni}, \mathrm{Si}, \mathrm{Mo}, \mathrm{C}$ e $\mathrm{N}$ confirmando a existência de carbetos $-\mathrm{M}_{23} \mathrm{C}_{6}$ e fase-n e (c) os padrões de difração SAED da matriz e da interface matriz/macla.

Figura 4.69 - (a) Imagem de STEM-BF de uma colônia de PD na Liga 33 envelhecida a $800{ }^{\circ} \mathrm{C}$ por $100 \mathrm{~h}$ e (b) imagens de STEM-BF/HAADF obtidas da região indicada pelo quadrado vermelho em (a) e os correspondentes mapas elementares de STEM/XEDS do $\mathrm{Cr}, \mathrm{Fe}, \mathrm{Ni}, \mathrm{Mo}, \mathrm{Si}, \mathrm{N}$ e C. As setas indicam três diferentes fases precipitadas na frente de reação da PD. O quadrado amarelo indica a região mostrada na Figura 4.72

Figura 4.70 - Imagens de MET-BF/CDF do nitreto- $\mathrm{M}_{2} \mathrm{~N}$ rico em $\mathrm{Cr}$ mostrado na Figura 4.69b e o respectivo padrão SAED no eixo de zona $0113 \ldots \ldots \ldots \ldots \ldots \ldots \ldots \ldots . . . . . . . . . . . . . .156$

Figura 4.71 - Imagem de STEM-BF da mesma região mostrada na Figura $4.69 \mathrm{~b}$ e três espectros pontuais obtidos por STEM/XEDS dos precipitados indicados pelos números 1 , 2, e 3 . Precipitado $n^{\circ} 1$ : fase- $\sigma$; precipitado $n^{\circ} 2$ : nitreto- $\mathrm{M}_{2} \mathrm{~N}$; precipitado $\mathrm{n}^{\circ}$ 3: fase $\mathrm{a}-\mathrm{Cr}$.

Figura 4.72 - Imagens de STEM-BF/HAADF obtidas da região indicada pelo quadrado amarelo na Figura 4.69 e os correspondentes mapas elementares obtidos por STEM/XEDS do $\mathrm{Cr}, \mathrm{Fe}, \mathrm{Ni}, \mathrm{Mo}, \mathrm{Si}, \mathrm{N}$ e C. Seta amarela: fase-n; seta branca: fase $\alpha-\mathrm{Cr}$; seta vermelha: fase- $\sigma$; setas verde e azul: nitreto- $\mathrm{M}_{2} \mathrm{~N}$. O retângulo indica a região mostrada na Figura 4.74 .

Figura 4.73 - Imagens de MET-BF/CDF mostrando o nitreto- $\mathrm{M}_{2} \mathrm{~N}$ indicado pela seta azul no mapa do $\mathrm{N}$ na Figura 4.72 e o respectivo padrão SAED do nitreto no eixo de zona 0110 .

Figura 4.74 - Imagem de STEM/BF obtida da região indicada pelo retângulo vermelho na Figura 4.72 e os correspondentes mapas elementares obtidos por STEM/XEDS do $\mathrm{Cr}, \mathrm{Fe}, \mathrm{Ni}, \mathrm{Mo}, \mathrm{Si}, \mathrm{N}, \mathrm{C}$ e $\mathrm{V}$. A seta indica o nitreto rico em $\mathrm{Cr}$ identificado via SAED na Figura 4.75.

Figura 4.75 - Imagens de MET-BF/CDF mostrando o nitreto- $\mathrm{M}_{2} \mathrm{~N}$ indicado pela seta na Figura 4.74 e padrões SAED, respectivamente, da matriz CFC, nitreto- $\mathrm{M}_{2} \mathrm{~N}$ e interface matriz CFC/nitreto- $\mathrm{M}_{2} \mathrm{~N}$, mostrando uma R.O. [1 $\left.\begin{array}{lll}1 & 1\end{array}\right]$ matriz $C F C / /$

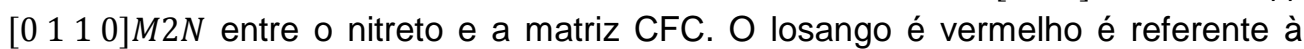
matriz-CFC e o retângulo amarelo é referente ao nitreto- $\mathrm{M}_{2} \mathrm{~N}$.

Figura 4.76 - Imagens de MET-BF/CDF da fase-n enriquecida em Si localizada na frente de reação da PD e dois padrões SAED em diferentes eixos de zona, [112] e [001]. Este precipitado está indicado pela seta amarela na imagem de STEM-BF na Figura 4.72a.

Figura 4.77 - Imagem STEM-BF e quatro espectros obtidos por STEM/XEDS dos precipitados indicados marcados pelos números 1, 2, 3 e 4 . Precipitado $n^{\circ} 1$ : fase- $\sigma$; precipitado $n^{\circ} 2$ : fase- $\eta$; precipitado $n^{\circ} 3$ : nitreto- $\mathrm{M}_{2} \mathrm{~N}$; precipitado $n^{\circ} 4$ : fase $\alpha-C r . \ldots \ldots . .164$ Figura 4.78 - Esquema do mecanismo de crescimento da colônia de PD na Liga 33 envelhecida a $800^{\circ} \mathrm{C}$ até 100 horas. 
Figura 4.79 - Mapas de EBSD da Liga 33 envelhecida a $800{ }^{\circ} \mathrm{C}$ por 50 h. (b) imagem de EBSD obtida da região indicada pelo retângulo em (a) mostrando que a orientação cristalina do grão de cima ("grão rosa") é transferida para a colônia de PD, a qual consome os grãos de baixo ("grão vermelho" e "grão azul").

Figura 4.80 - Mapas de EBSD e os respectivos mapas somente com CG delineados da Liga 33 na condição (a) como recebida; e envelhecida a $800^{\circ} \mathrm{C}$ por (b) $2 \mathrm{~h}$; e (c) 20 h.

Figura 4.81 - (a) e (c) Distribuição dos CG em relação à desorientação angular dos CG; (b) e (d) porcentagem de ocorrência da PD em relação à desorientação dos CG

Figura 4.82 - Imagens de STEM-BF da Liga 33 envelhecida a $800{ }^{\circ} \mathrm{C}$, os correspondentes mapas elementares obtidos por STEM/XEDS de uma região através do contorno da frente de reação e os respectivos perfis composicionais extraídos da região indicada pela linha no mapa elementar. (a) $30 \mathrm{~min}$; (b) $10 \mathrm{~h}$; (c) $20 \mathrm{~h}$; d) $50 \mathrm{~h}$; e) $100 \mathrm{~h}$.

Figura 4.83 - Variação da velocidade de propagação da frente de reação da PD na Liga 33 envelhecida a $800{ }^{\circ} \mathrm{C}$ por $2 \mathrm{~h}$ até $100 \mathrm{~h}$. 


\section{Lista de Tabelas}

Tabela 2.1 - Composição química nominal da Liga 33 (\% p.) [27].

Tabela 2.2 - Comparação da resistência contra corrosão da Liga 33 e outros materiais com aplicações similares [26][36][37][46]................................................... 28

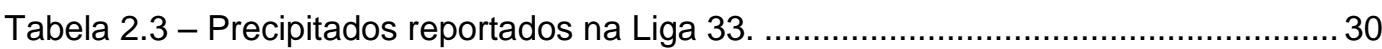

Tabela 3.1 - Composição química da Liga 33 usada neste estudo (\% p.). .....................56

Tabela 4.1 - Fases precipitadas identificadas na Liga 33 envelhecida a $800{ }^{\circ} \mathrm{C}$ até $100 \mathrm{~h}$ 168

\section{Lista de Abreviações}

$\%$ p. - porcentagem em peso

$\mathrm{Al}$ - aços inoxidáveis

BF - campo claro ("bright-field")

C.G. - contorno de grão

CBPF - Centro Brasileiro de Pesquisas Físicas

CCC - cúbico de corpo centrado

CFC - cúbico de face centrada

CDF - campo escuro centrado ("centered dark-field")

DF - campo escuro ("dark-field")

DIGM - migração do contorno de grão induzida por difusão ("diffusion-induced grain boundary migration")

EBSD - difração de elétrons retroespalhados ("electron backscatter diffraction")

FEG - canhão de elétrons por emissão de campo ("field emission gun")

K.S. - Kurdjumov-Sachs

MO - microscopia óptica

MEV - microscopia eletrônica de varredura

MET - microscopia eletrônica de transmissão

N.W. - Nishiyama-Wassermann

PD - precipitação descontínua

R.O. - relação de orientação

SAED - difração de elétrons de área selecionada ("selected area electron diffraction")

STEM - microscopia eletrônica de transmissão e varredura ("scanning transmission electron microscopy")

SE - elétrons secundários ("secondary electrons")

BSE - elétrons retroespalhados ("backscattered electrons")

SWC - "supercritical water environment"

SDD - "silicon drift detector"

XEDS - espectroscopia por dispersão de energia de raios-X ("X-ray energy dispersive spectroscopy") 
"Se soubéssemos o que estávamos fazendo, isto não se chamaria pesquisa"

Albert Einstein 


\section{Introdução}

É bem estabelecido que materiais aplicados em indústrias de produção e conversão de energia, combustíveis e nuclear são susceptíveis à instabilidade microestrutural e mudanças composicionais; tipicamente, precipitação de diferentes fases, quando submetidas a elevadas temperaturas de serviço, o que pode causar prejuízos nas operações industriais bem como impactos ao meio ambiente. Geralmente, os materiais estruturais aplicados em meios tão agressivos são constituídos de elementos substitucionais ( $\mathrm{Fe}, \mathrm{Cr}, \mathrm{Ni}, \mathrm{Mo}, \mathrm{Mn}$, entre outros) e intersticiais ( $\mathrm{C}$ e N), tais como aços inoxidáveis (AI) austeníticos, AI duplex e superduplex e ligas à base de $\mathrm{Ni}$. Em tais ligas multicomponentes é possível precipitar carbetos, nitretos, carbonitretos e compostos intermetálicos [1-7], os quais podem ser deletérios para as propriedades dos materiais quando formados nos contornos de grão (CG).

Talvez os fenômenos mais intrigantes nestes materiais multicomponentes seja a ocorrência concomitante de precipitação convencional (homogênea e heterogênea) e precipitação descontínua (PD). Enquanto a primeira é controlada pela difusão volumétrica, a PD é geralmente governada pela difusão pelo CG e migração do contorno, sendo que em algumas ligas multicomponentes, a difusão de volume também desempenha um importante papel no desenvolvimento da reação de PD [8][9]. A partir dos pontos de vista científico e industrial, a reação de PD é de grande interesse devido à influência negativa nas propriedades mecânicas [10-19] e de corrosão [20-22] de materiais estruturais, quando comparado com a precipitação convencional homogênea.

A reação de PD é uma transformação de fase no estado sólido, que ocorre preferencialmente em CG de alto ângulo. Fenomenologicamente, uma solução sólida supersaturada é decomposta em uma estrutura mais estável pela geração de uma fase precipitada e uma matriz com mesma estrutura cristalina da matriz original. A migração do CG de alto ângulo promove a difusão de átomos pelo CG deixando para trás uma estrutura heterogênea na forma de lamelas ou bastonetes juntamente com a matriz empobrecida em soluto. Assim, a reação de PD pode ser descrita essencialmente como precipitação no CG com concorrente migração do contorno. Em sistemas binários, a reação de PD envolve apenas uma espécie de 
soluto substitucional com difusividade da mesma ordem de grandeza que os átomos da matriz, o qual resulta em características bem definidas de crescimento [23][24]. Em sistemas multicomponentes contendo átomos substitucionais e intersticiais, ambos os solutos tem diferentes difusividades; notadamente solutos intersticiais tem difusividade ordens de grandeza maior que os substitucionais. Portanto, características morfológicas e de crescimento da PD em tais sistemas multicomponentes apresentam diferenças em relação àquelas observadas em sistemas binários, fazendo estes sistemas mais complexos para o estudo deste fenômeno [8][9][25].

Neste contexto, o material escolhido para esta pesquisa é uma liga de alto teor de $\mathrm{Cr}$ e $\mathrm{Ni}$, denominada Liga 33, a qual apresenta excelentes propriedades mecânicas e contra a corrosão [26-29]. A peculiaridade dos fenômenos de precipitação ocorridos na Liga 33, quando submetida a altas temperaturas, já foi comprovada, apresentando diferentes modos de precipitação (convencional e descontínua), e também diversos tipos de precipitados [3][30]. Uma característica adicional encontrada na Liga 33 após tratamento de envelhecimento, que difere de quase todos os relatos sobre a reação de PD em sistemas multicomponentes com matriz monofásica, é a ocorrência de mais de uma fase precipitada dentro da mesma colônia de PD [30]. Entretanto, uma completa identificação das fases precipitadas durante a evolução microestrutural da Liga 33 submetida a tratamento de envelhecimento, bem como das fases que constituem as colônias de PD não tem sido reportada na literatura científica universal. Neste contexto, considerando a complexidade da reação de PD observada na Liga 33, um estudo mais aprofundado sobre este fenômeno se faz necessário e com os resultados obtidos espera-se contribuir para o entendimento do fenômeno.

O objetivo deste trabalho foi estudar os fenômenos de precipitação na Liga 33 resultante do tratamento térmico de envelhecimento. Devido à influência negativa da PD nas propriedades dos materiais estruturais foi dedicada maior atenção a este fenômeno. As diferentes fases precipitadas que constituem as colônias de PD foram identificadas em termos da estrutura cristalina, composição química e morfologia. A instrumentação utilizada neste estudo experimental consistiu de microscópio óptico (MO), microscópio eletrônico de varredura (MEV/XEDS/EBSD) e microscópio eletrônico de transmissão e varredura (MET/STEM/XEDS). 
O presente trabalho foi estruturado da seguinte forma: o capítulo 1 apresenta uma breve introdução do fenômeno estudado e o trabalho realizado; no capítulo 2, é apresentada uma revisão bibliográfica sobre a Liga 33 e suas características, além dos diferentes modos de precipitação e tipos de precipitados já reportados nesta liga. Também, no capítulo 2 , é realizada uma descrição sobre o fenômeno de PD em sistemas binários, sistemas multicomponentes contendo átomos substitucionais e intersticiais e ligas à base de $\mathrm{Ni}$ com matriz bifásica. $\mathrm{O}$ capítulo 3 apresenta as características da Liga 33 na condição como recebida e descreve o procedimento experimental seguido em termos dos tratamentos térmicos realizados e das técnicas de caracterização utilizadas neste estudo. No capítulo 4, são apresentados e discutidos os resultados da evolução microestrutural durante o envelhecimento isotérmico obtidos por $\mathrm{MO}$, MEV/XEDS/EBSD e MET/STEM/XEDS da evolução microestrutural durante o envelhecimento isotérmico focando nos fenômenos ocorridos nos contornos de grão. O capítulo 5 apresenta as conclusões da presente tese de doutorado. Por fim, com respaldo das observações e tendências detectadas, no capítulo 6, são apresentadas as sugestões para trabalhos futuros. 


\section{Revisão bibliográfica}

\section{$2.1 \quad$ Liga 33}

Liga 33 - Nicrofer 3033 - é um material com matriz austenítica de alto teor de $\mathrm{Cr}$ e Ni, resistente à corrosão, desenvolvida pela Krupp-VDM e Bayer AG [27] nos anos 1990 na Alemanha. Seu desenvolvimento teve como objetivo a melhor combinação para excelente resistência contra corrosão, alta resistência mecânica, alta tenacidade e facilidade de transformação termomecânica. A excelente resistência da Liga 33 contra corrosão se deve ao alto teor de $\mathrm{Cr}$ somado ao $\mathrm{Mo}, \mathrm{Cu}$ e $\mathrm{N}$. Já o balanceado teor de $\mathrm{Fe}$, Ni e $\mathrm{Cr}$ juntamente ao soluto intersticial $\mathrm{N}$ na matriz CFC promove uma alta resistência mecânica e tenacidade [26][27][29][31-33]. A composição química nominal (\% p.) da Liga 33 é mostrada na Tabela 2.1.

Tabela 2.1 - Composição química nominal da Liga 33 (\% p.) [27].

\begin{tabular}{|c|c|c|c|c|c|c|c|c|c|c|c|}
\hline & $\mathbf{N i}$ & $\mathbf{C r}$ & $\mathbf{F e}$ & $\mathbf{C}$ & $\mathbf{M n}$ & $\mathbf{S i}$ & $\mathbf{C u}$ & $\mathbf{M o}$ & $\mathbf{N}$ & $\mathbf{P}$ & $\mathbf{S}$ \\
\hline min. & 30.0 & 31.0 & \multirow{2}{*}{ bal. } & & & & 0.3 & 0.5 & 0.35 & & \\
\cline { 1 - 10 } máx. & 33.0 & 35.0 & & 0.015 & 2.0 & 0.5 & 1.2 & 2.0 & 0.6 & 0.020 & 0.010 \\
\hline
\end{tabular}

Esta liga foi primeiramente utilizada por industrias de processamento químico [27][29][31][33-35]. Entretanto, com o passar dos anos foi verificado que a Liga 33 pode ser aplicada para reprocessamento de combustível nuclear, em tubos de alta pressão na faixa de temperatura de $\begin{array}{lllll}-196 & \text { a } & 450 & { }^{\circ} \mathrm{C}\end{array}$ [26][27][29][31][33-36], como camada de solda protetora em aplicações em caldeiras [37-40], e também aplicada em ambientes aquáticos supercrítico (SCW, "supercritical water environment") [41][42]. Recentemente, a Liga 33 foi considerada como uma potencial candidata para aplicação no armazenamento de resíduos nucleares em repositórios subterrâneos [43], em reatores aquáticos (água pura a $\sim 300{ }^{\circ} \mathrm{C}$ ) [44] e em sistemas de energia nuclear avançados em altas temperaturas ( $600{ }^{\circ} \mathrm{C}$ ou mais) [28][45]. Esta última aplicação, com o intuito de prevenir acidentes em usinas nucleares como o ocorrido em 2011 na Usina nuclear de Fukushima Daiichi no Japão. 


\subsubsection{Propriedades da Liga 33}

A ductilidade desta liga é significativamente mais alta que alguns aços inoxidáveis (AI) duplex e superduplex [29]. Entretanto, quando a Liga 33 foi submetida a processos de envelhecimento nas temperaturas de $700-900{ }^{\circ} \mathrm{C}$, foi verificada uma pequena perda na resistência ao impacto devido à precipitação da fase intermetálica $\sigma$ [26]. A Figura 2.1 ilustra um gráfico comparativo do limite de escoamento e resistência à tração entre a Liga 33 e outros $\mathrm{AI}$ e ligas à base de Ni com similares aplicações [26][46].

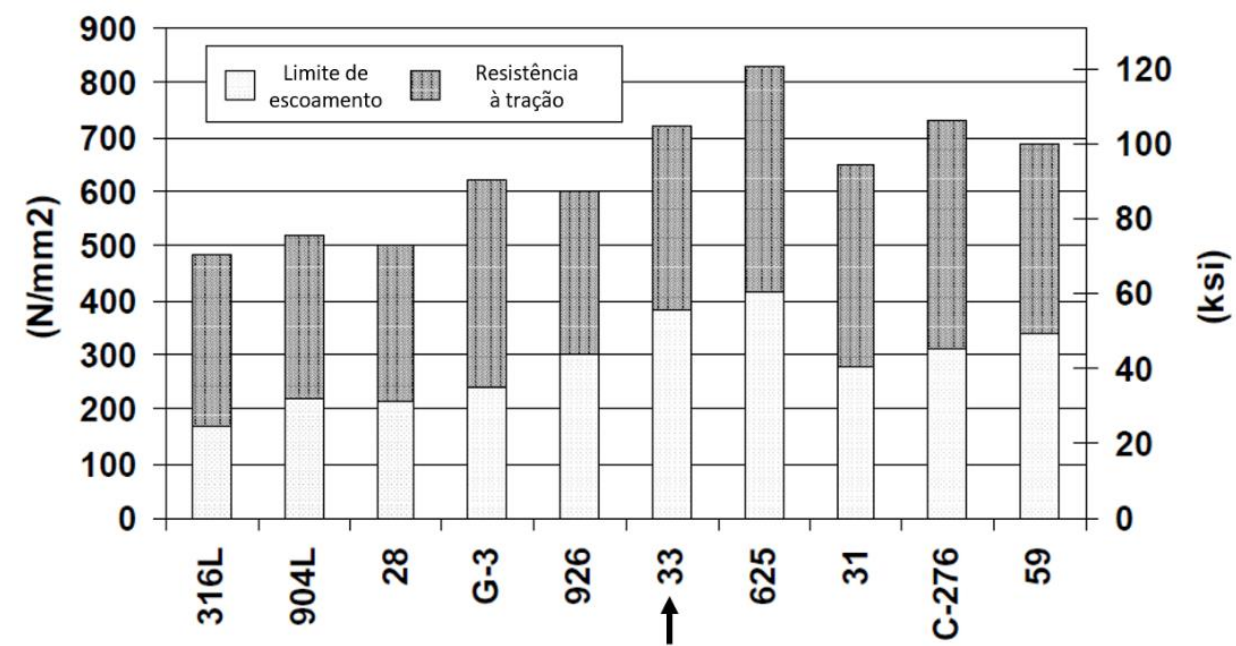

Figura 2.1 - Comparação do limite de escoamento e resistência à tração da Liga 33 e outras ligas utilizadas em ambientes agressivos (adaptado de [26][46]). A seta indica as propriedades da Liga 33.

É bem estabelecido que o elemento $\mathrm{Cr}$ é considerado essencial para a resistência contra a oxidação sob muitas condições de vapor e SCW [47]. Neste sentido, é conhecido que ligas austeníticas de alto teor de $\mathrm{Cr}$, tais como Incoloy 800H/HT (Fe-21Cr-32Ni) e os AI austeníticos tipo 310S (Fe-25Cr-20Ni), são resistentes contra a corrosão quando expostos em SCW [48-50]. Devido ao alto teor de Cr da Liga 33 [27], este material foi confirmado ser um opção para aplicações em SCW. Bsat e colaboradores [41] reportaram que a Liga 33 mostrou maior resistência à corrosão do que as Ligas $800 \mathrm{H}$ e AI austenítico tipo 304 (Fe19Cr-10Ni) em SWC exposta a $700{ }^{\circ} \mathrm{C}$ por 1000 h. Já Mahboubi et al. [42] afirmou que a Liga 33 é promissora para aplicações em SWC exposta a $625{ }^{\circ} \mathrm{C}$ por 500 h. Além disso, a Liga 33 também mostrou maior resistência à corrosão em tubos de caldeira quando comparado com outros tipos de materiais, tais como 
Liga T-22, Liga 304H, e Liga tipo 321 [37], AI austenítico tipo-309 (23Cr-13Ni$58 \mathrm{Fe})$ e Liga 22 (22Cr-57Ni-13Mo-3W) [40].

Além de excelente resistência em misturas de ácido nítrico/fluorídrico e em meio alcalino, a Liga 33 também mostrou boa resistência à corrosão em soluções de ácidos quentes [27][35]. A susceptibilidade à corrosão por tensão da Liga 33 em altas temperaturas aquáticas (“high-temperature water") foi reportada ser, no mínimo, equivalente a ligas à base de $\mathrm{Ni}$ e ligas à base de $\mathrm{Fe}$ [51]. A Tabela 2.2 faz uma comparação entre a resistência à corrosão da Liga 33 e outros materiais estruturais.

Tabela 2.2 - Comparação da resistência contra corrosão da Liga 33 e outros materiais com aplicações similares [26][36][37][46].

\begin{tabular}{|c|c|c|c|c|}
\hline & $\mathrm{H}_{2} \mathrm{SO}_{4}$ & $\mathrm{HNO}_{3}$ & $\mathrm{HNO}_{3}+\mathrm{HF}$ & $\begin{array}{c}\text { Ambientes com } \\
\text { cinzas de carvão } \\
\text { ("Coal Ash } \\
\text { Environments") }\end{array}$ \\
\hline Liga 33 & $\begin{array}{l}\text { > AI austenítico } \\
\text { Tipo-310L } \\
\text { (teste lab.) }\end{array}$ & $\begin{array}{l}\quad>\mathrm{AI} \\
\text { austenítico } \\
\text { tipo-310L }\end{array}$ & --- & $\begin{array}{c}\text { > AI austenítico } \\
\text { Tipo-310 }\end{array}$ \\
\hline Liga 33 & $\begin{array}{c}\text { > AI austenítico } \\
654 \text { SMO } \\
\text { (teste lab.) }\end{array}$ & --- & -- & --- \\
\hline Liga 33 & $\begin{array}{l}\text { > Liga } 28 \text { à base de } \mathrm{Ni} \\
\text { (teste lab.) }\end{array}$ & --- & $\begin{array}{c}\text { > Liga } 28 \text { à base de } \\
\mathrm{Ni}\end{array}$ & --- \\
\hline Liga 33 & --- & --- & --- & $>$ Liga 45 \\
\hline Liga 33 & \begin{tabular}{l}
\multicolumn{2}{c}{$>$ AI austenítico } \\
Tipo-316Ti e Tipo-304 \\
SS $\quad$ (teste em campo)
\end{tabular} & $\begin{array}{l}>\mathrm{AI} \\
\text { austenítico } \\
\text { Tipo-304L }\end{array}$ & -- & --- \\
\hline Liga 33 & --- & --- & $>$ Liga 31 & --- \\
\hline Liga 33 & $\begin{array}{c}\approx \text { Liga superferrítica } \\
\text { 28Cr-4Ni-2Mo } \\
\text { (teste lab.) }\end{array}$ & --- & --- & --- \\
\hline Liga 33 & $\begin{array}{c}\approx \text { Liga superferrítica } \\
\text { C-276 } \\
\text { (teste lab.) }\end{array}$ & --- & --- & --- \\
\hline Liga 33 & $\begin{array}{c}\text { > Liga } 825 \text { à base de Ni } \\
\text { (teste em campo) }\end{array}$ & --- & --- & --- \\
\hline Liga 33 & $\begin{array}{l}\text { > Ligas } 690 \text { e G-30 de } \\
\text { alto teor de } \mathrm{Cr} \text { e Ni } \\
\text { (teste em campo) }\end{array}$ & $\begin{array}{l}\text { > Liga G- } \\
30 \text { de alto } \\
\text { teor de } \mathrm{Cr} \\
\mathrm{e} \mathrm{Ni}\end{array}$ & $\begin{array}{c}\text { > Ligas } 690 \text { e G-30 } \\
\text { de alto teor de Cre } \\
\text { Ni }\end{array}$ & --- \\
\hline Liga 33 & --- & -- & $\begin{array}{c}\text { > Liga } 59 \text { à base de } \\
\mathrm{Ni}\end{array}$ & --- \\
\hline
\end{tabular}




\subsubsection{Precipitação na Liga 33}

Embora a Liga 33 tenha sido desenvolvida nos anos de 1990, existem poucos estudos abordando tanto os tipos de precipitados formados após tratamentos térmicos como os processos de precipitação que ocorrem neste material [3][30][42]. Portella et al. [3] reportaram que a microestrutura da Liga 33 envelhecida a $700{ }^{\circ} \mathrm{C}$ por $100 \mathrm{~h}$ apresentou características mais complexas em relação à microestrutura observada após o envelhecimento a $900{ }^{\circ} \mathrm{C}$ por $100 \mathrm{~h}$. Nesta última condição, os autores relataram que o tratamento térmico levou unicamente a precipitação da fase $\sigma$ no CG. Entretanto, no envelhecimento a $700{ }^{\circ} \mathrm{C}$ por $100 \mathrm{~h}$, foram reportados pequenos precipitados ao longo do $\mathrm{CG}$ e também colônias de PD com precipitados lamelares ricos em Cr. Utilizando análises por XEDS e padrões SAED ("selected area electron diffraction") (não mostrados no trabalho de Portella et al. [3]), os autores afirmaram a ocorrência de diversos precipitados no CG (Tabela 3). Já Mahboubi et al. [42] identificaram, por difração de raios-X, a fase $\alpha-C r$ após testes da Liga $33 \mathrm{em} \mathrm{SCW}$ exposta a $625^{\circ} \mathrm{C}$ por $500 \mathrm{~h}$, sendo afirmado pelos autores que tal fase $\alpha$-Cr era similar à reação de PD reportado por Portella et al. [3].

Spadotto et al. em recente estudo [30] sobre os processos de precipitação na Liga 33, observaram que o envelhecimento isotérmico a $700{ }^{\circ} \mathrm{C}$ por $100 \mathrm{~h}$ levou à formação de precipitados convencionais (nucleação homogênea e heterogênea), além de colônias de PD nos CG. Porém, ao submeter o material ao envelhecimento na temperatura de $900{ }^{\circ} \mathrm{C}$, os autores verificaram que a precipitação homogênea foi predominante juntamente com precipitação convencional nos CG, mas com pouca ocorrência de PD nesta temperatura de envelhecimento. Neste estudo, os autores identificaram, por análises de STEM/XEDS e padrões de difração de elétrons (SAED), três diferentes fases precipitadas após $700{ }^{\circ} \mathrm{C}$ por 100 h: carbeto- $\mathrm{M}_{23} \mathrm{C}_{6}$ e a fase intermetálica $\sigma$ no $\mathrm{CG}$ e a fase- $\eta$ enriquecida em Si na frente de reação da PD. A Tabela 2.3 apresenta as fases precipitadas na Liga 33 já reportadas na literatura. 
Tabela 2.3 - Precipitados reportados na Liga 33.

\begin{tabular}{|c|c|c|c|}
\hline Tipo do Precipitado & Condição da Liga 33 & Sítios de Precipitação & Referência \\
\hline $\begin{array}{l}{\text { Carbeto- } \mathrm{M}_{23} \mathrm{C}_{6}} \\
\text { (Estrutura } \mathrm{CFC} \text { ) }\end{array}$ & $\begin{array}{l}700^{\circ} \mathrm{C} \text { por } 100 \mathrm{~h} \\
7000^{\circ} \mathrm{C} \text { por } 100 \mathrm{~h}\end{array}$ & $\begin{array}{l}\mathrm{CG} \\
\mathrm{CG}\end{array}$ & $\begin{array}{l}3] \\
{[30]}\end{array}$ \\
\hline $\begin{array}{c}\text { Fase } \alpha-\mathrm{Cr} \\
\text { (estrutura CCC) }\end{array}$ & $\begin{array}{l}700{ }^{\circ} \mathrm{C} \text { por } 100 \mathrm{~h} \\
625^{\circ} \mathrm{C} \text { por } 500 \mathrm{~h} \\
\text { (após teste em SWC) }\end{array}$ & $\begin{array}{l}\text { CG e dentro da colônia } \\
\text { de PD }\end{array}$ & $\begin{array}{l}{[3]} \\
{[42]}\end{array}$ \\
\hline $\begin{array}{l}\text { Fase intermetálica } \sigma \\
\text { (estrutura tetragonal) }\end{array}$ & $\begin{array}{l}700^{\circ} \mathrm{C} \text { por } 100 \mathrm{~h} \\
900{ }^{\circ} \mathrm{C} \text { por } 100 \mathrm{~h}\end{array}$ & $\begin{array}{l}\mathrm{CG} \\
\mathrm{CG}\end{array}$ & $\begin{array}{c}\text { [3] [30] } \\
{[3]}\end{array}$ \\
\hline $\begin{array}{c}\mathrm{Cr}_{2}(\mathrm{CN}) \\
\text { (estrutura } \\
\text { ortorrômbica) }\end{array}$ & $700^{\circ} \mathrm{C}$ por $100 \mathrm{~h}$ & CG & [3] \\
\hline $\begin{array}{c}\text { nitreto- } \pi \\
\text { (estrutura cúbica) }\end{array}$ & $700{ }^{\circ} \mathrm{C}$ por $100 \mathrm{~h}$ & CG & [3] \\
\hline $\begin{array}{c}\text { fase- } \eta \\
\text { (estrutura cúbica- } \\
\text { diamante) }\end{array}$ & $700{ }^{\circ} \mathrm{C}$ por $100 \mathrm{~h}$ & frente de reação da PD & [30] \\
\hline
\end{tabular}

\subsection{Processos de Precipitação em Sistemas Metálicos}

É bem estabelecida em vários sistemas multicomponentes a concorrência de vários modos de precipitação, o que torna o estudo de tais fenômenos mais complexo. Talvez o mais intrigante em tais sistemas é a ocorrência concomitante dos modos de precipitação convencional e descontínua (PD) [2][4][15][16][18] [22][52-56]. Como os processos de precipitação são ativados termicamente, a temperatura de envelhecimento tem um papel chave na microestrutura resultante do material. Isso ocorre devido à influência da temperatura nos mecanismos de difusão que controlam tais processos nos materiais metálicos. Em baixas temperaturas de envelhecimento, a difusão pelo CG prevalece, e consequentemente a precipitação no CG é dominante. Em altas temperaturas, a difusão pela rede cristalina governará a reação de precipitação, favorecendo a 
precipitação homogênea. Assim, diferentes temperaturas de envelhecimento certamente resultarão em distintas características microestruturais.

\subsubsection{Precipitação Convencional em Sistemas Multicomponentes}

As reações de precipitação podem ocorrer, de modo geral, de duas maneiras - via nucleação homogênea e heterogênea. A nucleação homogênea envolve a formação espontânea (livre de interfaces) de um núcleo como resultado de flutuações composicionais na matriz. Neste modo de precipitação, a formação das fases secundárias geralmente ocorre apenas quando a força motriz para a nucleação é alta e/ou as estruturas cristalina da matriz e do núcleo são suficientemente similares para fazer a energia interfacial matriz/núcleo baixa [57]. Já a nucleação heterogênea ocorre em alguma interface pré-existente, tais como discordâncias, partículas de impurezas e, predominantemente, CG [58]. Em geral, a precipitação nos CG tem um efeito deletério para as propriedades dos materiais [59][60]. Por outro lado, a precipitação homogênea pode ter um papel de endurecimento de alguns materiais devido à interação precipitados/discordâncias [61].

Como o processo de nucleação requer a criação de uma interface matriz/precipitados $(\alpha / \beta)$, a formação de um núcleo na matriz tem um custo energético pela necessidade de superação de uma barreira energética $(\Delta \mathrm{G})$. A existência de tal barreira energética beneficia a formação dos precipitados heterogêneos, uma vez que a área total da interface $\alpha / \beta$ a ser criada é menor neste modo de precipitação. Deste modo, a formação de um precipitado homogêneo é dificultada quando comparada com a nucleação heterogênea. A variação de energia livre do sistema $(\Delta G)$ que acompanha a formação do núcleo pode ser expressa pelas equações a seguir:

$$
\begin{array}{rr}
\Delta G=-V \Delta G_{V}+A \gamma+V \Delta G_{s} & \text { (nucleação homogênea) } \\
\Delta G=-V \Delta G_{V}+A \gamma+V \Delta G_{s}-\Delta G_{d} & \text { (nucleação heterogênea) }
\end{array}
$$

onde $\mathrm{V}$ é o volume do núcleo formado; $\Delta G_{V}$ é a energia livre de volume formado; A é a área da interface $\alpha / \beta ; \gamma$ é a energia interfacial $\alpha / \beta ; \Delta G_{s}$ é a energia de deformação gerado pela formação do volume do núcleo; $\Delta G_{d}$ é a energia livre 
gerada pela destruição de um defeito cristalino (no caso da nucleação heterogênea). A nucleação ocorre quando o termo da energia livre total, $\Delta G$, é reduzido pelo aumento no tamanho do núcleo [58][62][63]. A Figura 2.2 mostra graficamente as equações 1 e 2 .

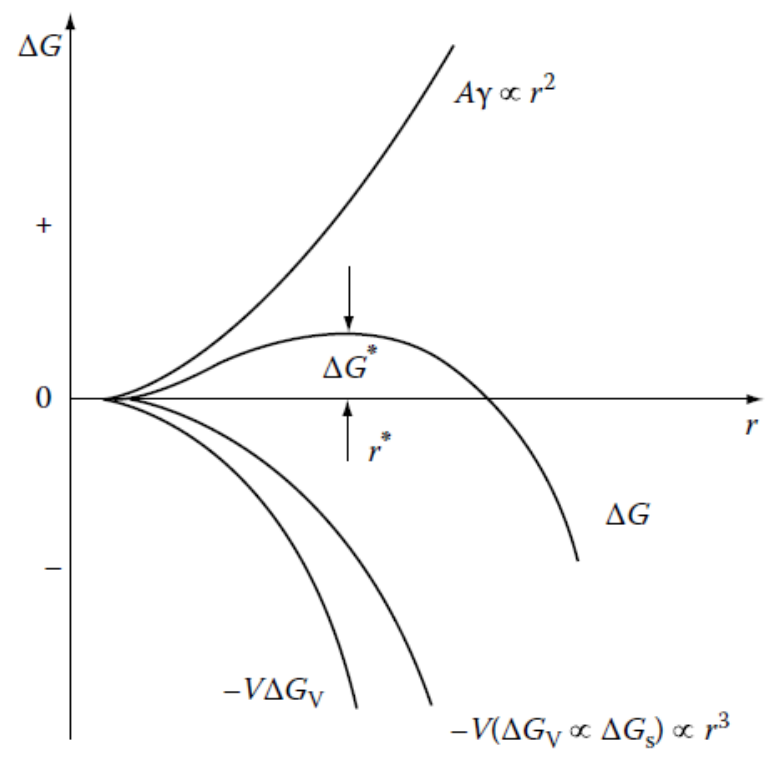

Figura 2.2 - Variação de $\Delta G$ com o raio crítico para a nucleação homogênea. Existe uma barreira energética $\Delta G^{*}$ para que a transformação ocorra (adaptado de [62]).

Existe sempre um tamanho crítico acima do qual as partículas nucleadas se tornam estáveis e abaixo são instáveis. No gráfico da Figura 2.2, considerando a formação de precipitados com morfologia esférica e partículas com pequenos raios, a energia livre de superfície é maior que a energia livre de volume e, então, a energia livre total $(\Delta G)$ é positiva. A situação muda quando o raio cresce em tamanho, de modo que com um raio maior a energia livre $(\Delta \mathrm{G})$ torna-se negativa. $\mathrm{O}$ raio, $\mathrm{r}^{*}$, é conhecido como o raio crítico. Abaixo desse valor, o núcleo aumenta sua energia livre diminuindo seu tamanho, de modo que núcleos com raios menores que $\mathrm{r}^{*}$ tendem a desaparecer. Por outro lado, núcleos com raios maiores que $\mathrm{r}^{*}$ tendem a diminuir sua energia livre com o aumento no raio da partícula. Por esta razão eles são estáveis e devem continuar a crescer [58].

A precipitação de fases secundárias nos CG é de grande interesse devido às influências negativas nas propriedades dos materiais. Contornos de grão constituem uma classe bem estudada de defeitos no estado sólido, que são de natureza estrutural, e que dependem para sua existência de uma desorientação 
entre cristais idênticos [64]. Algumas razões porque a precipitação no CG ocorre, preferencialmente, quando comparada à precipitação dentro dos grãos são: 1) uma razão termodinâmica é a diminuição da barreira de energia da nucleação heterogênea em relação ao seu valor para a nucleação homogênea; (2) o coeficiente de difusão do soluto em qualquer CG é geralmente maior que no volume, o que permite que átomos de soluto rapidamente migrem para qualquer novo núcleo no CG; (3) uma forte segregação, devido ao maior coeficiente de difusão, produz uma saturação de soluto no CG, e então a formação de núcleos de fases secundárias [63]. Além dessas razões mencionadas acima, que dizem respeito ao $\mathrm{CG}$ inteiro, precipitados podem se formar em defeitos intrínsecos do CG, tais como discordâncias e degraus no contorno.

Com a formação de precipitados nos CG, ocorre a formação de interfaces entre o cristal do núcleo precipitado e o cristal da matriz. De acordo com o modo que os cristais se ajustam entre si, pode ocorrer a formação de interfaces coerentes, semi-coerentes e incoerentes.

1 - Interfaces coerentes: quando dois cristais encaixam perfeitamente no plano da interface de modo que as duas redes são contínuas através da interface.

2 - Interfaces semi-coerentes: quando o desajuste entre as distâncias atômicas de cada lado da interface aumenta, surgem discordâncias periódicas, chamadas de discordâncias de desajuste ("misfit dislocations").

3 - Interface incoerente: resulta de uma relação de orientação aleatória entre o núcleo e a matriz.

Como descrito no item 2.1.2, estudos abordando os processos de precipitação bem como os tipos de precipitados formados na Liga 33 após tratamentos isotérmicos são bem reduzidos. Entretanto, os tipos de precipitados reportados na Liga 33 (Tabela 3) já foram extensivamente estudados em diversos tipos de materiais similares à Liga 33, no que diz respeito aos elementos que constituem o material, bem como às aplicações em indústrias de alto desempenho. A seguir, é apresentado um breve resumo sobre algumas características destes precipitados, listados na Tabela 3, e que foram observados no presente estudo. 


\subsubsection{Carbetos $-\mathrm{M}_{23} \mathrm{C}_{6}$ rico em $\mathrm{Cr}$}

Carbetos- $\mathrm{M}_{23} \mathrm{C}_{6}$ já foram reportados em várias ligas multicomponentes após tratamentos térmicos [1][2][52-54][65-87] e também em materiais expostos à radiação [72][73].

\section{Ocorrência dos carbetos- $\mathrm{M}_{23} \mathrm{C}_{6}$}

A precipitação de carbetos- $\mathrm{M}_{23} \mathrm{C}_{6}$ em $\mathrm{CG}$ já foi extensivamente reportada em aços inoxidáveis austeníticos [52-54][65][69-73][75-77] [80][82][84][86-88] e ligas à base de Ni [1][2][74][78][79][83][85]. A precipitação de fases secundárias, tais como carbetos, nos CG, é considerada um fenômeno comum em ligas metálicas devido à alta energia destas regiões na rede cristalina, na qual a taxa de difusão dos elementos formadores dos precipitados aumenta em relação à difusão pela rede cristalina [59]. Entretanto, é bem conhecido que este tipo de precipitação ocorre seletivamente nos CG e que a desorientação angular do CG desempenha um papel fundamental no processo de precipitação [1][2][65][74][76-78]. Aumentando a desorientação angular do $\mathrm{CG}$, a energia livre interfacial do contorno, em geral, também aumenta. Desta forma, diferentes desorientações no contorno representam uma mudança na energia do sistema [62][89]. Consequentemente, esta diferença na energia tem um efeito chave no comportamento da precipitação, o qual fornece evidência da existência de uma energia de nucleação crítica necessária ser ultrapassada para a precipitação ocorrer [76].

Além da precipitação nos $\mathrm{CG}$, a formação de carbetos- $\mathrm{M}_{23} \mathrm{C}_{6}$ também foi reportada ocorrer em contornos incoerentes de macla [1][2][53][65][66][70] [74][76][80][90] e dentro dos grãos da matriz [2][53][65][67][68][70][72][75] [86]. Entretanto, alguns autores [2][52][53] observaram que, com o aumento no tempo de envelhecimento, a precipitação deste tipo de carbeto ocorreu seguindo a sequência: precipitação intergranular $\rightarrow$ precipitação celular $\rightarrow$ precipitação intragranular. 


\section{Estrutura Cristalina e Composição Química do Carbeto- $\mathrm{M}_{23} \mathrm{C}_{6}$}

Carbetos- $\mathrm{M}_{23} \mathrm{C}_{6}$ tem uma estrutura cristalina cúbica de face centrada (CFC) (grupo espacial $F m \overline{3} m$ ) e parâmetro de rede $\mathbf{a}=1.050-1.073 \mathrm{~nm}$ [52] [53][54][59][65][70][72-75][81][91-94], o qual é aproximadamente três vezes maior que o parâmetro de rede da matriz CFC. Esta variação no parâmetro de rede do carbeto- $\mathrm{M}_{23} \mathrm{C}_{6}$ já foi associada com o aumento no teor de Mo no precipitado [70][95]. Normalmente, a relação de orientação (R.O.) cubo-a-cubo, (100) ${ }_{M_{23} C_{6}} /$ $/(100)_{\gamma} ;[100]_{M_{23} C_{6}} / /[100]_{\gamma}$, é reportada ocorrer entre o carbeto- $\mathrm{M}_{23} \mathrm{C}_{6}$ e a matriz CFC, [2][52-54][65][67][70][74][75][81-83][91][96].

Embora baseado em $\mathrm{Cr}_{23} \mathrm{C}_{6}$, além do alto teor de $\mathrm{Cr}$, este carbeto normalmente contém Mo, Fe e Ni e geralmente é reportado ser livre de $\mathrm{Si}$ [70][72][73][84][87][93][94], embora tenha sido recentemente reportado carbeto$\mathrm{M}_{23} \mathrm{C}_{6}$ contendo traços de $\mathrm{Si}$ [97]. Os elementos $\mathrm{Mn}, \mathrm{W}, \mathrm{Ti}, \mathrm{Al}$, Co também já foram reportados constituir o carbeto- $\mathrm{M}_{23} \mathrm{C}_{6}$ [73][85][93][94][97].

\section{Influência do Carbeto- $\mathrm{M}_{23} \mathrm{C}_{6}$ nas Propriedades dos Materiais}

A ocorrência de carbetos- $\mathrm{M}_{23} \mathrm{C}_{6}$ nos $\mathrm{CG}$ foi associada a efeitos deletérios nas propriedades contra a corrosão [86] e fragilização [87][98] em AI austeníticos. Entretanto, efeitos benéficos devido aos precipitados de carbetos- $\mathrm{M}_{23} \mathrm{C}_{6}$ foram reportados em algumas ligas [99][100][101].

\subsubsection{Fase-n enriquecida em Si}

Precipitados enriquecidos em Si, tais como a fase-G [72] [73][102-109], fase-H [110][111] e fase- $\eta$ [6][7][60][70][72][73][105][112-117] já foram reportados em vários tipos de ligas estruturais multicomponentes. Entretanto, a seguir é apresentado um breve resumo com as características somente da fase- $\eta$, já que a fase-G não foi observada no presente trabalho e, segundo, Maziasz [118] a fase-H deveria ter sido referida como fase- $\eta$. 


\section{Ocorrência}

Fase eta $(\eta)$ também referida na literatura como carbeto- $\eta\left(\mathrm{M}_{6} \mathrm{C}\right)$ e $\mathrm{Cr}_{3} \mathrm{Ni}_{2} \mathrm{SiX}(\mathrm{X}=\mathrm{C}$ ou $\mathrm{N}$ ) já foi reportada em aços inoxidáveis irradiados [6][72][73][105][112], aços inoxidáveis envelhecidos [6][7][70][105][112], ligas à base de Ni [6][114][115], entre outras. Dependendo da composição química da liga, esta fase enriquecida em $\mathrm{Si}$ pode precipitar como carbeto [70][72][73][105][113][114][116], nitreto [60] ou carbonitreto [7][117].

\section{Estrutura Cristalina e Composicão Química da Fase-n}

A fase- $\eta$ enriquecida em Si tem estrutura cúbica-diamante (grupo espacial $\mathrm{Fd} 3 \mathrm{~m})$ e parâmetro de rede na faixa de $\mathrm{a}=1.06-1.24 \mathrm{~nm}$ [6][60][72] [73][105][110][111][113][119][120]. Esta variação no parâmetro de rede é influenciada pela composição química do precipitado, a qual é consequência da composição da liga.

Em muitas ligas, a fase- $\eta$ apresenta parâmetro de rede próximo ao do carbeto- $\mathrm{M}_{23} \mathrm{C}_{6}$ (CFC) e também da fase-G (CFC), mas a fase cúbica-diamante é distinguível da estrutura CFC pela ausência das reflexões (200) em padrões de difração no eixo de zona [001] [6][73][105] bem como nas características químicas entre os precipitados [73]. Esta diferença entre ambos os padrões de difração ocorre porque o fator de estrutura da cúbica-diamante prevê ausências sistemáticas das reflexões (200), (420); reflexões que estão presentes para a estrutura CFC [121]. Entretanto, a presença da reflexão (200) não é uma prova direta da estrutura CFC porque dupla difração da matriz quando o precipitado tem uma R.O. cubo-a-cubo, carbetos- $\mathrm{M}_{23} \mathrm{C}_{6}$ selecionado pela abertura de área selecionada pode resultar na intensidade diferente de zero da reflexão (200) e confundir a identificação da fase precipitada [6].

A estrutura referida como $\eta$ inclui uma faixa composicional de $\mathrm{M}_{3} \mathrm{M}_{3}{ }^{\prime} \mathrm{X}$ a $\mathrm{M}_{3} \mathrm{M}_{2}$ 'SiX, onde $\mathrm{M}$ indica um soluto substitucional, tais como $\mathrm{Ni}, \mathrm{Fe}$, ou $\mathrm{Cr}$, enquanto $X$ indicada um elemento intersticial como $C$ ou $N$ [6][91][119]. A composição da fase- $\eta$ tem sido reportada ser flexível [91][116][113][119], mas em geral esta fase cúbica-diamante é enriquecida em Si, Ni e Cr, embora também possa ser constituída por outros elementos, tais como Fe, Mo, Mn, Nb e V [6][7] [72][73][105][111-113][117]. 


\subsubsection{Fase $\alpha-\mathrm{Cr}$}

Precipitados da fase $\alpha$ rica em $\mathrm{Cr}$ na forma convencional (homogênea e heterogênea), chamado de $\alpha-\mathrm{Cr}$, já foram reportados em diversos materiais, tais como ligas a base de Ni [61][85][122-133], metal de solda de liga à base de Ni [134][135], ligas binárias Ni-Cr [136-138] e ternárias [139][140], aços inoxidáveis [102][109].

\section{Ocorrência}

A fase $\alpha$-Cr já foi reportada ocorrer tanto nos CG [123][124][127][129] como no interior dos grãos [61][85][124][125][131] do material. Em algumas ligas multicomponentes contendo menos de $30 \%$ p. Cr, precipitados na forma convencional da fase $\alpha$-Cr foram observados apenas após longos tempos de envelhecimento [85][109][122][123][126][127]. A nucleação desta fase rica em $\mathrm{Cr}$ foi verificada ocorrer na vizinhança da fase- $\delta\left(\mathrm{Ni}_{3} \mathrm{Nb}\right)$ [122][123][128][129], sendo associada ao alto teor de $\mathrm{Cr}$ existente na região adjacente à fase- $\delta$ devido a segregação deste elemento [123][129].

\section{Estrutura Cristalina e Composição Química da Fase $\alpha-\mathrm{Cr}$}

A fase $\alpha$ rica em $\mathrm{Cr}$ tem estrutura cúbica de corpo centrada (CCC) (grupo espacial $\operatorname{lm} 3 \mathrm{~m}$ ) e parâmetro de rede de a $=0.286-0.290 \mathrm{~nm}$ [85][102][124]. Vários autores reportaram que a fase $\alpha-\mathrm{Cr}$ tem uma R.O. Kurdjumov-Sachs (K-S) $(1-10)_{\alpha} / /(1-11)_{\gamma},[111]_{\alpha} / /[011]_{\gamma}$ com a matriz CFC [124][125][138]; entretanto outra R.O. entre a fase $\alpha$-Cr e a matriz CFC foi observada, [211] $]_{\gamma} / /[110]_{\alpha}[138]$. Geralmente, a fase- $\alpha$ é rica em $\mathrm{Cr}$ contendo $\mathrm{Mo}, \mathrm{Fe}$ e Ni; porém outros elementos podem ser absorvidos pela sua estrutura cristalina [85][102][124-126] [130][131][134].

\section{Influência da Fase a-Cr nas Propriedades dos Materiais}

A formação da fase- $\alpha$ rica em $\mathrm{Cr}$ foi reportada ser deletéria para as propriedades mecânicas dos materiais

$[61][123][124]$ [128][129][131][132][135][141]. Entretanto, efeitos benéficos, tais como aumento da resistência à fluência, resultante da precipitação desta fase também foram observados em algumas ligas [61][125][133]. 


\subsubsection{Fase Intermetálica $\sigma$}

Em geral, a formação da fase- $\sigma$ ocorre em temperaturas na faixa entre 500$1100{ }^{\circ} \mathrm{C}$ [4][9][52][54][55][70][72][73][75][84][86][142-159] dependendo das condições de envelhecimento, deformação prévia e composição química da liga [143], sendo reportada em algumas ligas somente após longos tempos de envelhecimento [4][52][70][144][145].

\section{Ocorrência}

A ocorrência da fase- $\sigma$ foi reportada em diversos tipos de materiais estruturais, tais como aços inoxidáveis austeníticos [9][4][52][54][55][70][73] [75][84][86][144-155][160-162], liga à base de Ni [156][163] e aços inoxidáveis duplex [56][157-159][164]. Esta fase intermetálica normalmente precipita nos CG [4][55][70][72][75][142], porém sua formação também foi reportada ocorrer dentro dos grãos [52][55][70] e em contornos incoerentes de macla [70]. Entretanto, atualmente foi reportado [55][56] a fase- $\sigma$ como o principal precipitado constituindo colônias de PD, ou seja, na forma lamelar.

\section{Estrutura Cristalina e Composição Química da Fase- $\sigma$}

A fase- $\sigma$ tem estrutura tetragonal (grupo espacial $\mathrm{P} 4_{2} / \mathrm{mnm}$ ) [4][52][54] [70][141][142][145-148][156][163]. Embora esta fase intermetálica seja normalmente reportada com parâmetro de rede $\mathbf{a}=0.880 \mathrm{~nm}$ e $\mathbf{c}=0.454 \mathrm{~nm}$ [9][52][73][142], variações nestes valores já foram reportados [54][70][142], as quais resultam de diferenças na composição química da fase- $\sigma$ [75]. Também já foram verificadas algumas variações na R.O. entre a fase- $\sigma$ e a matriz CFC, dependendo do liga na qual ocorreu a precipitação [54][55][70] [149][150][157][160]. A composição da fase intermetálica $\sigma$ pode variar com a composição da liga [165], porém normalmente tal fase é reportada ser enriquecida em Cr, Fe e Mo contendo Ni, Mn e Si [70][72][73][84][142][145]. 


\section{Influência da Fase- $\sigma$ nas Propriedades dos Materiais}

A fase intermetálica $\sigma$ é de grande interesse no campo tecnológico de ligas estruturais multicomponentes porque normalmente sua ocorrência, em torno do CG, tem efeitos deletérios nas propriedades mecânicas e de corrosão destes materiais $\quad[4][54][70][75][86][134][142][147][151-154][161][162][166]$. Entretanto, existem casos em que certas propriedades são melhoradas com a precipitação desta fase [142][155][158][159][164].

\subsubsection{Nitreto- $\mathrm{M}_{2} \mathrm{~N}$ rico em $\mathrm{Cr}$}

Aços inoxidáveis austeníticos contendo $\mathrm{N}$ são susceptíveis à formação do nitreto rico em $\mathrm{Cr}$ do tipo $\mathrm{M}_{2} \mathrm{~N}$, quando submetidos a tratamentos térmicos de envelhecimento na faixa de temperatura de 550-1000 ${ }^{\circ} \mathrm{C}$ [4][7][8][9][14-16] [18][22][54][75][144][167-171].

\section{Ocorrência}

$\mathrm{O}$ nitreto- $\mathrm{M}_{2} \mathrm{~N}$ rico em $\mathrm{Cr}$ já foi reportado em diversos tipos de materiais estruturais multicomponentes, tais como AI austeníticos [4][7-9][14-16] [18][22][54][75][144][167-170], AI duplex e superduplex [5][172] e AI martensítico [171]. Este tipo de nitreto foi observado se formar em CG [4][9][15][18][22][75][167], dentro dos grãos da matriz [9][18][22][54] e em contornos incoerentes de macla [18]. Entretanto, vários autores [4][15][16][18] [22][54] observaram que a precipitação do nitreto- $\mathrm{M}_{2} \mathrm{~N}$ ocorreu seguindo a sequência: precipitação heterogênea no CG, precipitação celular (ou descontínua) e precipitação dentro dos grãos.

\section{Estrutura Cristalina e Composição Química do Nitreto- $\mathbf{M}_{2} \mathbf{N}$}

$\mathrm{O}$ nitreto- $\mathrm{M}_{2} \mathrm{~N}$ tem estrutura hexagonal (grupo espacial $\mathrm{P} 6(3) / \mathrm{mmc}$ ) e parâmetro de rede normalmente reportado aproximadamente sendo $\mathbf{a}=0.48 \mathrm{~nm}$ e $\mathbf{b}=0.45 \mathrm{~nm}$ [7][18][54][75]. Entretanto, uma variação no parâmetro de rede foi observada por outros autores [9][171]. Diferentes R.O. entre o nitreto- $\mathrm{M}_{2} \mathrm{~N}$ e a matriz CFC foram verificadas em distintas ligas [8][54][75][168][169]. Embora reportado frequentemente como $\mathrm{Cr}_{2} \mathrm{~N}$, o nitreto- $\mathrm{M}_{2} \mathrm{~N}$ rico em $\mathrm{Cr}$ pode conter 
outros elementos substitucionais, tais como $\mathrm{Ni}$, Mo, $\mathrm{Fe}, \mathrm{Mn}$ e $\mathrm{Si}$ [4][7] [9][144][54].

\section{Influência do Nitreto- $\mathrm{M}_{2} \mathrm{~N}$ nas Propriedades dos Materiais}

Normalmente a formação do nitreto- $\mathrm{M}_{2} \mathrm{~N}$ rico em $\mathrm{Cr}$ é reportada ser deletéria para as propriedades mecânicas e contra a corrosão dos materiais [14-16] [22][167][171].

Em muitas ligas, o processo de precipitação se torna mais complicado pelo fato que a nucleação ocorre tanto de forma homogênea como heterogênea. Como a nucleação heterogênea é mais fácil de ocorrer, os precipitados podem crescer resultando na formação de colônias de precipitados na região dos CG. Tais colônias são resultado do fenômeno de precipitação descontínua, o qual é descrito a seguir.

\subsection{Fenômeno de Precipitação Descontínua}

Precipitação descontínua (PD), de ocorrência em dezenas de sistemas binários, ternários e multicomponentes [23][24] é uma transformação de fase no estado sólido controlada via difusão interfacial, de ocorrência preferencialmente em CG de alto ângulo [24]. Fenomenologicamente, uma solução sólida supersaturada $\left(\alpha_{0}\right)$ é decomposta em uma estrutura bifásica $(\alpha+\beta)$ mais estável atrás de um CG avançando, pela geração de uma fase precipitada $(\beta)$ e a matriz $(\alpha)$ com mesma estrutura cristalina da fase original, porém empobrecida em soluto [23][24]. Assim, esta transformação resulta da migração do contorno de alto ângulo [173] em direção à matriz supersaturada, o qual consome átomos de soluto gerando uma colônia (ou célula) contendo lamelas ou bastonetes alternados de uma fase precipitada e a matriz empobrecida em soluto [23][24]. O esquema ilustrando a reação de PD é mostrado na Figura 2.3. 


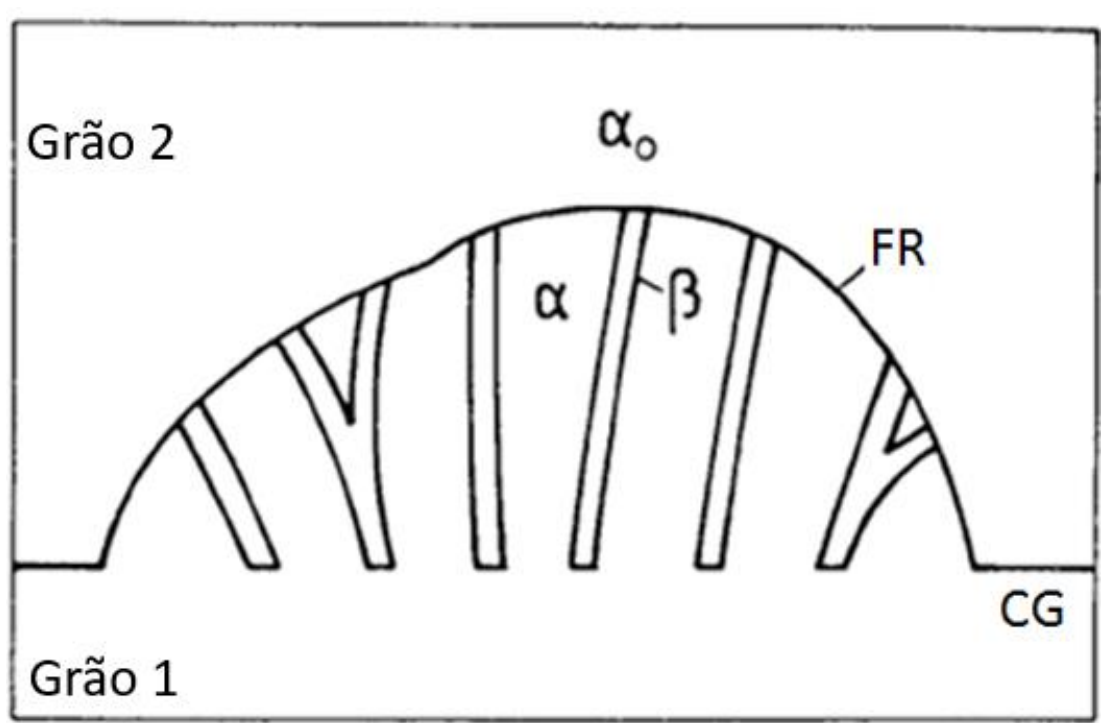

Figura 2.3 - Diagrama esquemático da precipitação descontínua ocorrendo no contorno de grão (CG). FR: frente de reação; $\alpha_{0}$ : matriz supersaturada em soluto; $\alpha$ : matriz empobrecida em soluto; $\beta$ : precipitados lamelares descontínuos (adaptado de [23]).

Também chamada de precipitação celular [62], neste tipo de reação, o CG em movimento atua como frente de reação sob a ação de forças de capilaridade e/ou química, além de atuar como caminho de alta difusividade. Como regra, a relação de orientação do grão inicial (grão 1 na Figura 2.3) é transferida para a colônia de PD crescendo. Isto significa que a lamela $\alpha$ tem a mesma orientação cristalina que a matriz a partir da qual a lamela inicia seu crescimento. Assim, a reação descontínua pode ser descrita essencialmente como precipitação no CG com concorrente migração do contorno, os quais são controlados pela estrutura e propriedades de cada contorno [174-176]. O termo "descontínua" é dado para este fenômeno porque a frente de reação avançando marca uma descontinuidade tanto na orientação cristalina como na concentração de soluto [24].

Uma vez iniciado o movimento do CG, a energia livre química disponível atua como força motriz para o crescimento da reação [23]. Assim, a migração do contorno de célula é controlada pela diferença no potencial químico entre a matriz supersaturada à frente do contorno de célula e a matriz dentro da célula a qual contém uma estrutura de equilíbrio. Então, o mecanismo de difusão dominante ocorre ao longo do contorno de célula avançando e é considerado que a difusão de volume na matriz supersaturada é desprezível para o fenômeno de PD em sistemas binários. 
A partir de ambos os pontos de vistas, científico e industrial, a reação de PD é de grande interesse devido ao efeito deletério sobre propriedades mecânicas, físicas e químicas em muitas ligas comerciais [23][24]. Entretanto, a PD pode ter efeitos positivos em propriedades de transporte e no refino do tamanho de grão através da repetição de ciclos térmicos [24].

\subsubsection{Precipitação Descontínua em Sistemas Binários}

Estudos sobre reações descontínuas tiveram inicialmente foco em ligas binárias contendo apenas solutos substitucionais, tais como Pb-Sn [177][178], Al-Zn [174][179], Al-Mg [180], Cu-In [181][182]. Nestes tipos de materiais, existem contribuições bem estabelecidas que abordam mecanismos de iniciação [177-179][181] e modelos de crescimento cinético [182-187]. Porém, é considerado que devido à variedade de eventos necessários para ocorrer a reação de PD e, ainda, pelo grande número de fatores que podem influenciar tais eventos, qualquer regra simples, capaz de prever a ocorrência da reação descontínua, certamente terá exceções.

Embora a relação entre estrutura do contorno, energia, mobilidade e difusividade seja complexa, é geralmente observado que contornos incoerentes de alto ângulo são locais preferenciais para a ocorrência da PD [23][24]. De modo geral, pode-se ter em mente que o início da reação descontínua depende de dois fatores: precipitação nos contornos e mobilidade dos mesmos em presença de precipitados, o que claramente depende da estrutura individual dos contornos [23][24].

\section{Mecanismos de Iniciação da PD}

Considerações modernas sobre mecanismos de iniciação para a reação descontínua começaram com o desenvolvimento do mecanismo "pucker" proposto por Tu e Turnbull [177][178]. Este mecanismo é agora bem estabelecido como um mecanismo frequentemente operativo em diversas ligas, embora não universal, para a iniciação da PD [24]. Em geral, três diferentes mecanismos de iniciação da PD foram propostos e observados operar em diferentes ligas, e existem evidências que todos podem operar no mesmo sistema dependendo da 
liga e suas condições. Estes essencialmente se dividem em mecanismo onde a precipitação no CG ocorre primeiro e atua para iniciar o movimento do contorno [177][178] e mecanismos nos quais a migração do contorno precede a precipitação [179][181][188]. A seguir, é realizada uma breve descrição destes três diferentes mecanismos para a iniciação da PD.

\section{1) Migração do contorno de grão induzida por precipitação}

O mecanismo proposto por Tu e Turnbull [177][178] em ligas $\mathrm{Pb}-\mathrm{Sn}$ começa a partir da formação de núcleos no CG. De acordo com este mecanismo, placas do precipitado $\beta$ nucleiam no contorno original entre dois grãos supersaturados, com o precipitado em forma de placa tendo uma interface semicoerente (baixa energia) com o grão ao qual a placa está incorporada, e uma interface incoerente (alta energia) com o outro grão. O CG então migra em torno da interface de alta energia substituindo-a por uma interface coerente/semicoerente de baixa energia. A força motriz para esta migração é a redução da energia de superfície $\alpha / \beta$ resultante da substituição da interface de alta energia para uma de baixa energia. O processo de nucleação acima se repete ao longo do CG até vários, identicamente orientados, precipitados $\beta$ paralelos estarem incorporadas em um dos grãos. Estes precipitados migram para a frente alimentadas pela difusão interfacial de soluto, carregando o contorno $\alpha / \alpha$ ' junto com eles. No mecanismo proposto por Tu e Turnbull, a relação precipitado/matriz é a principal exigência para iniciar a reação de PD. Este mecanismo é conhecido como “pucker” e está ilustrado na Figura 2.4. 

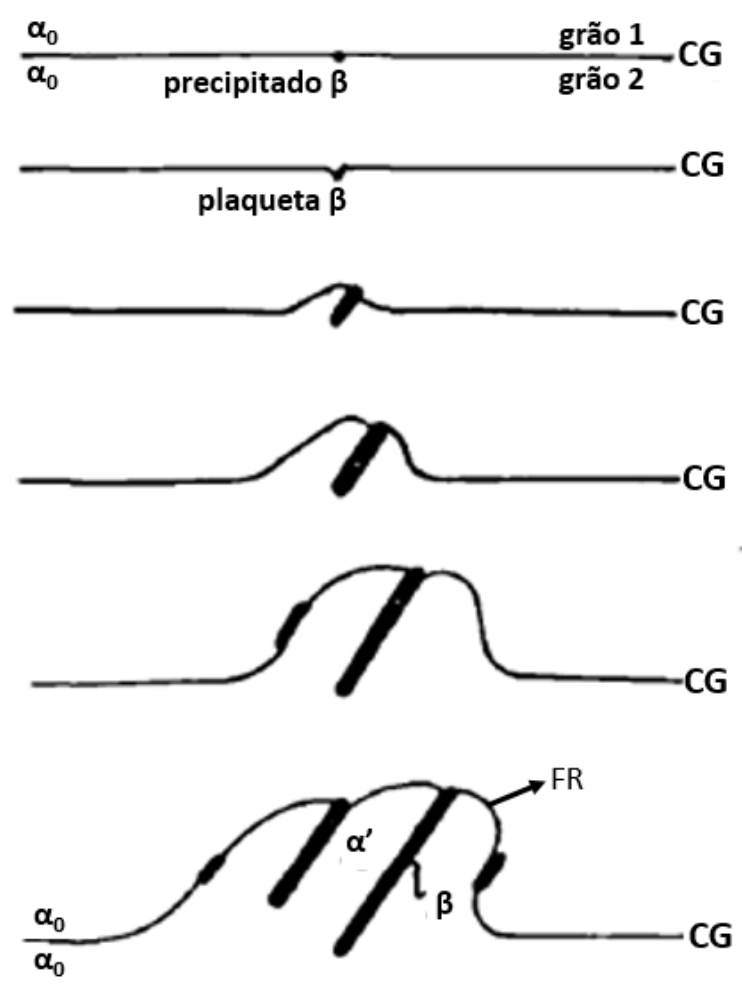

FR $\rightarrow$ frente de reação

CG $\rightarrow$ contorno de grão

Figura 2.4 - Ilustração do mecanismo "pucker" de iniciação da PD proposto por Tu e Turnbull. $\alpha_{0} \rightarrow$ matriz supersaturada; $\alpha$ ' $\rightarrow$ matriz empobrecida em soluto; $\beta \rightarrow$ fase precipitada (adaptado de [23])

\section{2) Precipitação nos Contornos de Grão em Movimento}

Em algumas ligas binárias exibindo PD, tais como Cu-In [181][182], Mg-Al [189] nenhuma relação de orientação parece existir entre a fase precipitada no início da reação de PD e a matriz empobrecida, e a lamela parece ter a habilidade de mudar de direção e ramificar durante o desenvolvimento da colônia de PD [181]. Dentro deste grupo foram propostos dois mecanismos, que diferem entre si em qual é a força motriz para a iniciação da reação: força de capilaridade ou força química. No mecanismo proposto por Fournelle and Clark [181] , foi considerado que a migração do CG sem precipitado, migrando sob a ação de forças de capilaridade ativadas termicamente e com uma leve curvatura no contorno, é a responsável por fornecer a força motriz para a migração.

Como ilustrado na Figura 2.5, após o contorno percorrer uma pequena distância, ocorre a formação de alotriomorfos resultante do acúmulo de soluto no $\mathrm{CG}$, fazendo com que a área atrás do contorno em movimento fique empobrecida 
em soluto. À medida que o contorno se curva, ocorre um aumento no empobrecimento de soluto na região atrás do contorno devido ao particionamento de soluto na interface $\alpha / \alpha$ ' avançando. O soluto segregado pelo contorno em movimento se acumula nos alotriomorfos iniciais, os quais fixarão o contorno. Estes precipitados atuam como receptores para o soluto segregando ao longo da interface avançando. A migração do contorno na mesma direção é favorecida pelo gradiente composicional através do contorno devido à região empobrecida atrás do contorno migrando. Estes precipitados iniciais podem se ramificar ou novos precipitados podem nuclear na interface avançando, para formar a estrutura lamelar final.
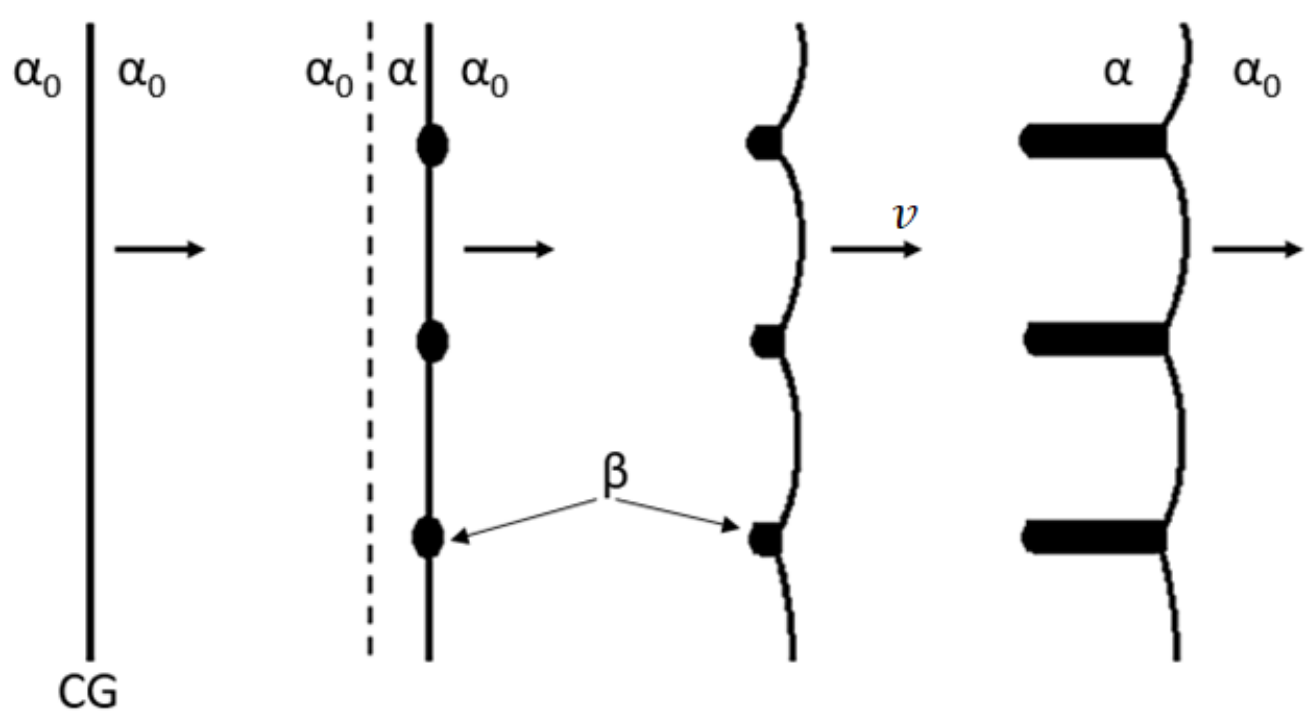

Figura 2.5 - llustração do mecanismo de Fournelle e Clark para a iniciação da reação de PD. $\alpha_{0}$ : matriz supersaturada; $\alpha$ : matriz empobrecida em soluto; $\beta$ : fase precipitada; $C G$ : contorno de grão; $\rightarrow$ representa o CG em movimento; v: velocidade de propagação do CG (adaptado de [181]).

Relações cristalográficas entre os núcleos iniciais e os grãos adjacentes parecem ter mínima influência na estrutura celular final. Estas observações sugerem que a relação cristalográfica entre a matriz transformada e os precipitados é de secundária importância no desenvolvimento da reação celular neste mecanismo [181]. Assim, uma clara diferença entre o mecanismo proposto por Fournelle e Clark [181] e por Tu e Turnbull [177][178] é que no primeiro a orientação matriz/precipitado é de pequena importância. Então, em sistemas em que nenhum plano de hábito específico é observado, o mecanismo "pucker" provavelmente não é operativo [24]. 
Observações sugerem que ambos os mecanismos: (1) migração induzida por precipitação por Tu e Turnbull e (2) precipitação em contornos em movimento por Fournelle e Clark podem operar na mesma liga dependendo da temperatura de envelhecimento. Uma interessante observação verificada sobre os mecanismos de iniciação é a relação entre baixa temperatura de envelhecimento e migração induzida por precipitação e, similarmente, entre alta temperatura de envelhecimento e migração do contorno sem precipitação [24].

Dentro deste mesmo grupo de iniciação da PD (precipitação nos CG em movimento) foi proposto outro mecanismo por Solórzano e Lopes [179] Os autores observaram que os precipitados nuclearam no $\mathrm{CG}$ em movimento inicialmente movido por difusão dos átomos de soluto e não por forças de capilaridade. Assim, o CG migrou induzido por uma força química devido a difusão do soluto ao longo do contorno. Resultados microanalíticos mostraram que nos estágios que antecedem a reação descontínua, a região percorrida pelo contorno fica empobrecida em soluto. Soluto que fará os precipitados heterogêneos crescerem atrás dos contornos em movimento. Neste mecanismo de iniciação da reação de PD, o fenômeno de migração do contorno de grão induzida por difusão (DIGM, “diffusion-induced grain boundary migration”) precede a PD. O esquema deste mecanismo é mostrado na Figura 2.6.
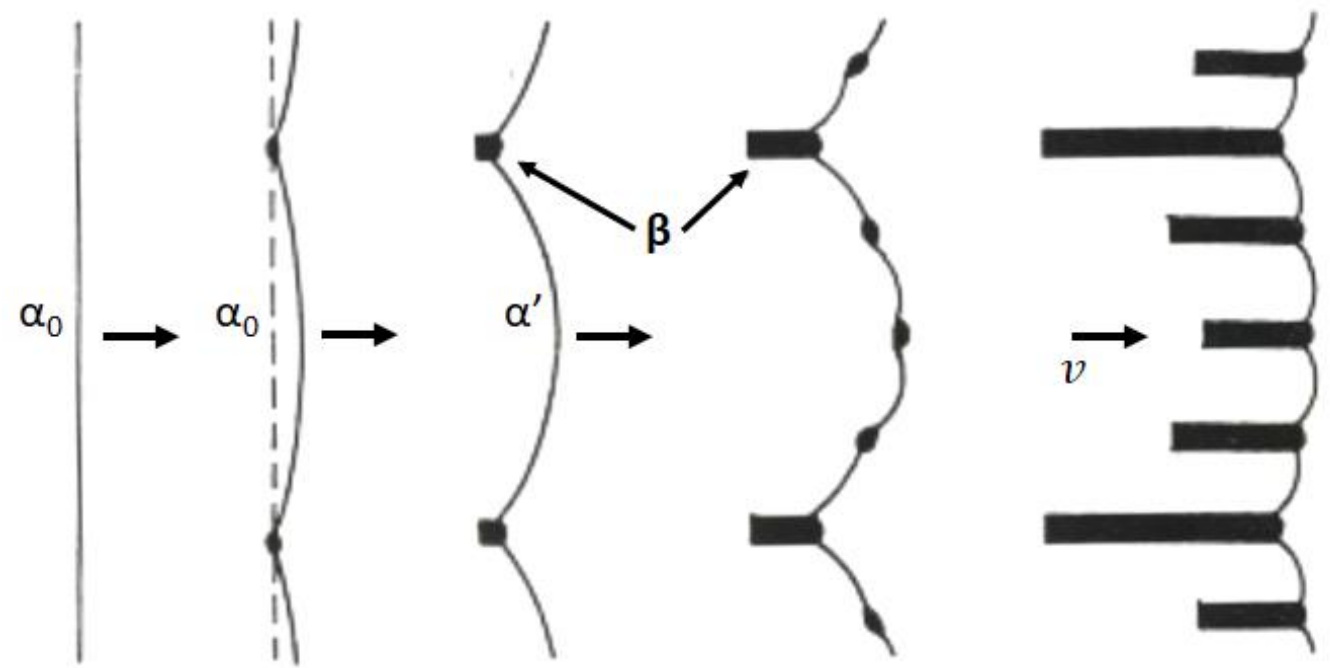

Figura 2.6 - Ilustração do mecanismo de iniciação da PD proposto por Solórzano e Lopes. $\alpha_{0}$ : matriz supersaturada; $\alpha$ : matriz empobrecida em soluto; $\beta$ : precipitado; $\rightarrow$ representa o CG em movimento; v: velocidade de propagação do CG (adaptado de [179]. 


\section{Crescimento da Colônia de PD}

As características ideais do crescimento da reação descontínua, sobre os quais teorias e mecanismos são construídos são de uma frente aproximadamente planar e um espaçamento interlamelar constante. Entretanto, é muito mais comum encontrar colônias de PD com a frente de reação irregular e espaçamento interlamelar com significativas variações, mesmo dentro de células individuais. É estabelecido que o desenvolvimento destas diferenças morfológicas pode ser relacionado à estrutura original do CG [24][176].

$\mathrm{Na}$ tentativa de relacionar qual mecanismo de iniciação da PD pode estar envolvido no processo de crescimento da colônia, Hillert [190] propôs duas possibilidades de configurações na frente de reação avançando, as quais são mostradas na Figura 2.7. Na Figura 2.7a, o contorno $\alpha_{0} / \alpha$ ' é empurrado pelo crescimento do precipitado $\beta$ e na Figura $2.7 \mathrm{~b}$ o precipitado $\beta$ é puxado pelo contorno avançando. Neste sentido, pode ser assumido que em (a) a força motriz para a migração do contorno é induzida pela precipitação, enquanto em (b) a migração do CG é a principal componente da força motriz [24].

(a)

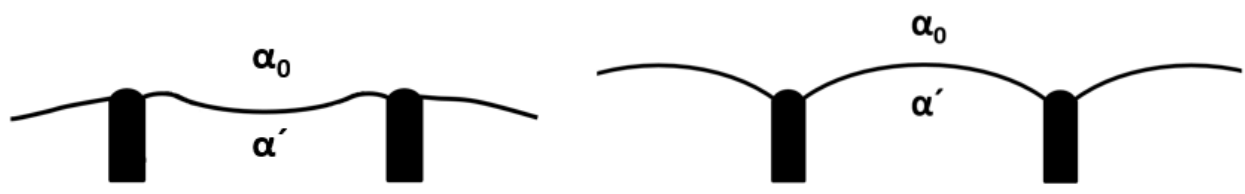

Figura 2.7 - Morfologias possíveis da frente de reação durante o crescimento de acordo com Hillert [190]. Em (a) o crescimento dos precipitados empurra o contorno e em (b) o contorno avançando conduz 0 crescimento das lamelas. $\alpha_{0}$ : matriz supersaturada em soluto; $\alpha$ ': matriz empobrecida em soluto (adaptado de [190]).

Como observado em muitos sistemas onde ocorre a reação de PD, o crescimento de uma colônia de PD pode consumir a matriz supersaturada tanto para um como para os dois lados do mesmo CG. Williams e Butler [24] e Baumann et al. [191] observaram, em ligas binárias, que a formação de morfologia "double seam", a qual é resultado da migração do contorno para ambos os lados do mesmo CG, ocorre preferencialmente a baixas temperaturas e pode ter como precursor o mecanismo proposto por Tu e Turnbull. Por outro lado, em altas temperaturas de envelhecimento, onde mais colônias com morfologia 
"single seam" foram observadas em relação a "double seam", o mecanismo proposto por Fournelle e Clark foi operativo como o responsável pela iniciação da PD. A temperatura de transição entre os dois tipos de morfologias mencionados acima é considerada a metade da temperatura absoluta de fusão $\left(\mathrm{T}_{\mathrm{F}}\right)$ do material [24][191][192]. A segunda forma de desenvolvimento da reação de PD, mencionada acima, (morfologia “double seam”) foi descrita por Fournelle [193] como mecanismo em S, o qual está ilustrado na Figura 2.8.

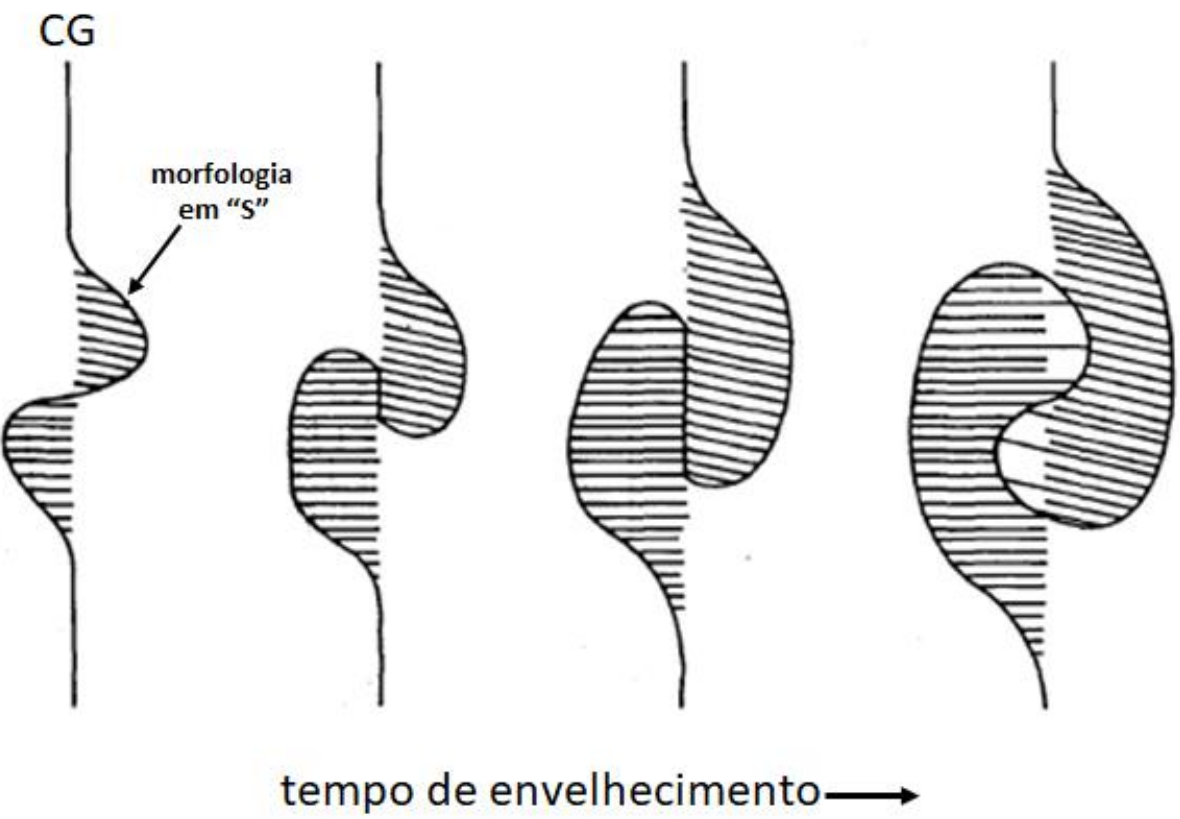

Figura 2.8 - Ilustração do mecanismo de crescimento em S proposto por Fournelle. CG $\rightarrow$ contorno de grão (adaptado de [192]).

Como observado na Figura 2.8, com o crescimento da colônia para ambos os lados do contorno durante o tratamento térmico de envelhecimento, as colônias de PD de um lado tendem a englobar as que estão crescendo do outro lado, podendo formar uma dupla camada de precipitados como produto final, como mostrado na Figura 2.9. Como mencionado anteriormente, essa morfologia de crescimento ocorre predominantemente em baixas temperaturas $\left(<\mathrm{T}_{\mathrm{F}} / 2\right)$ [41][193][194]. 


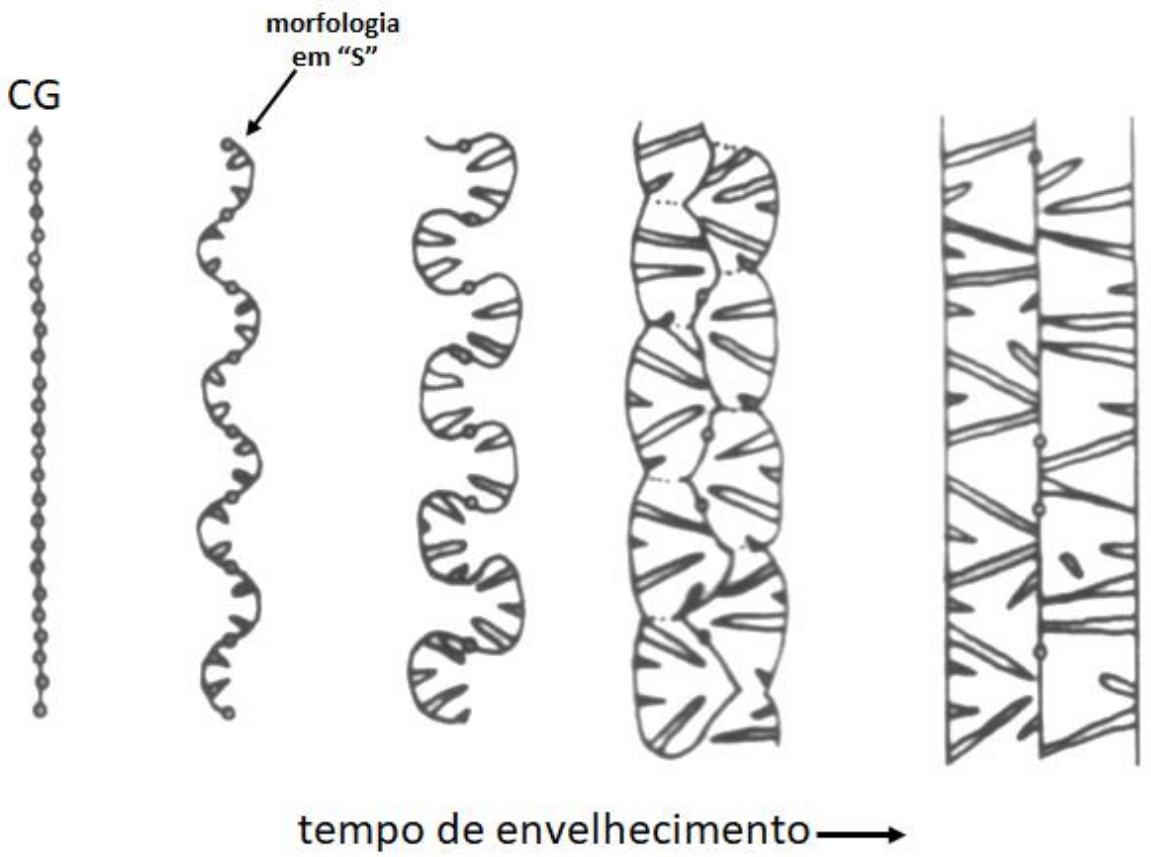

Figura 2.9 - llustração do crescimento em $S$ resultando na morfologia de dupla camada. $C G \rightarrow$ contorno de grão (adaptado de [24]).

Em sistemas binários, nos quais os mecanismos de iniciação e modelos cinéticos foram propostos, as características da cinética de crescimento da reação de PD mostram que a taxa de migração da frente de reação é constante para uma dada temperatura de envelhecimento. Além disso, a composição química na matriz não-transformada, isso na ausência de outra fase precipitada, também permanece constante, já que a reação de PD é controlada pela de difusão de soluto na interface avançando [24][174][181][184][185]. Tal característica não é observada em ligas multicomponentes contendo ambos solutos substitucionais e intersticiais, onde é observado a reação de PD, tornando tais sistemas mais complexos para o estudo deste fenômeno. 


\subsubsection{Precipitação Descontínua em Sistemas Multicomponentes}

\subsubsection{Ligas contendo Solutos Substitucionais e Intersticiais}

Como descrito no item anterior deste trabalho, os estudos sobre reação de PD tiveram início em sua maioria em sistemas binários contendo apenas átomos de soluto substitucionais. A reação de PD em tais sistemas contendo soluto com difusividade da mesma ordem de grandeza que a matriz apresenta características de crescimento bem definidas, tais como a taxa de migração do contorno constante, i.e. a reação ocorre no estado estacionário [23][24]. Entretanto, em sistemas multicomponentes contendo ambos solutos substitucional e intersticial, os quais têm diferentes difusividades, algumas características da reação podem mudar quando comparada com os sistemas binários. Diferentemente do observado em sistemas binários, no qual a reação de PD ocorre no estado estacionário, em sistemas multicomponentes contendo solutos substitucionais e intersticiais o crescimento da PD ocorre no estado não-estacionário [4][148], i.e. a taxa de migração do contorno diminui com o tempo de reação. Então, as características controlando a reação de PD em tais sistemas multicomponentes não são as mesmas observadas em sistemas binários e a reação se torna mais complexa devido aos dois diferentes mecanismos de difusão que podem estar operando, difusão pelo CG e difusão volumétrica. Como consequência da complexidade destes materiais multi-elementares, algumas características de crescimento da PD em tais sistemas multicomponentes, e também o tipo dos precipitados que constituem as colônias, podem sofrer alterações quando a composição do material é modificada [8][53][148][168][195-198]. Entretanto, vale ser destacado que, em todas as ocorrências sobre a reação de PD reportadas na literatura disponível, a fase inicialmente nucleada no CG cresce junto com a migração do contorno, tornando-se a principal fase precipitada dentro da colônia de PD, i.e. os precipitados lamelares.

\section{Ocorrência da Reação de PD}

Reações de PD foram reportados ocorrer na faixa de temperatura de 700$1100^{\circ} \mathrm{C}$ em diversos materiais multicomponentes contendo átomos substitucional 
e intersticial, tais como AI austeníticos [4][8][9][16][18][52][53][148][168] [196-198], ligas à base de Ni [1][74][195][199], Ligas Incoloy 800 e 825 [12][13][20], AI duplex e superduplex [5][11][172]. Em tais ligas multicomponentes contendo solutos substitucional e intersticial, normalmente as colônias de PD são constituídas ou de precipitados lamelares de carbeto- $\mathrm{M}_{23} \mathrm{C}_{6}$ rico em Cr [1][2][11-13][20][52][53][74][195][197-199] ou nitreto- $\mathrm{M}_{2} \mathrm{~N}$ rico em Cr [4][5][8][9][16][18][148][168][172][196][200][201]. Porém, recentemente foram publicados estudos reportando a ocorrência de colônias de PD constituídas de lamelas da fase intermetálica $\sigma$ como a principal fase precipitada dentro da colônia [55][56][202].

A seguir, uma breve descrição é apresentada com algumas características da reação de PD em sistemas multicomponentes contendo ambos átomos substitucionais gerando colônias constituídas dos diferentes tipos de precipitados acima mencionados.

\section{Precipitação Descontínua de Carbetos $\left(\mathrm{M}_{23} \mathrm{C}_{6}\right.$ e VC)}

Embora a migração do $\mathrm{CG}$ resultante da precipitação de carbetos- $\mathrm{M}_{23} \mathrm{C}_{6}$ tivesse sido observada em materiais multicomponentes contendo solutos substitucionais e intersticiais [20], características morfológicas do fenômeno de PD não tinham sido reportadas até 1971, quando Hillert e Lagneborg estudando um AI austenítico observou a formação de colônias de PD contendo carbetos$\mathrm{M}_{23} \mathrm{C}_{6}$ [197]. Com o desenvolvimento de diversos tipos de ligas multicomponentes para aplicações industriais e o aumento no interesse em relação ao papel da reação de PD nestes materiais, diversos estudos sobre a reação de PD contendo carbetos- $\mathrm{M}_{23} \mathrm{C}_{6}$ foram reportados ocorrer nas temperaturas entre 700$900{ }^{\circ} \mathrm{C}$ em materiais estruturais, tais como AI duplex [11], AI austeníticos [52][53][197], ligas à base de Ni [1][2][74][195][199][203], Ligas Incoloy $800 \mathrm{e}$ 825 [12][13][20]. A ocorrência de colônias de PD contendo carbetos de vanádio (VC) também foi observada em uma liga Fe-Mn-V-C [176][204].

Algumas características sobre a ocorrência de colônias de PD constituídas de carbetos- $\mathrm{M}_{23} \mathrm{C}_{6}$ ricos em $\mathrm{Cr}$ que foram reportadas: ocorrência de precipitados lamelares como partículas dentro da colônia [1][2][74][176] e a formação da fase intermetálica $\sigma$ na frente de reação da PD [52]. Vale reforçar o fato de que, nos 
casos mencionados acima, a fase inicialmente nucleada no $\mathrm{CG}$ (carbeto- $\mathrm{M}_{23} \mathrm{C}_{6}$ ) cresceu com a migração do contorno e tornou-se a principal fase precipitada dentro da colônia de PD, ou seja, o carbeto precipitado no CG se tornou o carbeto lamelar descontínuo. Além que, normalmente, uma matriz monofásica decompõese em uma estrutura celular contendo duas fases dentro da colônia de PD: uma matriz empobrecida em soluto e uma fase precipitada (carbeto). Geralmente, a ocorrência de $\mathrm{PD}$ contendo carbetos- $\mathrm{M}_{23} \mathrm{C}_{6}$ é deletéria para as propriedades mecânicas [53][205] e de corrosão [20] dos materiais.

\section{Precipitação Descontínua de Nitretos $-\mathrm{M}_{2} \mathrm{~N}$ ricos em $\mathrm{Cr}$}

A ocorrência de PD contendo nitretos- $\mathrm{M}_{2} \mathrm{~N}$ lamelares, em ligas multicomponentes contendo ambos os átomos substitucional e intersticial, já foi reportada ocorrer na faixa de temperatura de 700-1100 ${ }^{\circ} \mathrm{C}$ em AI duplex e superduplex [5][172] e AI austeníticos [4][8][9][15][16][18][25][144][148] [168][196][198][200][201][206-208]. Como observado na reação de PD contendo carbetos, existem diferenças de uma liga para outra quando avaliado qual mecanismo de difusão governa o crescimento da reação de PD contendo nitretos. Kikuchi et al. [8] reportaram que a precipitação celular de nitretos- $\mathrm{M}_{2} \mathrm{~N}$ ocorreu no estado não estacionário, o que também foi confirmado por outros autores [8][9][17][25][26][200]. A ocorrência de precipitados lamelares como partículas também foi observada dentro das colônias [8][9][168], bem como a formação da fase intermetálica $\sigma$ na frente de reação da colônia [4][148].

Como reportado em PD contendo carbetos, também em colônias contendo nitretos o processo de formação das colônias é o mesmo: a fase inicialmente nucleada no CG (nitreto) cresce juntamente com a migração da frente de reação e torna-se a principal fase precipitada dentro da colônia de PD. Aqui, também uma matriz monofásica se decompõe em uma estrutura celular contendo duas fases dentro da colônia de PD: uma matriz empobrecida em soluto e uma fase precipitada (nitreto). 


\section{Precipitação Descontínua da Fase Intermetálica $\sigma$}

Recentemente, colônias de PD constituídas de fase- $\sigma$ lamelar, ao invés de nitretos ou carbetos, foram observadas em AI austenítico [55], AI duplex [56] e liga à base de Ni [202]. Zhang et al. [56] observaram a formação de colônia celular constituída de fase- $\sigma$ e afirmaram que o processo de crescimento da fase- $\sigma$ celular foi sucessivamente controlado pela difusão intergranular e então pela difusão volumétrica do $\mathrm{Cr}$ e $\mathrm{Mo}$, mas não envolveu a difusão de $\mathrm{C}$ nem $\mathrm{N}$ devido à baixa solubilidade destes elementos intersticiais na fase intermetálica $\sigma$ [54][209], mesmo a liga contendo alto teor de N. Já Zhang et al. [55] reportaram que, aumentando o tempo de envelhecimento, ocorreu a nucleação de nitretos$\mathrm{M}_{2} \mathrm{~N}$ ricos em $\mathrm{Cr}$ tanto na frente de reação da colônia com lameladas da fase- $\sigma$ como na interface da fase- $\sigma$ /matriz CFC e, que com a continuação no processo de envelhecimento, uma nova fase precipitada com estrutura tetragonal, chamada fase-R, também foi observada dentro da colônia de PD.

Como mencionado anteriormente, as características de crescimento controlando as reações de PD em sistemas multicomponentes contendo solutos substitucionais e intersticiais não são as mesmas observadas em sistemas binários contendo apenas solutos substitucionais. No primeiro, a reação de PD torna-se mais complexa (como descrito acima) por causa do envolvimento de dois mecanismos de difusão, difusão pelo CG (como em sistemas binários) e difusão volumétrica. Porém, mesmo nos sistemas multicomponentes citados acima, as características da reação de PD bem como os tipos de precipitados formados dentro da colônia podem variar de sistema para sistema. Assim, vale mais uma vez ser reforçado que a fase inicialmente formada no CG (carbeto, nitreto ou fase$\sigma)$ torna-se a principal fase precipitada dentro da colônia de PD com o aumento no tempo de reação.

\section{Precipitação Descontínua da Fase $\alpha-C r$}

Embora Portella et al. [3] tenha reportado a ocorrência da fase $\alpha$-Cr no CG e dentro da colônia de PD na Liga 33 envelhecida a $700{ }^{\circ} \mathrm{C}$ por 100 h, os autores afirmaram que os precipitados lamelares constituindo a colônia não foram identificados como fase $\alpha$-Cr com estrutura CCC. Neste sentido, colônias de PD 
contendo a fase $\alpha$-Cr como a principal fase precipitada não são muito comuns serem encontradas em ligas multicomponentes, embora já tenha sido reportada sua ocorrência como PD em ligas binárias Ni-Cr [136-138] e ternárias [139][140]. Luo e Weartherly [136] reportaram em uma liga binária Ni-Cr que a reação de PD foi dominante durante o envelhecimento em temperaturas menores que $950{ }^{\circ} \mathrm{C} \mathrm{e}$ que uma R.O. K-S foi encontrada entre a fase $\alpha$-Cr e a matriz, a qual também foi reportada por outros autores [137]. Entretanto, Miller et al. [138] encontrou uma R.O. do tipo N-W entre os precipitados lamelares da fase $\alpha$-Cr e a matriz.

Como mostrado acima, as reações de PD já foram reportadas em vários sistemas multicomponentes, sendo sensíveis a pequenas variações na composição dos materiais bem como alterações na temperatura de envelhecimento que o material é submetido. Estas alterações podem resultar em diferentes mecanismos de iniciação e crescimento da PD, bem como na formação de diferentes fases precipitadas dentro das colônias (carbetos, nitretos, fase- $\sigma$, fase-P) tornando o estudo do fenômeno de PD mais complexo nos materiais multicomponentes contendo átomos substitucionais e intersticiais.

\subsubsection{Precipitação Descontínua em Ligas à base de Ni com Matriz Bifásica}

Uma forma não-usual de colônias de PD foi observada em ligas à base de Ni [10][210][213-219]. Em tais materiais, uma matriz supersaturada bifásica (matriz + precipitados) se decompõe em uma colônia constituída por 3 diferentes fases: uma matriz $\gamma$ contendo precipitados lamelares da fase $\mathrm{P}$ (ortorrômbica grupo espacial Pnma [10][210][213][214][217][216][219]) e lamelas precipitadas $\gamma$, como mostrado a seguir:

$$
\gamma_{\text {matriz supersaturada }}+\gamma_{\text {precipitados }} \rightarrow\left(\gamma_{\text {matriz }}+\gamma_{\text {precipitados }}\right)+\text { Fase } P
$$

Entretanto, alguns autores [10][219] verificaram que neste tipo de reação de PD, curiosamente, a matriz supersaturada $\gamma$ foi transformada em precipitados $\gamma$ e os precipitados $\gamma^{\prime}$ tornou-se a nova matriz $\gamma$, como mostrado a seguir. Este tipo de transformação não ocorre na reação descontínua em sistemas binários nem em 
sistemas multicomponentes com matriz monofásica, nos quais a matriz permanece a mesma.

$\gamma_{\text {matriz supersaturada }}+\gamma_{\text {precipitados }}^{\prime} \rightarrow\left(\gamma_{\text {matriz }}^{\prime}+\gamma_{\text {precipitados }}\right)+$ Fase $P$

Também como observado em colônias de PD constituídas de carbetos e nitretos, a fase-P encontrada dentro das colônias neste tipo de reação descontínua pode variar entre lamelas e partículas [10][210]. A formação de colônias de PD contendo a fase-P em ligas à base de Ni tem sido reportada como deletéria para as propriedades mecânicas [218][219] destes materiais. 


\section{Procedimento Experimental}

\subsection{Liga 33 como recebida}

$\mathrm{O}$ material usado neste trabalho foi uma liga à base de Cr-Fe-Ni-N resistente à corrosão - Liga 33 ou Nicrofer 3033 (UNS20033) desenvolvida pela Krupp-VDM AG e Bayer AG, Alemanha [27]. O material na condição como recebido constitui uma chapa solubilizada de $5 \mathrm{~mm}$ de espessura com composição química mostrada na Tabela 3.1.

Tabela 3.1 - Composição química da Liga 33 usada neste estudo (\%p.).

\begin{tabular}{|c|c|c|c|c|c|c|c|c|c|c|}
\hline $\mathrm{Cr}$ & $\mathrm{Fe}$ & $\mathrm{Ni}$ & $\mathrm{Mo}$ & $\mathrm{Cu}$ & $\mathrm{N}$ & $\mathrm{C}$ & $\mathrm{Mn}$ & $\mathrm{P}$ & $\mathrm{S}$ & $\mathrm{Si}$ \\
\hline 32.75 & *Bal. & 31.35 & 1.49 & 0.54 & 0.40 & 0.012 & 0.63 & 0.014 & 0.002 & 0.30 \\
\hline
\end{tabular}

*Bal. $=$ Balanço

\subsection{Tratamentos Térmicos de Envelhecimento}

Amostras da Liga 33 na condição como recebida com dimensões: $(10 \mathrm{~mm}$ largura $\times 10 \mathrm{~mm}$ comprimento x $5 \mathrm{~mm}$ altura) foram isotermicamente envelhecidas na temperatura de $800{ }^{\circ} \mathrm{C}$ por $10 \mathrm{~min}, 30 \mathrm{~min}, 1 \mathrm{~h}, 2 \mathrm{~h}, 5 \mathrm{~h}, 10 \mathrm{~h}, 20$ $\mathrm{h}, 50 \mathrm{~h}$ e $100 \mathrm{~h}$. Todas as amostras após o envelhecimento foram resfriadas por têmpera em água em temperatura ambiente. A maioria dos tratamentos térmicos foram realizados na PUC-Rio - Brasil, porém tratamentos complementares também foram realizados na Universidade de Manchester - UK durante o período do doutorado-sanduíche realizado na citada universidade.

\subsection{Técnicas de Caracterização Micro/NanoEstrutural e Analítica}

A fim de entender os processos de precipitação na Liga 33, tendo maior foco o fenômeno de PD, a microestrutura das amostras na condição como recebida e após os tratamentos térmicos foi analisada e documentadas por microscopia ótica (MO), microscopia eletrônica de varredura (MEV) e microscopia eletrônica de transmissão e varredura (MET/STEM, "scanning transmission electron microscopy"). Ambos os microscópios eletrônicos tinham acoplado um espectrômetro de dispersão de energia de raios-X (XEDS, "X-ray energy dispersive spectroscopy"). Todas as amostras para análises no MO, MEV, e MET/STEM foram preparadas da mesma maneira. Fatias das amostras da Liga 
33 tratadas termicamente e na condição como recebida foram obtidas. Tais fatias foram lixadas até atingir a espessura de aproximadamente $100 \mu \mathrm{m}$ de espessura, e assim, discos de $3 \mathrm{~mm}$ de diâmetro foram extraídos das folhas finas resultantes do processo de lixamento. Para finalizar o preparo das amostras, polimento/ataque eletrolítico com uma solução de $20 \%$ de ácido perclórico e $80 \%$ de metanol foi realizado em um instrumento de polimento eletrolítico de duplo jato (Tenupol 5Struers) na temperatura de $-40{ }^{\circ} \mathrm{C}$ e voltagem de $13 \mathrm{~V}$.

A seguir, é realizada uma breve descrição das técnicas de caracterização utilizadas neste estudo.

\subsubsection{Microscopia Óptica (MO)}

A caracterização por MO foi realizada em um microscópio Carl Zeiss, Axioplan 2 Imaging com captura digital da imagem por uma câmera Axiocam HR CCD (Carl Zeiss) no Laboratório de Caracterização de Materiais da PUC-Rio Brasil.

Na microscopia metalúrgica [221], o principal modo de obtenção de imagens é fazendo o uso da reflexão da luz. A amostra metálica pode ser iluminada tanto verticalmente, i.e. normal à superfície da amostra ao longo do eixo óptico do microscópio, ou obliquamente, produzindo iluminação nos modos campo claro e campo escuro, respectivamente. No modo campo claro (BF, "bright-field"), o feixe de luz proveniente dos grãos que são perpendiculares ao feixe incidente é refletida de volta para a lente objetiva do microscópio, enquanto a luz proveniente de defeitos cristalinos na microestrutura (tais como CG), e áreas inclinadas da superfície, é refletida para longe da lente objetiva, assim o defeito tem um contraste escuro. Por outro lado, com a iluminação no modo campo escuro (DF, “dark-field") a luz refletida em superfícies que são quase perpendiculares com o eixo óptico do microscópio é refletida para longe da lente objetiva, enquanto a luz provenientes de defeitos na microestrutura é enviada direto para a lente objetiva [221]. A Figura 3.1 ilustra imagens obtidas no MO no modo campo claro e campo escuro. 

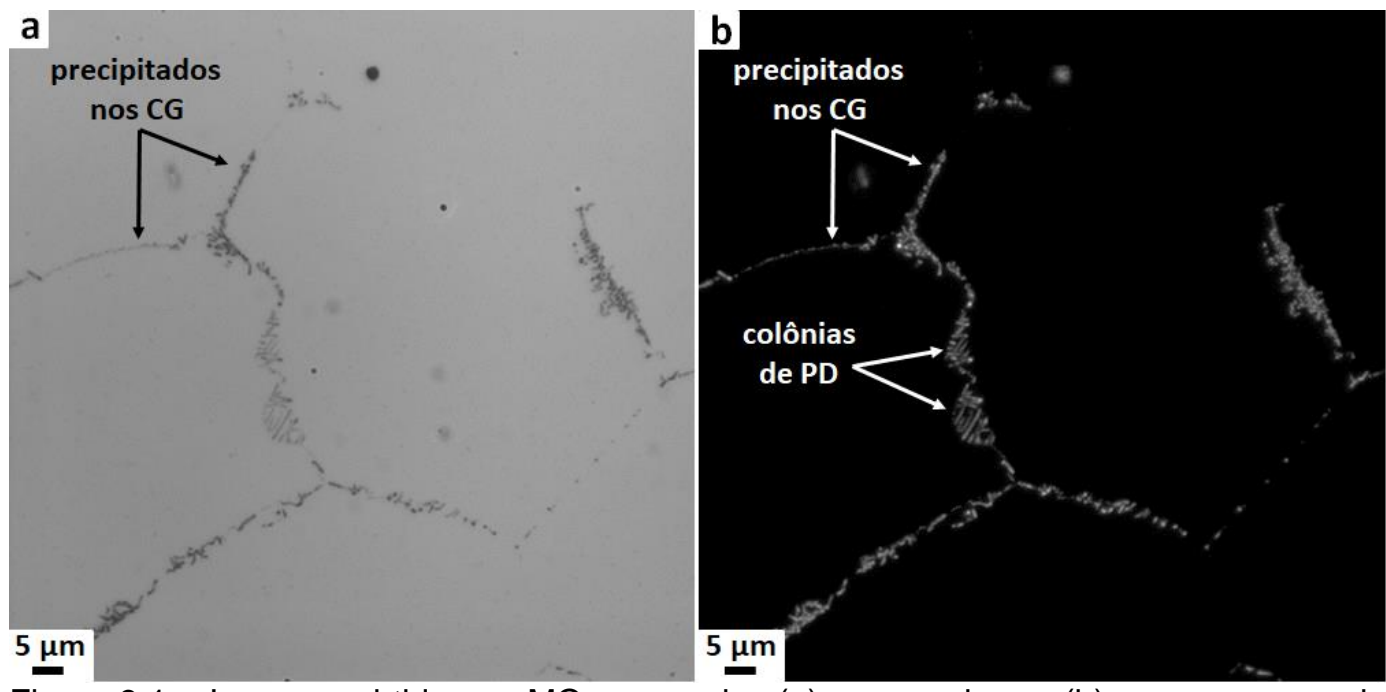

Figura 3.1 - Imagens obtidas no MO nos modos (a) campo claro e (b) campo escuro da Liga 33 envelhecida a $800{ }^{\circ} \mathrm{C}$ por 2 h. CG: contorno de grão; PD: precipitação descontínua.

\subsubsection{Microscopia Eletrônica de Varredura (MEV)}

O microscópio eletrônico de varredura (MEV) é um instrumento que permite a observação e caracterização de materiais orgânicos e inorgânicos heterogêneos e superfícies na escala micrométrica e submicrométrica. Nesta técnica, a área analisada é irradiada com um feixe de elétrons finamente focalizado, o qual pode ser estático ou varrer a superfície da amostra. Os tipos de sinais produzidos quando o feixe eletrônico atinge a superfície da amostra incluem elétrons secundários (SE, "secondary electrons"), elétrons retroespalhados (BSE, "backscattered electrons"), elétrons Auger, raios-X característicos, e outros. Estes sinais (Figura 3.2) são gerados de um específico volume de emissão dentro da amostra (Figura 3.3) e tais sinais podem ser utilizados para estudar diversas características da amostra do material de interesse (composição, topografia da superfície, cristalografia, etc.) [222]. No MEV, os sinais de maior interesse para os estudos de materiais metálicos são os elétrons secundários e retroespalhados juntamente com os raios- $\mathrm{X}$ característicos, os quais serão brevemente descritos a seguir. 


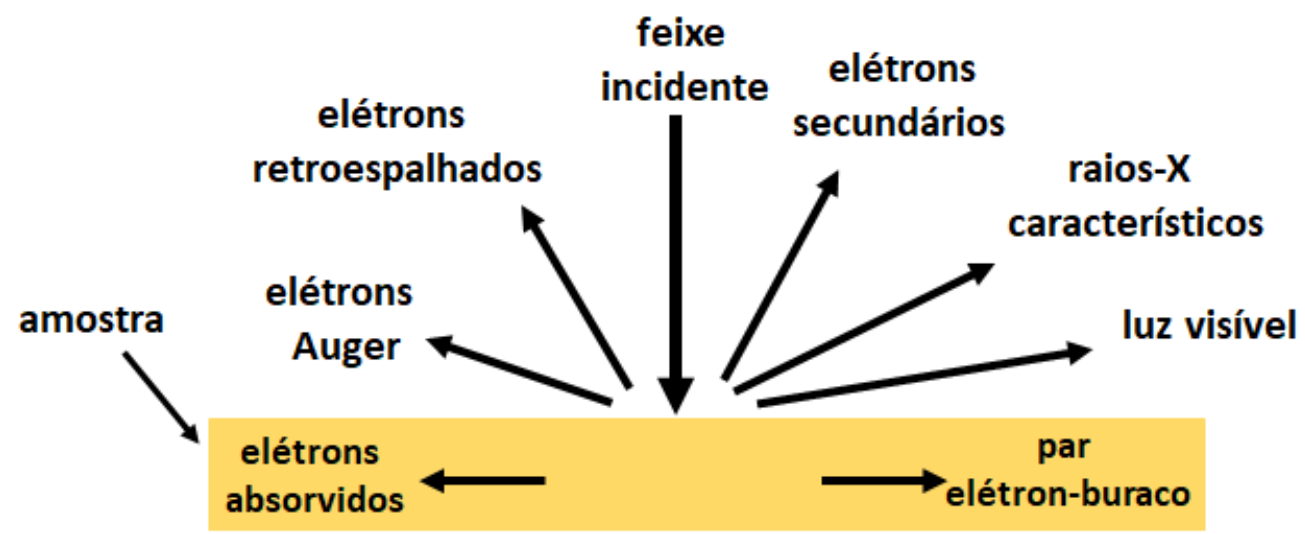

Figura 3.2 - Sinais gerados na interação do feixe de elétrons com a amostra no MEV (adaptado de [220]).

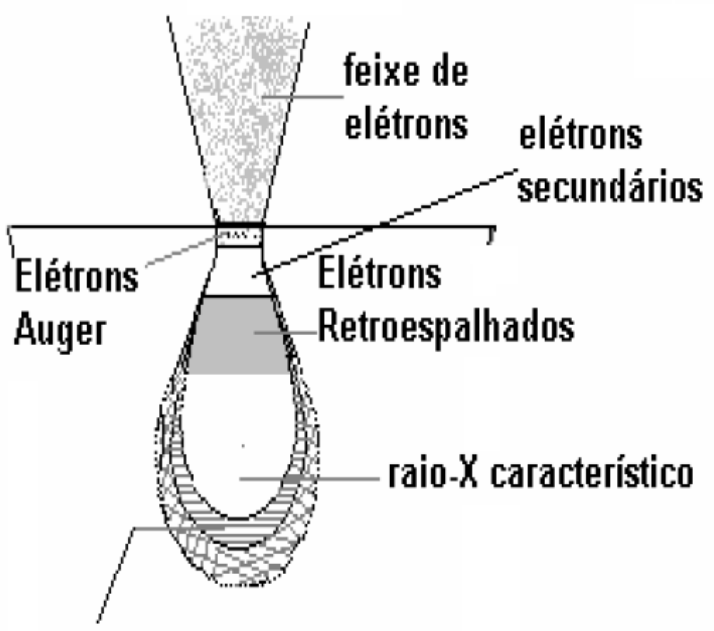

\section{Fluorescência de raio-X}

Figura 3.3 - Volume de interação dos sinais emitidos pela amostra no MEV. As dimensões na figura são ilustrativas (adaptado de [257]).

Elétrons secundários (SE) são elétrons ejetados da camada mais externa da amostra durante o espalhamento inelástico na interação do feixe de elétrons em comparação com os elétrons retroespalhados. Este tipo de elétrons é definido baseados na sua energia cinética; que é, todos elétrons emitidos da amostra com energia menor de $50 \mathrm{eV}$ são considerados elétrons secundários. Como mostrado na Figura 3.3, a emissão dos elétrons secundários é confinada em um volume próximo da interação do feixe eletrônico, permitindo a captura de excelentes informações topográficas da amostra (Figura 3.4a) [222].

Os elétrons retroespalhados (BSE) são elétrons de alta energia resultantes do espalhamento elástico. Este tipo de elétrons fornece um sinal extremamente 
útil para a geração de imagens no $\mathrm{MEV}$ e, consequentemente, para o estudo e caracterização de materiais metálicos. Este sinal tem menor resolução topográfica que os elétrons secundários, porém com seu uso é possível obter informação relacionada com o número atômico do material, fornecendo informações cristalográficas e com contraste de composição [222]. Um exemplo de imagens de MEV-BSE é mostrado na Figura 3.4b.

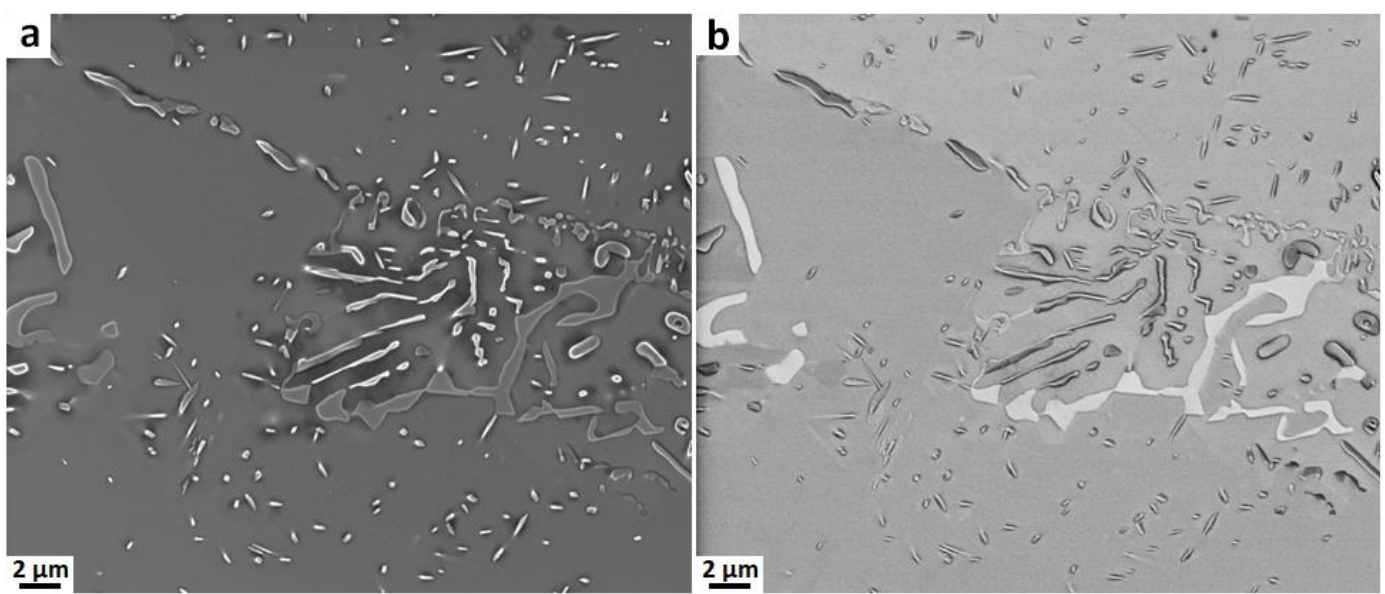

Figura 3.4 - Imagens de MEV da Liga 33 envelhecida a $800{ }^{\circ} \mathrm{C}$ por $50 \mathrm{~h}$ obtidas com (a) elétrons secundários e (b) elétrons retroespalhados.

Os raios-X característicos são gerados pelo bombardeamento de elétrons na amostra, o que gera a emissão de raios-X com energias características contendo informações sobre a composição química da amostra. Na microanálise de raios-X é utilizado um espectrofotômetro de energia dispersiva de raios-X (XEDS) para contar e classificar os raios- $\mathrm{X}$ de acordo com sua energia. Com o uso desta técnica é possível obter espectros pontuais, mapeamento elementar bem como realizar uma análise em linha na amostra de interesse.

\subsubsection{Difração de Elétrons Retroespalhados (EBSD)}

A difração por elétrons retroespalhados (EBSD) causou um impacto impressionante na caracterização de materiais por ser uma técnica automatizada que permite obter a orientação cristalina em uma amostra muito rapidamente [223]. A aquisição e análises de dados (padrões de difração) são realizadas rotineiramente por softwares sofisticados, produzindo conjuntos de dados extremamente ricos que podem ser interpretados quanto à textura cristalográfica, estrutura de deformação local, orientação e forma dos grãos [223][224]. Assim, a técnica de EBSD permite a medida de microtextura, quantificação microestrutural, 
caracterização de CG e de fase, identificação de fase e determinação de tensão local em materiais cristalinos multifásicos de qualquer estrutura cristalina [225].

Mapas de EBSD são formados pela aquisição e análises de padrões de difração de Kikuchi a partir da superfície de uma amostra no MEV [225]. Os mapas são formados pelo movimento do feixe de elétrons focalizado na superfície da amostra, ponto a ponto, através de posições na superfície da amostra. A cada ponto, elétrons retroespalhados são difratados nos planos da rede cristalina dentro do volume de interação feixe/amostra, de acordo com a Lei de Bragg. A amostra é geralmente inclinada $\left(60^{\circ}\right.$ a $\left.80^{\circ}\right)$ em direção ao detector, como ilustrado na Figura 3.5, para aumentar a qualidade do padrão detectado. Cada padrão de difração consiste de muitas bandas de intensidade elevada. Tais bandas parecem à primeira vista ter bordas retas paralelas, mas na verdade as bordas são levemente curvas e são a hipérbole formada pela intersecção dos cones de difração de Kossel com o plano do detector. Os padrões são transferidos para o computador para a indexação e determinação da orientação do cristal [224][225].

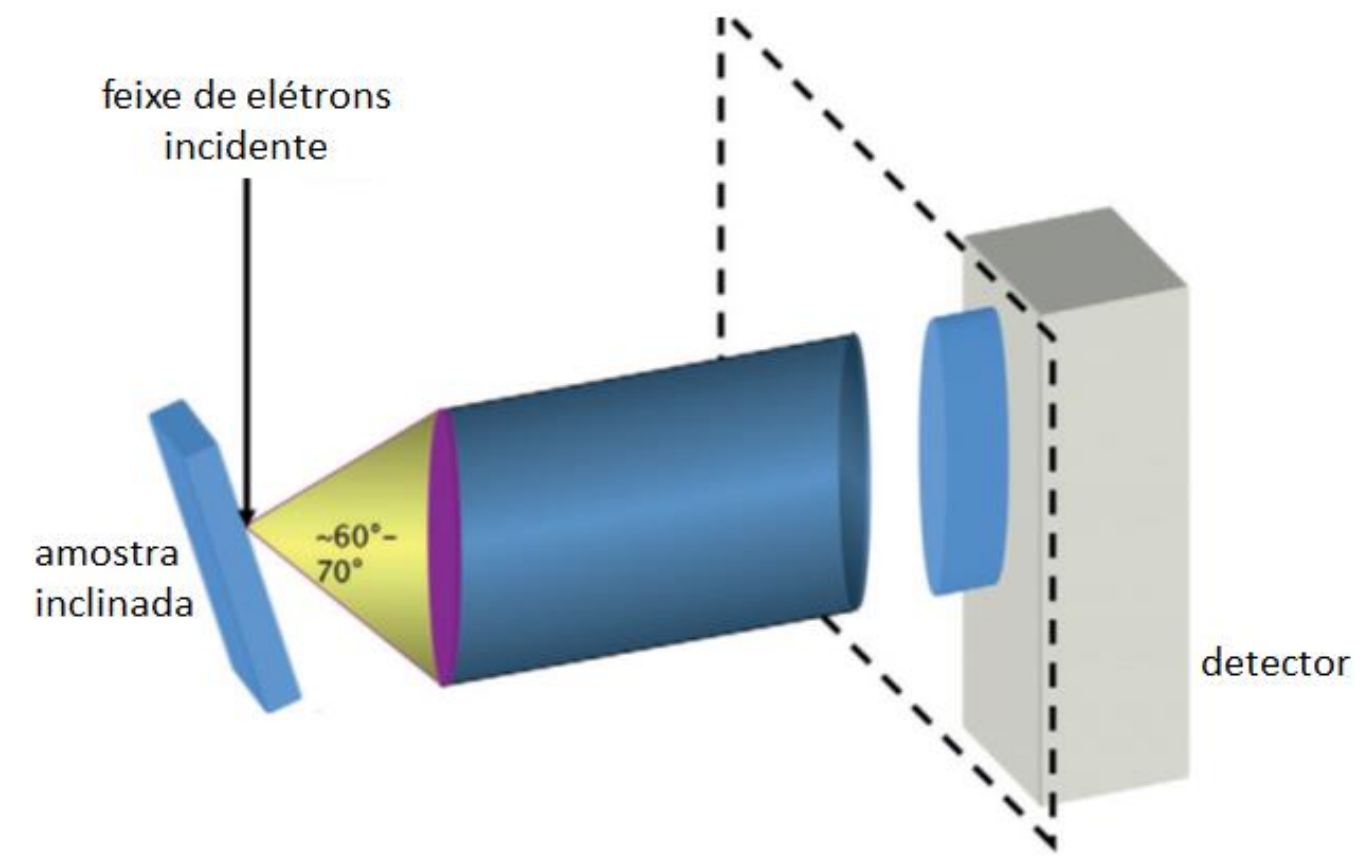

Figura 3.5 - Diagrama esquemático mostrando o conjunto experimental simplificado para observações por EBSD (adaptado de [224]).

Nenhuma técnica de microscopia fornece corretas informações sem uma adequada preparação de amostras. Para EBSD, processos de metalografia padrão, tais como corte da amostra, lixamento e polimento são os pontos iniciais. Entretanto, como o padrão de EBSD é gerado a partir de uma camada superficial 
muito fina ( 40nm) de material, adicional cuidado deve ser tomado para assegurar que as etapas finais do polimento deixe a superfície da amostra livre de qualquer dano do corte/lixamento [224].

EBSD tem sido usado para muitos aspectos de caracterização de materiais incluindo caracterização de tipos de CG, estabelecendo relações epitaxiais entre camadas sobre substratos em sistemas metálicos, semicondutores e supercondutores, caracterizando textura e suas alterações durante deformação e recozimento em ligas metálicas e amostras geológicas, estabelecendo tamanho de grão e componentes de textura durante a deformação e recozimento, entre outros [224].

A caracterização microestrutural realizada durante este trabalho foi realizada em vários MEV dependendo da disponibilidade de uso dos equipamentos. Os específicos MEV utilizados estão listados abaixo:

\section{- Zeiss Sigma (Universidade de Manchester - UK)}

O Zeiss Sigma é um MEV com canhão por emissão de campo (FEG, “field emission gun") equipado com instrumento Oxford X-Max 150 SDD para análises microanalíticas por XEDS e sistema de análise Aztec. Este microscópio foi principalmente utilizado na obtenção de imagens em SE/BSE da superfície da amostra utilizando $5 \mathrm{kV}$ e para as análises por XEDS foi utilizado $15 \mathrm{kV}$. Para o mapeamento elementar por XEDS foi utilizado $300 \mu$ s de "pixel dwell time" num total de tempo por mapeamento de $900 \mathrm{~s}$ e o tempo de aquisição nas análises pontuais por XEDS foi de $100 \mathrm{~s}$ de "live time" para cada espectro obtido. Para a obtenção de mapas cristalográficos por EBSD foi usado $20 \mathrm{kV}$ de energia do feixe.

\section{- Zeiss Ultra 55 (Universidade de Manchester - UK)}

O Zeiss Ultra 55 também é um MEV-FEG, equipado com detector Oxford EDX $\mathrm{Si}(\mathrm{Li})$ e sistemas de análises INCA, foi usado para observação da superfície das amostras e captura de imagens em SE/BSE utilizando $5 \mathrm{kV}$ de energia do feixe de elétrons. 


\section{- FEI Magellan (Universidade de Manchester - UK)}

O MEV-FEG FEI Magellan XHR equipado com instrumento Oxford Xmax 80 SDD e sistema de EBSD de alta resolução foi utilizado para obter imagens nos modos SE/BSE, bem como mapas cristalográficos por EBSD da matriz austenítica da Liga 33. Para a captura das imagens e mapas cristalográficos (EBSD) foram utilizados $5 \mathrm{kV}$ e $20 \mathrm{kV}$, respectivamente.

\section{- JEOL JSM 7100F (CBPF - Brasil)}

O MEV-FEG JEOL 7100F, equipado com instrumento Oxford Xmax 80 SDD e detector EBSD, foi utilizado para obter imagens nos modos SE/BSE, bem como mapas cristalográficos por EBSD. Para a captura das imagens e mapas cristalográficos foram utilizados $20 \mathrm{kV}$.

\subsubsection{Microscopia Eletrônica de Transmissão (MET)}

\subsubsection{Microscopia Eletrônica de Transmissão Convencional (CTEM, "Conventional Transmission Electron Microscopy")}

O microscópio eletrônico de transmissão (MET) juntamente com suas técnicas associadas é um dos mais versáteis instrumentos de caracterização micro e nanoestrutural utilizados nas ciências dos materiais. A interação do feixe de elétrons com a amostra muito fina pode gerar um número de diferentes sinais, ilustrado na Figura 3.6, os quais podem ser utilizados para construir imagens, obter padrões de difração e realizar análises espectroscópicas. Assim, com o uso do MET é possível estudar os materiais no que se refere à características morfológicas e estruturais, composição química, além de propriedades eletrônicas.

O MET é considerado por muitos como a mais poderosa ferramenta para a ciência dos materiais. Este instrumento opera com os mesmos princípios básicos que o microscópio óptico, mas com o uso de elétrons ao invés de luz visível. Devido ao comprimento de onda dos elétrons ser muito menor que o da luz visível, a resolução alcançada nas imagens de MET é muitas ordens de grandeza maior que as imagens obtidas no MO. Neste equipamento, um canhão de elétrons no topo do MET emite elétrons que são acelerados e focalizados com o uso de lentes eletromagnéticas em um feixe muito fino, da ordem de poucos nanômetros. 
Esse feixe eletrônico de alta energia passa através de uma amostra fina (10 - 50 nm) e, com a interação entre os elétrons e os átomos do material (amostra) é possível utilizar os sinais gerados para estudar e caracterizar o material de interesse, no que se refere a estrutura e defeitos cristalinos e composição química tanto na escala nano como atômica.

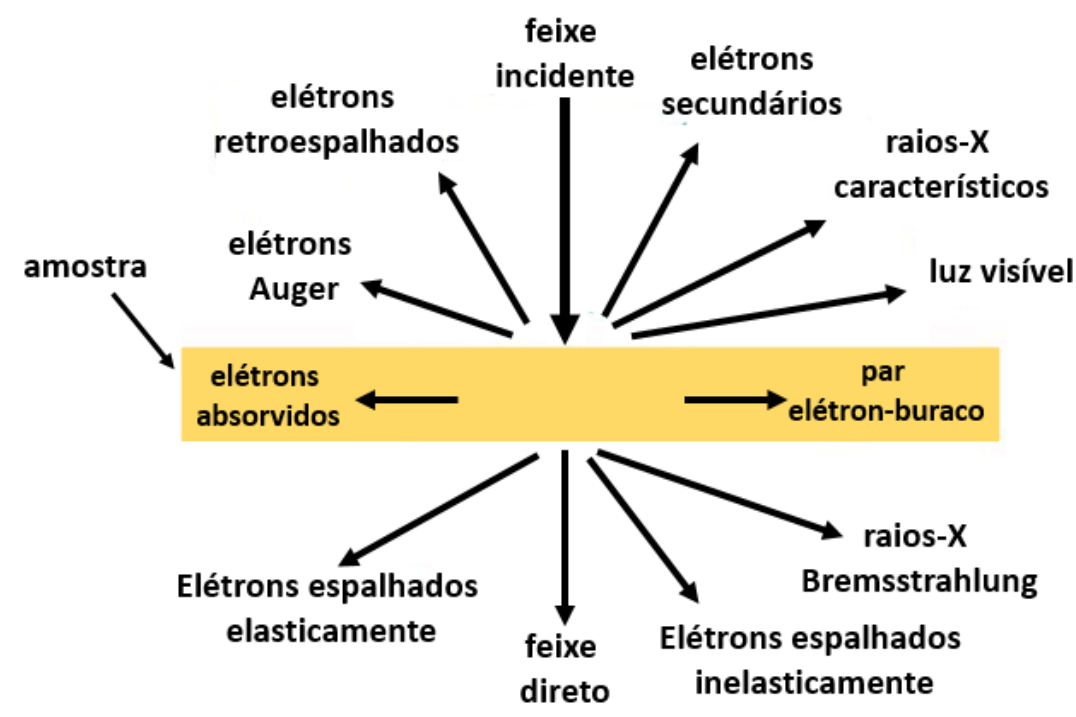

Figura 3.6 - Sinais gerados na interação do feixe de elétrons com a amostra no MET (adaptado de [220]).

No MET, dos diversos sinais que são gerados pela interação do feixe de elétrons com a amostra, são utilizados com mais frequência o feixe direto (não difratado), feixes difratados e os raios-X característicos. No modo de operação chamado de convencional, os elétrons que atravessam a amostra, não-difratados e difratados pela rede cristalina do material (isso, para materiais cristalinos), são utilizados para obter imagens nos modos campo claro (BF) e campo escuro (DF). Durante a operação do MET, ao selecionar o feixe direto, localizado no centro do padrão SAED, com a abertura da lente objetiva, uma imagem no modo BF é gerada (Figura 3.7a). Porém, caso um dos feixes difratados pela amostra seja selecionado, ao invés do feixe direto, uma imagem no modo DF é obtida. Para obter uma imagem no modo DF, como mostra a Figura 3.7b, a abertura da lente objetiva é deslocada para selecionar o feixe difratado, o que pode gerar/aumentar problemas com astigmatismo e aberrações. Uma alternativa é a obtenção da imagem em campo escuro centrado (CDF, "centered dark field"), no qual o feixe incidente é inclinado num ângulo igual ao ângulo de espalhamento (20) de modo 
que o feixe difratado seja posicionado no mesmo ponto que o feixe direto (Figura 3.7c). Este modo de operação do MET torna possível a obtenção de imagens por contraste de difração, o qual depende da orientação cristalina da região analisada em relação ao feixe de elétrons; além de possibilitar, via padrão SAED, a identificação de diferentes fases presentes no material. A Figura 3.8 apresenta um par de imagens em BF/CDF juntamente com o padrão SAED obtido da interface precipitado/matriz (indicado pelo círculo).

a)

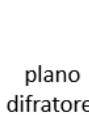

eixo óptico

difratores

\& feixe

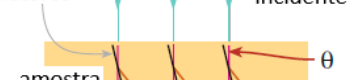

amostra
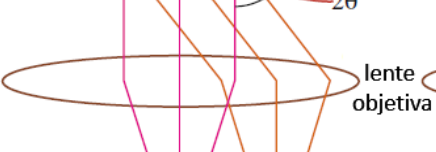

feixe direto

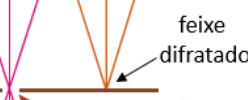

abertura da lente objetiva

b)

eixo óptico

plano
difratores

|

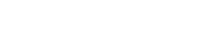

Figura 3.7 - llustração do diagrama de raios mostrando o processo de obtenção de imagens em (a) BF, (b) DF e (c) CDF no modo contraste de difração (adaptado de [220]). 

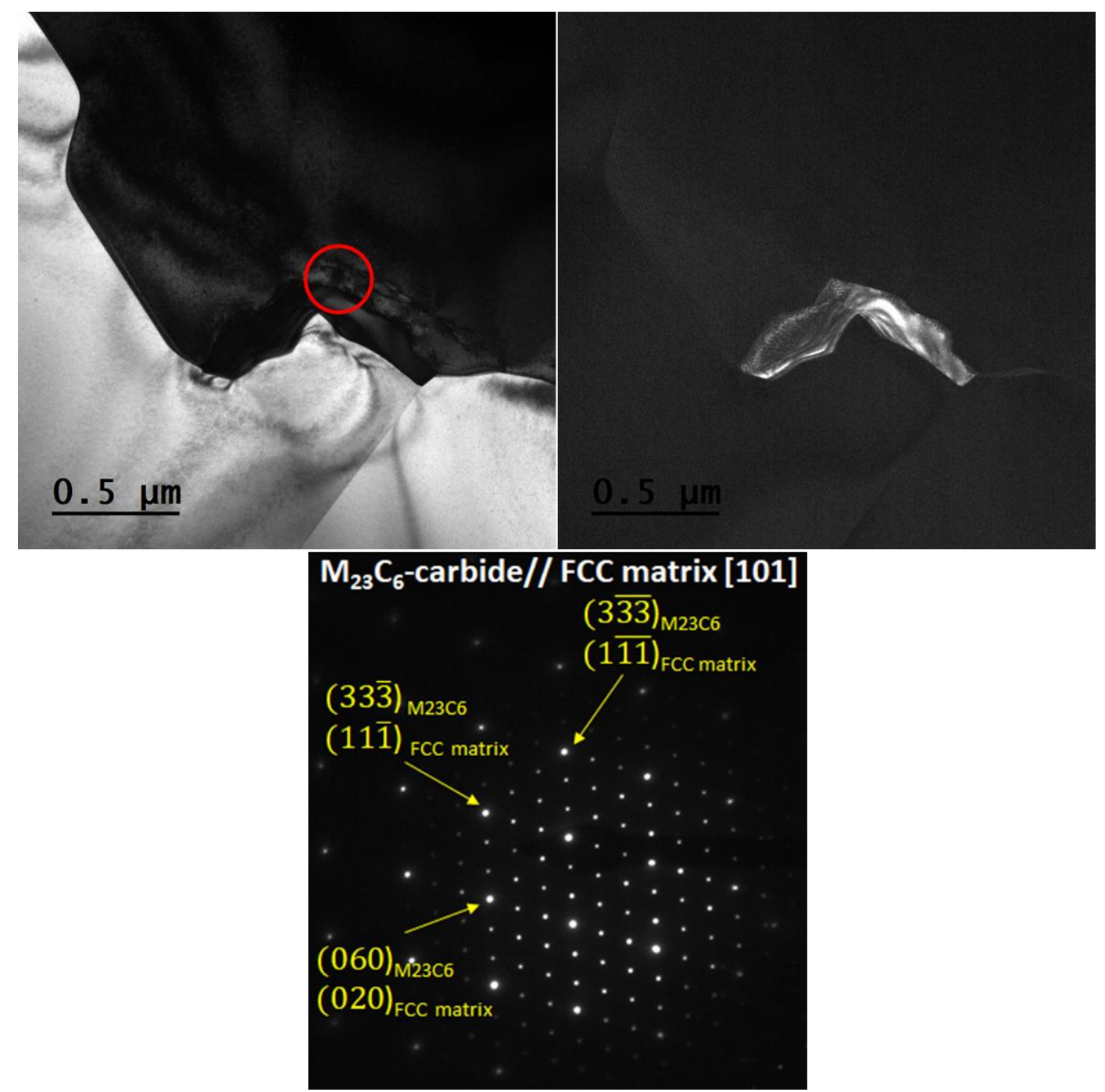

Figura 3.8 - Par de imagens no modo (a) BF e (b) DF da Liga 33 envelhecida a $800{ }^{\circ} \mathrm{C}$ por $1 \mathrm{~h}$ mostrando um carbeto-M23C6 com forma de "L" no CG e o respectivo padrão SAED obtido da interface precipitado/matriz (indicado pelo círculo).

\subsubsection{Microscopia Eletrônica de Transmissão e Varredura (STEM, "Scanning Transmission Electron Microscopy")}

A técnica de STEM combina princípios de MET e MEV, na qual um feixe muito fino $(\sim 1 \mathrm{~nm})$ é utilizado para varrer a amostra enquanto alguns sinais previamente escolhidos são coletados para formar a imagem. No modo STEM, múltiplos detectores podem ser usados simultaneamente, possibilitando a obtenção de imagens geradas por várias faixas de ângulos de difração, o que fornece informações complementares entre elas. Os detectores usuais incluem um detector BF que intercepta o feixe direto e um detector de campo escuro anular (ADF, “annular dark-field”) que está localizado em torno do feixe direto e assim pode coletar os elétrons espalhados pela amostra. O ângulo mais interno deste 
detector pode ser alterado, o que possibilita maior eficiência para coletar os elétrons espalhados, já que aumenta a dependência do número atômico (Z) para a formação da imagem. Esta última configuração é normalmente referida por imagens de campo escuro de alto ângulo (HAADF, "high-angle annular darkfield”) [226]. Uma ilustração da configuração destes detectores no modo STEM é apresentada na Figura 3.9.

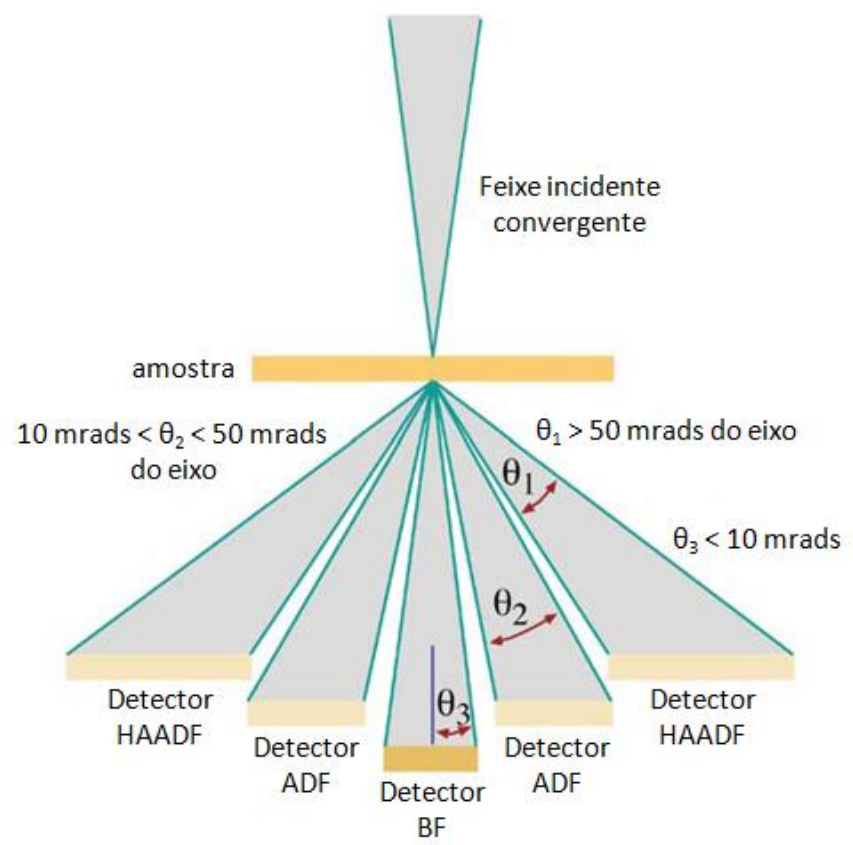

Figura 3.9 - llustração do esquema dos detectores no modo STEM (adaptado de [220]).

Vários METs foram utilizados durante este trabalho, para realizar a caracterização microestrutural da Liga 33, dependendo da disponibilidade de uso do equipamento. Para obtenção de imagens por contraste de difração foram usados os seguintes microscópios: Phillips CM20, FEI Tecnai G2 T20, FEI Tecnai TF30 e JEOL JEM 2100F. As análises elementares por XEDS foram realizados no MET FEI Talos F200X. A seguir é feita uma breve descrição os METs utilizados durante este trabalho:

- MET Philips CM20 LaB 6 operado a 200 kV equipado com câmera CCD Gatan. Este microscópio foi utilizado para obtenção de imagens em BF/DF e padrões SAED. 
- MET FEI Tecnai G2 T20 LaB 6 operado a $200 \mathrm{kV}$ equipado com instrumento Oxford Xmax 80 SDD e sistema de análises AZTEC para XEDS, detectores BF/ADF para STEM e câmera CCD Gatan. Este equipamento foi principalmente utilizado para obter imagens em BF/DF, bem como padrões SAED. Eventualmente, foram realizadas algumas análises por XEDS neste MET.

- MET-FEG FEI Tecnai F30 operado a 300 kV e equipado com câmera CCD para aquisição de imagens, detector HAADF no modo STEM e detector Oxford Xmax 80 SDD para análises por XEDS. Este equipamento foi utilizado para obter imagens por contraste de difração nos modos BF/DF, bem como padrões SAED.

- MET FEI Talos F200X com canhão X-FEG com tecnologia ChemSTEM foi operado a $200 \mathrm{kV}$. Este microscópio possui 4 SDDs para aumentar a coleta de raios-X característicos e, assim, melhorar as análises do mapeamento elementar por XEDS. Este sistema foi utilizado para avaliar qualitativamente o particionamento de soluto, bem como a composição química dos precipitados formados durante o processo de envelhecimento ao qual a Liga 33 foi submetida. Neste estudo, as análises pontual por XEDS foram realizadas com tempo de aquisição de 100 s ("live time") para cada espectro e $500 \mu$ s para a obtenção dos mapas elementares por XEDS e um total de tempo de aquisição por mapa de $1800 \mathrm{~s}$ em STEM-XEDS.

- JEOL FEG JEM 2100F operado a 200 kV equipado instrumento EDS Thermo SEVEN para análises de XEDS. Este equipamento foi utilizado para obtenção de imagens nos modos contraste por difração e também em STEM. 


\section{Resultados e Discussão}

\subsection{Microestrutura da Liga 33 na condição como recebida}

A Figura 4.1a mostra uma imagem de MO-BF da microestrutura da Liga 33 na condição como recebida, a qual consiste em uma estrutura de grãos equiaxiais com tamanho médio de grão de $70 \mu \mathrm{m}$ em uma matriz austenítica com maclas de recozimento. Nesta magnificação, a ocorrência de precipitação não pode ser revelada. Neste sentido, com a intenção de verificar a existência tanto de precipitados como de segregação ou empobrecimento de algum elemento na Liga 33 na condição como recebida, foram realizadas análises por MET/STEM/XEDS. A imagem de MET-BF na Figura 4.1b mostra que nesta condição a Liga 33 não contém precipitados, o que é confirmado pelos mapas elementares de XEDS do $\mathrm{Cr}, \mathrm{Fe}$ e Ni mostrados na Figura 4.2. Tais mapas obtidos em diferentes regiões da amostra da Liga 33 mostrando CG confirmam a inexistência de qualquer zona de enriquecimento ou empobrecimentos em $\mathrm{Cr}$, $\mathrm{Fe}$ e $\mathrm{Ni}$.

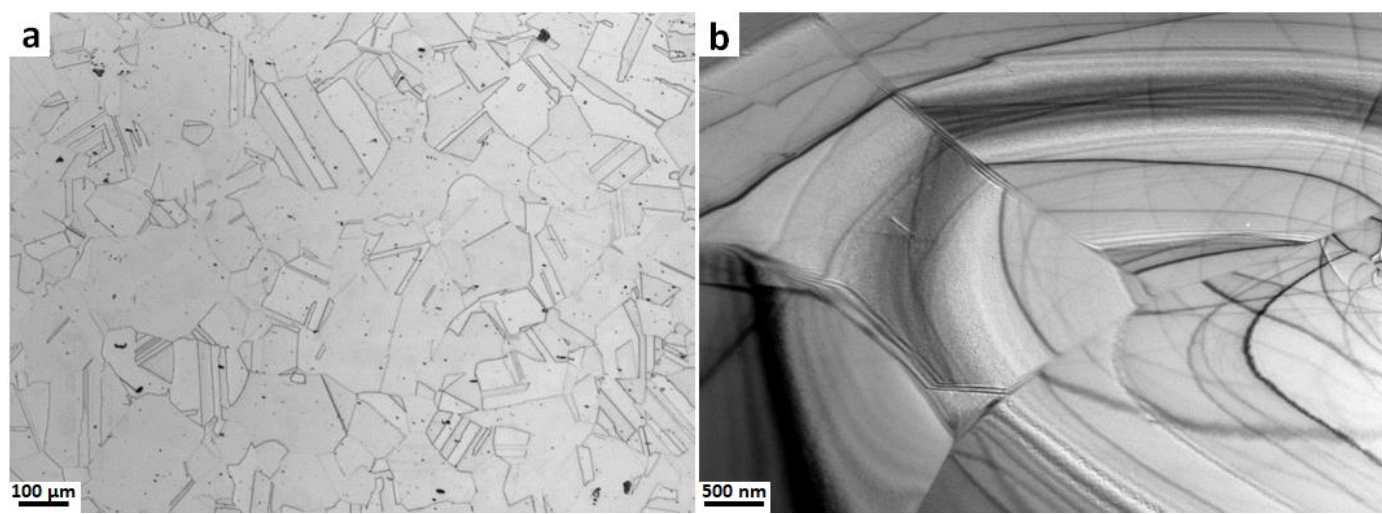

Figura 4.1 - Imagem da Liga 33 na condição como recebida por (a) MO-BF e (b) METBF.
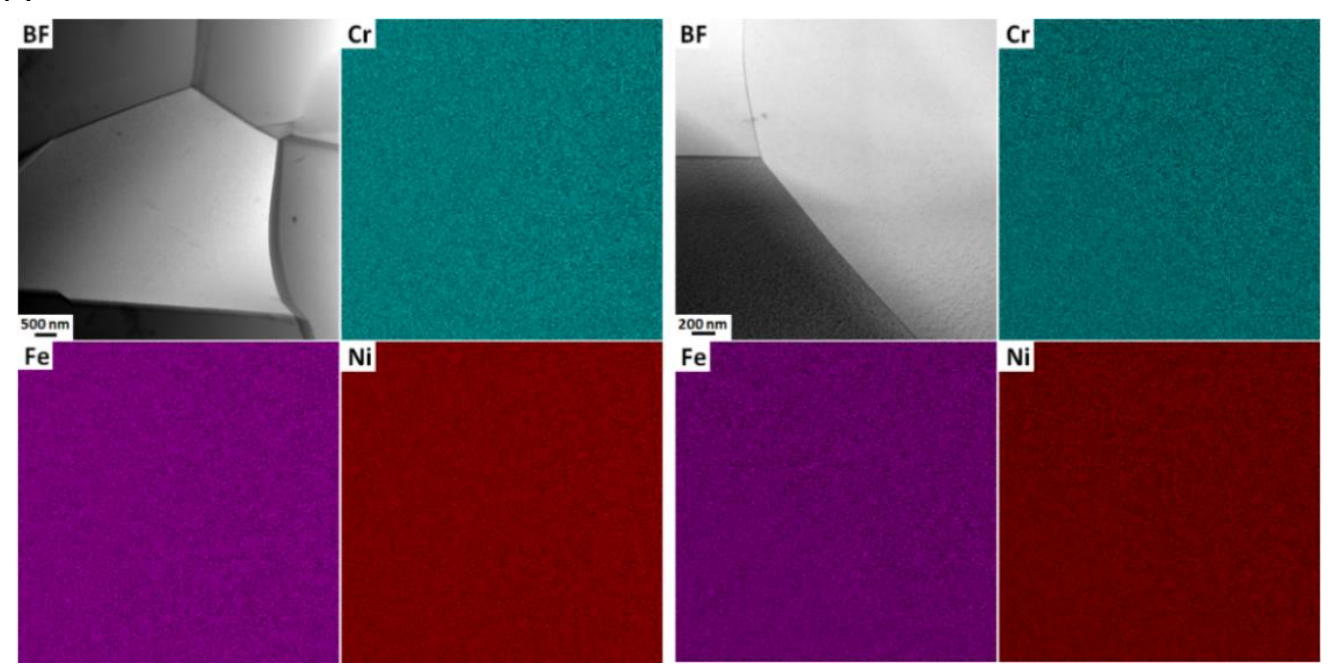

Figura 4.2 - Imagens de STEM-BF da Liga 33 na condição como recebida mostrando vários $\mathrm{CG}$ e os correspondentes mapas elementares obtidos por STEM/XEDS do $\mathrm{Cr}, \mathrm{Fe}$, and $\mathrm{Ni}$ em duas diferentes regiões da amostra. 


\subsection{Estágios Iniciais dos Fenômenos de Precipitação do CG na Liga 33 Envelhecida a $800^{\circ} \mathrm{C}$}

A Figura 4.3 apresenta imagens por MEV-SE da Liga 33 envelhecida a $800{ }^{\circ} \mathrm{C}$ por $10 \mathrm{~min}$ e $30 \mathrm{~min}$, respectivamente. Como mostrado em ambas as imagens, as características de precipitação nos CG são diferentes em cada contorno. Na Figura 4.3a, é verificada a ocorrência da migração de um dos contornos bem como a formação de precipitados neste contorno, enquanto o outro CG permaneceu estático e sem precipitados. Quando o tempo de envelhecimento foi aumentado para $30 \mathrm{~min}$, a densidade de precipitados e a distância de migração dos contornos ondulados aumentou, como verificado na Figura 4.3b. Nesta figura, diferentes comportamentos na precipitação foram verificados em cada contorno. Precipitados irregulares em um CG ondulado, o qual migrou para ambos os lados e precipitados menores no outro $\mathrm{CG}$ estático. Estas diferentes características observadas nos fenômenos de precipitação nos CG ocorrem devido a propriedades individuais de contorno [76][77].

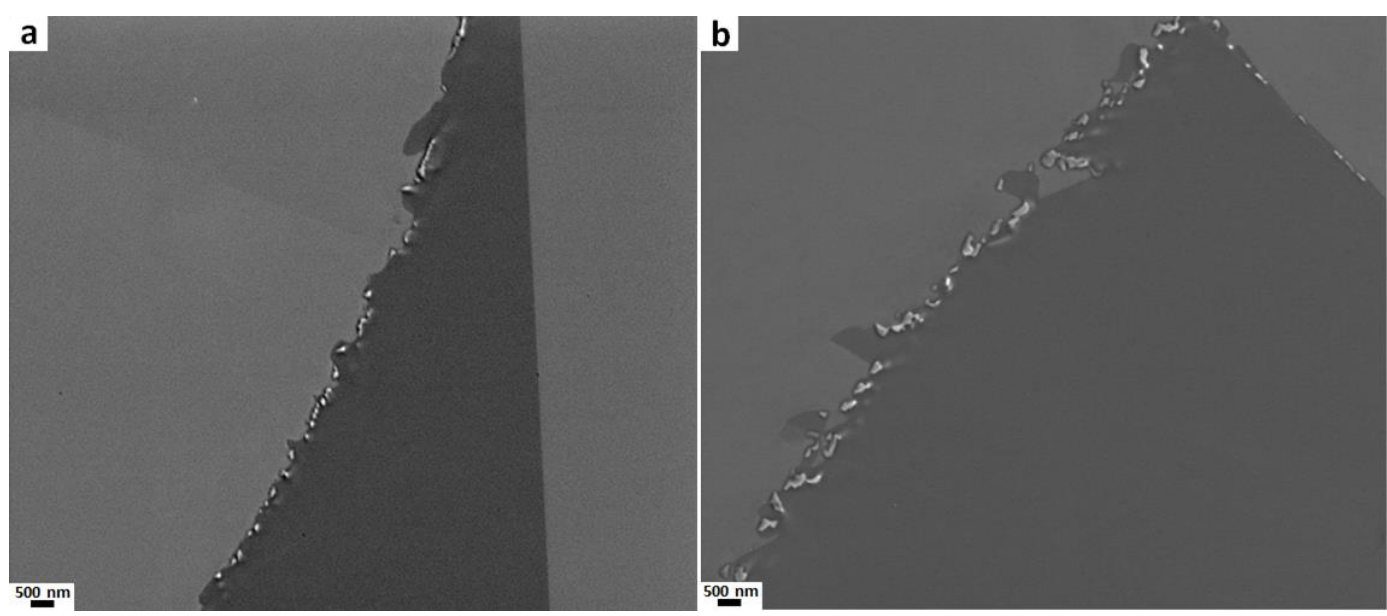

Figura 4.3 - Imagens de MEV-SE da Liga 33 envelhecida a $800{ }^{\circ} \mathrm{C}$ por (a) 10 min e (b) $30 \mathrm{~min}$.

Com o objetivo de identificar os precipitados formados nos estágios iniciais do processo de envelhecimento, amostras da Liga 33 nas condições mencionadas acima (10 min e $30 \mathrm{~min}$ ) foram preparadas para análises por MET/STEM/XEDS e alguns resultados obtidos são apresentados a seguir. A Figura 4.4 ilustra dois pares de imagens de MET-BF/CDF mostrando um precipitado formado no CG na Liga 33 envelhecida a $800{ }^{\circ} \mathrm{C}$ por $10 \mathrm{~min}$. Baseado no padrão SAED mostrado na Figura 4.4c, este precipitado foi identificado como carbeto- $\mathrm{M}_{23} \mathrm{C}_{6}$ com estrutura $\mathrm{CFC}$ e com uma R.O. cubo-a-cubo com a matriz 
CFC, $\left[\begin{array}{lll}0 & 0 & 1\end{array}\right]_{M_{23} C_{6}} / /\left[\begin{array}{lll}0 & 0 & 1\end{array}\right]_{\text {matriz } C F C}$. É verificado que ambas as redes cristalinas compartilham uma simetria cúbica e diferem em parâmetros de rede aproximadamente por um fator de 3. Carbetos- $\mathrm{M}_{23} \mathrm{C}_{6}$ já foram reportados como a primeira fase formada em CG em ligas multicomponentes estruturais [52] [70][82][117] e este carbeto foi reportado no CG por Portella et al. [3] na Liga 33 envelhecida a $700{ }^{\circ} \mathrm{C}$ por $100 \mathrm{~h}$. Tal precipitação em CG é considerada um fenômeno comum em ligas metálicas devido à alta energia de alguns contornos, o que aumenta a taxa de difusão de elementos formadores de fases secundárias nestas regiões da rede cristalina [59]. Este processo de precipitação envolve a redistribuição de solutos [76] e a nucleação de novas fases ocorre principalmente em discordâncias no $\mathrm{CG}$, as quais atuam como sítios preferenciais para a nucleação dos precipitados [69]. A formação destes carbetos é rápida devido à segregação de elementos formadores destes precipitados, principalmente $\mathrm{Cr}$, ao longo de sítios de nucleação, tais como CG, e pela mais rápida difusão de átomos intersticiais de $\mathrm{C}[70]$.

Estudos reportados em diferentes tipos de materiais estruturais, tais como AI austenítico e ligas à base de Ni [1][2][65][74][76-79][227] mostraram que a precipitação de carbetos- $\mathrm{M}_{23} \mathrm{C}_{6}$ ricos em $\mathrm{Cr}$ é fortemente influenciada pelo tipo de CG. Trillo e Murr [76][77] demonstraram a necessidade do CG fornecer uma energia mínima para a nucleação dos carbetos- $\mathrm{M}_{23} \mathrm{C}_{6}$. Além disso, os autores encontraram que, com o aumento no tempo de envelhecimento, os carbetos- $\mathrm{M}_{23} \mathrm{C}_{6}$ formaram em contornos com menor desorientação angular. Lim et al. [2] também observaram que a precipitação de carbetos foi retardada em contornos de baixo ângulo quando comparado com CG de alto ângulo.

Na Figure 4.4b, as imagens de MET-BF/CDF mostram discordâncias na interface carbeto- $\mathrm{M}_{23} \mathrm{C}_{6} /$ matriz-CFC, as quais estão indicadas pelas setas. $\mathrm{O}$ surgimento de tais discordâncias é consequência do desajuste entre o parâmetro de rede do carbeto e da matriz, o qual indica a existência de uma interface semicoerente entre eles [228]. Quando tais carbetos- $\mathrm{M}_{23} \mathrm{C}_{6}$ são formados em contornos com alto ângulo de desorientação, cada núcleo do carbeto deve ter uma R.O. similar, i.e. cubo-a-cubo (como mostrado no padrão SAED na Figura 4.4a), com um dos grãos austeníticos a fim de minimizar a energia de ativação para a nucleação [77][228][229]. No presente caso (Figura 4.4), o precipitado possui 
uma R.O. cubo-a-cubo com o grão com contraste mais escuro (grão de cima na imagem).

Carbetos- $\mathrm{M}_{23} \mathrm{C}_{6}$ ricos em $\mathrm{Cr}$ tem uma estrutura $\mathrm{CFC}$ (grupo espacial $F m \overline{3} m$ ) e parâmetro de rede a $=1.050-1.070 \mathrm{~nm}$ [52][53][70][72-74][91], o qual é aproximadamente três vezes maior que o da matriz CFC, como mostrado na Figura 4.4. Alguns autores associaram a variação no parâmetro de rede deste carbeto com o aumento no teor de Mo no carbeto [70][95]. Vários autores [2][52][53][70][74][91] reportaram a R.O. entre o carbeto- $\mathrm{M}_{23} \mathrm{C}_{6}$ e a matriz CFC como cubo-a-cubo: $(100)_{M_{23} C_{6}} / /(100)_{\gamma}$ e $[100]_{M_{23} C_{6}} / /[100]_{\gamma}$, o qual é a mesma R.O. mostrada no padrão SAED na Figura 4.4.

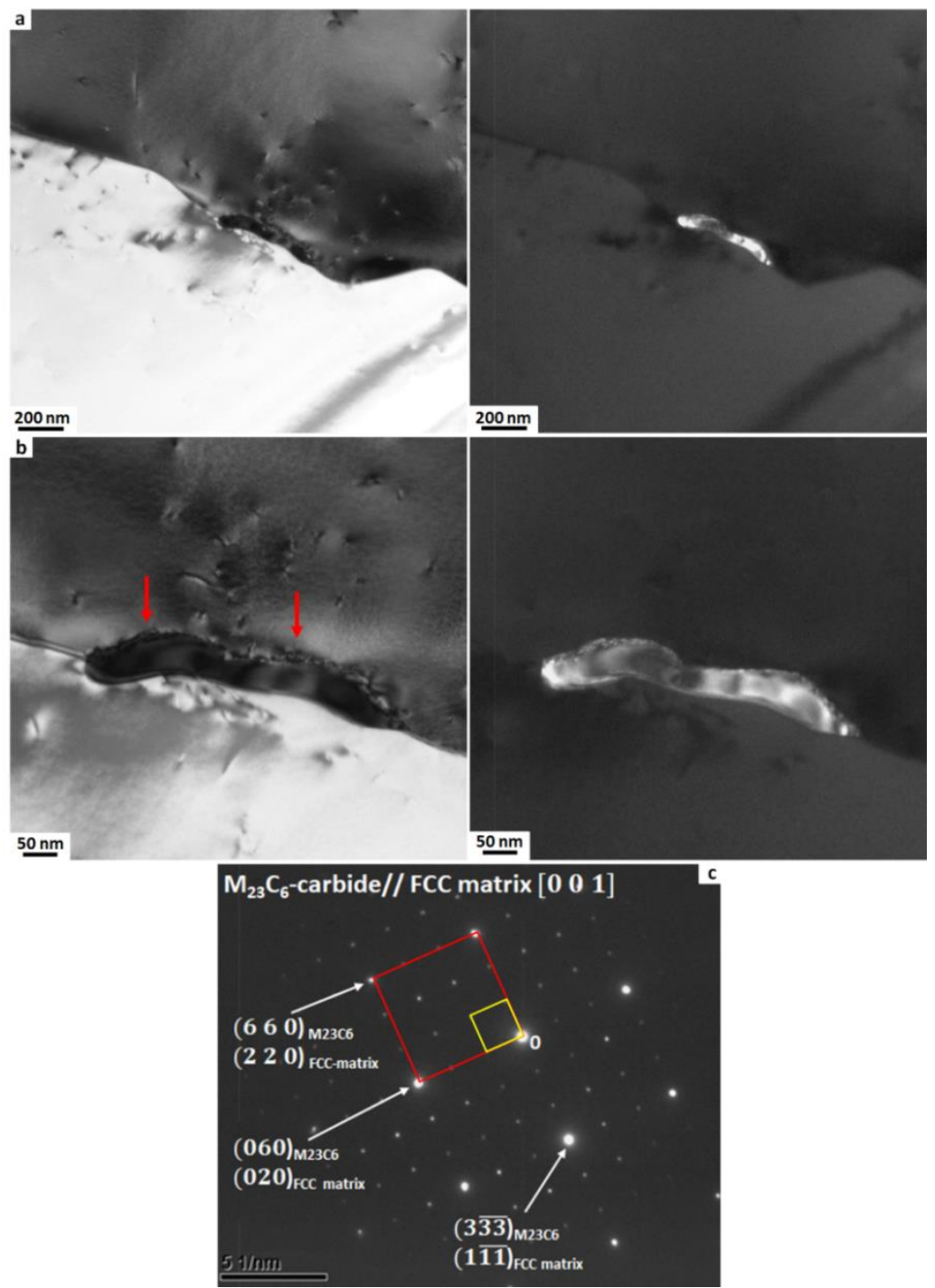

Figura 4.4 - (a) e (b) Pares de imagens de MET-BF/CDF de um carbeto- $\mathrm{M}_{23} \mathrm{C}_{6}$ no $\mathrm{CG}$ formado durante o envelhecimento a $800^{\circ} \mathrm{C}$ por $10 \mathrm{~min}$ e (c) padrão SAED obtido no eixo de zona [001] mostrando uma R.O. cubo-a-cubo, $\left[\begin{array}{lll}0 & 0 & 1\end{array}\right]_{M_{23} C_{6}} / /\left[\begin{array}{lll}0 & 0 & 1\end{array}\right]_{\text {matriz-CFC }}$. As setas em (b) indicam discordâncias na interface carbeto- $\mathrm{M}_{23} \mathrm{C}_{6} /$ matriz CFC. O quadrado vermelho é referente à matriz-CFC e o quadrado amarelo é referente ao carbeto- $\mathrm{M}_{23} \mathrm{C}_{6}$. 
A imagem de STEM-BF na Figura 4.5a mostra um ponto triplo na Liga 33 envelhecida a $800{ }^{\circ} \mathrm{C}$ por $10 \mathrm{~min}$, a partir do qual dois dos contornos parecem estar livres de precipitados (contornos A e B) e no outro CG (contorno C), a precipitação de fases secundárias ocorreu juntamente com a migração do contorno. A imagem de STEM-BF mostrada na Figura 4.5b foi obtida a partir da região indicada pelo retângulo vermelho na Figura 4.5a. Nesta figura são observadas as mesmas características que na Figura 4.4, o precipitado cresceu ao longo do segmento de contorno que ocorreu a migração. A Figura $4.5 \mathrm{c}$ apresenta imagens de MET-BF/CDF e a Figura 4.5d mostra um padrão SAED no eixo de zona [101] obtido a partir da interface do carbeto- $\mathrm{M}_{23} \mathrm{C}_{6}$ e do grão da matriz $\mathrm{CFC}$ localizado no lado esquerdo desta imagem. É verificada a existência de uma R.O. $[101]_{M_{23} C_{6}} / /[101]_{\text {matriz-CFC }}$, entre o carbeto e a matriz. Também nesta figura é observada a existência de empilhamento de discordâncias, provavelmente tendo o carbeto como fonte de sua atividade. Este tipo de discordâncias pode ser resultado do alívio da tensão local gerada pela nucleação dos carbetos nos CG [99]. Resultados do mapeamento elementar por STEM/XEDS no CG mostrados na Figura 4.6 (obtida da mesma região mostrada na Figura 4.5b) indicam que o carbeto- $\mathrm{M}_{23} \mathrm{C}_{6}$ é enriquecido em $\mathrm{Cr}$, Mo e $\mathrm{C}$, além da formação de zonas empobrecida de $\mathrm{Cr}$ e enriquecidas em Fe e Ni na região do CG (Esta observação foi consistente em outros CG com precipitados nesta mesma condição de envelhecimento). 

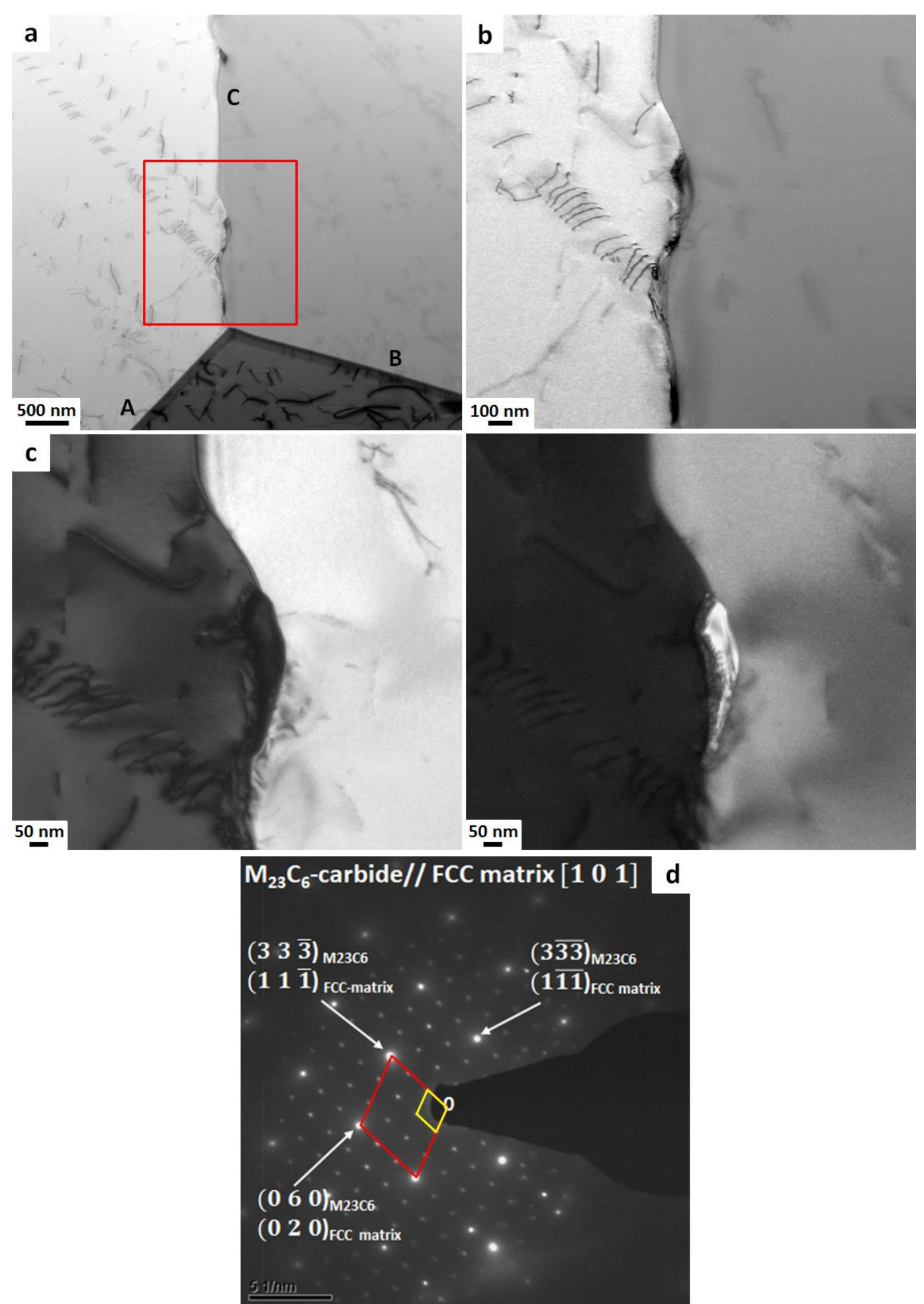

Figura 4.5 - (a) Imagem de STEM-BF de um ponto triplo na Liga 33 envelhecida a 800 ${ }^{\circ} \mathrm{C}$ por $10 \mathrm{~min}$; (b) imagem de STEM-BF obtida da região indicada pelo retângulo vermelho em (a); (c) imagens de MET-BF/CDF do carbeto- $\mathrm{M}_{23} \mathrm{C}_{6}$ no $C G$ e (d) padrão SAED mostrando uma relação cubo-a-cubo, [101] ${ }_{M_{23} C_{6}} / /[101]_{\text {matriz-CFC }}$. O losango vermelho é referente à matriz-CFC e o losango amarelo é referente ao carbeto- $\mathrm{M}_{23} \mathrm{C}_{6}$. 


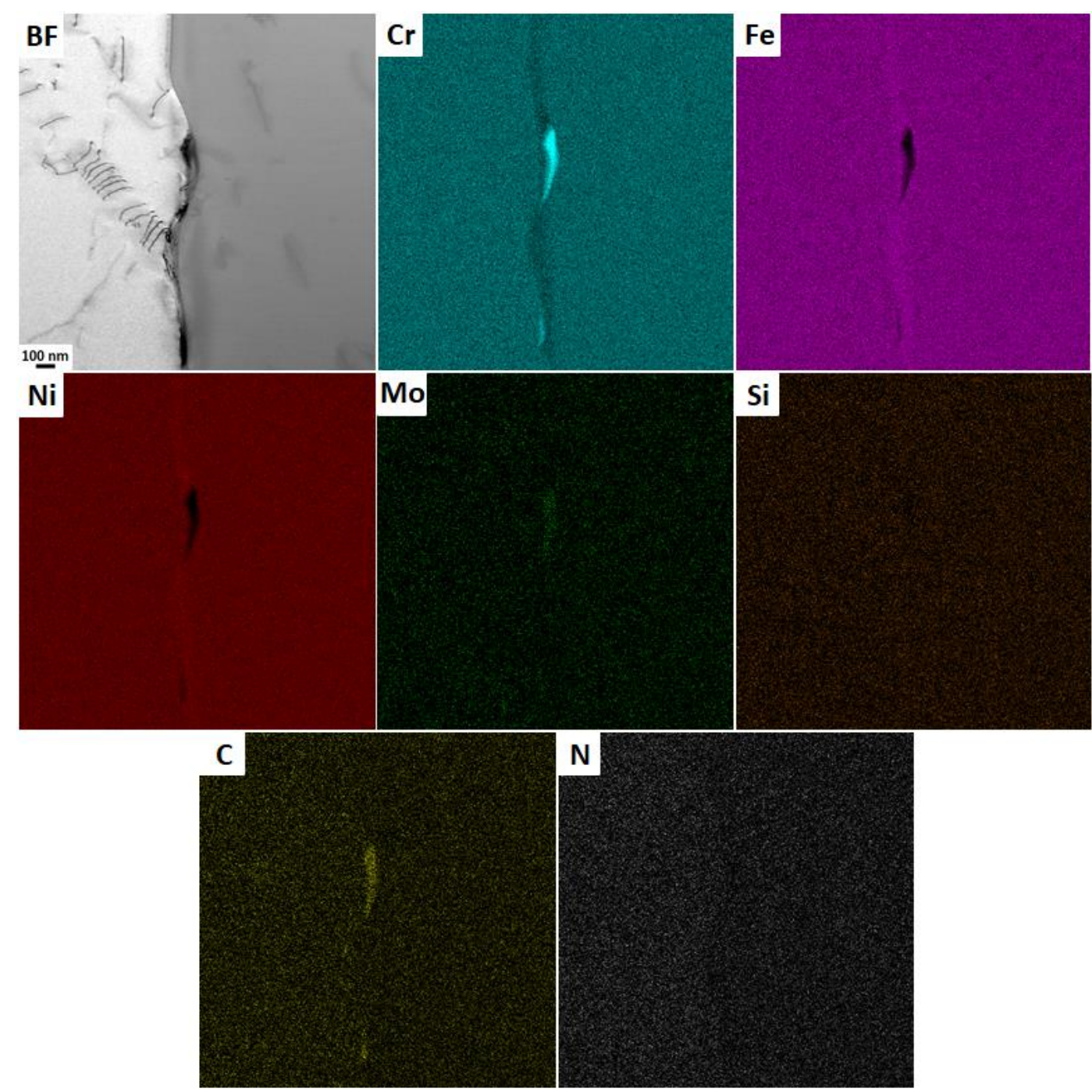

Figura 4.6 - Imagem de STEM-BF da mesma região mostrada na Figura 4.5b e os correspondentes mapas elementares por STEM-XEDS do Cr, Fe, Ni, Mo, Si, C, and N.

A imagem de MET-BF na Figura 4.7 mostra um CG decorado por precipitados e também a migração do contorno em algumas regiões deste contorno, como a mostrada na Figura 4.8 obtida na região indicada pelo quadrado vermelho na Figura 4.7. Na Figura 4.8 são apresentadas imagens de MET$\mathrm{BF} / \mathrm{CDF}$ e os correspondentes padrões SAED. Todos os precipitados neste CG também foram identificados como carbetos- $\mathrm{M}_{23} \mathrm{C}_{6}$, como verificado no padrão de difração na inserção na Figura $4.8 \mathrm{~b}$ mostrando uma R.O. [112] $]_{M_{23} C_{6}} / /$ $[112]_{\text {matriz }-C F C}$. O espectro pontual obtido por STEM/XEDS, mostrado na Figura 4.8c, confirma que o carbeto- $\mathrm{M}_{23} \mathrm{C}_{6}$ no $\mathrm{CG}$ da Figura $4.8 \mathrm{~b}$ é rico em $\mathrm{Cr}$ contendo $\mathrm{Mo}, \mathrm{Fe}$ e Ni. A composição química qualitativa do carbeto- $\mathrm{M}_{23} \mathrm{C}_{6}$ encontrada no presente trabalho é coerente com o reportado por outros autores [70][72][73][84][87][93][94]. 


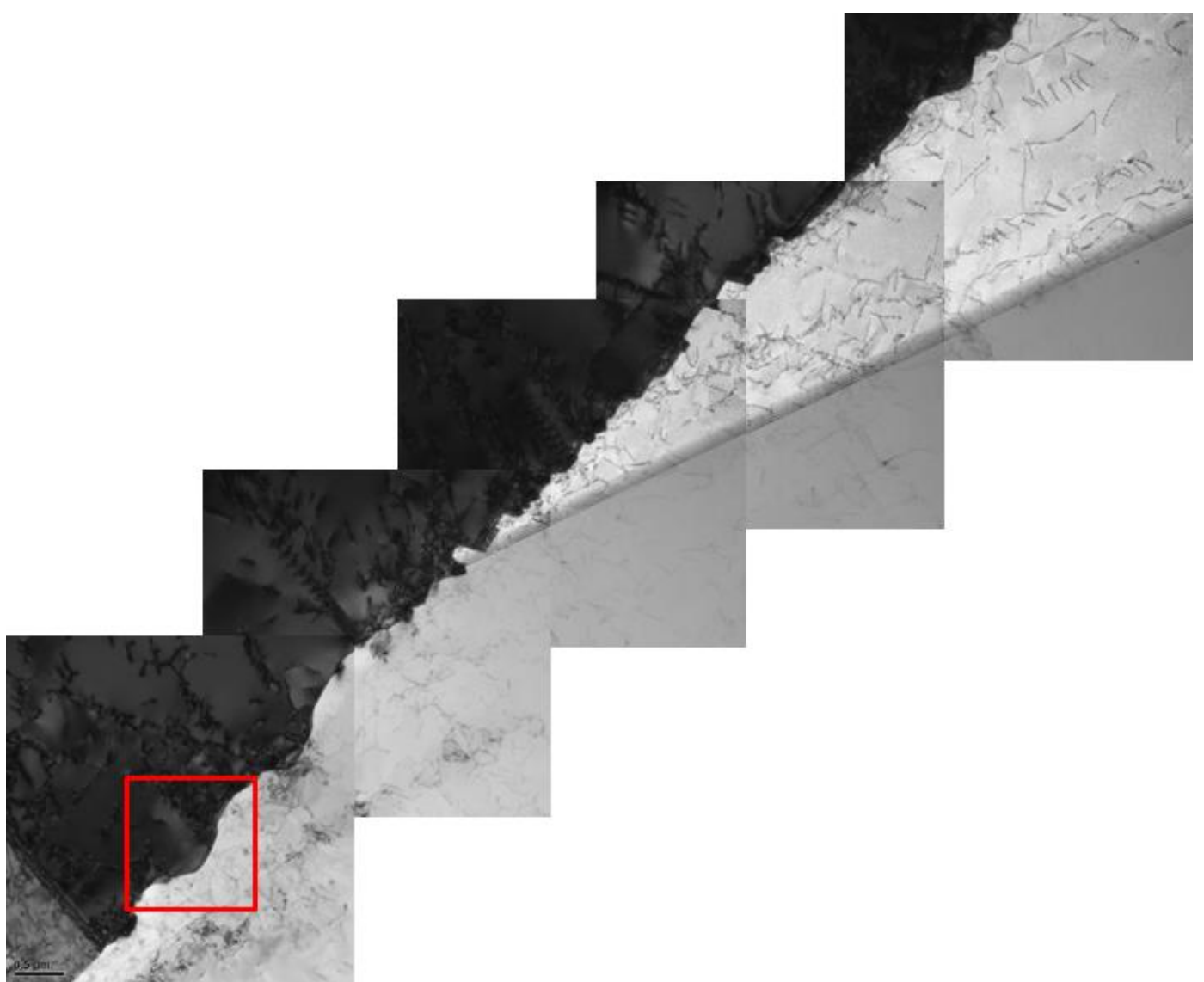

Figura 4.7 - Imagem de MET-BF mostrando precipitados no CG bem como a migração em algumas regiões deste contorno na Liga 33 envelhecida a $800{ }^{\circ} \mathrm{C}$ por $10 \mathrm{~min}$. O quadrado vermelho indica a região mostrada na Figura 4.8. 

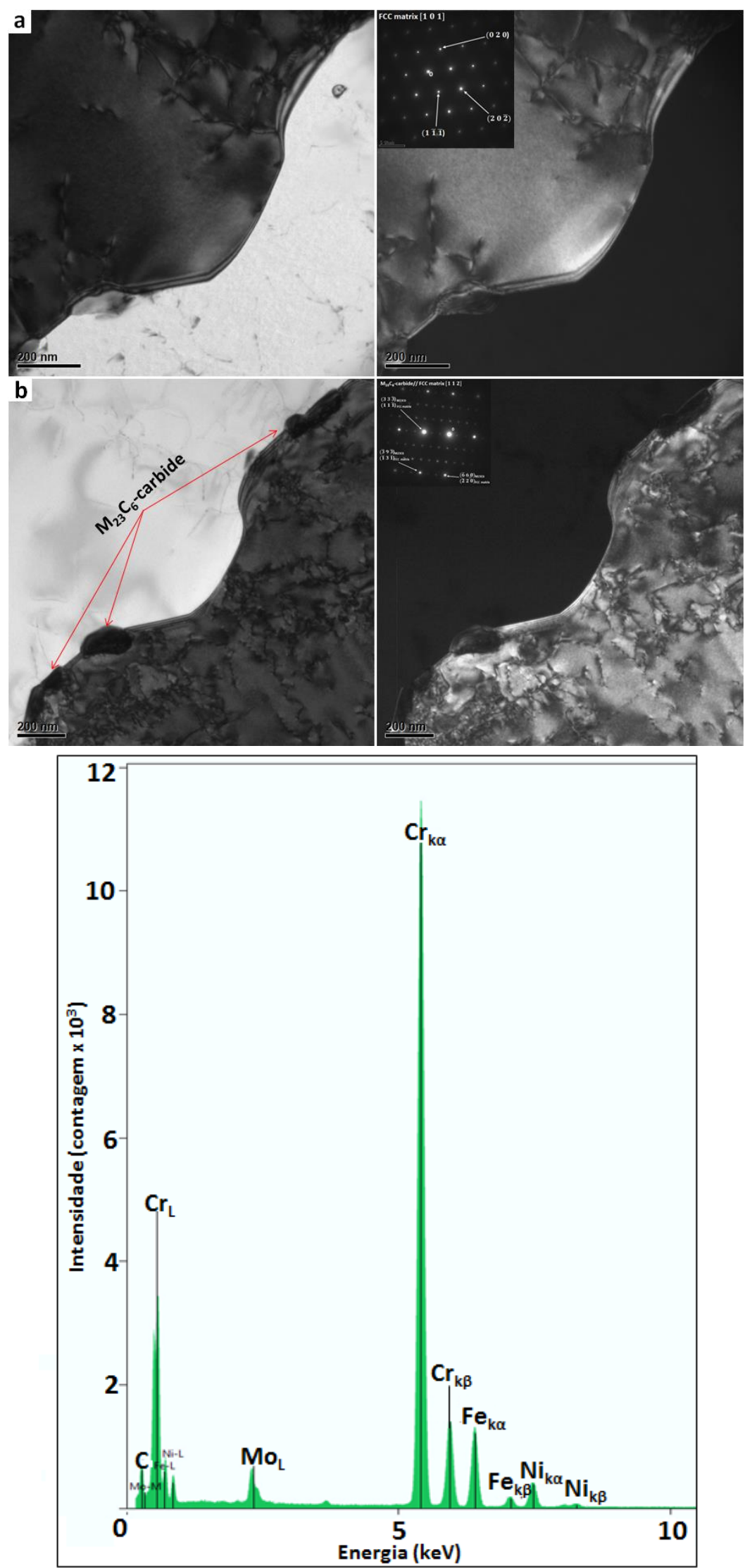

Figura 4.8 - (a) e (b) Imagens de MET-BF/CDF mostrando a migração do CG na Liga 33 envelhecida a $800^{\circ} \mathrm{C}$ por 10 min e padrões SAED obtidos da matriz CFC e da interface carbeto- $\mathrm{M}_{23} \mathrm{C}_{6} /$ matriz $\mathrm{CFC}$, respectivamente; e (c) espectro pontual obtido por STEM/XEDS do carbeto mostrado em (a). 
Nas imagens mostradas na Figura 4.8 foi verificado que os carbetos no CG tem R.O. com o grão que está sendo consumido pelo contorno avançando. Este comportamento é oposto daquele observado anteriormente nas Figura 4.4 e 4.5, onde o carbeto- $\mathrm{M}_{23} \mathrm{C}_{6}$ tinha R.O. com o grão que iniciou o movimento de migração na direção do grão adjacente. Assim, pode ser afirmado que na Liga 33 a migração do $\mathrm{CG}$ ocorreu tanto na direção do grão no qual os precipitados nuclearam (Figura 4.8), como na direção do grão oposto ao qual ocorreu a precipitação dos carbetos (Figura 4.4 e 4.5). Tais observações parecem indicar que a direção de migração do CG na Liga 33 envelhecida a $800{ }^{\circ} \mathrm{C}$ não foi dependente de qual grão ocorreu a precipitação do carbeto, i.e. a precipitação não tem influência na migração do contorno. Assim, uma tentativa de discussão a partir dos resultados encontrados neste trabalho, relacionando com os mecanismos de iniciação da reação de PD comumente reportados na literatura (já apresentados neste trabalho no item 2.3.1) é realizada a seguir. Como descrito anteriormente, Tu e Turnbull [177][178], Fournelle e Clark [181] e Solórzano e Lopes [179] estudaram os estágios iniciais da reação de $\mathrm{PD}$ em sistemas binários e estabeleceram diferentes mecanismos em ligas binárias.

De acordo com o mecanismo Tu-Turnbull, também chamado do mecanismo "pucker", a formação dos precipitados em um CG inicialmente estático é vista como a razão para a migração do contorno. A força motriz para a migração do contorno é a redução da energia da superfície dos precipitados nos CG com a migração do contorno pela interface de maior energia para substituí-la por uma interface de menor energia (Figura 2.4). Tais precipitados crescem carregando/empurrando o contorno na direção da matriz não-transformada. Este mecanismo proposto por Tu e Turnbull implica que a relação cristalográfica entre os alotriomorfos iniciais e um dos grãos estabelece tanto a direção de crescimento da célula como a morfologia das lamelas celulares [177][178]. No mecanismo "pucker", se a nucleação dos alotriomorfos ocorre em um grão, subsequente crescimento do precipitado ocorrerá no sentido do grão adjacente, carregando o contorno na direção da migração. O mecanismo proposto por Tu e Turnbull já foi reportado ocorrer em ligas multicomponentes contendo solutos substitucionais e intersticiais [9][172][202]. Carvalho et al. [172] sugeriram que a reação de PD de nitretos- $\mathrm{M}_{2} \mathrm{~N}$ em um $\mathrm{AI}$ austenítico $(\mathrm{Fe}-25 \mathrm{Cr}-5 \mathrm{Ni}-0.87 \mathrm{~N})$ foi iniciada pelo mecanismo proposto por Tu and Turnbull [177][178]. Vandershaeve et al. [9] 
reportaram que a nucleação da PD em uma $\mathrm{AI}$ austenítico (Fe-19Mn-18Cr-0.9N) surgiu da redução da energia de superfície dos precipitados nos CG com a migração do contorno pela interface de maior energia para substituí-la por uma interface de menor energia. Os autores concluíram que tal mecanismo de iniciação da PD possuía a mesma força motriz que o mecanismo "pucker" de Tu e Turnbull [177][178].

Já o mecanismo proposto por Fournelle-Clark descreve que no início do envelhecimento, o CG começa a migrar sob influência de forças de capilaridade. Quando o contorno migra, a segregação de soluto ao longo deles forma alotriomorfos no CG, os quais fixam o contorno (como mostrado na Figura 2.6 no item 2.3.1). Quando o processo de precipitação continua, o CG continua a curvarse, empobrecendo em soluto a área atrás do contorno em movimento devido à segregação de soluto, o qual alimenta o crescimento dos precipitados. Agora, tendo desenvolvido uma força motriz a partir do empobrecimento de soluto atrás do contorno (forças químicas), o contorno curvado continua a migrar, formando um conjunto de precipitados no CG. Tais precipitados tornam-se as lamelas precipitadas dentro da colônia de PD juntamente com a migração do contorno. Neste mecanismo, as relações cristalográficas entre os alotriomorfos iniciais e os grãos adjacentes tem uma influência mínima na estrutura celular final [181].

$\mathrm{O}$ terceiro mecanismo também descreve que o precipitado nucleia no contorno em movimento, mas neste o contorno inicia a migração induzido pela difusão de soluto no contorno (força química) e não por capilaridade (como no mecanismo proposto por Fournelle e Clark). Solórzano e Lopes [179] mostraram que a região varrida pelo contorno em movimento era empobrecida em soluto e na ausência de tanto forças de capilaridade e de tração pelos precipitados, o papel da força motriz química no contorno avançando foi proposto pelos autores (mostrado no item 2.7 - revisão bibliográfica). Assim, neste mecanismo de iniciação da PD o fenômeno de migração de grão induzido por difusão (DIGM, "diffusion-induced grain-boundary migration") precede o crescimento da PD.

Como descrito acima, o mecanismo Tu-Turnbull parece não estar operando na iniciação da reação de PD na Liga 33 porque, como foi mostrado (Figuras 4.4, 4.5 e 4.8), a direção de migração do CG parece não ser influenciada pela nucleação do precipitado e também a migração ocorre sem conexão com o precipitado, as quais são exigências para este mecanismo. Quando o mecanismo 
proposto por Fournelle-Clark é comparado com os resultados mostrados neste trabalho (Figuras 4.4, 4.5 e 4.8), é possível encontrar algumas similaridades: (1) foi observado que o contorno curvou-se entre os precipitados no CG (Figura 4.8) e (2) parece que a direção de migração do CG não tem dependência da nucleação do precipitado. Entretanto, com o aumento no tempo de envelhecimento, a formação dos precipitados lamelares da colônia de PD na Liga 33 não foi consequência dos precipitados inicialmente nucleados no CG (como será mostrado no decorrer deste trabalho). Assim, de certa forma esta última observação exclui o mecanismo proposto por Fournelle e Clark como sendo o único mecanismo de iniciação para a reação de PD operando na Liga 33 envelhecida a $800{ }^{\circ} \mathrm{C}$. No entanto, parece que tal mecanismo pode ter alguma participação na iniciação da PD neste sistema devido às similaridades mencionadas acima, para os quais o mecanismo "pucker" parece não ter nenhuma. Porém, ao analisar mais resultados obtidos na presente investigação, o fenômeno DIGM parece desempenhar um importante papel na iniciação e crescimento da reação da PD na Liga 33 envelhecida a $800{ }^{\circ} \mathrm{C}$, como é mostrado e discutido a seguir.

A imagem de STEM-BF na Figura 4.9 mostra um carbeto- $\mathrm{M}_{23} \mathrm{C}_{6}$ no $\mathrm{CG}$ e o correspondente mapeamento elementar por STEM/XEDS do Cr. Nesta figura, é verificado que a nucleação do precipitado no CG resultou na formação de uma zona empobrecida em $\mathrm{Cr}$ em torno do precipitado, principalmente na região onde o contorno parece ter iniciado a migração na direção do grão adjacente (indicado pela seta). Este mesmo comportamento é também mostrado na Figura 4.10, uma zona empobrecida em $\mathrm{Cr}$ foi observada em torno do carbeto- $\mathrm{M}_{23} \mathrm{C}_{6}$ no $\mathrm{CG}$. É conhecido que tais zonas empobrecidas em $\mathrm{Cr}$ na região dos $\mathrm{CG}$ tem efeito deletério para as propriedades de alguns materiais estruturais [230-234]. Também, é observado na Figura 4.10 que o CG adjacente ao precipitado parece ter iniciado a migração para ambos os lados do contorno, como indicado pelas setas. Este movimento do GB foi considerado os estágios iniciais da reação de PD na Liga 33 envelhecida a $800{ }^{\circ} \mathrm{C}$.

Baseado nos resultados mostrados anteriormente, pode ser sugerido que após a formação do precipitado no contorno inicialmente estático, ocorre um reajuste das posições dos CGs devido à criação do volume do núcleo, o qual pode provocar um deslocamento inicial do contorno da sua posição original. Ao mesmo tempo que ocorre tal movimento inicial do contorno, um empobrecimento em $\mathrm{Cr}$ 
surge na região adjacente ao precipitado devido à difusão de Cr para a formação do partícula, como observado nas Figuras 4.9 e 4.10. O empobrecimento em $\mathrm{Cr}$ resulta em um gradiente composicional através do contorno, o qual é considerado a força motriz química para a migração do contorno na direção da matriz supersaturada. Assim, pode-se argumentar que o fenômeno DIGM desempenha um importante papel como precursor da iniciação da reação de PD na Liga 33 envelhecida a $800{ }^{\circ} \mathrm{C}$. Interpretação similar foi feita por Hillert e Lagneborg [197] em um AI austenítico (Fe-35Ni-20Cr), porém os autores indicaram a existência de um gradiente composicional utilizando imagens de MO com ataque químico preferencial, o que foi mostrado no presente trabalho utilizando técnicas analíticas.
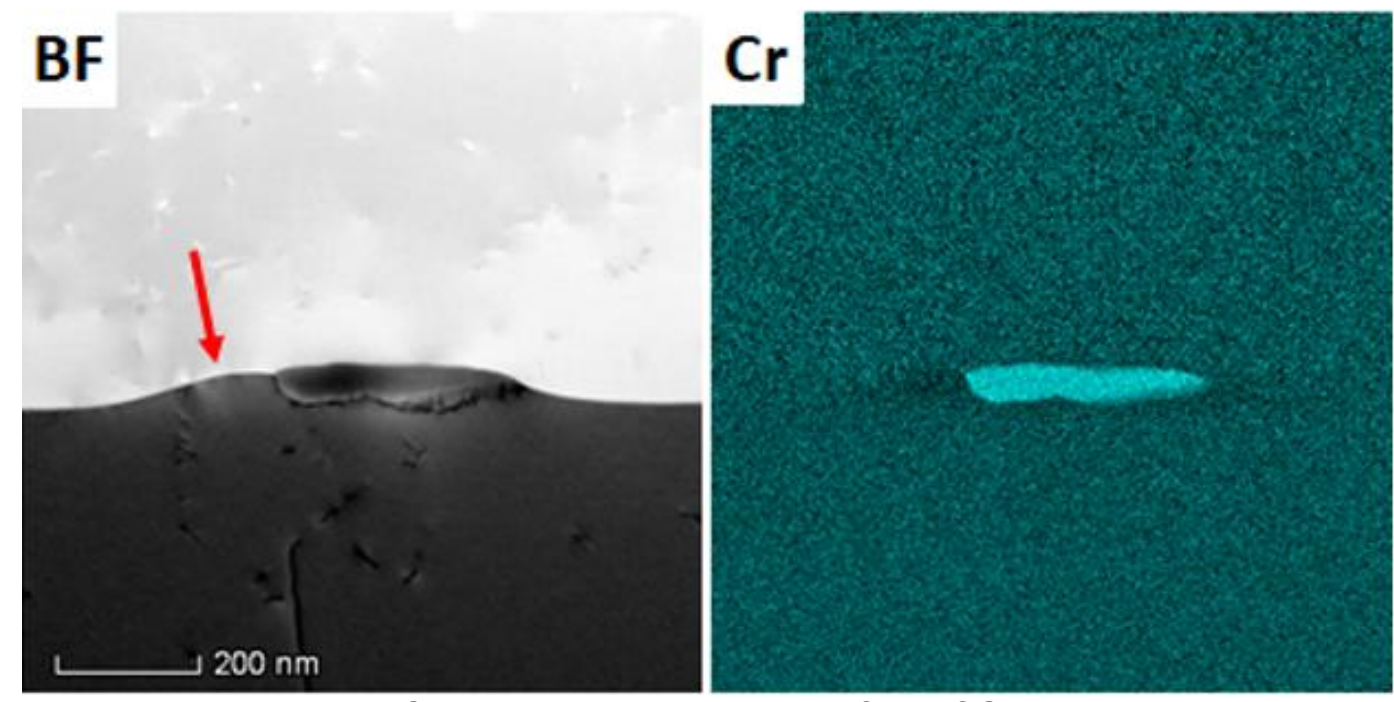

Figura 4.9 - Imagem de STEM-BF de um carbeto- $\mathrm{M}_{23} \mathrm{C}_{6}$ no $\mathrm{CG}$ na Liga 33 envelhecida a $800{ }^{\circ} \mathrm{C}$ por 10 min e o correspondente mapa elementar obtido por STEM/XEDS do $\mathrm{Cr}$. A seta indica o início da migração do CG. 


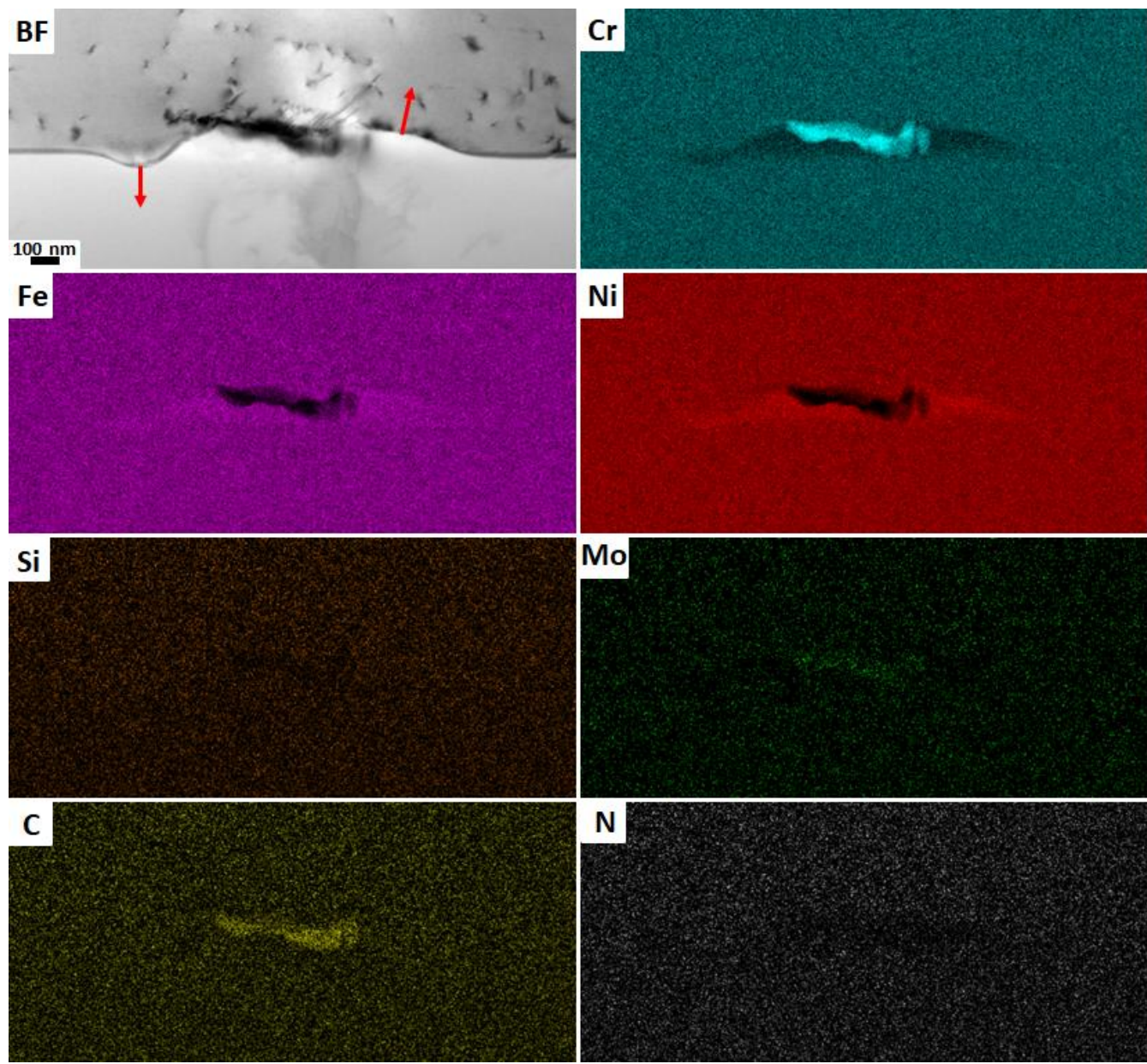

Figura 4.10 - Imagem de STEM-BF de um carbeto- $\mathrm{M}_{23} \mathrm{C}_{6}$ na Liga 33 envelhecida a 800 ${ }^{\circ} \mathrm{C}$ por 10 min e os correspondentes mapas elementares obtidos por STEM/XEDS do $\mathrm{Cr}$, $\mathrm{Fe}, \mathrm{Ni}, \mathrm{Si}, \mathrm{Mo}, \mathrm{C}$, and N. As setas indicam o início da migração do CG em direções opostas.

Quando o tempo de envelhecimento foi aumentado de $10 \mathrm{~min}$ para $30 \mathrm{~min}$, foi possível verificar que os contornos de grão continuaram a migração na direção do grão adjacente e os precipitados aumentaram de tamanho em relação à condição mostrada nas Figuras 4.3 a 4.10. Os resultados observados após o envelhecimento por 30 min e que são mostrados a seguir reforçam a ideia que o fenômeno DIGM está operando na iniciação da reação de PD na Liga 33. As imagens de MET-BF/CDF na Figura 4.11 mostram um CG decorado com precipitados na Liga 33 envelhecida a $800{ }^{\circ} \mathrm{C}$ por $30 \mathrm{~min}$, onde é observado a migração do contorno para ambos os lados do contorno. A partir do padrão SAED obtido da região indicada pelo círculo na imagem de MET-CDF, os precipitados no $\mathrm{CG}$ foram identificados como carbetos- $\mathrm{M}_{23} \mathrm{C}_{6}$ com estrutura CFC e R.O. $[112]_{M_{23} C_{6}} / /[112]_{\text {matriz-CFC }}$ com a matriz CFC. Nesta imagem é observada uma pronunciada migração do $\mathrm{CG}$ sem que os precipitados cresçam 
acompanhando a migração do CG. De fato, os precipitados fixam a migração do contorno na posição original do CG, resultando em uma típica morfologia do Ofenômeno DIGM. Também é possível observar que a frente de reação avançando na Figura 4.11 apresenta uma morfologia facetada em algumas regiões (indicadas pelas setas), as quais já foram relacionadas à mudanças na orientação do plano do CG durante a migração da frente de reação da PD [235].

Na Figura 4.11 é verificado que a migração do CG ocorreu para os dois lados do mesmo contorno. Como será mostrado no decorrer deste trabalho, um número significativo da migração do CG tanto para um lado como para os dois lados do contorno foram observados e documentados. Uma relação entre a temperatura de envelhecimento, direção de migração do CG e mecanismo de iniciação para a reação da PD já foi realizada baseando-se em resultados obtidos em sistemas binários. Williams e Butler [24] e Baumann et al. [191] mostraram que a temperatura de envelhecimento pode influenciar os estágios iniciais da PD. Eles observaram que a morfologia "double seam", a qual é consequência da migração para ambos os lados do contorno (Figura 4.11) é favorecida em baixas temperaturas de envelhecimento, sendo relacionado à ocorrência deste tipo de morfologia como resultado da iniciação da PD pelo mecanismo de Tu-Turnbull. Por outro lado, em altas temperaturas, na qual um maior número de morfologias "single seam" em relação às "double seams" foram observadas, o mecanismo de Fournelle e Clark foi operativo. Foi proposta a temperatura de transição entre a morfologia "single seam" e "double seams" sendo $T_{\mathrm{f}} / 2$, onde $\mathrm{T}_{\mathrm{f}}$ é a temperatura de fusão do material [24][191].

Neste contexto, a Liga 33 tem uma temperatura de fusão entre 1330-1370 ${ }^{\circ} \mathrm{C}$ [27], o que indica a temperatura de transição entre as morfologias "single seam" e "double seam" de 665-685 ${ }^{\circ} \mathrm{C}$ nesta liga. Como neste estudo a Liga 33 foi envelhecida a $800{ }^{\circ} \mathrm{C}$ era de se esperar que a morfologia predominante fosse "single seam", ou seja, ocorresse a predominância de colônias de PD crescendo somente para um dos lados do CG, o que foi confirmado com os resultados obtidos no presente trabalho. Assim, pode ser sugerido que a relação descrita acima relacionando a temperatura de envelhecimento com a morfologia da PD predominante pode ser aplicada na Liga 33 quando envelhecida a $800{ }^{\circ} \mathrm{C}$. 


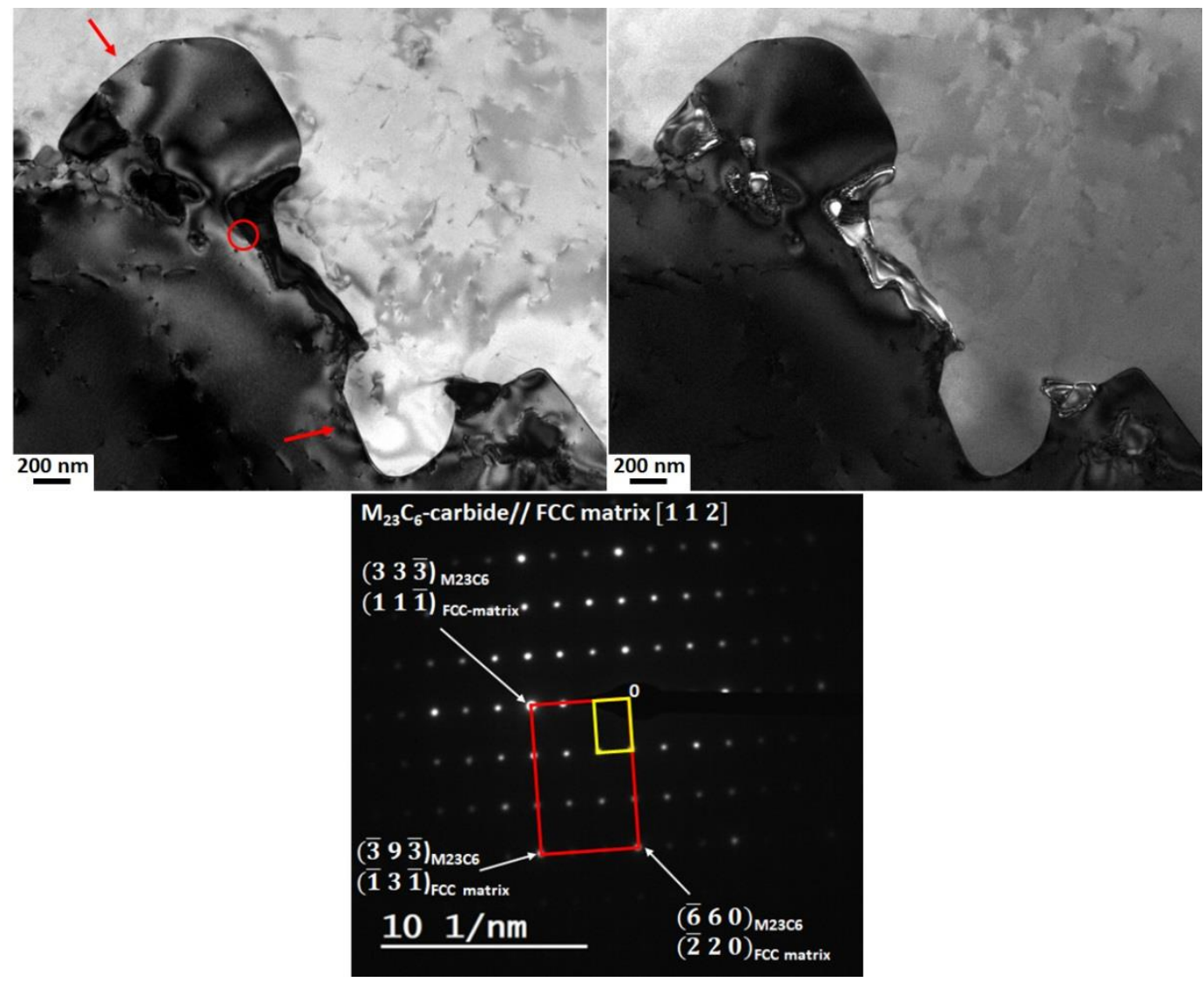

Figura 4.11 - Imagens de MET-BF/CDF mostrando a migração do CG para ambos os lados do contorno na Liga 33 envelhecida a $800^{\circ} \mathrm{C}$ por 30 min e um padrão SAED obtido a partir da região indicada pelo círculo. Os precipitados no $C G$ foram identificados como carbetos $-\mathrm{M}_{23} \mathrm{C}_{6}$ com R.O. [112] $]_{M_{23} C_{6}} / /[112]_{\text {matriz }-C F C}$ com a matriz CFC. As setas indicam regiões facetadas do $C G$ avançando. $O$ retângulo vermelho é referente à matrizCFC e o retângulo amarelo é referente ao carbeto- $\mathrm{M}_{23} \mathrm{C}_{6}$.

A Figura 4.12 apresenta uma imagem de STEM-BF da Liga 33 envelhecida a $800{ }^{\circ} \mathrm{C}$ por $30 \mathrm{~min}$ mostrando um CG decorado por diversos precipitados juntamente com a migração do contorno somente para um lado deste contorno. Nesta figura, é possível verificar que a matriz austenítica é livre de precipitação, mas contém uma grande densidade de discordâncias. A Figura 4.13 mostra imagens de STEM-BF/HAADF e os correspondentes mapas elementares obtidos por STEM/XEDS obtidos a partir da região indicada pelo retângulo vermelho na Figura 4.12. Nesta figura, é observada a migração do CG ancorado por carbetos- $\mathrm{M}_{23} \mathrm{C}_{6}$ ricos em $\mathrm{Cr}$ na posição original do contorno. Como observado nos resultados mostrados anteriormente, zonas empobrecidas em $\mathrm{Cr}$ e enriquecidas em $\mathrm{Fe}$ e $\mathrm{Ni}$ também foram observadas na região varrida pelo contorno avançando e ao redor dos precipitados na Figura 4.13. Tal enriquecimento em Fe e Ni também foi observado por Kikuchi et al. [25] estudando a reação de $\mathrm{PD}$ de nitretos- $\mathrm{M}_{2} \mathrm{~N}$ em um $\mathrm{AI}$ austenítico (Fe-25Cr-20Ni). 
Uma cuidadosa análise no mapeamento elementar mostrado na Figura 4.13 revelou um enriquecimento em $\mathrm{Si}$ na região próxima ao carbeto- $\mathrm{M}_{23} \mathrm{C}_{6}$, o qual está indicado pela seta no mapa de Si na Figura 4.13. Esta zona enriquecida em Si é apresentada mais claramente nos mapas elementares da Figura 4.14, confirmando a existência do enriquecimento em $\mathrm{Si}$ ao redor do carbeto no CG. Características similares em relação ao particionamento de soluto observado na Figura 4.13 e 4.14 também foram verificadas em outra região do mesmo CG, a qual é indicada pelo quadrado amarelo na Figura 4.12. Os resultados obtidos a partir desta outra região são apresentados nas Figuras 4.15 e 4.16.

Como observado na Figura 4.13, o contorno migrou numa extensão significativa, ancorado pelos precipitados heterogêneos no CG, deixando para trás uma região empobrecida em $\mathrm{Cr}$, resultante da combinação dos fenômenos de migração do CG, difusão interfacial e precipitação, conhecido como DIGM. Neste fenômeno, descoberto em 1972 por den Broader [236], os CG são induzidos a migrar quando átomos de soluto são difundidos ao longo dos contornos. A motivação geral para tal efeito é a mudança no potencial químico dos átomos de soluto como resultado combinado de difusão e migração do contorno [237-239]. Recentemente, o fenômeno DIGM foi associado a efeitos deletérios nas propriedades de corrosão de ligas Ni-Cr-Fe [230][240][241].

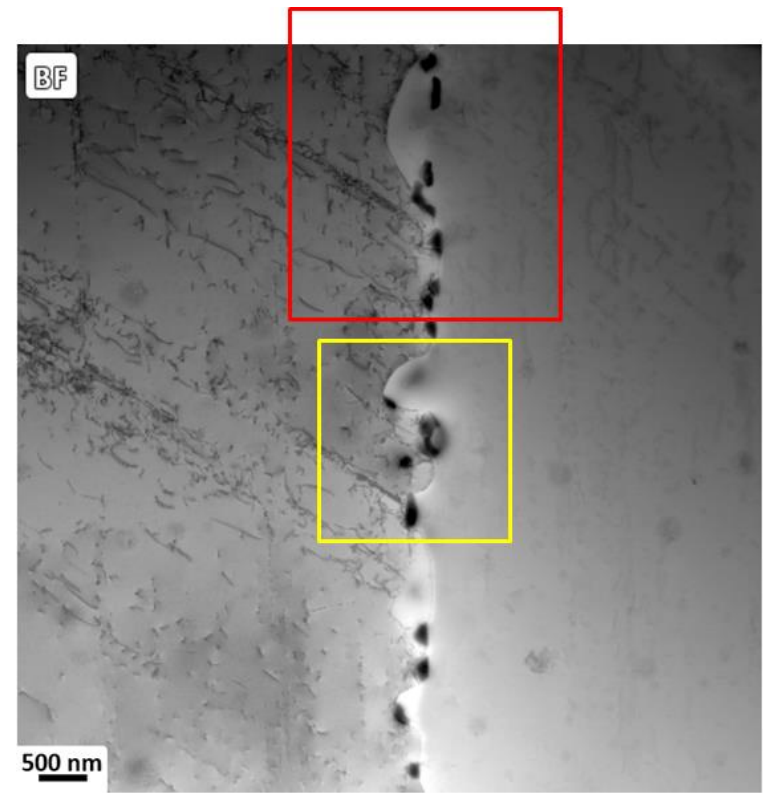

Figura 4.12 - Imagem de STEM-BF mostrando um CG decorados por precipitados na Liga 33 envelhecida a $800^{\circ} \mathrm{C}$ por 30 minutos. 


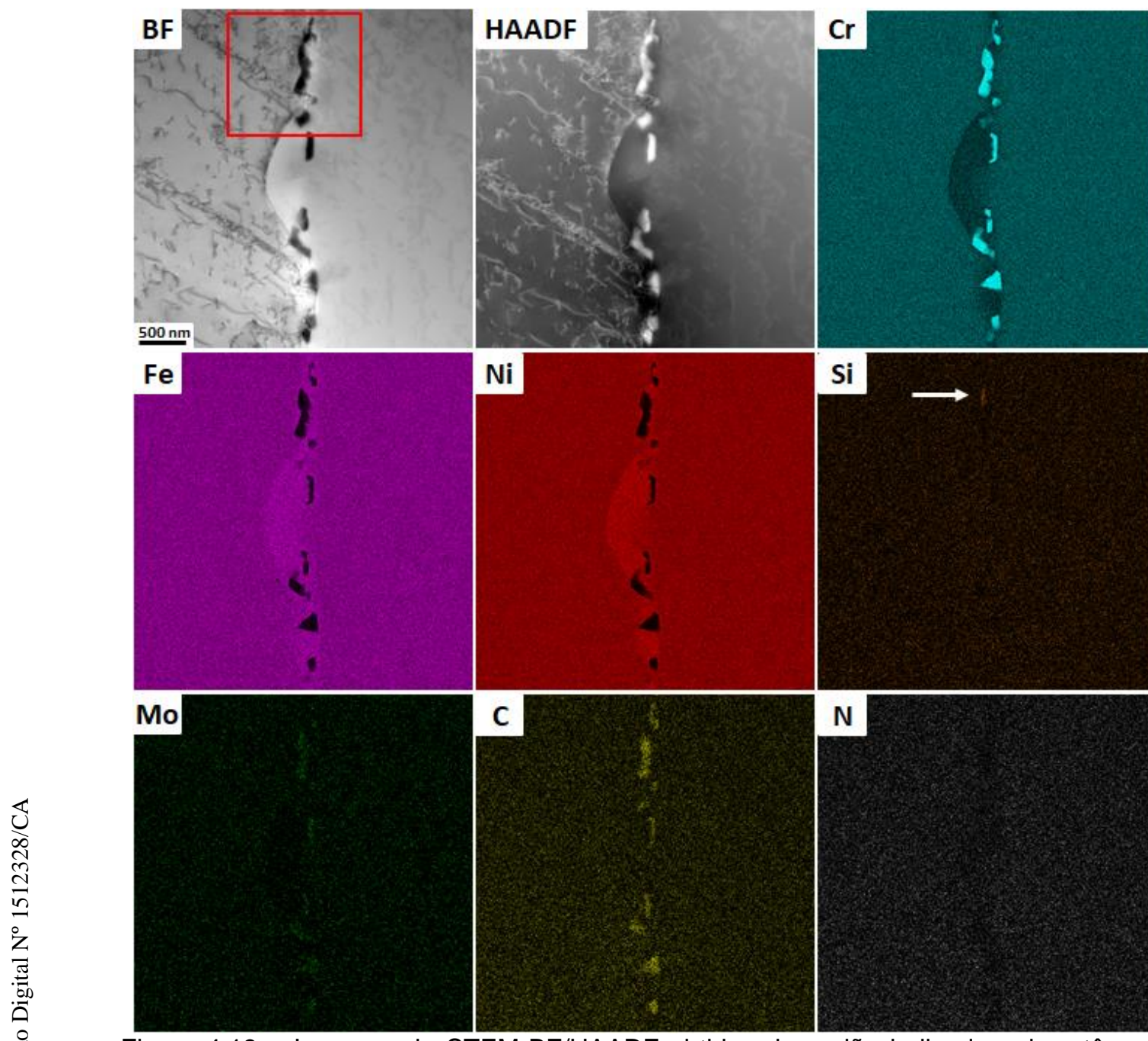

Figura 4.13 - Imagens de STEM-BF/HAADF obtidas da região indicada pelo retângulo vermelho na Figura 4.12 e os correspondentes mapas elementares obtidos por $\mathrm{STEM} / \mathrm{XEDS}$ do $\mathrm{Cr}, \mathrm{Fe}, \mathrm{Ni}, \mathrm{Si}, \mathrm{Mo}, \mathrm{C}$, and $\mathrm{N}$. O quadrado indica a região mostrada na Figura 4.14 e a seta indica a região onde ocorreu o enriquecimento em $\mathrm{Si}$. 


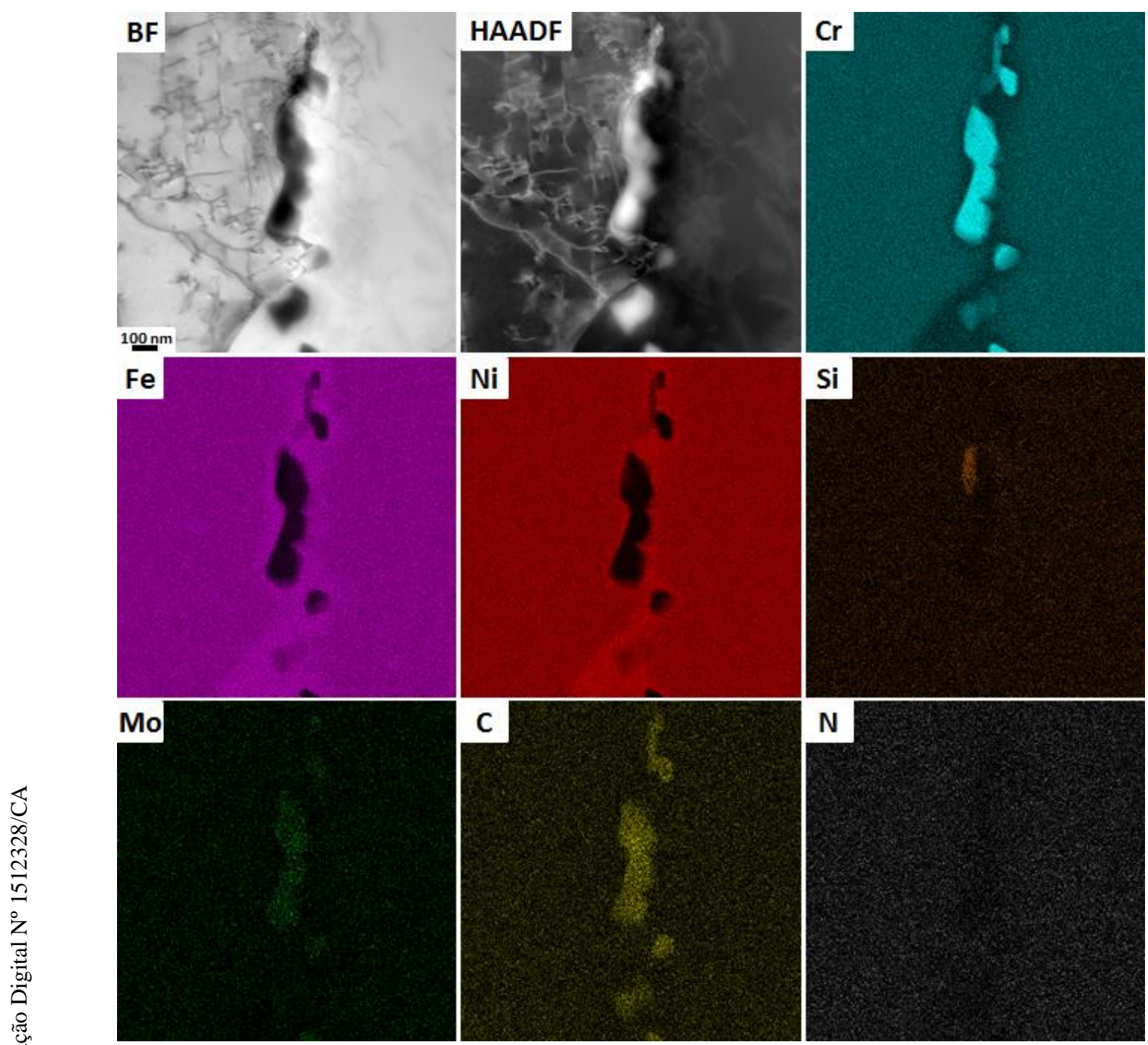

Figura 4.14 - Imagens de STEM-BF/HAADF obtida da região indicada pelo quadrado vermelho na Figura 4.13 e os correspondentes mapas elementares obtidos por $\mathrm{STEM} / \mathrm{XEDS}$ do $\mathrm{Cr}$, $\mathrm{Fe}, \mathrm{Ni}, \mathrm{Si}, \mathrm{Mo}, \mathrm{C}$, and $\mathrm{N}$. 


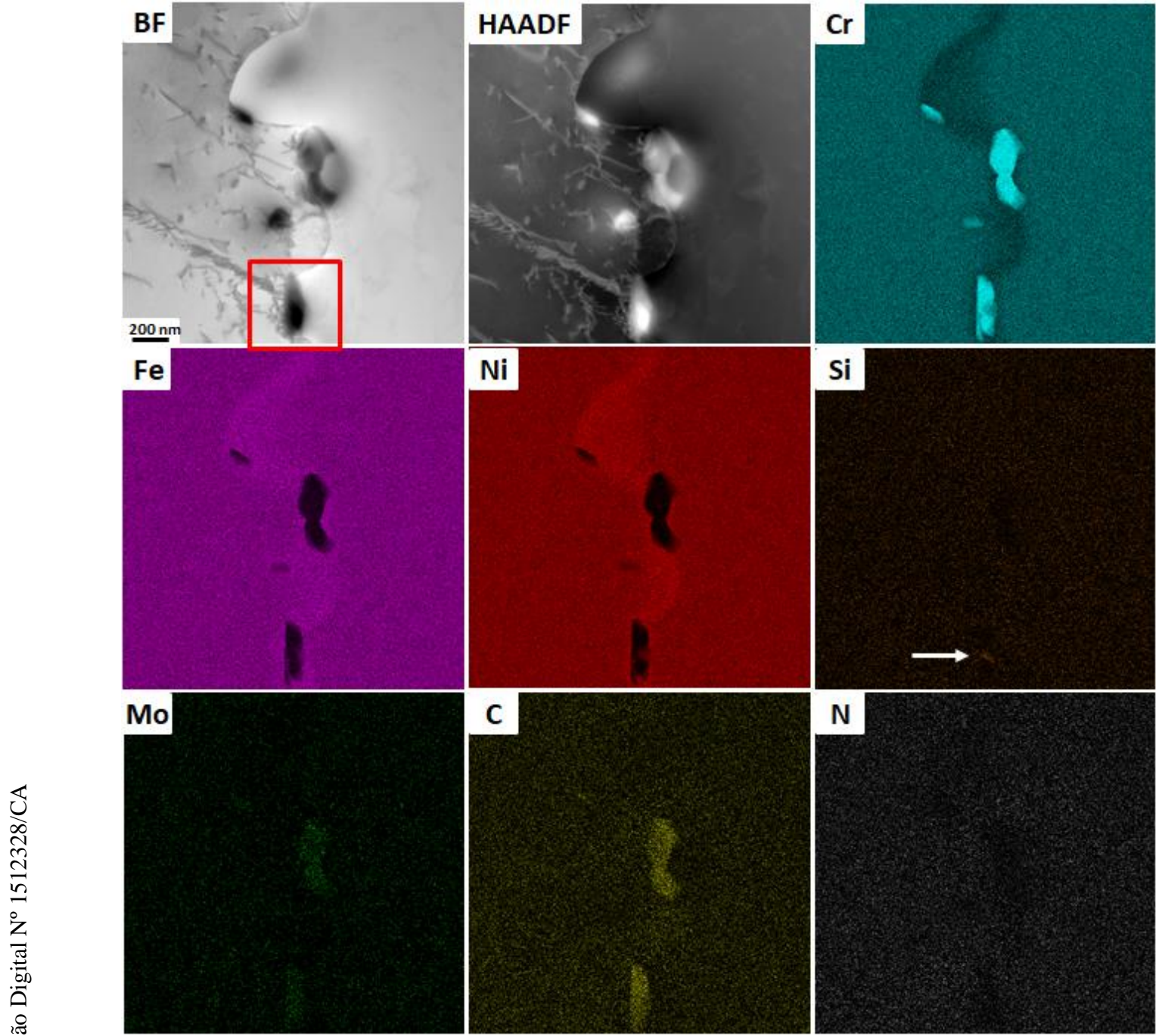

Figura 4.15 - Imagens de STEM-BF/DF obtidas da região indicada pelo quadrado amarelo na Figura 4.12 e os correspondentes mapas elementares obtidos por STEM/XEDS do $\mathrm{Cr}, \mathrm{Fe}, \mathrm{Ni}, \mathrm{Si}, \mathrm{Mo}, \mathrm{C}$, and $\mathrm{N}$. O quadrado indica a região mostrada na Figura 4.16 e a seta indica a região onde ocorreu o enriquecimento em $\mathrm{Si}$. 


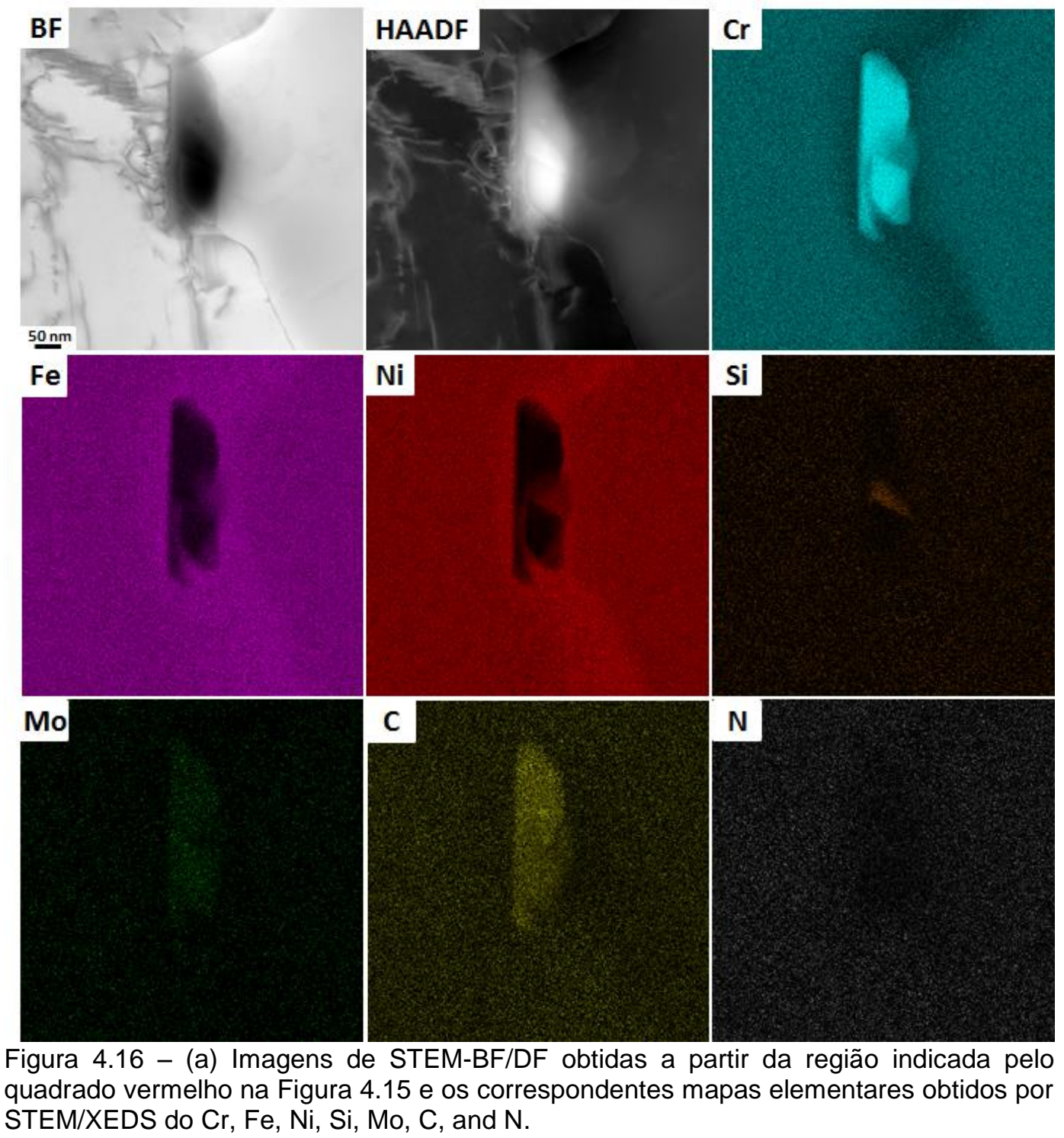

A Figura 4.17 ilustra o estágio inicial do desenvolvimento de colônias de PD na Liga 33 envelhecida a $800{ }^{\circ} \mathrm{C}$ por 30 min e os correspondentes mapas elementares obtidos por STEM/XEDS do Cr, Fe, Ni, Si, Mo, C e N. Nesta figura é possível verificar que o contorno migrando não tem conexão com alguns precipitados formados na posição original do contorno, o qual forma um arco para frente. Uma relação entre a configuração da frente de reação da PD com o tipo de força motriz que pode estar operando para a migração do contorno foi feita por Hillert [190], que apontou que uma configuração na qual o contorno está curvado para frente dos precipitados tem a migração do contorno como força motriz para o crescimento da PD. Neste sentido, baseado na configuração observada na Figura 4.17, a qual é similar àquela descrita por Hillert, pode-se argumentar que a migração do CG, induzida pela difusão interfacial, é a principal componente da 
força motriz para o crescimento das colônias de PD na Liga 33 envelhecida a 800 ${ }^{\circ} \mathrm{C}$, podendo descartar o crescimento devido ao crescimento do precipitado formado inicialmente na posição original do CG (como proposto pelo mecanismo de Tu e Turnbull).

Como observado anteriormente em todas as análises por STEM/XEDS nas amostras da Liga 33 envelhecida a $800{ }^{\circ} \mathrm{C}$, a Figura 4.17 também mostra zonas de empobrecimento em $\mathrm{Cr}$ e enriquecimento em $\mathrm{Fe}$ e $\mathrm{Ni}$ na região varrida pelo contorno avançando, porém neste contorno foi também verificado a existência do enriquecimento em Si na região varrida pelo contorno. Tal enriquecimento é mostrado na Figura 4.18, a qual foi obtida da região indicada pelo quadrado vermelho na Figura 4.17.

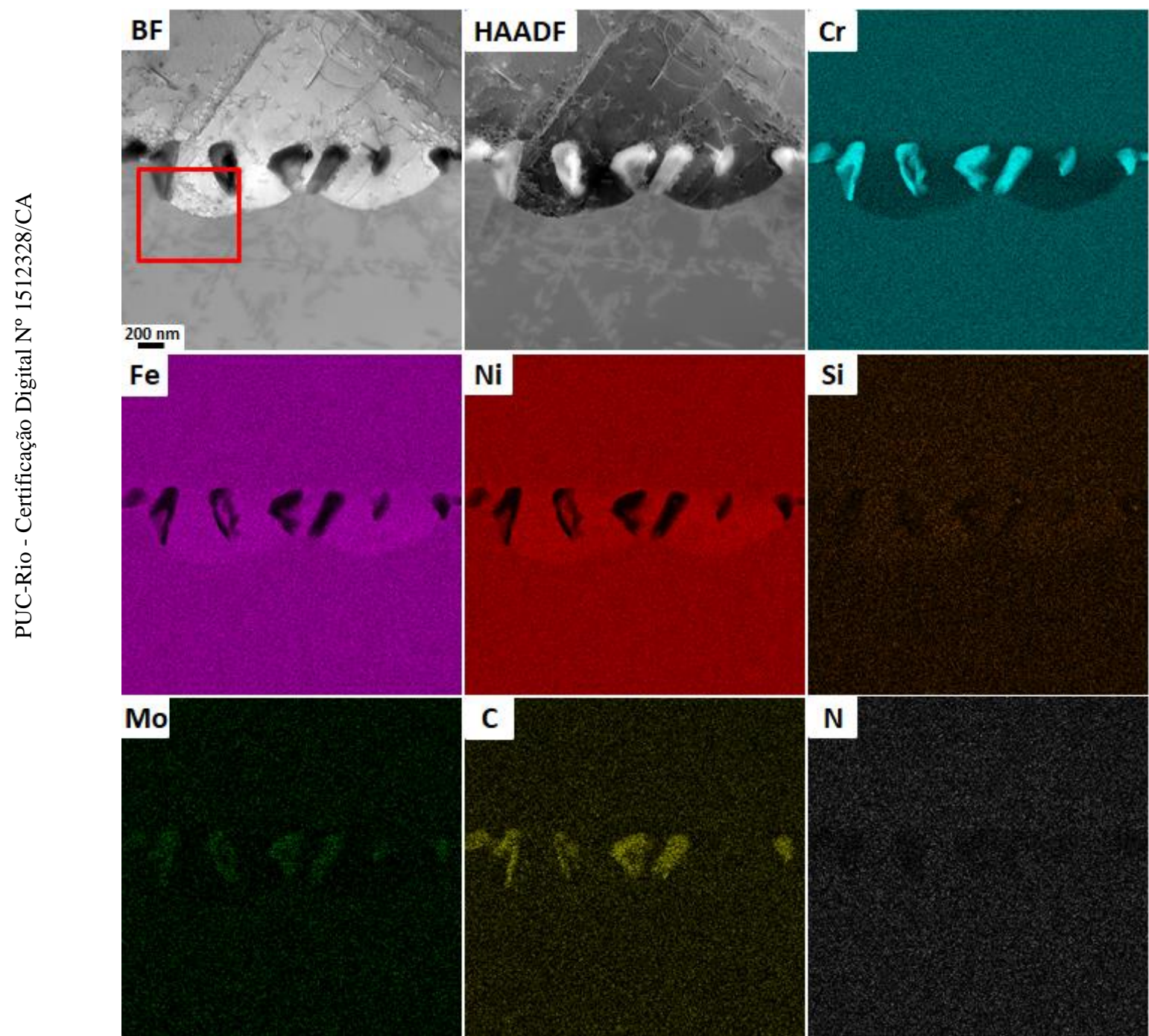

Figura 4.17 - Imagens de STEM-BF/HAADF mostrando os estágios iniciais da reação de PD na Liga 33 envelhecida a $800{ }^{\circ} \mathrm{C}$ por 30 min e os correspondentes mapas elementares obtidos por STEM/XEDS do $\mathrm{Cr}, \mathrm{Fe}, \mathrm{Ni}, \mathrm{Si}, \mathrm{Mo}, \mathrm{C}$ e N. O quadrado indica a região mostrada na Figura 4.18. 


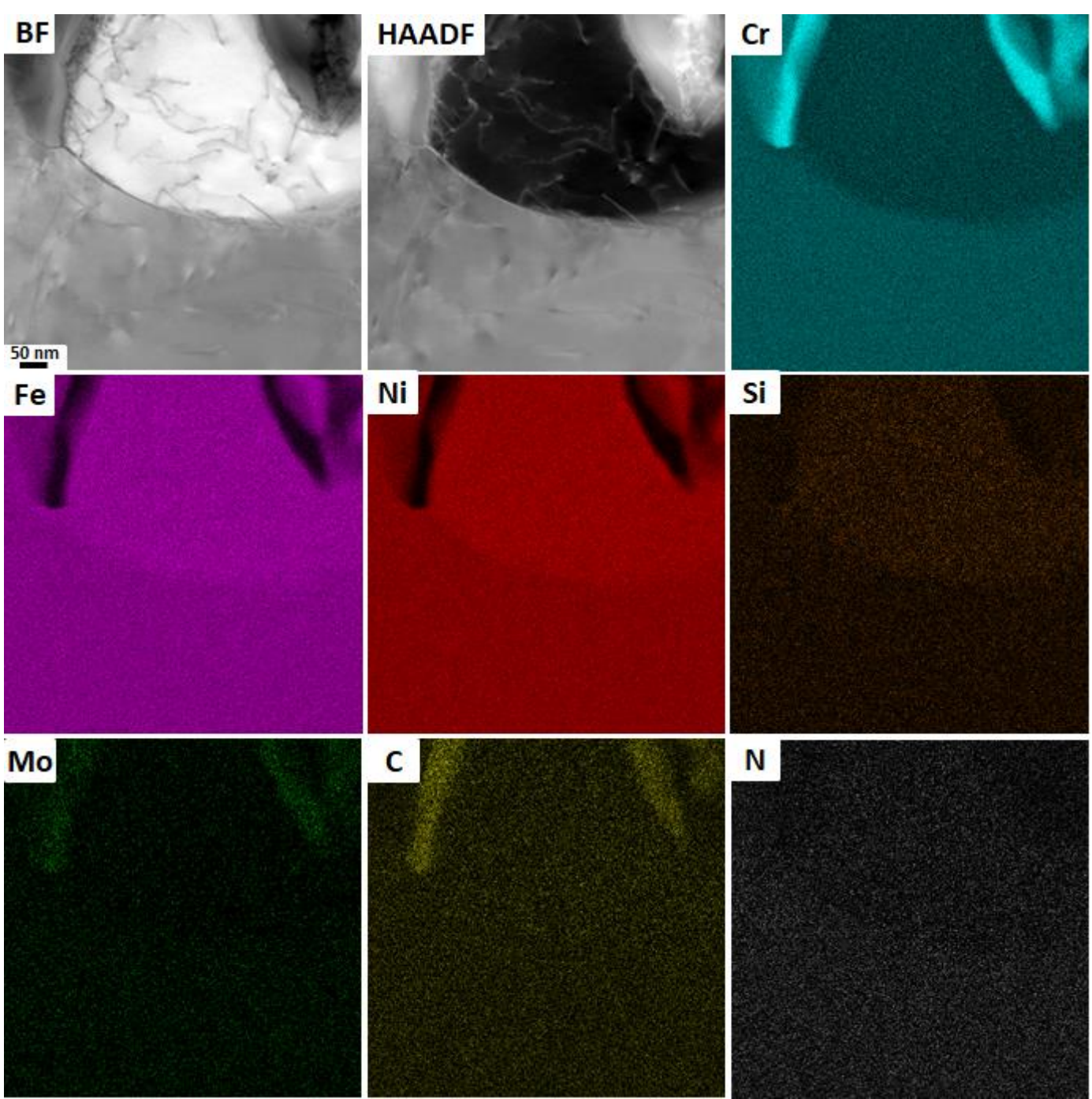

Figura 4.18 - Imagens de STEM-BF/HAADF obtidas da região indicada pelo quadrado vermelho na Figura 4.17 e os correspondentes mapas elementares obtidos por STEM/XEDS do $\mathrm{Cr}$, Fe, Ni, Si, Mo, C e N.

Como mostrado nos resultados apresentados anteriormente foi observado um enriquecimento em $\mathrm{Si}$ em algumas regiões próximas ao carbeto- $\mathrm{M}_{23} \mathrm{C}_{6}$ (Figuras 4.14 e 4.16) e também na região varrida pelo contorno em movimento (Figura 4.18). Porém, nas Figuras 4.19 e 4.20 mostradas a seguir (e no decorrer deste trabalho) são apresentados resultados obtidos por STEM/XEDS mostrando que a segregação de Si em alguns casos ocorre juntamente com a segregação de N. A imagem de STEM-BF na Figura 4.20 obtida da região indicada pelo retângulo vermelho na Figura 4.19 mostra parte do contorno decorado por precipitados juntamente com os mapas elementares obtidos por STEM/XEDS. Nesta figura são observadas características similares às observadas anteriormente, zonas empobrecidas em $\mathrm{Cr}$ e enriquecidas em $\mathrm{Fe}$ e $\mathrm{Ni}$ na região varrida pelo contorno avançando e também ao redor dos carbetos- $\mathrm{M}_{23} \mathrm{C}_{6}$ ricos em $\mathrm{Cr}$. 
Entretanto, uma nova fase precipitada parece ter se formado associada ao carbeto nesta região do contorno. Os resultados observados nos mapas elementares indicam que este novo precipitado era enriquecido em $\mathrm{Si}, \mathrm{N}, \mathrm{Ni}$, Mo e $\mathrm{N}$. $\mathrm{Na}$ Figura 4.20, são apresentados dois espectros obtidos por STEM/XEDS dos diferentes precipitados encontrados na Liga 33 envelhecida a $800{ }^{\circ} \mathrm{C}$ por 30 minutos. $\mathrm{O}$ espectro 1 foi obtido do carbeto- $\mathrm{M}_{23} \mathrm{C}_{6}$ rico em $\mathrm{Cr}$ contendo $\mathrm{Fe}$, Mo e baixos níveis de $\mathrm{Ni}$ e o espectro 2 foi obtido da fase enriquecido em $\mathrm{Si}, \mathrm{Cr}, \mathrm{Ni}$, Mo e $\mathrm{N}$ contendo baixos níveis de Fe e V (este último elemento não é reportado na composição química da Liga 33). $\mathrm{O}$ alto pico do elemento $\mathrm{C}$ pode ser proveniente da matriz, e/ou dos carbetos existentes ao redor na fase enriquecida em Si e N, ou também ser contaminação, não sendo possível afirmar, ainda, se a nova fase é um nitreto ou carbonitreto.

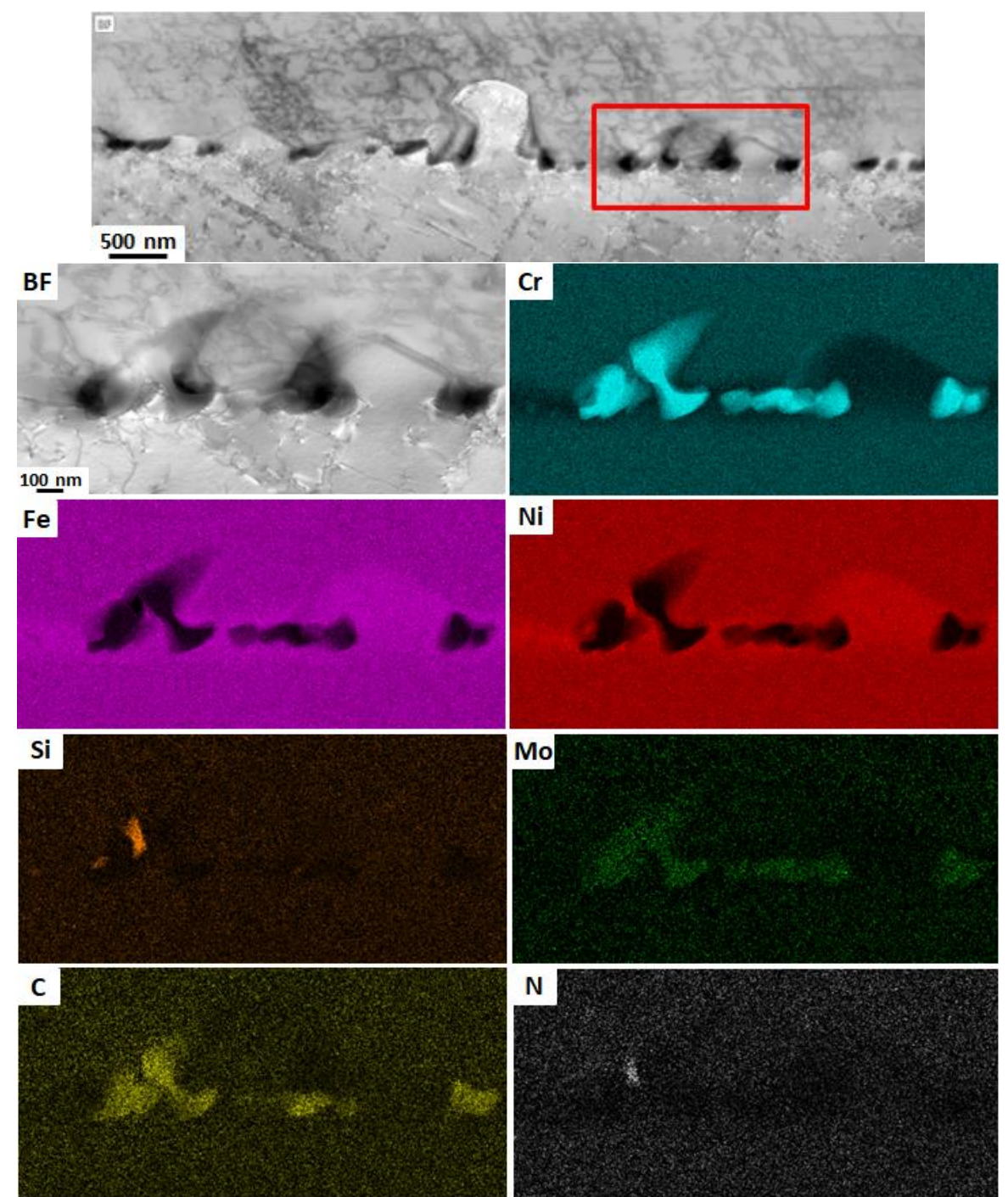

Figura 4.19 - Imagem de STEM-BF mostrando um CG decorado por precipitados na Liga 33 envelhecida a $800{ }^{\circ} \mathrm{C}$ por 30 min e uma imagem de STEM-BF obtida da região indicada pelo retângulo vermelho em (a) e os correspondentes mapas elementares obtidos por STEM/XEDS do $\mathrm{Cr}, \mathrm{Fe}, \mathrm{Ni}, \mathrm{Si}, \mathrm{Mo}, \mathrm{C}$ e N. 

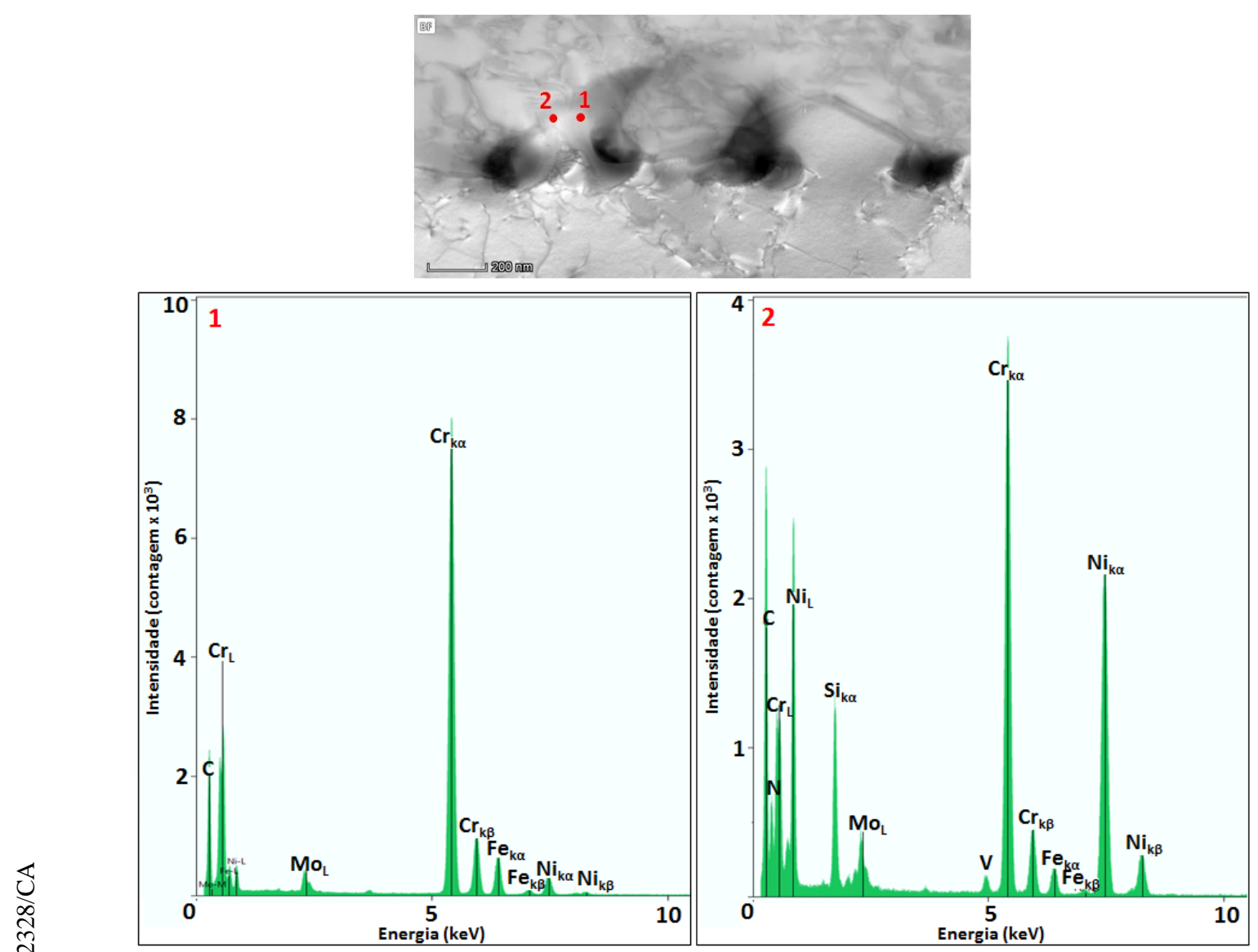

Figura 4.20 - Imagem de STEM-BF mostrada na Figura 4.19 e dois espectros pontuais obtidos por STEM/XEDS dos precipitados indicados pelos números 1 e 2 .

Baseado nas observações morfológicas/topológicas juntamente com as análises analíticas obtidas por STEM/XEDS e por difração de elétrons (SAED) apresentadas nas Figuras 4.3 até 4.20 é possível fazer algumas conclusões em relação aos fenômenos de precipitação no CG na Liga 33 envelhecida a $800{ }^{\circ} \mathrm{C}$ até 30 minutos:

- O primeiro precipitado formado foi o carbeto- $\mathrm{M}_{23} \mathrm{C}_{6}$ rico em $\mathrm{Cr}$ com estrutura CFC e R.O. cubo-a-cubo com a matriz CFC. Além do carbeto, uma fase enriquecida em $\mathrm{Si}, \mathrm{Ni}, \mathrm{Cr}$, Mo e $\mathrm{N}$ foi confirmada, a qual foi observada formar em associação com o carbeto.

- Zonas empobrecidas em $\mathrm{Cr}$ e enriquecidas em $\mathrm{Ni}$ e $\mathrm{Fe}$ foram observadas na região varrida pelo contorno e também ao redor dos carbetos- $\mathrm{M}_{23} \mathrm{C}_{6}$. Foi verificada também a existência de um enriquecimento em $\mathrm{Si}$ em regiões próximas ao carbeto- $\mathrm{M}_{23} \mathrm{C}_{6}$, bem como na região varrida pelo contorno migrando.

- A migração do CG foi observada ocorrer tanto para um lado como para os dois lados do mesmo contorno. Em alguns casos, o CG migrou consideravelmente sem conexão com os precipitados formados na posição original do $\mathrm{CG}$, indicando que o fenômeno DIGM tem um papel fundamental como precursor da reação de PD na Liga 33. 


\subsection{Precipitação Descontínua no envelhecimento a $800^{\circ} \mathrm{C}$ por $1 \mathrm{~h}$ até $100 \mathrm{~h}$ - Observações por MO e MEV}

A evolução microestrutural da Liga 33 resultante do envelhecimento isotérmico à $800{ }^{\circ} \mathrm{C}$ por tempos de $1 \mathrm{~h}$ até $100 \mathrm{~h}$ é ilustrada por MO na Figura 4.21. No estágio inicial do processo de envelhecimento, novas fases de carbetos$\mathrm{M}_{23} \mathrm{C}_{6}$ precipitaram preferencialmente nos $\mathrm{CG}$, como indicado pelas setas na Figura 4.21a. Quando o tempo de envelhecimento foi aumentado para 2 horas, foi observado que a fração volumétrica dos precipitados intergranulares aumentou, quase ocupando todos os CG (Figura 4.21b). Após 5 horas de envelhecimento, os precipitados parecem ter preenchido todos os contornos. Nesta condição, foi verificada a ocorrência de precipitados intragranulares distribuídos por alguns grãos da matriz CFC (indicada pelo círculo vermelho na Figura 4.21c), além da formação de colônias de PD bem desenvolvidas em alguns CG. A Figura 4.21d mostra que o envelhecimento por $10 \mathrm{~h}$ resultou no aumento da fração volumétrica tanto da precipitação convencional (homogênea e heterogênea) como das colônias de PD. Entretanto, a partir de $20 \mathrm{~h}$ de envelhecimento (Figura 4.21e) parece que ocorreu uma diminuição na taxa de crescimento das colônias de PD em direção do grão adjacente, bem como o aumento na fração volumétrica da precipitação dentro dos grãos. É possível verificar que após $100 \mathrm{~h}$ de envelhecimento o material é praticamente preenchido por precipitação homogênea (Figura 4.21g). Vale destacar o fato que após 50 horas de envelhecimento (Figura 4.21f) a distinção por MO entre os precipitados que constituem somente a colônia de PD daqueles que precipitaram dentro dos grãos, mas não pertencendo à colônia, fica mais difícil de ser realizada.

Assim, pode-se concluir que, baseado nas observações da evolução microestrutural dos resultados obtidos por MO e apresentados na Figura 4.21, a sequência de precipitação na Liga 33 envelhecida a $800{ }^{\circ} \mathrm{C}$ por $1 \mathrm{~h}$ até $100 \mathrm{~h}$ foi: precipitação heterogênea nos $\mathrm{CG} \rightarrow$ colônias de PD em alguns CG $\rightarrow$ precipitação homogênea dentro dos grãos da matriz CFC. Este comportamento nos processos de precipitação foi reportado por vários autores [2][16][18][52] [55][171]. Lee et al. [52] e Lim et al. [2] relataram a mesma sequência de precipitação do carbeto- $\mathrm{M}_{23} \mathrm{C}_{6}$ em um AI austenítico (18Cr-9Mn-0.4N-0.4N) após envelhecimento a $850{ }^{\circ} \mathrm{C}$ e uma liga à base de Ni (Liga Inconel 690) envelhecida 
a $720{ }^{\circ} \mathrm{C}$, respectivamente. Lee et al. [18] também reportou a ocorrência da mesma sequência em uma AI austenítico (18Cr-18Mn-2Mo-0.9N) envelhecida a $850{ }^{\circ} \mathrm{C}$, porém a fase precipitada neste caso foi o nitreto- $\mathrm{M}_{2} \mathrm{~N}$. Entretanto, Zhang et al. [55] observou em um AI austenítico (25Cr-22Ni-8Mo-0.5N) envelhecido a $900{ }^{\circ} \mathrm{C}$ a mesma sequência de precipitação, porém o precipitado foi identificado como a fase intermetálica $\sigma$.

Neste sentido, como foi mostrado que o processo de envelhecimento da Liga 33 a $800{ }^{\circ} \mathrm{C}$ leva à precipitação no $\mathrm{CG}$ e subsequente formação de colônias de PD e precipitação dentro dos grãos (Figura 4.21) e sabendo que o primeiro precipitado formado no $\mathrm{CG}$ na Liga 33 foi o carbeto- $\mathrm{M}_{23} \mathrm{C}_{6}$ (item 4.2), é esperado que a fase que constituirá a colônia de PD na Liga 33 será do mesmo tipo de carbeto formado inicialmente no $\mathrm{CG}\left(\mathrm{M}_{23} \mathrm{C}_{6}\right.$-carbeto). Porém, como será mostrado no decorrer deste trabalho, a principal fase precipitada constituindo as colônias de $\mathrm{PD}$ na Liga 33 (i.e. os precipitados lamelares) não é o carbeto- $\mathrm{M}_{23} \mathrm{C}_{6} \mathrm{e}$ sim a fase- $\alpha$ rica em $\mathrm{Cr}$. 


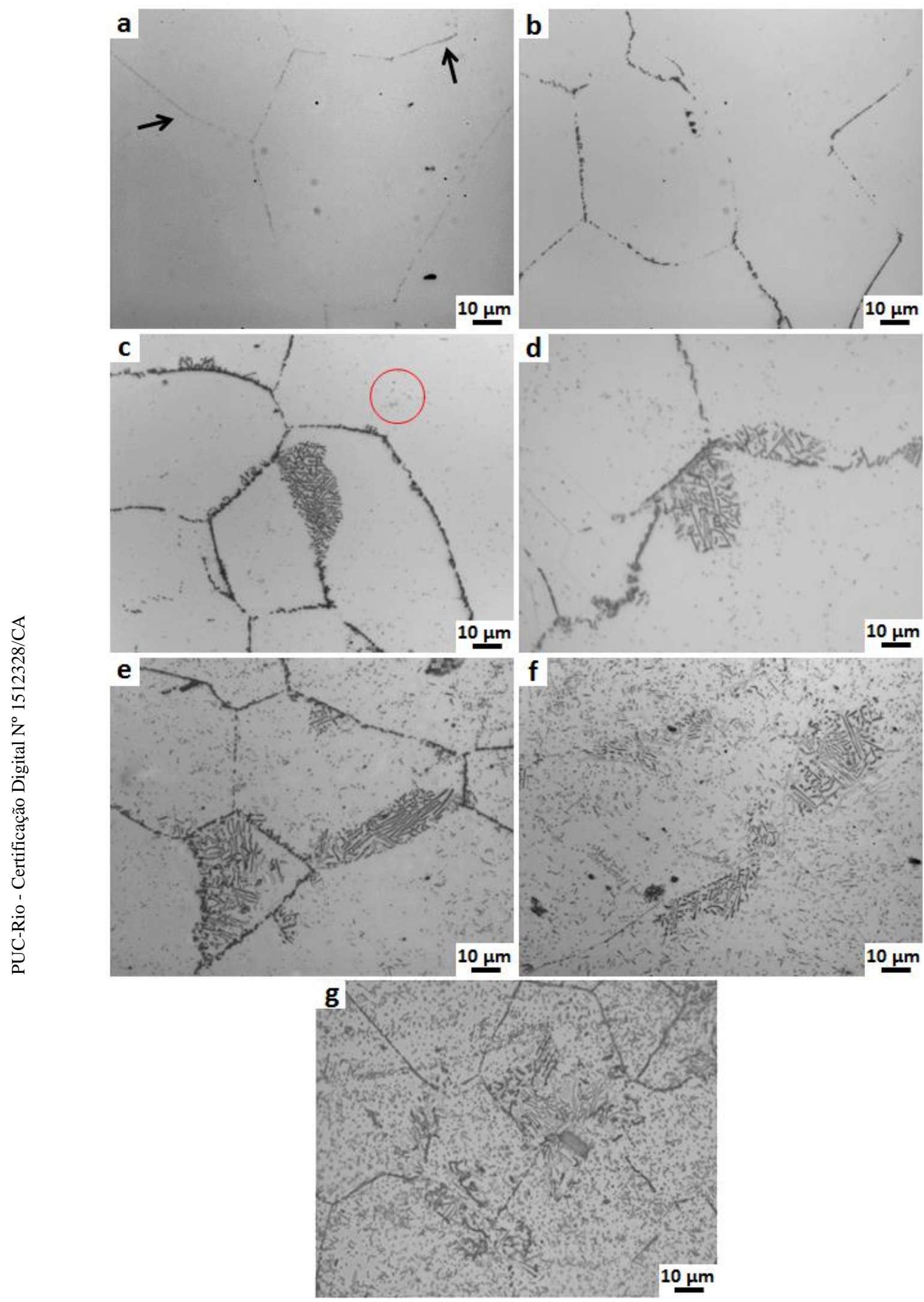

Figura 4.21 - Imagens de MO-BF da Liga 33 envelhecida a $800{ }^{\circ} \mathrm{C}$ por (a) $1 \mathrm{~h}$; (b) $2 \mathrm{~h}$; (c) $5 \mathrm{~h}$; (d) $10 \mathrm{~h}$; (e) $20 \mathrm{~h}$; (f) $50 \mathrm{~h}$; e (g) $100 \mathrm{~h}$. O círculo em (c) indica precipitados intragranulares. 
A seguir são apresentados alguns dos resultados obtidos por MEV/XEDS com o objetivo de mostrar as características morfológicas dos processos de precipitação na Liga 33, dando maior atenção à reação de PD nos CG. A Figura 4.22 mostra imagens de MEV-SE de diferentes produtos da precipitação nos CG na Liga 33 envelhecida a $800{ }^{\circ} \mathrm{C}$ por $1 \mathrm{~h}$. Na Figura 4.22a, é clara a diferença nas morfologias dos precipitados nos diferentes CG, além de lamelas irregulares de precipitados crescendo ao longo contorno que migrou. Na Figura 4.22b, é observado que o contorno migrou para ambos os lados do mesmo contorno. Nesta mesma figura, diferentes comportamentos em relação a migração do contorno foram verificados. Enquanto em algumas regiões a migração foi acompanhada pelo crescimento do precipitado (setas vermelhas), em outras regiões o CG migrou sem conexão com o precipitado (setas amarelas). Como será mostrado ao longo deste trabalho, frequentemente foi observado o contorno migrando à frente da ponta do precipitado formado no CG (Figura 4.22c) ou sem conexão com o precipitado no contorno (Figura 4.22d). Um exemplo é mostrado na Figura 4.22d, na qual o ponto triplo mostra três $\mathrm{CG}$ com precipitados grosseiros em diferentes morfologias e tamanhos. Enquanto o CG posicionado no lado direito desta imagem, marcado com a, permaneceu estático, o CG marcado b migrou em uma direção com concomitante precipitação e o CG marcado c migrou para ambos os lados mostrando regiões com precipitação grosseira e outras livres de precipitação, o que indica, neste último, a que o fenômeno DIGM tem um importante papel na migração do CG na Liga 33 envelhecida a $800{ }^{\circ} \mathrm{C}$. 

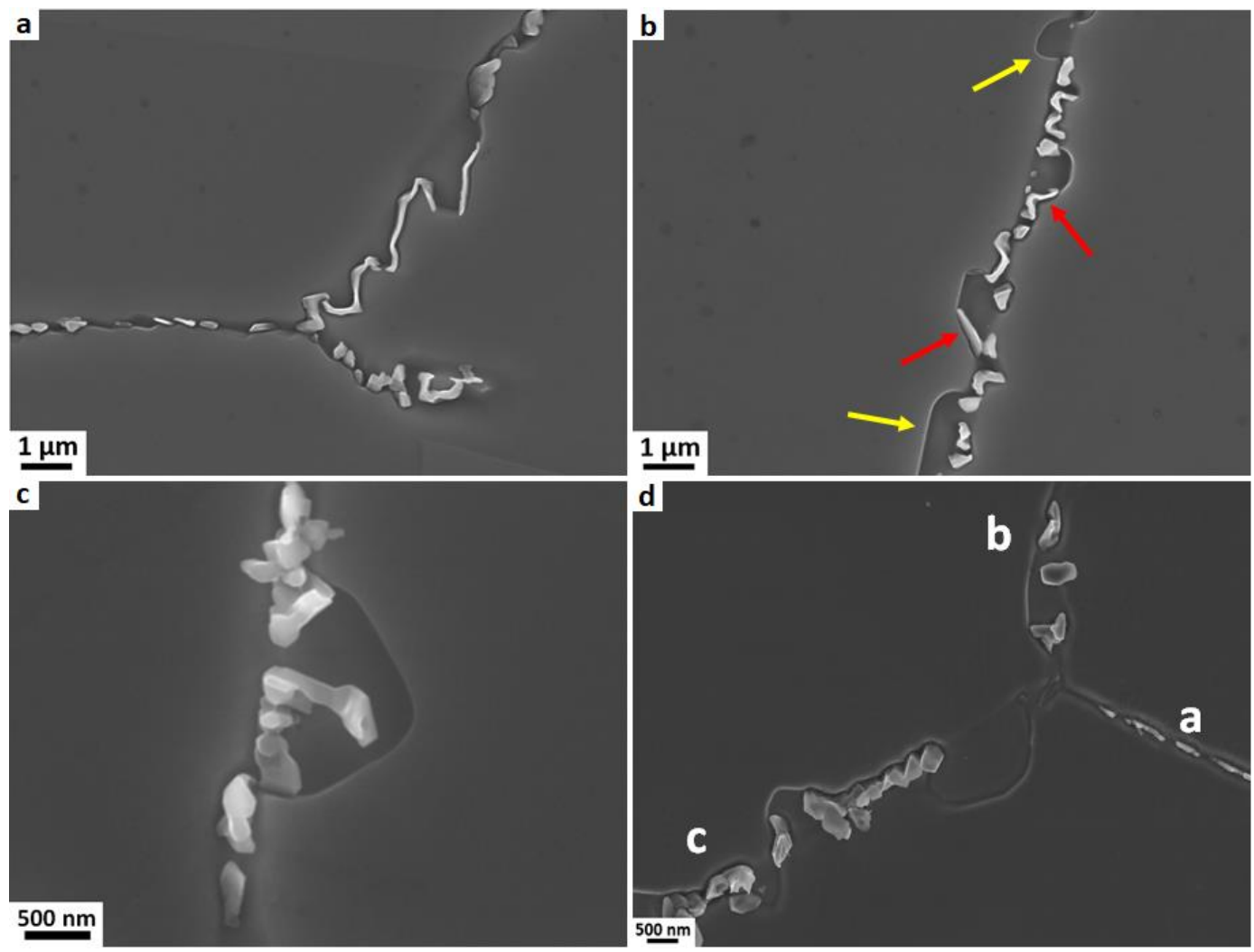

Figura 4.22 - Imagens de MEV-SE mostrando diferentes produtos e topologias da precipitação nos CG na Liga 33 envelhecida a $800{ }^{\circ} \mathrm{C}$ por $1 \mathrm{~h}$. As setas vermelhas indicam segmentos do CG que migrou juntamente com o crescimento do precipitado e as setas amarelas indicam segmentos do CG que migrou sem conexão com precipitado no CG.

Quando o tempo do tratamento térmico foi aumentado para $2 \mathrm{~h}$ foi observada a existência de colônias de PD em desenvolvimento em alguns CG. A Figura 4.23 mostra diferentes colônias observadas na Liga 33 envelhecida a $800{ }^{\circ} \mathrm{C}$. Na Figura 4.23a, a ocorrência de precipitados na posição original do CG foi observada, além da migração do contorno na direção da matriz CFC. É também claro o desenvolvimento de alguns precipitados crescendo juntamente com a migração do CG e outros que nuclearam na frente de reação da PD. Na Figura 4.23b, a colônia de PD mostra características similares àquelas observadas na Figura 4.23a. Precipitados menores na posição original do CG comparado com aqueles da Figura 4.23a, além de alguns precipitados crescendo juntamente com a migração do contorno também foram observados. Tais observações corroboram a premissa que a taxa de nucleação no CG e o crescimento da precipitação depende de propriedades estruturais e energéticas de cada contorno. Além disso, na específica colônia de PD mostrada na Figura 4.23b, a multiplicação de precipitados lamelares por ramificação ("branching") foi observada, os quais estão 
indicados pelas setas. Este mecanismo de multiplicação de lamelas já foi reportado em sistemas binários [181].

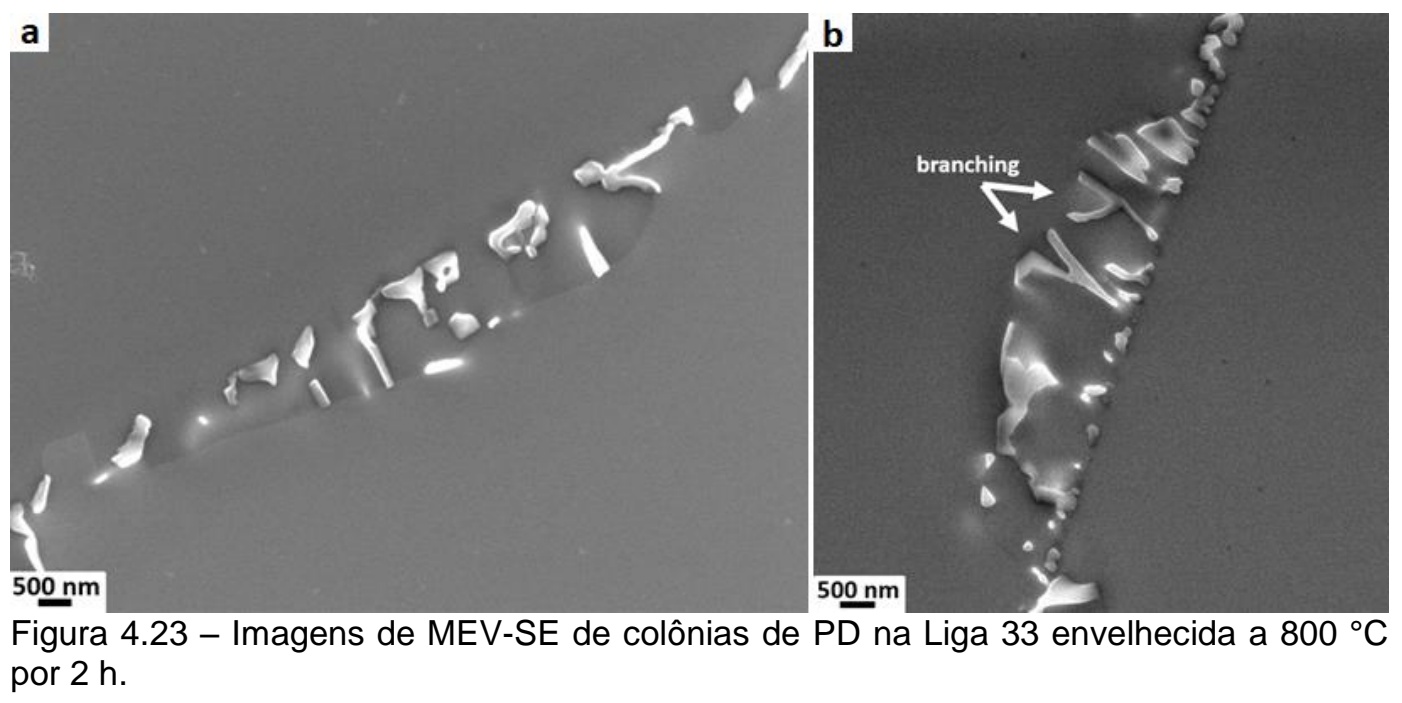

A Figura 4.24a apresenta uma imagem de MEV-SE em baixo aumento da Liga 33 envelhecida a $800{ }^{\circ} \mathrm{C}$ por $5 \mathrm{~h}$ mostrando que quase todos os $\mathrm{CG}$ estão decorados por precipitados, além de colônias de PD em alguns destes contornos. A Figura 4.24b, obtida da região indicada pelo retângulo vermelho na Figura 4.24a, mostra a diferença dos produtos de precipitação nos diferentes CG. Nesta figura, a colônia de PD não é constítuida apenas de precipitados lamelares. Enquanto precipitados lamelares e irregulares nuclearam na posição original do CG, dentro da colônia ambos precipitados com morfologia lamelar (indicados pelos círculos) e precipitados nodulares (indicados pelos quadrados) foram observados. Tal observação, de precipitados com morfologias tanto lamelar como nodular dentro de colônias de PD, já foi reportada por vários autores [1][2][8-10] [74][168][176][210]. Também nesta colônia de PD foi observado que os precipitados lamelares cresceram em mais de uma direção cristalográfica. 

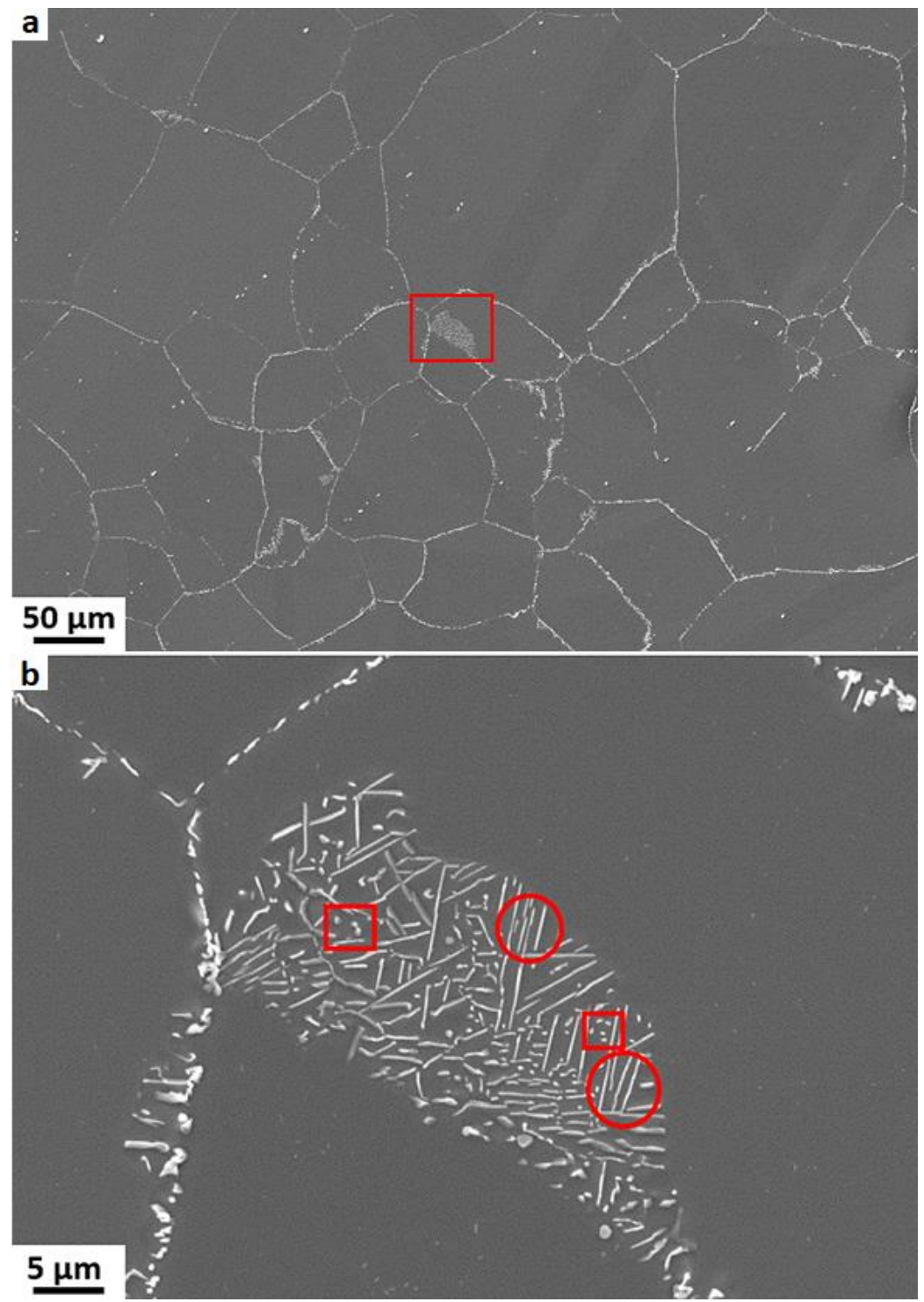

Figura 4.24 - Imagens de MEV-SE da Liga 33 envelhecida a $800^{\circ} \mathrm{C}$ por 5 h. (a) Imagem em baixo aumento e (b) colônia de PD bem desenvolvida obtida da região indicada pelo retângulo em (a). Os círculos e quadrados em (b) indicam precipitados com morfologia lamelar e nodular, respectivamente.

As imagens de MEV-SE/BSE na Figura 4.25 mostram uma colônia de PD com típica morfologia frequentemente observada na Liga 33 envelhecida a $800{ }^{\circ} \mathrm{C}$ durante este trabalho. Nesta específica colônia, resultante do envelhecimento por 5 h, são observados pequenos precipitados na posição original do $\mathrm{CG}$, enquanto precipitados particulados (nodulares) e lamelares nuclearam dentro da colônia, sendo que as lamelas cresceram na direção da matriz CFC. Essa observação foi consistente ao longo desta investigação. Esta imagem de MEV-BSE confirma a regra da reação de $\mathrm{PD}$, na qual a relação de orientação do grão inicial é transferida para a colônia, resultando que a região varrida pelo contorno avançando, tem a mesma orientação cristalina que a matriz na qual a lamela começou a crescer. Isto 
é evidente na imagem de MEV-BSE na Figura 4.25b onde o grão de cima na imagem (contraste cinza claro) e a matriz lamelar onde o contorno migrou tem o mesmo contraste de orientação cristalina. É possível observar também nesta figura a ocorrência de, pelo menos, três diferentes fases: a matriz CFC, precipitados lamelares e pequenos com contraste cinza e uma fase precipitada com contraste mais claro (contraste de alto número atômico, $\mathrm{Z}$ - high- $\mathrm{Z}$ contrast) na frente de reação, estas últimas estão indicadas pelas setas.

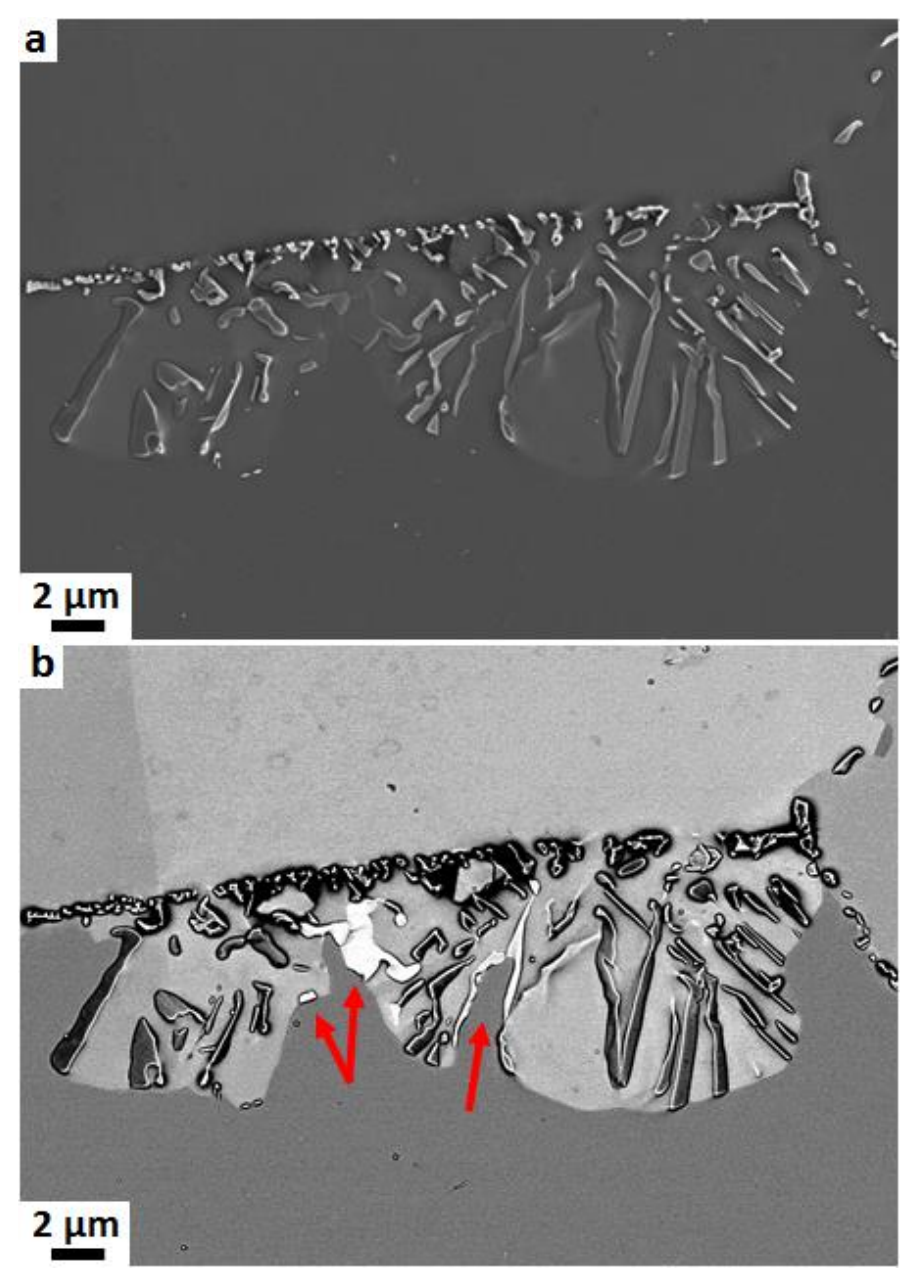

Figura 4.25 - Imagem de MEV (a) SE and (b) BSE da Liga 33 mostrando uma colônia de PD bem desenvolvida com precipitados com diferentes morfologias resultante do envelhecimento a $800{ }^{\circ} \mathrm{C}$ por $5 \mathrm{~h}$. As setas indicam uma fase precipitada com contraste mais claro em relação às outras fases precipitadas dentro da colônia de PD.

Quando o tempo de envelhecimento da Liga 33 foi aumentado de $5 \mathrm{~h}$ para 10 h, a fração volumétrica tanto da precipitação convencional como a descontínua também aumentou. A Figura 4.26 apresenta uma imagem de MEV-SE da Liga 33 envelhecida a $800{ }^{\circ} \mathrm{C}$ por $10 \mathrm{~h}$ mostrando precipitados em todos os CG e precipitados intragranulares com morfologia de agulhas distribuídos dentro dos 
grãos austeníticos. Tais precipitados na matriz não aparecem proeminentemente nesta imagem em baixa magnificação.

Como mostrado também na Figura 4.25, a ocorrência dentro da colônia de PD de ambos precipitados irregulares e lamelares, além de pequenos precipitados na posição original do CG foi observada na colônia da Figura 4.26. Vale a pena destacar que os precipitados lamelares, os quais crescem paralelos entre si, nuclearam e começaram a crescer adjacente ao CG e não no CG como afirmado na teoria clássica de PD. Esta mesma figura (Figura 4.26) mostra os mapas elementares obtidos por MEV/XEDS dos átomos substitucionais $\mathrm{Cr}, \mathrm{Fe}, \mathrm{Ni}, \mathrm{Si}$ e Mo, nos quais é verificado que todos os precipitados parecem ser enriquecidos em Cr e que existem precipitados ricos em Si tanto dentro da colônia de PD como na posição original do CG, e também nos contornos que permaneceram estáticos.

Uma análise química mais cuidadosa realizada nas regiões indicadas pelos retângulos vermelho e amarelo na Figura 4.26 mostra características interessantes em relação ao processo de precipitação da Liga 33. É verificado que enquanto todos os precipitados na região mais próxima da frente de reação da PD (retângulo vermelho na Figura 4.26) são enriquecidos em $\mathrm{Cr}$, alguns deles são também enriquecidos em Si e que os precipitados lamelares parecem não conter Si (Figura 4.27a). Porém, na região mais próxima da posição original do CG (retângulo amarelo na Figura 4.26) foi verificado que os precipitados enriquecidos em Si nuclearam preferencialmente nesta região (Figura 4.27b), i.e. eles se formaram preferencialmente na posição original do CG e adjacente ao CG do que dentro da colônia. Também, foi verificado que a concentração de Mo foi maior nos precipitados localizados na posição original do CG do que nas lamelas precipitadas dentro da colônia de $\mathrm{PD}$, sugerindo que a natureza dos precipitados formados no CG e dentro da colônia pode ser diferente. 


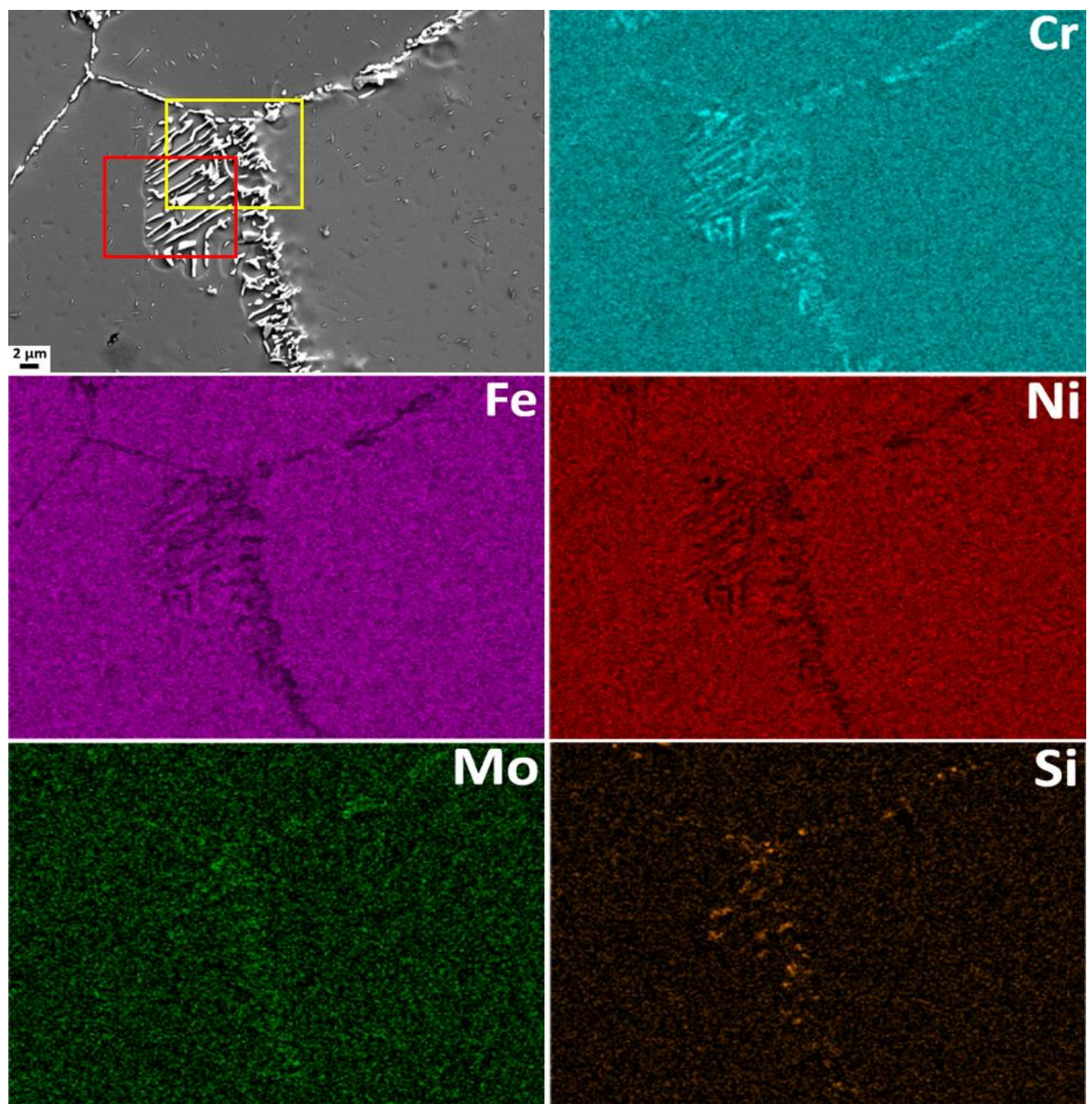

Figura 4.26 - Imagem de MEV-SE da Liga 33 envelhecida a $800{ }^{\circ} \mathrm{C}$ por $10 \mathrm{~h}$ mostrando uma colônia de PD, além de precipitados convencionais e os correspondentes mapas elementares obtidos por MEV/XEDS de $\mathrm{Cr}$, Fe, Ni, Mo e Si.

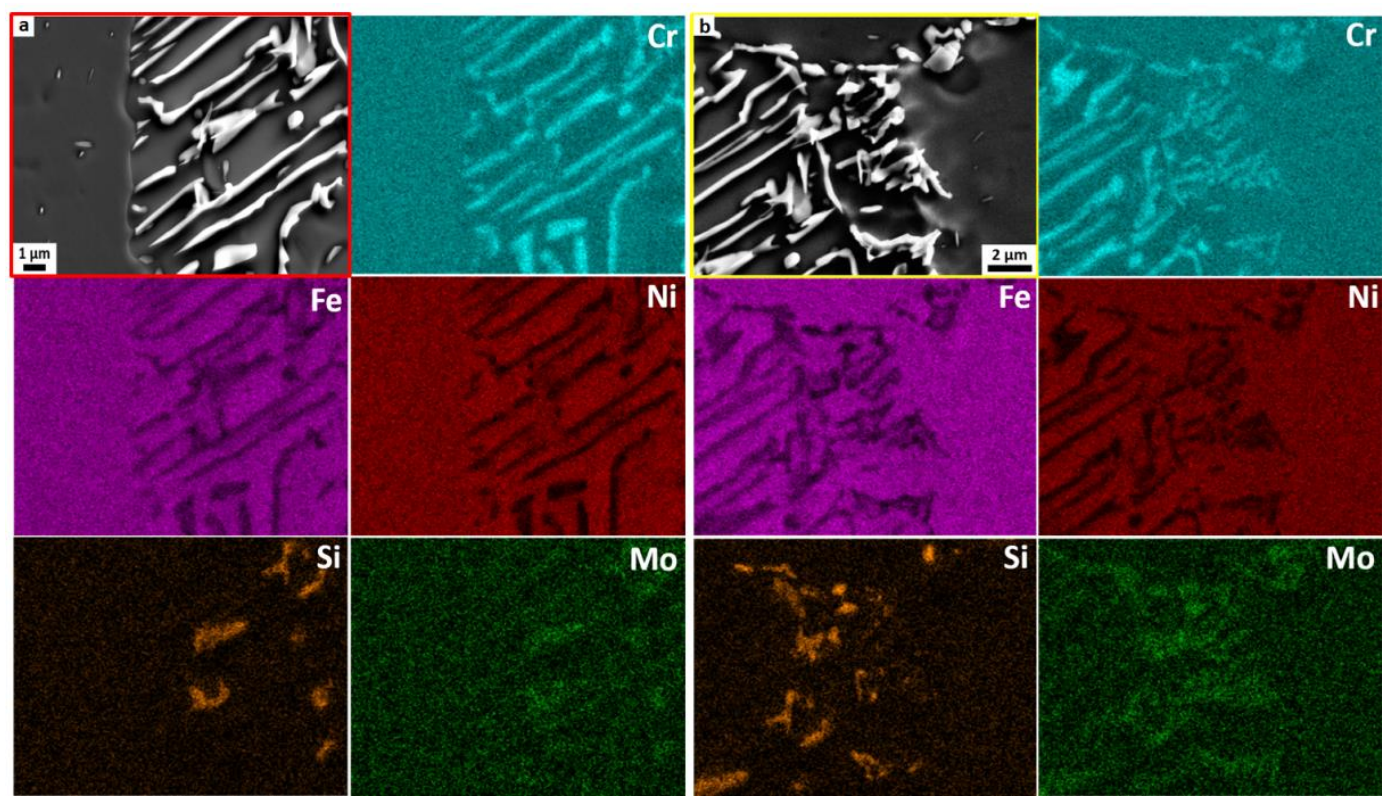

Figura 4.27 - Imagens de MEV-SE da Liga 33 envelhecida a $800{ }^{\circ} \mathrm{C}$ por $10 \mathrm{~h}$ obtida da região indicada pelo (a) retângulo vermelho e (b) retângulo amarelo na Figura 4.26 e os correspondentes mapas elementares obtidos por MEV/XEDS do Cr, Fe, Ni, Mo e Si. 
A Figura 4.28 mostra outra colônia de PD resultante do envelhecimento à $800{ }^{\circ} \mathrm{C}$ por 10 h. Nesta imagem de MEV-SE, a colônia cresceu para os dois lados do mesmo CG formando uma morfologia conhecida por "double-seam" [191-193]. Os mapas elementares obtidos por MEV/XEDS mostram o particionamento dos solutos substitucionais $\mathrm{Cr}, \mathrm{Fe}, \mathrm{Ni}$, Si e Mo. Como observado na Figura 4.28 todos os precipitados eram enriquecidos em $\mathrm{Cr}$, mas alguns deles continham maior teor de Si que outros. Uma análise cuidadosa realizada no mapeamento do elemento $\mathrm{Si}$ na Figura 4.28 mostra que os precipitados enriquecidos em Si se formaram tanto na posição original do CG (setas vermelhas na Figura 4.28) como na frente de reação da PD (setas amarelas na Figura 4.28). O mapeamento de XEDS obtido da região indicada pelo retângulo vermelho na Figura 4.28 indica a existência de, pelo menos, 3 diferentes fases precipitadas constituindo esta colônia de PD, como mostrado na Figura 4.29. Nestes mapas elementares, é verificado que o precipitado indicado pelo $\mathrm{n}^{\circ} 1$ era rico em $\mathrm{Cr}$; o precipitado indicado pelo $\mathrm{n}^{\circ} 2$ era enriquecido em $\mathrm{Cr}$ e Mo contendo $\mathrm{Fe}$ e $\mathrm{Si}$; e o precipitado indicado pelo $\mathrm{n}^{\circ} 3$ era enriquecido em $\mathrm{Si}$ e Mo contendo $\mathrm{Cr}$ e Ni.

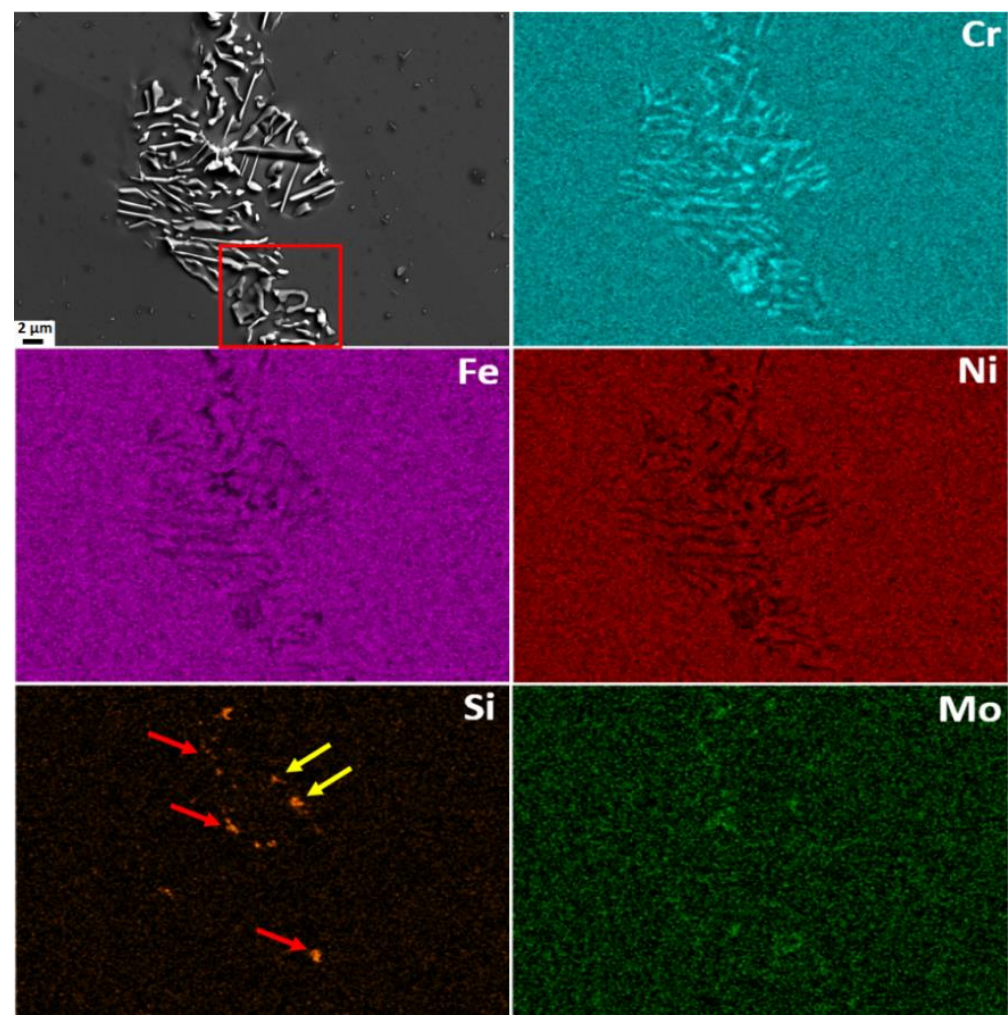

Figura 4.28 - Imagem de MEV-SE da Liga 33 envelhecida a $800{ }^{\circ} \mathrm{C}$ por $10 \mathrm{~h}$ mostrando uma colônia de PD com morfologia "double seam" e os correspondentes mapas elementares obtidos por MEV/XEDS do $\mathrm{Cr}, \mathrm{Fe}, \mathrm{Ni}$, Mo e $\mathrm{Si}$. As setas vermelhas indicam precipitados enriquecidos em Si formados na frente de reação da PD e as setas amarelas indicam precipitados enriquecidos em $\mathrm{Si}$ na posição original do $\mathrm{CG}$. O retângulo vermelho indica a região mostrada na Figura 4.29. 

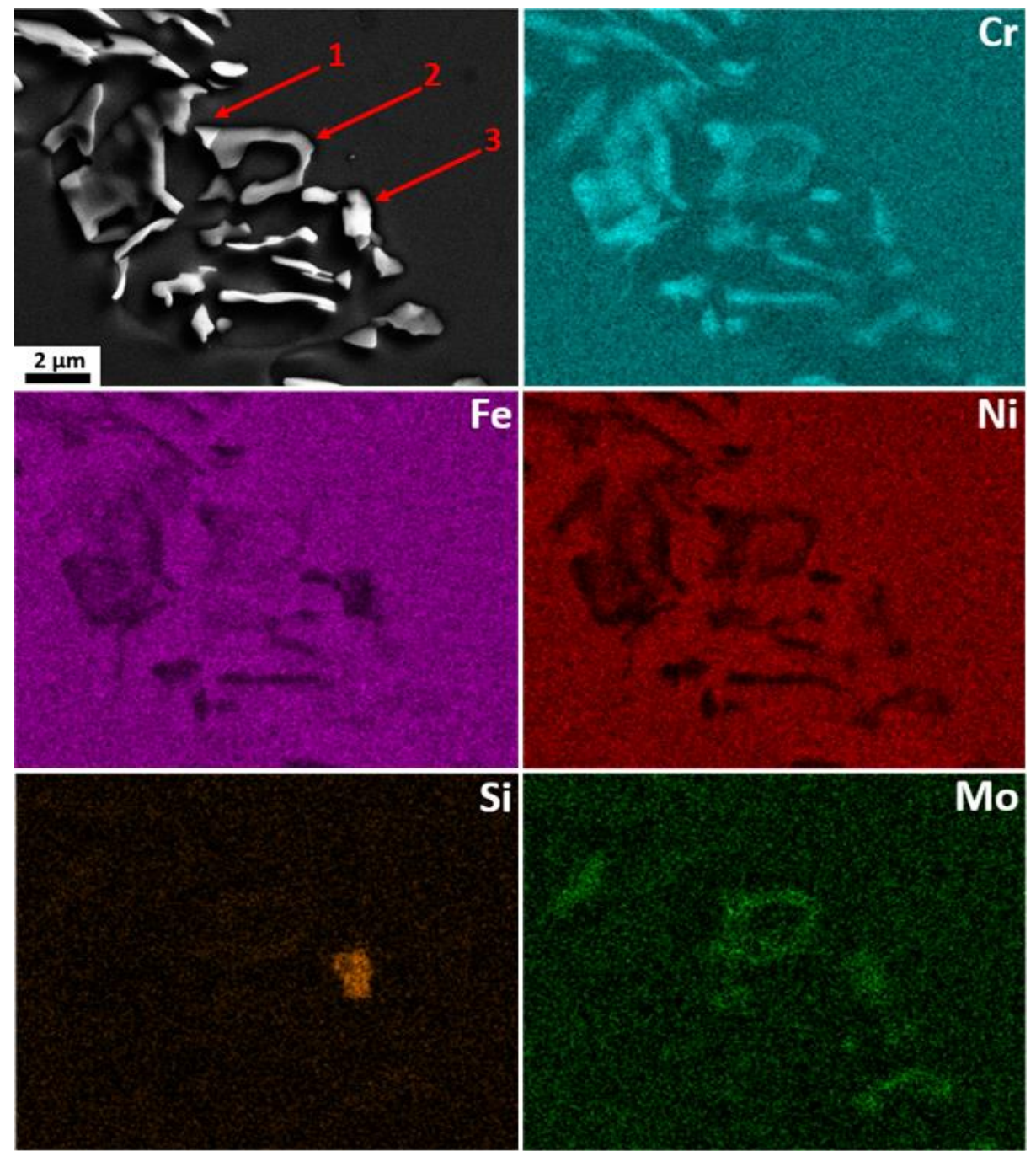

Figura 4.29 - Imagem de MEV-SE da Liga 33 envelhecida a $800{ }^{\circ} \mathrm{C}$ por $10 \mathrm{~h}$ obtida da região indicada pelo retângulo vermelho na Figura 4.28 e os correspondentes mapas elementares obtidos por MEV/XEDS do $\mathrm{Cr}, \mathrm{Fe}, \mathrm{Ni}$, Mo e Si. Precipitado ${ }^{\circ}$ 1: rico em $\mathrm{Cr}$; precipitado $n^{\circ}$ 2: enriquecido em $\mathrm{Cr}$ e Mo; precipitado $n^{\circ}$ 3: enriquecido em Si e Mo.

A Figura 4.30 mostra imagens de MEV-SE da Liga 33 envelhecida por 20 h, 50 h e 100 h nas Figuras 4.30a, 4.30b e 4.30c, respectivamente. Nestas imagens, é verificado que com o processo de envelhecimento as colônias de PD diminuem a taxa de crescimento (como também verificado na imagem 4.21) e assim a fração volumétrica das colônias torna-se praticamente estável. Concomitante com a diminuição da taxa de migração da frente de reação da PD, ocorre o aumento na fração volumétrica dos precipitados homogêneos dentro da matriz CFC. Como observado na Figura 4.30c, a matriz é praticamente preenchida por precipitados após $100 \mathrm{~h}$ de envelhecimento, não sendo possível fazer uma distinção de quais precipitados formaram dentro da colônia e quais formaram na matriz, como já tinha sido mostrado na Figura 4.21g. Assim, pode ser inferido que 
a força motriz para a migração da colônia de PD diminui devido tanto pela nucleação de novas fases precipitadas dentro da matriz como também pelo crescimento dos precipitados já existentes, os quais são alimentados pela difusão de soluto proveniente da matriz CFC.

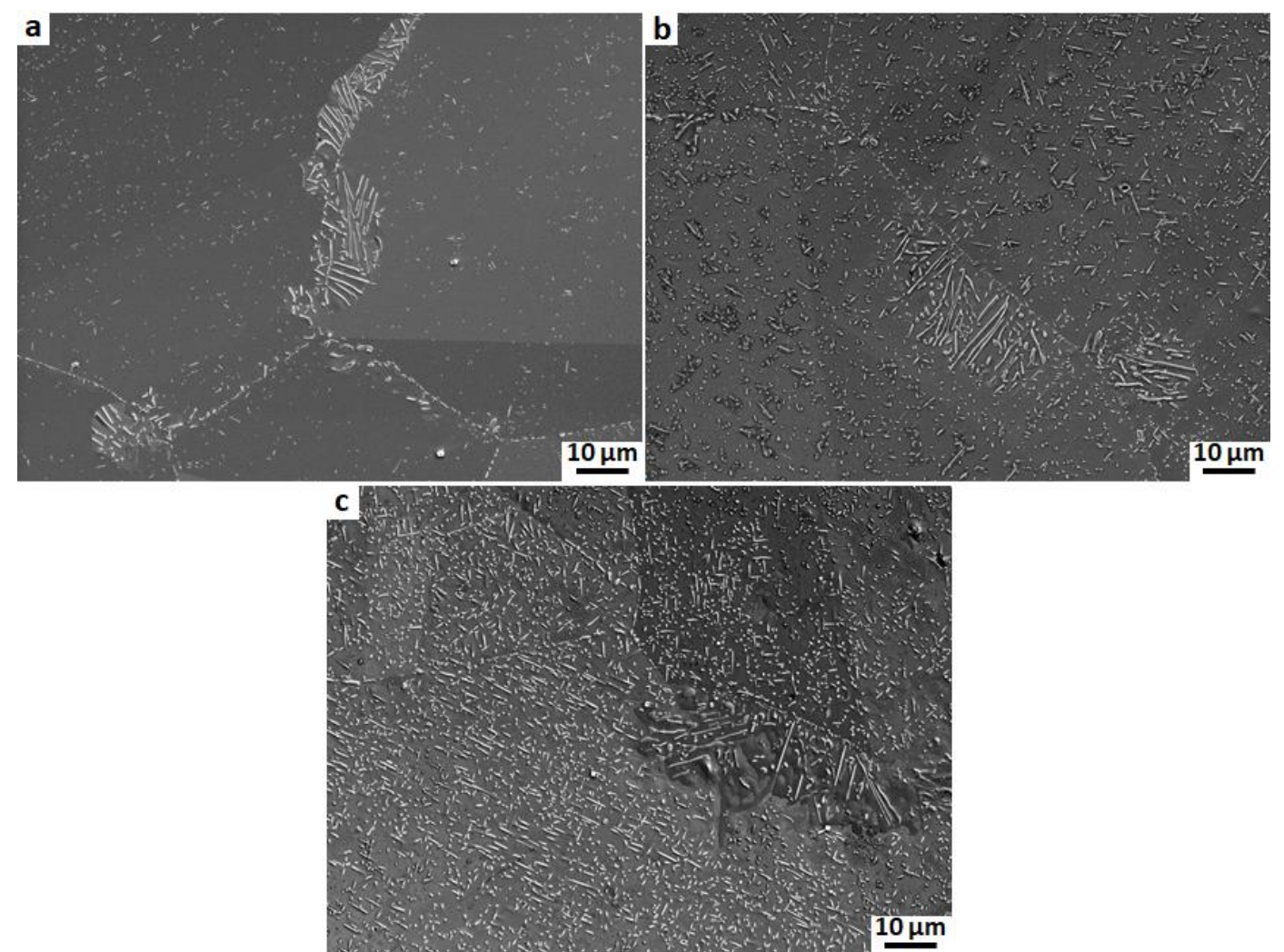

Figura 4.30 - Imagens de MEV-SE da Liga 33 envelhecida a $800{ }^{\circ} \mathrm{C}$ por (a) $20 \mathrm{~h}$; (b) $50 \mathrm{~h} ; \mathrm{e} \mathrm{(c)} 100 \mathrm{~h}$.

A seguir, são apresentados alguns resultados mostrando características morfológicas e também elementares observadas na microestrutura (com foco na reação de PD) da Liga 33 envelhecida por 20 h até 100 h. A Figura 4.31 ilustra imagens de MEV-BSE da Liga 33 envelhecida a $800{ }^{\circ} \mathrm{C}$ por $20 \mathrm{~h}$. Na imagem em baixa magnificação na Figura 4.31a, a ocorrência de precipitados convencionais, bem como colônias de PD em alguns CG foi observada. Na imagem da Figura 4.31b obtida da região indicada pelo retângulo vermelho em 4.31a, é mostrada uma colônia de PD bem desenvolvida que cresceu para ambos os lados do contorno resultando numa morfologia "double seam", como também mostrado nas Figuras 4.28 e 4.30a. Entretanto, quando comparado as morfologias dos precipitados formados dentro da colônia em ambos os lados do contorno na Figura $4.31 b$, é possível verificar diferenças entre eles. Enquanto em um lado do contorno (lado direito na imagem) os precipitados lamelares cresceram paralelos 
entre si praticamente em uma direção, no lado oposto (lado esquerdo da imagem) a colônia contém precipitados tanto lamelares como na forma de partículas. Esta diferença pode ser uma consequência das diferenças cristalográficas existentes entre as diferentes direções de propagação da colônia.

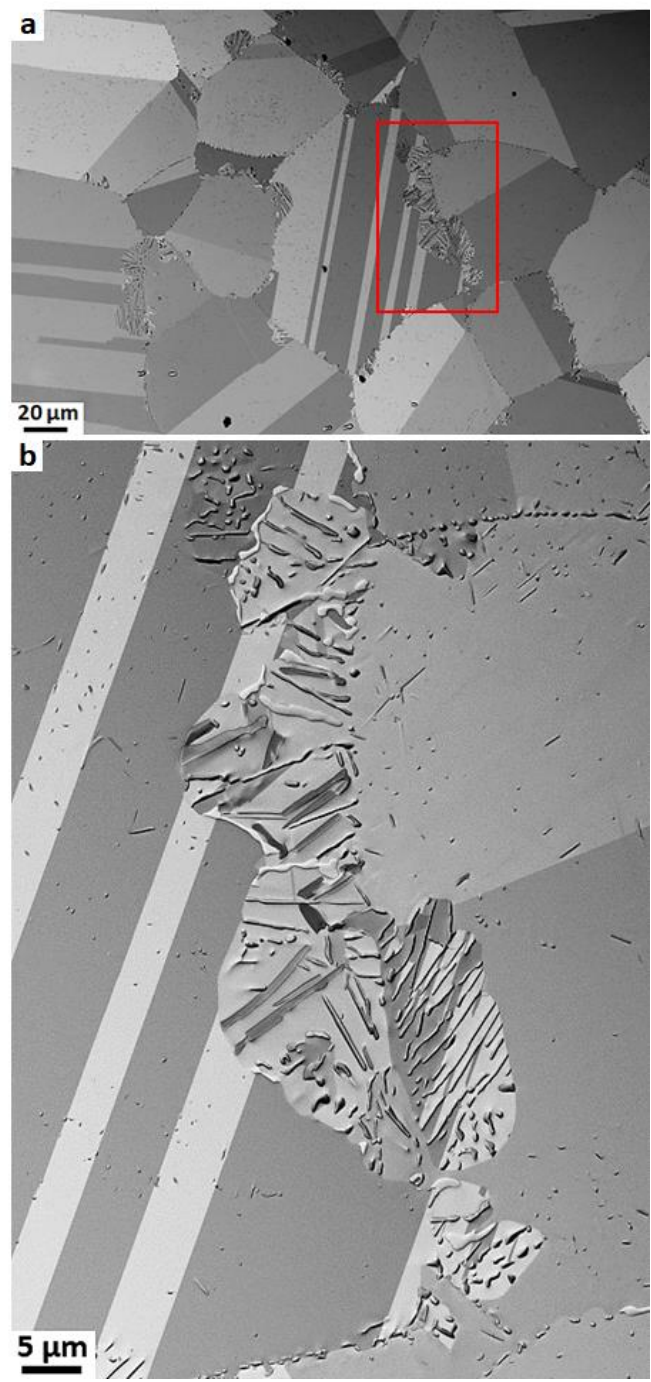

Figura 4.31 - Imagens de MEV-BSE da Liga 33 envelhecida a $800{ }^{\circ} \mathrm{C}$ por 20 horas (a) imagem em baixa magnificação mostrando a microestrutura geral e (b) colônia de PD obtida da região indicada pelo retângulo vermelho em (a) mostrando uma morfologia "double seam".

A imagem de MEV-BSE na Figura 4.32 mostra precipitados convencionais e uma colônia de PD formada no CG da Liga 33 envelhecida a 800 ${ }^{\circ} \mathrm{C}$ por 20 h. Colônias com estas características foram frequentemente observadas durante este trabalho. Nesta colônia, é verificado que pequenos precipitados se formaram e permaneceram na posição original do $\mathrm{CG}$, além de precipitados tanto lamelares como na forma de partículas dentro da colônia de PD, i.e. na região varrida pela frente de reação. Também foram observados precipitados grosseiros 
com contraste mais claro na frente de reação da PD (indicado pelas setas vermelhas). Interessante notar que os precipitados lamelares dentro da colônia cresceram em mais de uma direção cristalográfica, o que está claro na região indicada pela seta amarela na Figura 4.32, onde existe uma abrupta mudança de direção de crescimento das lamelas.

A ocorrência de precipitados lamelares e nodulares dentro de colônias de PD já foi estudada por outros autores. Ainsley et al. [176] sugeriram, em uma liga austenítica (Fe-Mn-V-C), que efeitos cristalográficos podem influenciar o desenvolvimento de colônias de PD contendo precipitação lamelar e/ou nodular. Os autores reportaram que colônias de PD com precipitados lamelares foram observada em CG com alta densidade de sítios coincidentes (contorno de baixa energia). Por outro lado, em contornos com pobre ajuste atômico (contorno de alta energia), precipitados nodulares foram observados constituir as colônias. Neste último caso, se o contorno migrar para uma orientação tal que a densidade de átomos coincidentes no plano do contorno é alta, a natureza dos precipitados durante o crescimento da reação de PD pode mudar de uma morfologia nodular para lamelar. Isto mostra que a morfologia dos precipitados dentro da colônia, bem como a morfologia da colônia, depende da estrutura individual do CG no qual a reação de PD ocorre. Ainsley et al. [176] também afirmaram que o crescimento não planar da frente de reação é associado à precipitação nodular, enquanto o crescimento planar é acompanhado por precipitação lamelar. Esta última afirmação parece fazer sentido ao analisar a maioria das colônias observadas no presente trabalho, as quais contêm tanto precipitados lamelares como nodulares e também apresentam uma frente planar irregular. 


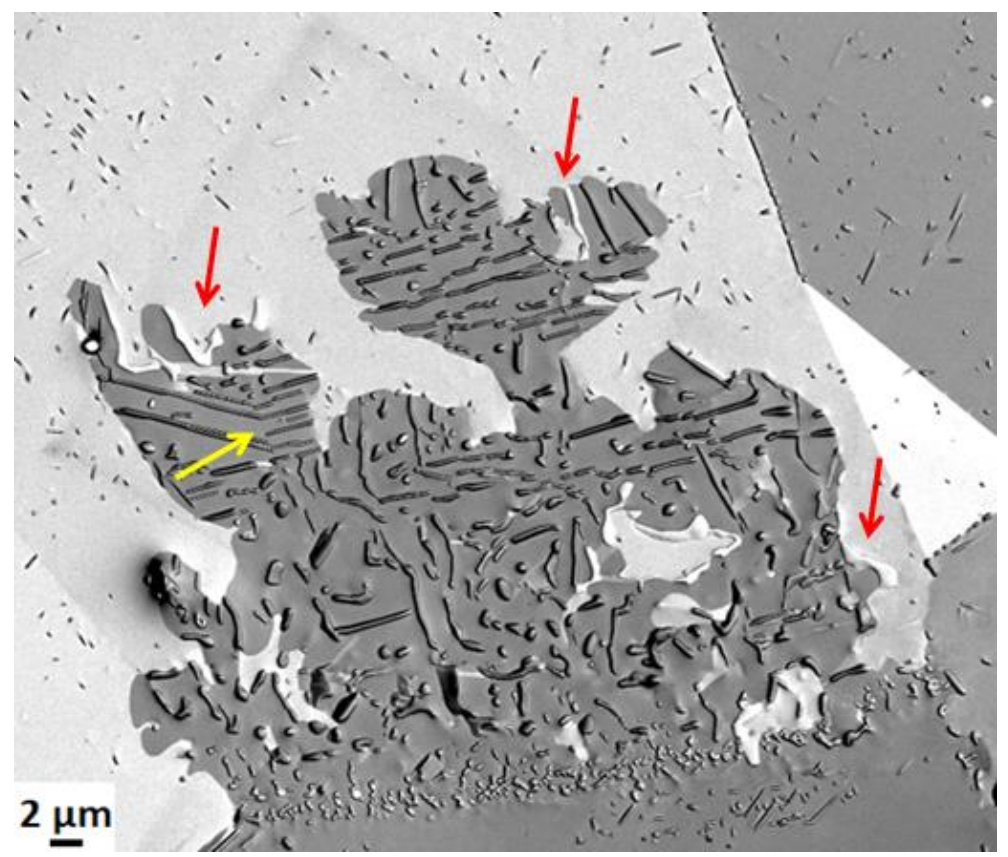

Figura 4.32 - Imagem de MEV-BSE de uma colônia de PD bem desenvolvida na Liga 33 envelhecida a $800^{\circ} \mathrm{C}$ por $20 \mathrm{~h}$ contendo tanto precipitados lamelares como nodulares na região varrida pela irregular frente de reação da PD. As setas vermelhas indicam precipitados, com contraste mais claro, formados na frente de reação da PD e a seta amarela indica uma mudança abrupta na direção cristalográfica de crescimento das lamelas precipitadas dentro da colônia de PD.

Os resultados obtidos pelas análises por XEDS no MEV das amostras da Liga 33 envelhecida por 20 h e 50 h (esta última condição não mostradas no presente trabalho) indicam que as características químicas das fases precipitadas dentro das colônias de PD nestas duas condições mencionadas acima são similares. As Figuras 4.33 e 4.34 apresentam mapeamentos elementares por XEDS da Liga 33 envelhecida a $800{ }^{\circ} \mathrm{C}$ por $20 \mathrm{~h}$. Como observado, todos os precipitados formados nos CG e dentro da colônia de PD eram enriquecidos em Cr. Entretanto, alguns destes precipitados, tanto no CG como dentro das colônias, eram também enriquecidos em Si e Mo, além da verificação de uma outra fase com contraste mais claro, a qual é enriquecida em Cr e Mo. Em geral, é possível afirmar, baseado nos resultados por MEV/XEDS, que as colônias de PD na Liga 33 resultante do envelhecimento isotérmico a $800{ }^{\circ} \mathrm{C}$ por $1 \mathrm{~h}$ até $50 \mathrm{~h}$ contém três diferentes fases precipitadas: (1) precipitados ricos em $\mathrm{Cr}$ no $\mathrm{CG}$ e dentro da colônia; (2) precipitados enriquecidos em Si e Mo no CG e dentro da colônia; (3) precipitados enriquecidos em $\mathrm{Cr}$ e Mo com contraste mais claro na imagem de MEV/BSE, esta última fase frequentemente observada na frente de reação da PD. 

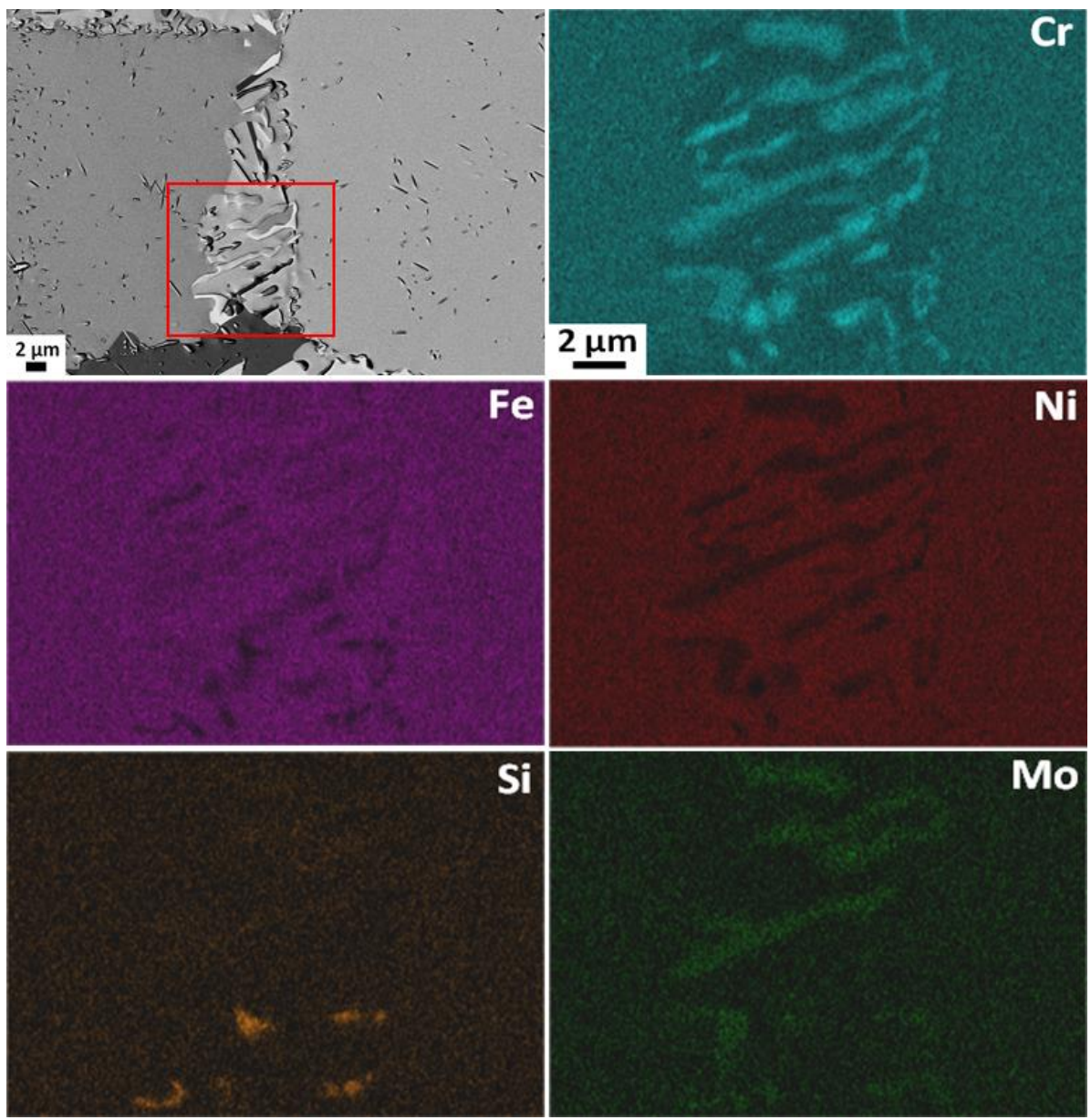

Figura 4.33 - Imagem de MEV-BSE da Liga 33 envelhecida a $800^{\circ} \mathrm{C}$ por $20 \mathrm{~h}$ e os correspondentes mapas elementares por XEDS do $\mathrm{Cr}$, Fe, Ni, Si e Mo obtidos da região indicada pelo quadrado vermelho.

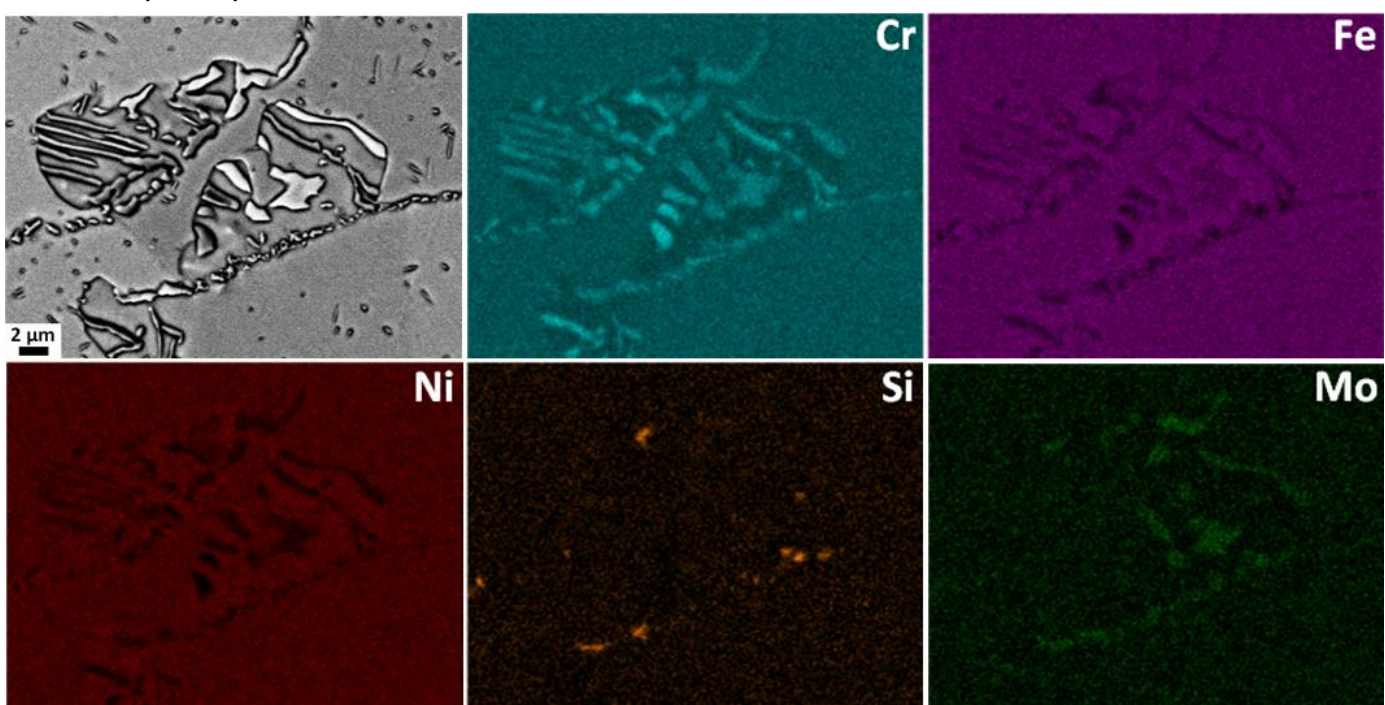

Figura 4.34 - Imagem de MEV-BSE da Liga 33 envelhecida a $800^{\circ} \mathrm{C}$ por $20 \mathrm{~h}$ mostrando colônias de PD e os correspondentes mapeamentos de XEDS do $\mathrm{Cr}$, Fe, Ni, Si e Mo.

A imagem de MEV-SE na Figura 4.35a mostra um complexo produto de precipitação na Liga 33 resultante do envelhecimento a $800{ }^{\circ} \mathrm{C}$ por $100 \mathrm{~h}$. Nesta figura, a colônia de PD está em um estágio avançado de desenvolvimento, o que 
dificulta definir quais precipitados constitui a colônia e quais foram nucleados na matriz à frente do contorno da colônia de PD. Pode-se dizer que durante o crescimento da colônia de PD, após longos tempos de envelhecimento, o contorno avançando interage com os precipitados da matriz resultante em um efeito topológico complexo. Baseado no contraste composicional mostrado na imagem de MEV-BSE na Figura 4.35b, é possível verificar a ocorrência de, pelo menos, três diferentes fases precipitadas na colônia resultante do envelhecimento a $100 \mathrm{~h}$ : precipitados lamelares e na forma de partículas com contraste cinza, precipitados grosseiros com contraste mais claro e precipitados com contraste escuro. Este último, o qual ainda não tinha sido observado no presente trabalho, parece ter nucleado e crescido associado com outro precipitado já existente. Embora baseado na imagem de MEV/BSE na Figura $4.35 \mathrm{~b}$ é verificado a ocorrência de três diferentes fases precipitadas, nos mapas elementares por XEDS na Figura 4.36, obtidos da região indicada pelo quadrado vermelho na Figura 4.35b, a existência de, pelo menos, quatro diferentes fases precipitadas foram confirmadas: (1) precipitados enriquecidos em Si e Mo contendo Ni e Cr; (2) precipitados ricos em $\mathrm{Cr}$ contendo N; (3) precipitados enriquecidos em $\mathrm{Cr}$ e Mo contendo $\mathrm{Fe}$ e $\mathrm{Si}$; e (4) precipitados lamelares e particulados ricos em $\mathrm{Cr}$.

A fim de obter informações mais precisas sobre a composição química das diferentes fases precipitadas observadas na Liga 33 envelhecida a $800{ }^{\circ} \mathrm{C}$ por 100 apresentadas nas Figuras 4.35 e 4.36, análises pontuais por MEV/XEDS foram realizadas. Como mostrado na Figura 4.37, o precipitado ${ }^{\circ} 1$ era enriquecido em $\mathrm{Si}, \mathrm{Cr}$, Ni e Mo contendo Fe, N e V, sugerindo um nitreto enriquecido em Si. O precipitado $\mathrm{n}^{\circ} 2$ com contraste mais escuro rico em $\mathrm{Cr}$ contendo $\mathrm{N}$ e baixos teores de $\mathrm{Mo}, \mathrm{Fe}$ e $\mathrm{Ni}$, sugere um nitreto de cromo. O precipitado $\mathrm{n}^{\circ} 3$ com contraste mais claro era enriquecido em $\mathrm{Cr}$, Mo e Fe contendo Si e Ni. O precipitado $n^{\circ} 4$, na forma de lamelas e partículas, eram ricos em $\mathrm{Cr}$ contendo $\mathrm{Fe}$ e baixos teores de Mo e Ni. Devido ao baixo pico do Si nos espectros 2 e 4, tal elemento não foi considerado constituir os precipitados 2 e 4 na Figura 4.37. Vale a pena mencionar que os resultados dos espectros pontuais mostrados na Figura 4.37 não podem ser considerados conclusivos sobre a composição química dos precipitados formados na Liga 33 devido à limitações da técnica de XEDS no MEV, tais como volume de interação feixe-amostra. Entretanto, a composição química qualitativa 
dos precipitados obtidos por STEM/XEDS, de forma mais conclusiva, foi obtida e será apresentado no decorrer do presente trabalho.

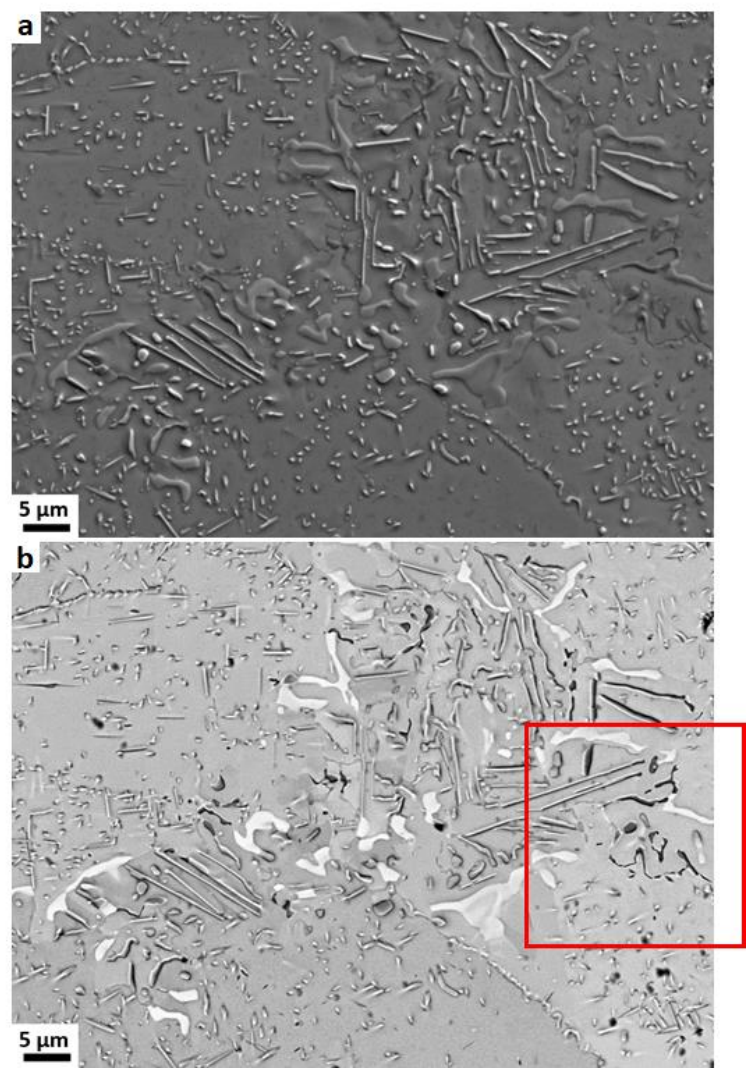

Figura 4.35 - Imagem de MEV (a) SE e (b) BSE da Liga 33 envelhecida a $800{ }^{\circ} \mathrm{C}$ por 100 h. O quadrado indica a região mostrada nas Figuras 4.36 e 4.37.

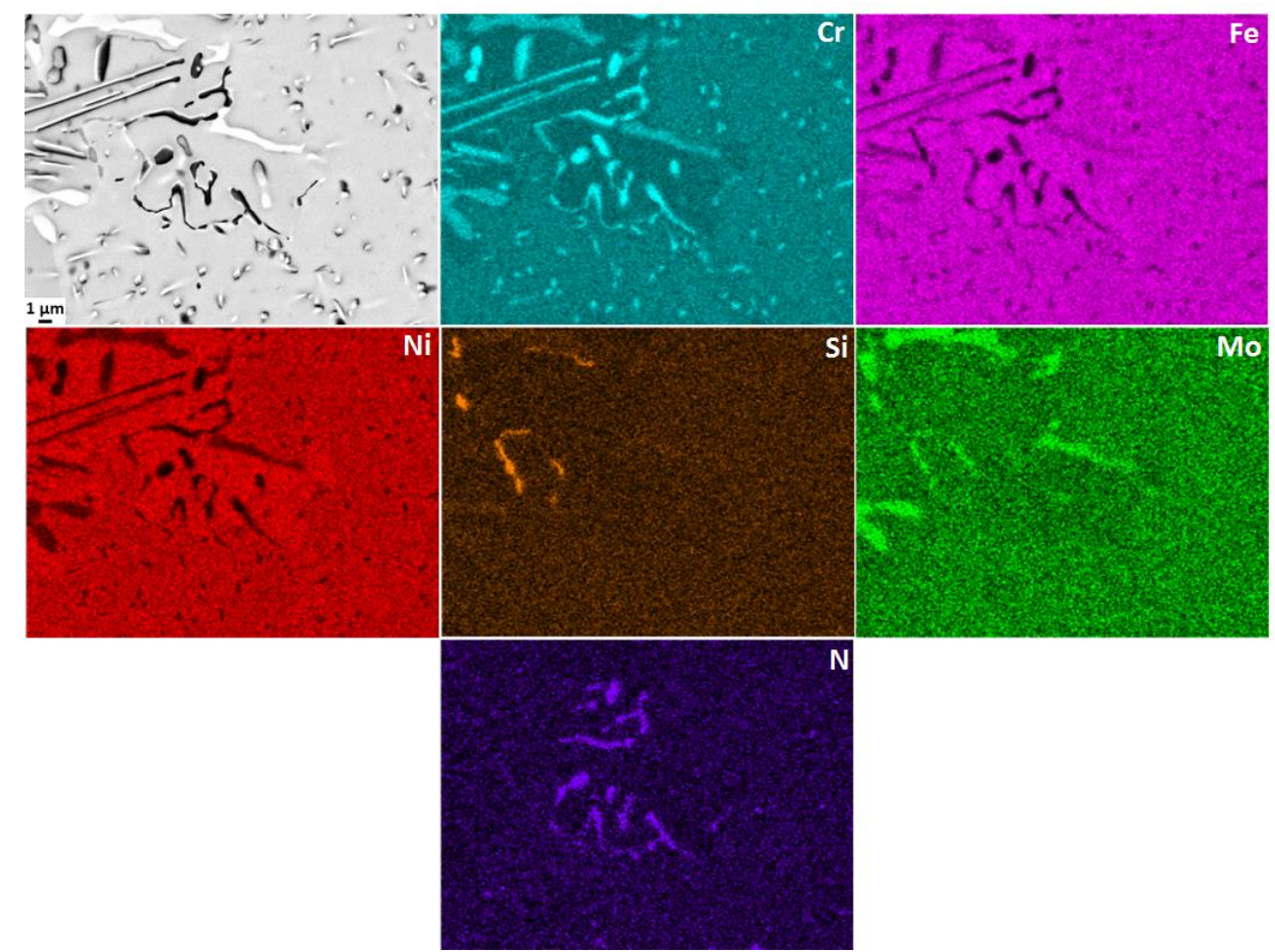

Figura 4.36 - Imagem de MEV-BSE da Liga 33 envelhecida a $800^{\circ} \mathrm{C}$ por $100 \mathrm{~h}$ obtida da região indicada pelo quadrado na Figura $4.37 \mathrm{~b}$ e os correspondentes mapas elementares do $\mathrm{Cr}, \mathrm{Fe}, \mathrm{Ni}, \mathrm{Si}, \mathrm{Mo}$ e N. 

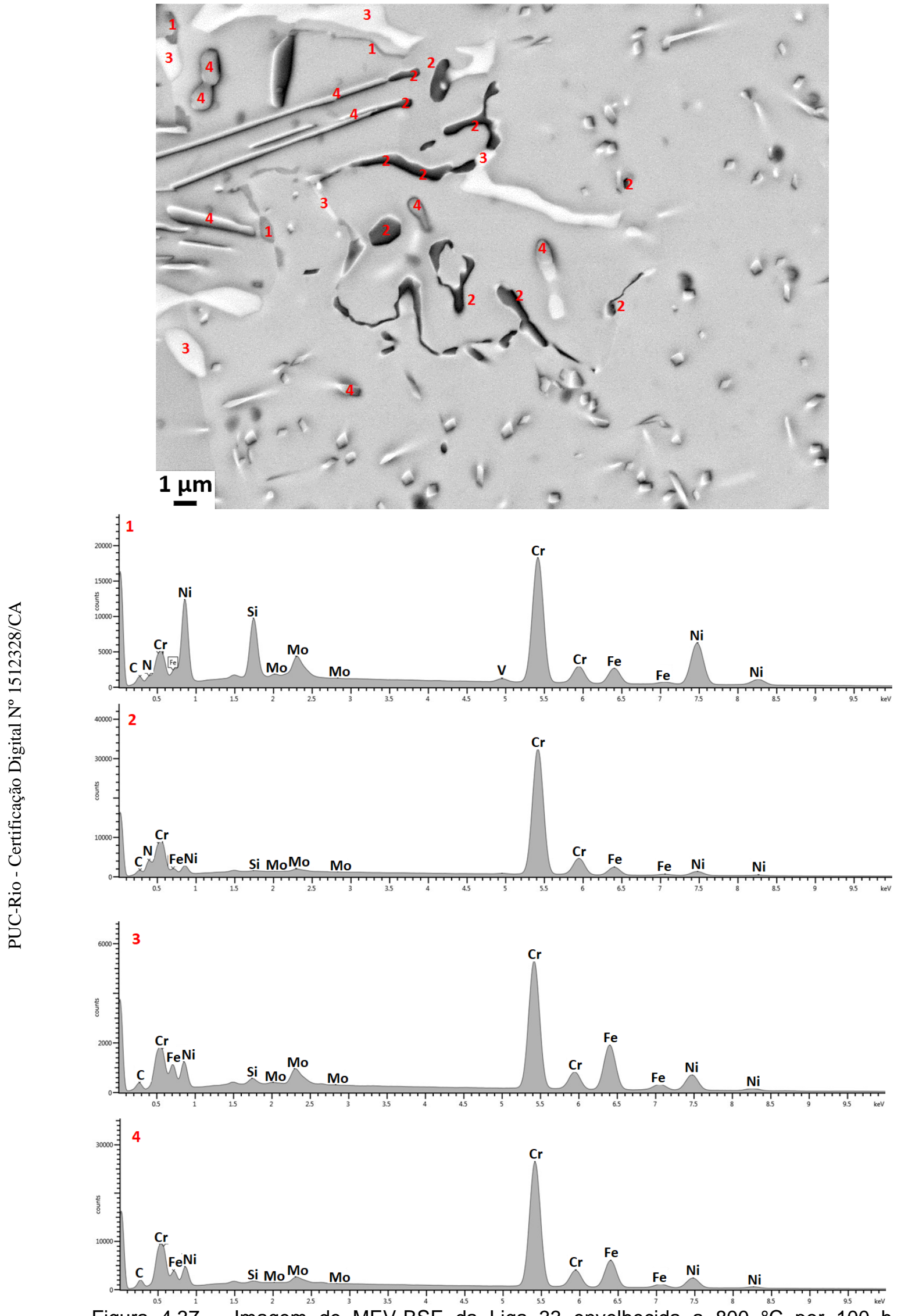

Figura 4.37 - Imagem de MEV-BSE da Liga 33 envelhecida a $800{ }^{\circ} \mathrm{C}$ por $100 \mathrm{~h}$ mostrando a mesma região mostrada na Figura 4.35 e os espectros pontuais por XEDS dos precipitados indicados pelos números 1, 2, 3 e 4 . 
Os resultados obtidos por MO e MEV/XEDS da evolução microestrutural da Liga 33 envelhecida a $800{ }^{\circ} \mathrm{C}$ por $1 \mathrm{~h}$ até $100 \mathrm{~h}$ mostram que:

- A sequência de precipitação ocorre da seguinte maneira: precipitação intergranular $\rightarrow$ precipitação descontínua no $\mathrm{CG} \rightarrow$ precipitação intragranular dentro dos grãos da matriz CFC.

- A formação das colônias de PD na Liga 33 se desenvolveram com as seguintes características: precipitados ricos em $\mathrm{Cr}$ nuclearam nos $\mathrm{CG}$ nos estágios iniciais do tratamento térmico e cresceram durante o envelhecimento isotérmico nesta temperatura. Em alguns casos, a migração do contorno ocorreu com o contorno conectado ao precipitado formado inicialmente no CG, mas em outros casos o contorno migrou sem conexão com tais precipitados, o que sugere que o fenômeno DIGM pode estar operando no desenvolvimento da PD. Fases enriquecidas em Si também precipitaram na posição original do CG durante o processo de envelhecimento. Tais precipitados parecem ocorrer adjacentes aos precipitados ricos em $\mathrm{Cr}$ no CG. Com o aumento do tempo de envelhecimento, fases ricas em $\mathrm{Cr}$ nuclearam também adjacentes ao $\mathrm{CG}$ e cresceram como precipitados lamelares para dentro da matriz CFC. Eventualmente, precipitados enriquecidos em Si também se formaram dentro da colônia de PD, i.e. na região varrida pela frente de reação. Durante o processo de envelhecimento, a taxa de migração da frente de reação diminui até cessar o movimento, praticamente após $100 \mathrm{~h}$ de envelhecimento, tempo no qual a matriz está praticamente preenchida por precipitados homogêneos.

- Ocorreu a formação de, pelo menos, quatro diferentes fases precipitadas na colônia de PD: (1) precipitados ricos em $\mathrm{Cr}$ com morfologia particulada e lamelas; (2) nitreto enriquecidos em $\mathrm{Si}$; (3) precipitados enriquecidos em $\mathrm{Cr}$ e Mo; (4) nitretos ricos em Cr. 


\subsection{Fenômenos de Precipitação no CG e Identificação das Fases na Liga 33 envelhecida a $800^{\circ} \mathrm{C}$ : Análise por MET/STEM}

\subsubsection{Precipitação no envelhecimento por $1 \mathrm{~h}$ até $10 \mathrm{~h}$}

Nesta seção, uma tentativa de identificar as diferentes fases precipitadas na Liga 33, resultantes do envelhecimento isotérmico a $800^{\circ} \mathrm{C}$ por $1 \mathrm{~h}, 2 \mathrm{~h}, 5 \mathrm{~h}$ e 10 $\mathrm{h}$, é apresentada por meio de análises de MET, STEM/XEDS e difração de elétrons de área selecionada (SAED). Na imagem de STEM-BF na Figura 4.38a, é mostrada uma colônia de PD nos estágios iniciais do seu processo de crescimento formada durante o envelhecimento por $1 \mathrm{~h}$. Todos os precipitados neste contorno foram identificados como carbeto- $\mathrm{M}_{23} \mathrm{C}_{6}$ ricos em $\mathrm{Cr}$. É verificado que enquanto alguns dos precipitados crescem acompanhando a migração do contorno, outros carbetos permanecem na posição original do CG na forma de pequenas partículas. Concomitante com os precipitados no $\mathrm{CG}$, zonas empobrecidas em $\mathrm{Cr}$ e enriquecidas em $\mathrm{Fe}$ e $\mathrm{Ni}$ foram observadas na região varrida pelo contorno avançando. Como mencionado anteriormente, tais zonas tem um efeito indesejável na corrosão sob tensão em ligas à base de Ni [230-234].

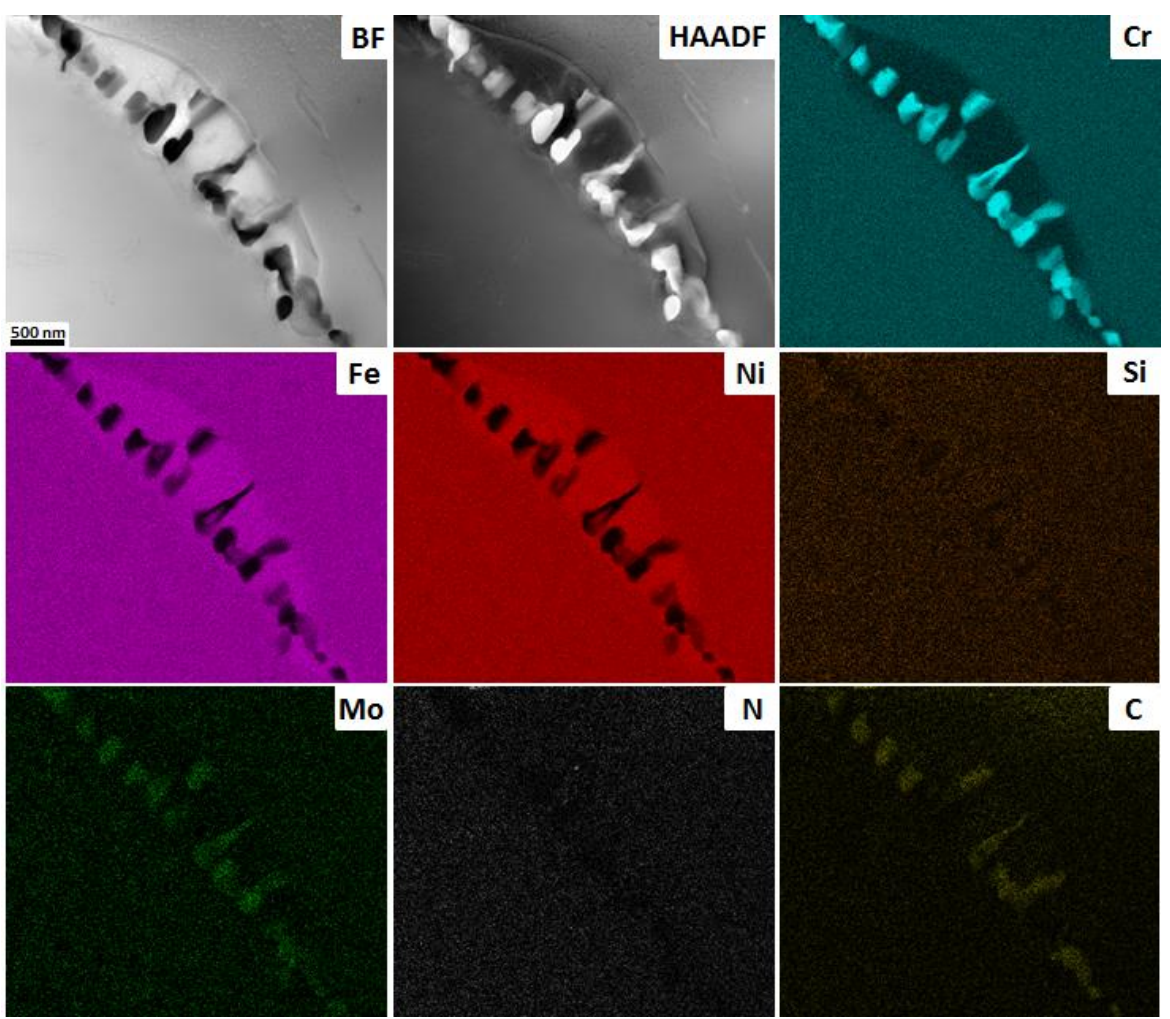

Figura 4.38 - (a) Imagem de STEM-BF de uma colônia de PD nos estágios iniciais do processo de crescimento e os correspondentes mapas elementares obtidos por STEM/XEDS do $\mathrm{Cr}, \mathrm{Fe}, \mathrm{Ni}, \mathrm{Mo}, \mathrm{Si}, \mathrm{N}$ e C. 
A Figura 4.39 mostra uma imagem de STEM-BF de um outro CG na Liga 33 envelhecida a $800{ }^{\circ} \mathrm{C}$ por $1 \mathrm{~h}$ e os correspondentes mapas elementares obtidos por STEM/XEDS. O resultado do mapeamento elementar mostra características similares àquelas observadas anteriormente neste trabalho. Carbetos- $\mathrm{M}_{23} \mathrm{C}_{6}$ ricos em $\mathrm{Cr}$ com diferentes morfologias são observados em um contorno ondulado migrando para os dois lados deste mesmo CG. Porém, neste específico contorno mostrado na Figura 4.40, um enriquecimento em Si (indicado pela seta amarela) foi detectado na região adjacente ao carbeto- $\mathrm{M}_{23} \mathrm{C}_{6}$, na mesma região onde $\mathrm{o}$ empobrecimento em $\mathrm{Cr}$ e enriquecimento em $\mathrm{Fe}$ e Ni ocorreram.

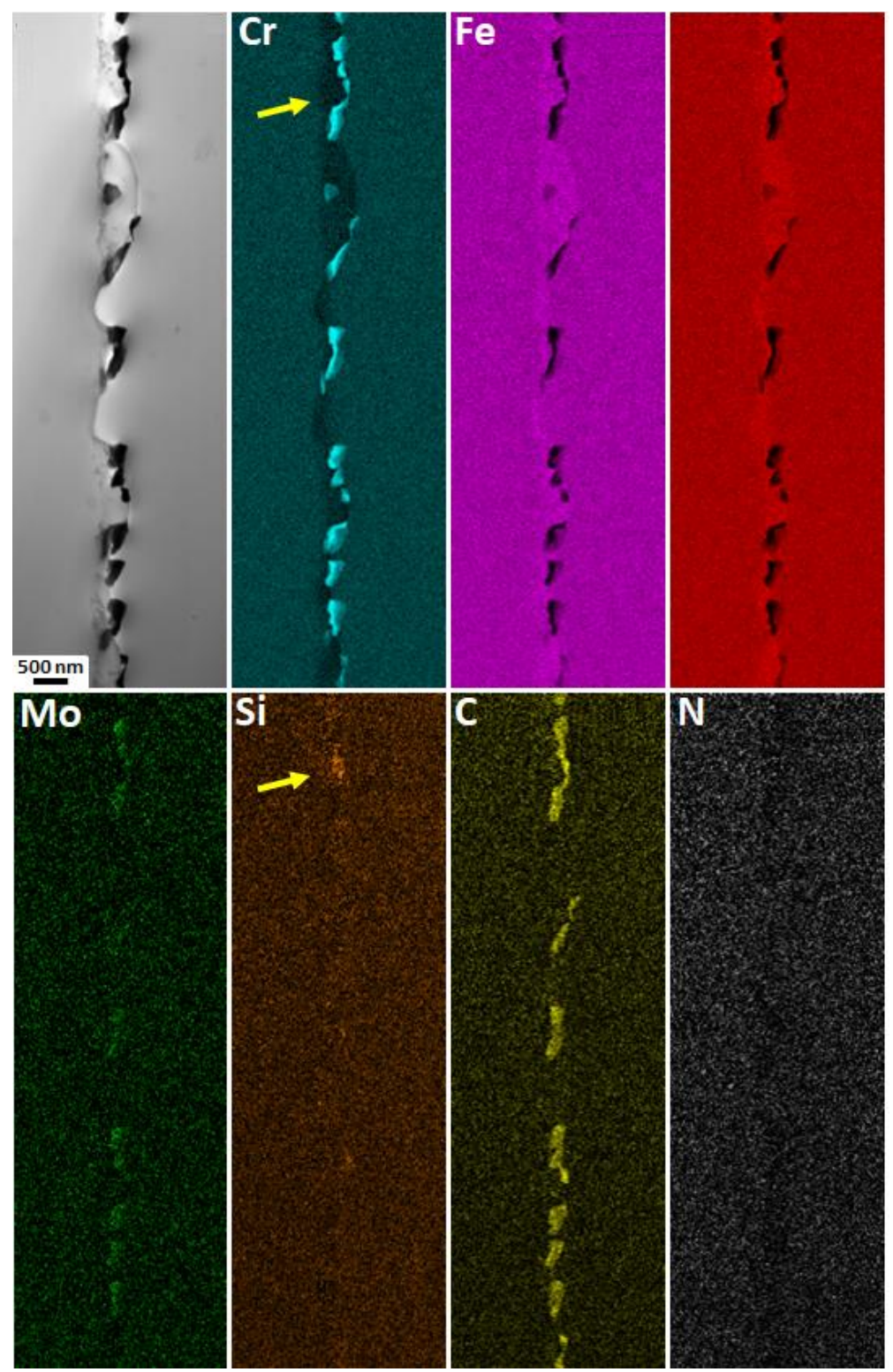

Figura 4.39 - (a) Imagem de STEM-BF mostrando carbetos- $\mathrm{M}_{23} \mathrm{C}_{6}$ em um contorno ondulado na Liga 33 envelhecida a $800{ }^{\circ} \mathrm{C}$ por $1 \mathrm{~h}$ e os correspondentes mapas elementares obtidos por STEM/XEDS do $\mathrm{Cr}, \mathrm{Fe}, \mathrm{Ni}, \mathrm{Mo}, \mathrm{Si}, \mathrm{C}$ e N. As setas indicam a região onde ocorreu o enriquecimento em Si concomitante ao empobrecimento em $\mathrm{Cr}$. 
Como mostrado anteriormente, após $30 \mathrm{~min}$ de envelhecimento foram observadas zonas enriquecidas em Si (Figuras 4.14 e 4.16) e, também, uma fase enriquecida em $\mathrm{Si}$ adjacentes ao carbeto- $\mathrm{M}_{23} \mathrm{C}_{6}$ (Figuras 4.19 e 4.20). Como esperado, com o aumento no tempo de envelhecimento para $1 \mathrm{~h}$, também foi verificado a existência de regiões enriquecidas em $\mathrm{Si}$ ao redor dos carbetos$\mathrm{M}_{23} \mathrm{C}_{6}$, como mostrado nas Figuras 4.39 e 4.40. Tais observações permitem inferir que a formação da fase enriquecida em Si e $\mathrm{N}$ ocorre em função da precipitação do carbeto. Como a solubilidade do $\mathrm{N}$ neste carbeto é muito baixa [242] e, também, como o elemento $\mathrm{Si}$ normalmente seja reportado não constituir o carbeto- $\mathrm{M}_{23} \mathrm{C}_{6}$ [70][72][73][84][93][94][87], tais elementos são segregados nas regiões adjacentes ao carbeto formado no CG. Com isso, a formação do precipitado enriquecido em Si e N pode ser acelerada. A mesma ideia pode ser aplicada ao elemento $\mathrm{Ni}$, o qual também constitui a fase precipitada enriquecida em Si e, também, não está em grande concentração no carbeto- $\mathrm{M}_{23} \mathrm{C}_{6}$.

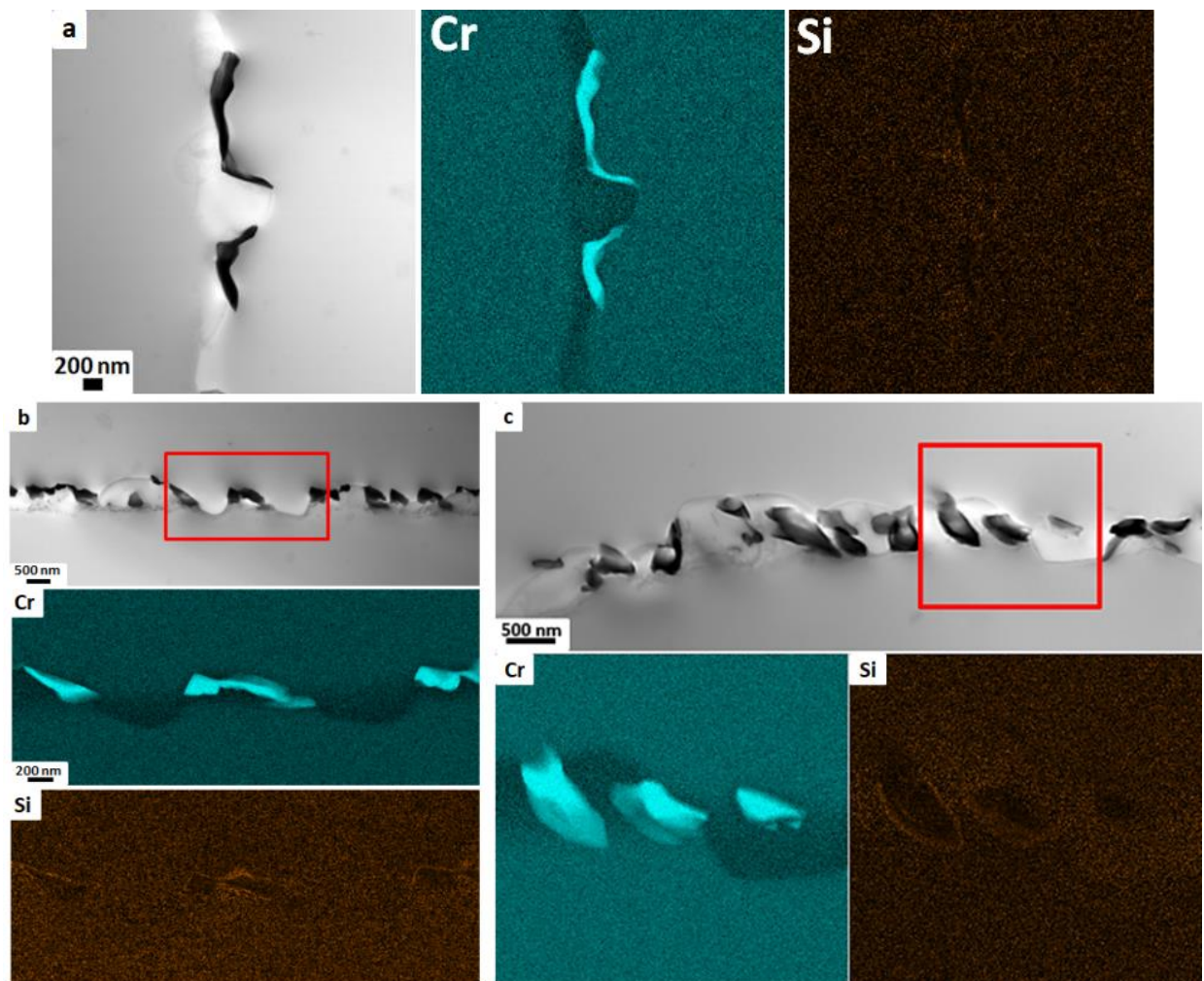

Figura 4.40 - Imagens de STEM-BF e os correspondentes mapas elementares obtidos por STEM/XEDS do $\mathrm{Cr}$ e Si de três diferentes CG decorados com carbetos- $\mathrm{M}_{23} \mathrm{C}_{6}$ na Liga 33 envelhecida a $800{ }^{\circ} \mathrm{C}$ por $1 \mathrm{~h}$ mostrando o enriquecimento em Si ao redor dos carbetos. 


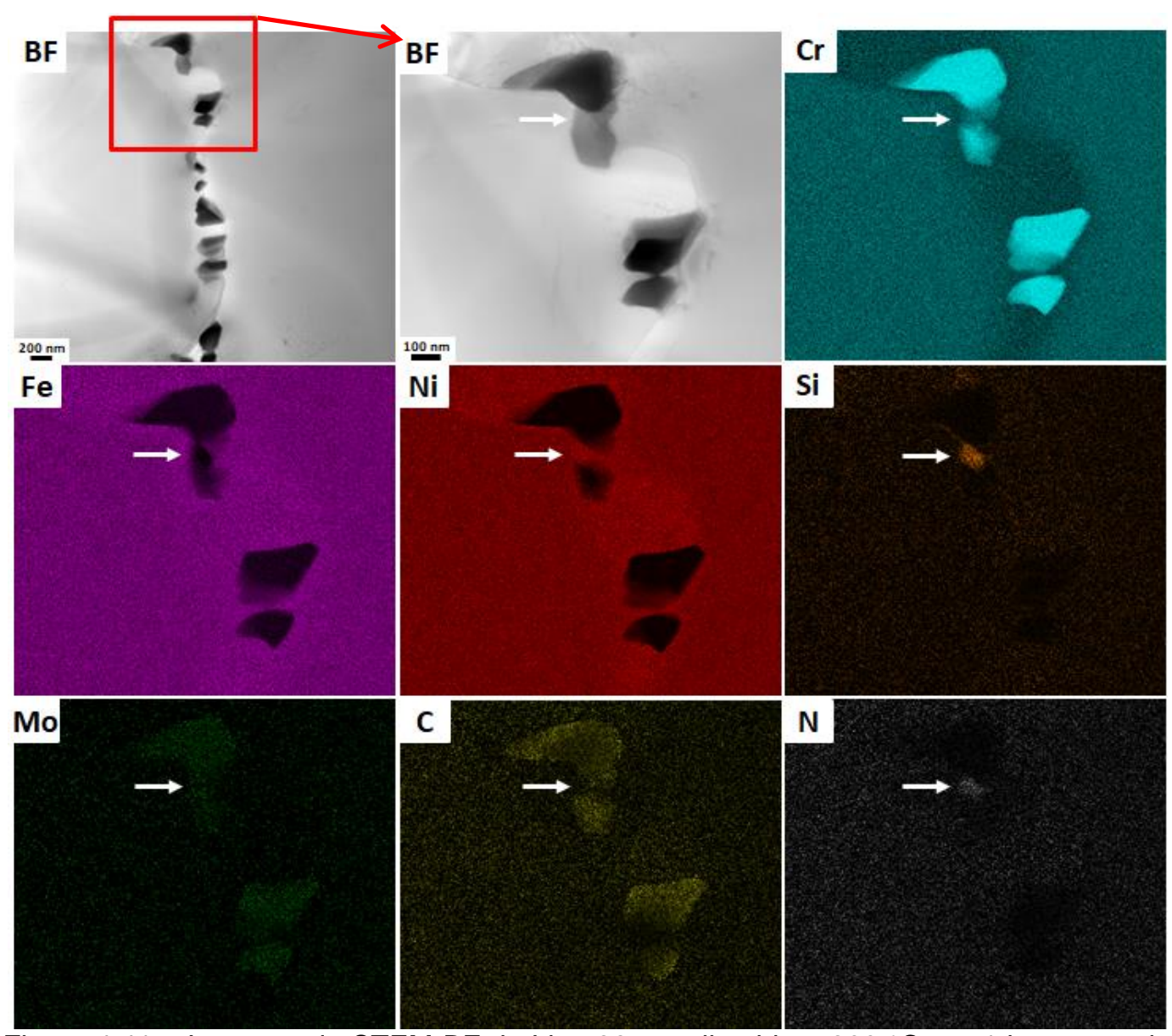

Figura 4.41 - Imagens de STEM-BF da Liga 33 envelhecida a $800{ }^{\circ} \mathrm{C}$ por $1 \mathrm{~h}$ mostrando um CG decorado com carbetos-M23C6 e os correspondentes mapas elementares obtidos por STEM/XEDS do $\mathrm{Cr}$, Fe, Ni, Si, Mo, C e N. A formação de uma fase enriquecida em $\mathrm{Si}$, Ni e $\mathrm{N}$ foi observada, a qual está indicada pela seta branca.

A Figura 4.42 apresenta um conjunto de imagens obtidas no modo contraste de difração com o objetivo de ilustrar características da reação de PD na Liga 33, resultante do envelhecimento a $800{ }^{\circ} \mathrm{C}$ por $1 \mathrm{~h}$, o qual inclui migração do contorno, difusão e processos de precipitação. A imagem de MET-BF na Figura 4.42a mostra uma pronunciada curvatura do contorno do grão de cima com contraste mais escuro. A imagem de MET-CDF na Figura 4.42b corrobora a topografia da curvatura do CG. Outra imagem de MET-CDF mostrada na Figura $4.42 \mathrm{c}$ revelou carbetos- $\mathrm{M}_{23} \mathrm{C}_{6}$ na posição original do contorno crescendo juntamente com a migração do contorno (indicados pelas setas vermelhas), os quais são mostrados nas imagens de MET-CDF na Figura 4.43. 

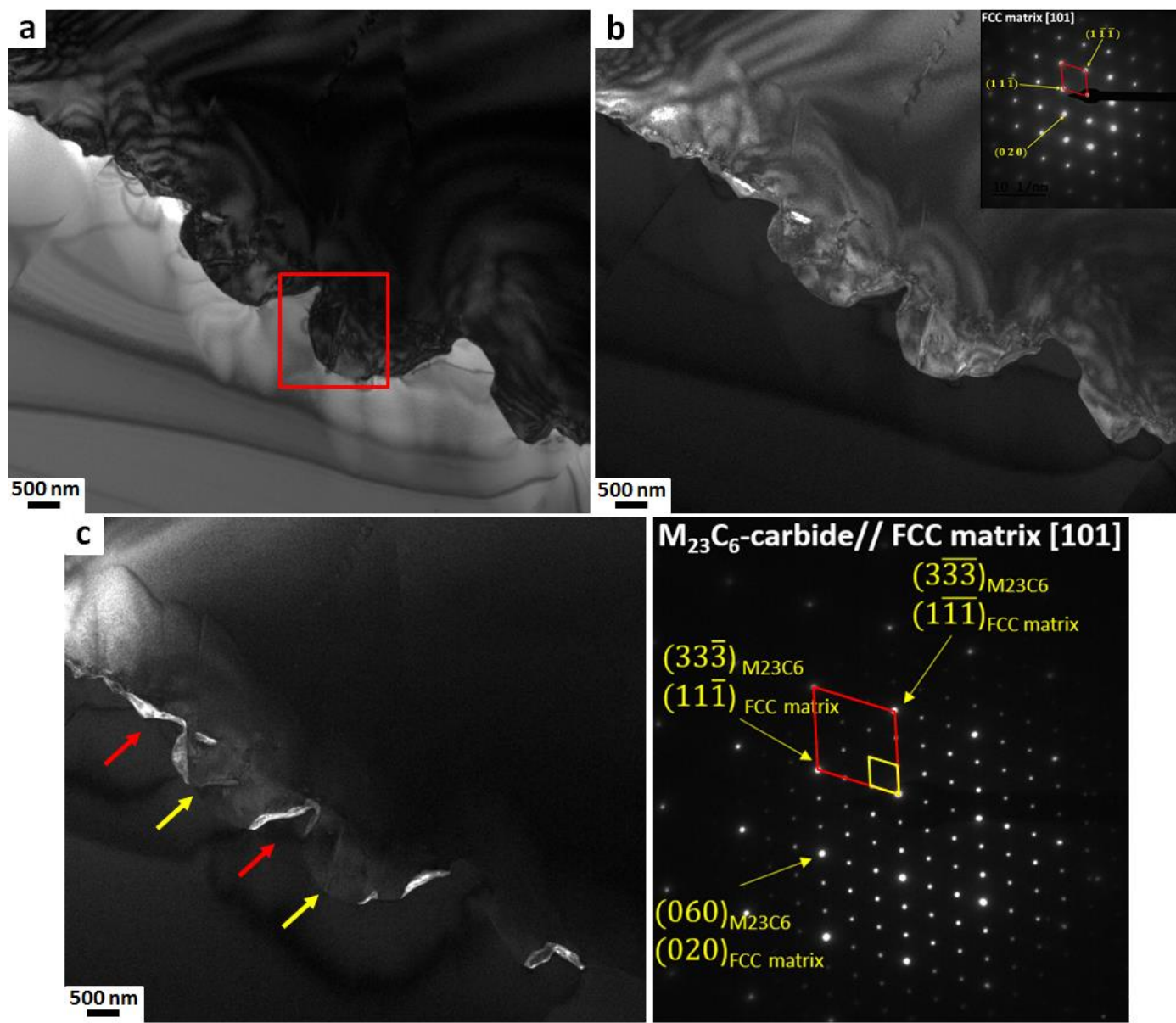

Figura 4.42 - (a) Imagem de MET-BF de um contorno curvado na Liga 33 envelhecida a $800{ }^{\circ} \mathrm{C}$ por $1 \mathrm{~h}$; (b) respectiva imagem de MET-CDF e o correspondente padrão SAED obtido do grão de cima na imagem em (a); e (c) imagem de MET-CDF revelando carbetos- $\mathrm{M}_{23} \mathrm{C}_{6}$ no $\mathrm{CG}$ e o padrão SAED obtido da interface carbeto/matriz mostrando a R.O. $[101]_{M_{23} C_{6}} \|[101]_{\text {matriz-CFC }}$. O losango vermelho é referente à matriz-CFC e o losango amarelo é referente ao carbeto- $\mathrm{M}_{23} \mathrm{C}_{6}$.

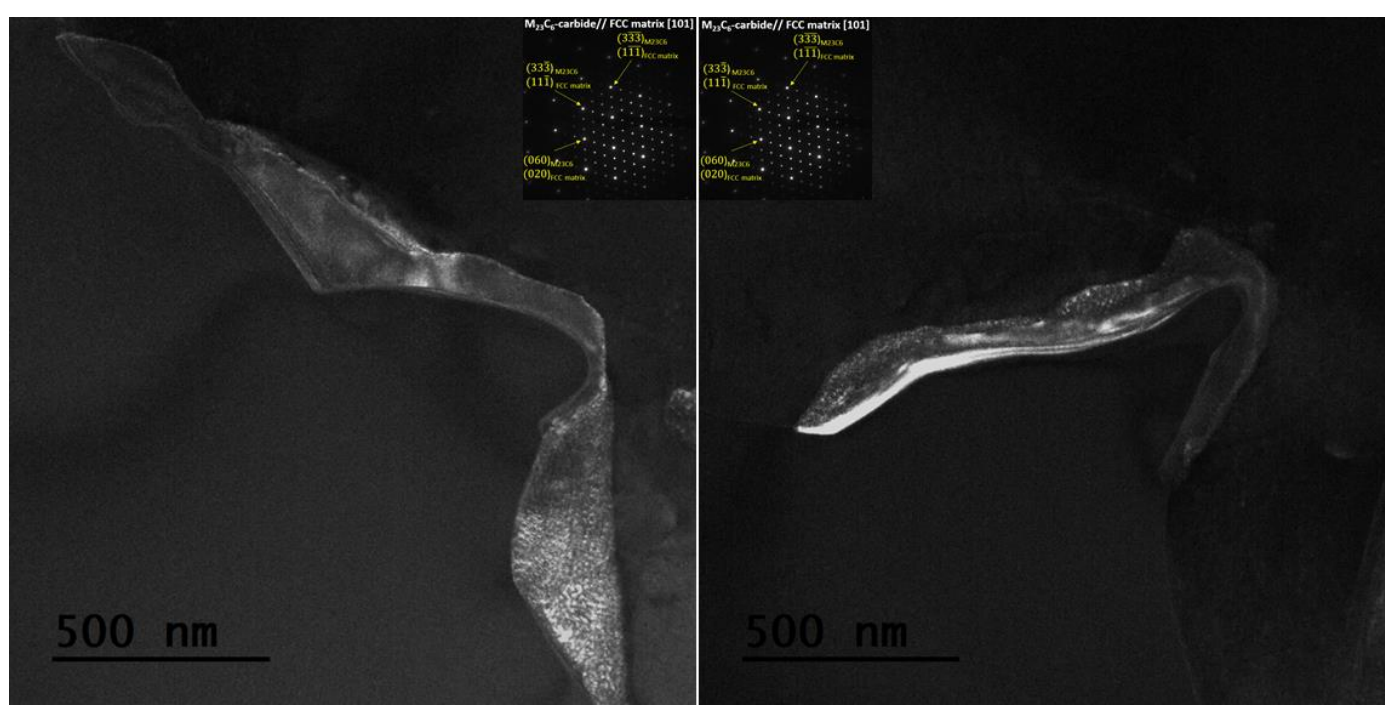

Figura 4.43 - Imagens de MET-CDF mostrando os carbetos- $\mathrm{M}_{23} \mathrm{C}_{6}$ indicados pelas setas vermelhas na Figura 4.42. Inserção: padrão SAED obtido da interface carbeto/matriz mostrando a R.O. $\left[\begin{array}{lll}1 & 0 & 1\end{array}\right]_{M_{23} C_{6}} / /\left[\begin{array}{lll}1 & 0 & 1\end{array}\right]_{\text {matriz-CFC }}$. 
Além dos carbetos- $\mathrm{M}_{23} \mathrm{C}_{6}$ identificados na posição original do contorno na Figura 4.42, a existência de outro tipo de fase precipitada na forma lamelar foi verificada, as quais estão indicadas pelas setas amarelas na Figura 4.42c. A Figura 4.44 mostra um par de imagens de MET-BF/CDF obtidas da região indicada pelo quadrado vermelho na Figura 4.42. A partir do padrão SAED mostrado na Figura 4.44c, é possível identificar os precipitados lamelares como a fase $\alpha-\mathrm{Cr}$ com estrutura CCC. A R.O. K-S, (-110) $\alpha$-Cr $\left\|(-111)_{\text {matriz-CFC, }}[111]_{\alpha-C r}\right\|[101]_{\text {matriz-CFC }}$ entre a fase $\alpha$-Cr e a matriz CFC foi verificada, a qual também foi reportada por outros autores [138][124][125]. Precipitados da fase $\alpha-C r$, porém na forma convencional, já foram reportados em várias ligas estruturais multicomponentes, tais como ligas à base de Ni [61][124-126][131] e AI [102][109]. Entretanto, colônias de PD contendo a fase $\alpha$-Cr como principal fase não é muito comum serem encontradas em ligas multicomponentes, já tendo sido reportada ligas binárias Cr-Ni [136][137]. Embora Portella et al. [3] tenham reportado a ocorrência da fase $\alpha-\mathrm{Cr}$ no $\mathrm{CG}$ e dentro da colônia de PD na Liga 33 envelhecida a $700{ }^{\circ} \mathrm{C}$ por $100 \mathrm{~h}$, os autores afirmaram que os precipitados lamelares constituindo a colônia não foram identificadas como fase $\alpha-\mathrm{Cr}$ com estrutura CCC.

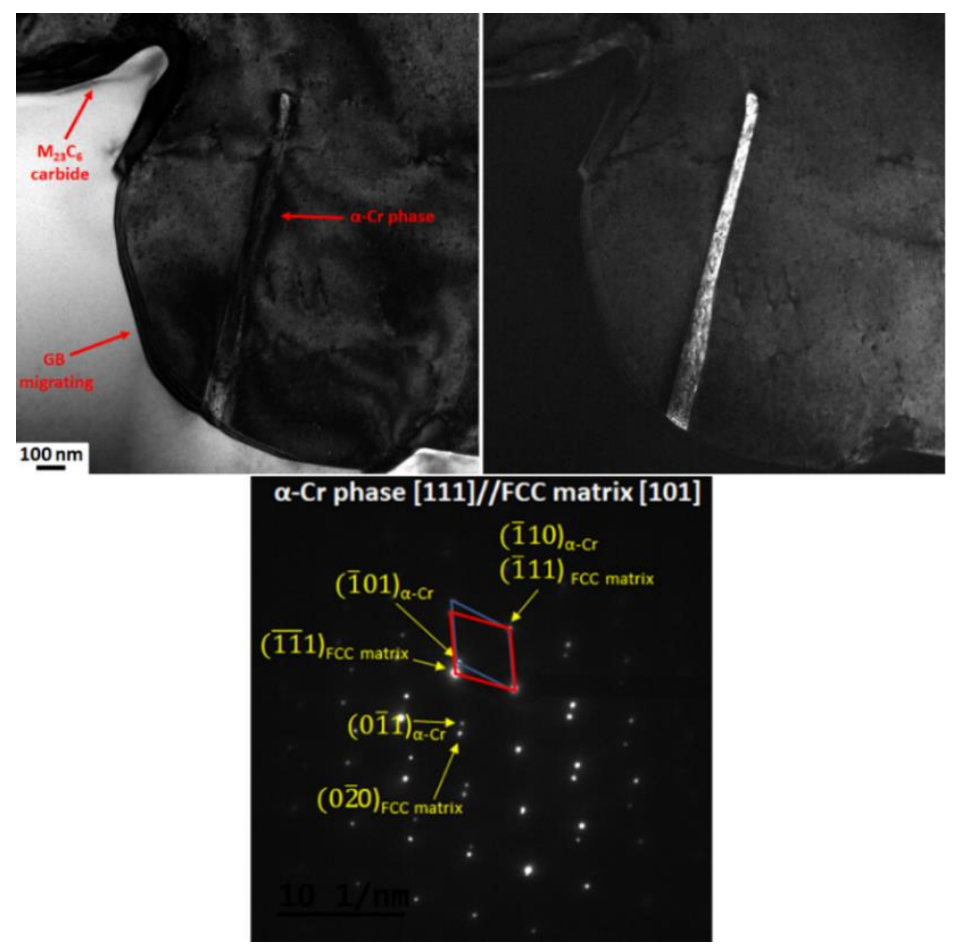

Figura 4.44 - Imagens de MET-BF/CDF obtida da região indicada pelo quadrado vermelho na Figura 4.42 mostrando o precipitado lamelar, o qual foi identificado como a fase $\alpha-C r$ com estrutura CCC. A R.O. K-S foi verificada, $(-110)_{\alpha-C r} \|(-111)_{\text {matriz-CFC }}$, $[111]_{\alpha-C r} \|[101]_{\text {matriz-CFC. }}$ O losango vermelho é referente à matriz-CFC e o losango azul é referente à fase $\alpha-\mathrm{Cr}$. 
Quando o tempo de envelhecimento foi aumentado de $1 \mathrm{~h}$ para $2 \mathrm{~h}$, foi observado que a migração dos CG bem como a fração volumétrica dos precipitados formados nos contornos aumentou. A Figura 4.45 mostra uma imagem de MET-BF decorado por precipitados resultantes do envelhecimento a $800{ }^{\circ} \mathrm{C}$ por $2 \mathrm{~h}$. Nesta figura, diferentes características em relação à interação dos precipitados com o contorno migrando foram observadas. Enquanto algumas regiões do contorno avançando estavam conectadas com a ponta do precipitado (indicado pelas setas vermelhas), em outras regiões o CG migrou sem conexão com os precipitados (indicado pelas setas pretas). O último comportamento reforça a ideia de que a migração do contorno é a principal força motriz para o crescimento da colônia de PD. Neste sentido, baseado na configuração da frente de reação da PD observado na Figura 4.45 e, também na afirmação feita por Hillert [190], pode ser sugerido que o fenômeno DIGM tem um importante papel no desenvolvimento da reação de PD na Liga 33, já que a migração do contorno não é influenciada pelo crescimento dos precipitados formados no CG.

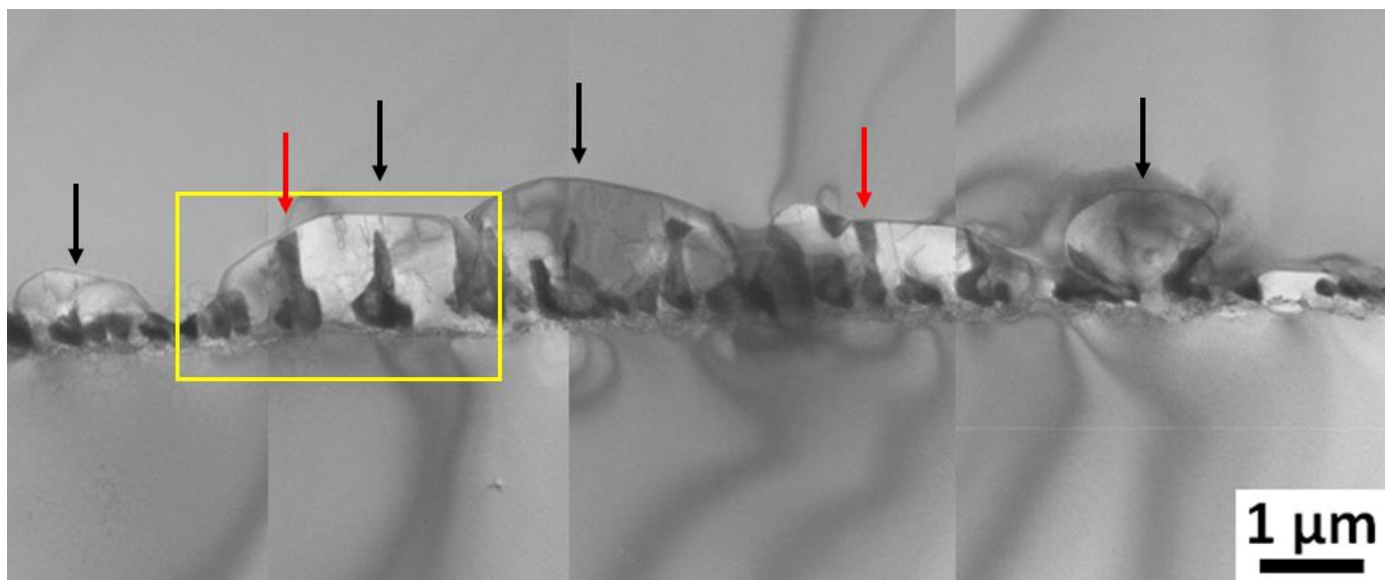

Figura 4.45 - Imagem de STEM-BF de um CG decorado por precipitados, o qual representa os estágios iniciais da reação de PD na Liga 33. O retângulo amarelo indica a região onde foi obtido o mapeamento elementar por STEM/XEDS mostrado na Figura 4.46. Seta vermelha: migração do contorno conectado com o precipitado; seta amarela: migração do contorno sem conexão com o precipitado.

A Figura 4.46 mostra o particionamento de soluto obtido por STEM/XEDS na região indicada pelo retângulo amarelo na Figura 4.45. Como mostrado nas figuras anteriores, um empobrecimento em $\mathrm{Cr}$ e enriquecimento em $\mathrm{Fe}$ e Ni foi verificado na região varrida pela frente de reação avançando. Além disso, é possível observar que todos os precipitados eram enriquecidos em $\mathrm{Cr}$ e Mo, mas alguns deles também eram mais ricos em $\mathrm{Si}, \mathrm{N}$ e $\mathrm{Ni}$ que outros precipitados. Como esperado, os precipitados enriquecidos em $\mathrm{Cr}$, Mo e C foram 
identificados via padrão SAED como carbetos- $\mathrm{M}_{23} \mathrm{C}_{6}$. Vale reforçar a observação que os precipitados enriquecidos em $\mathrm{Si}$ formaram sempre associado com o carbeto- $\mathrm{M}_{23} \mathrm{C}_{6} \mathrm{e}$, ambos os precipitados apresentaram padrões SAED similares. Também na Figura 4.46 é apresentado o resultado da análise por XEDS em linha obtida a partir da região indicada pela seta branca no mapa elementar do Cr. É possível observar uma descontinuidade bem acentuada na composição do $\mathrm{Cr}$ através da frente de reação da $\mathrm{PD}$, tal característica é considerada como regra geral no fenômeno da reação de PD [24] e confirma a existência de um gradiente composicional à frente do contorno migrando mostrando a existência de uma força motriz química como a responsável pela migração do contorno, i.e. o fenômeno DIGM.
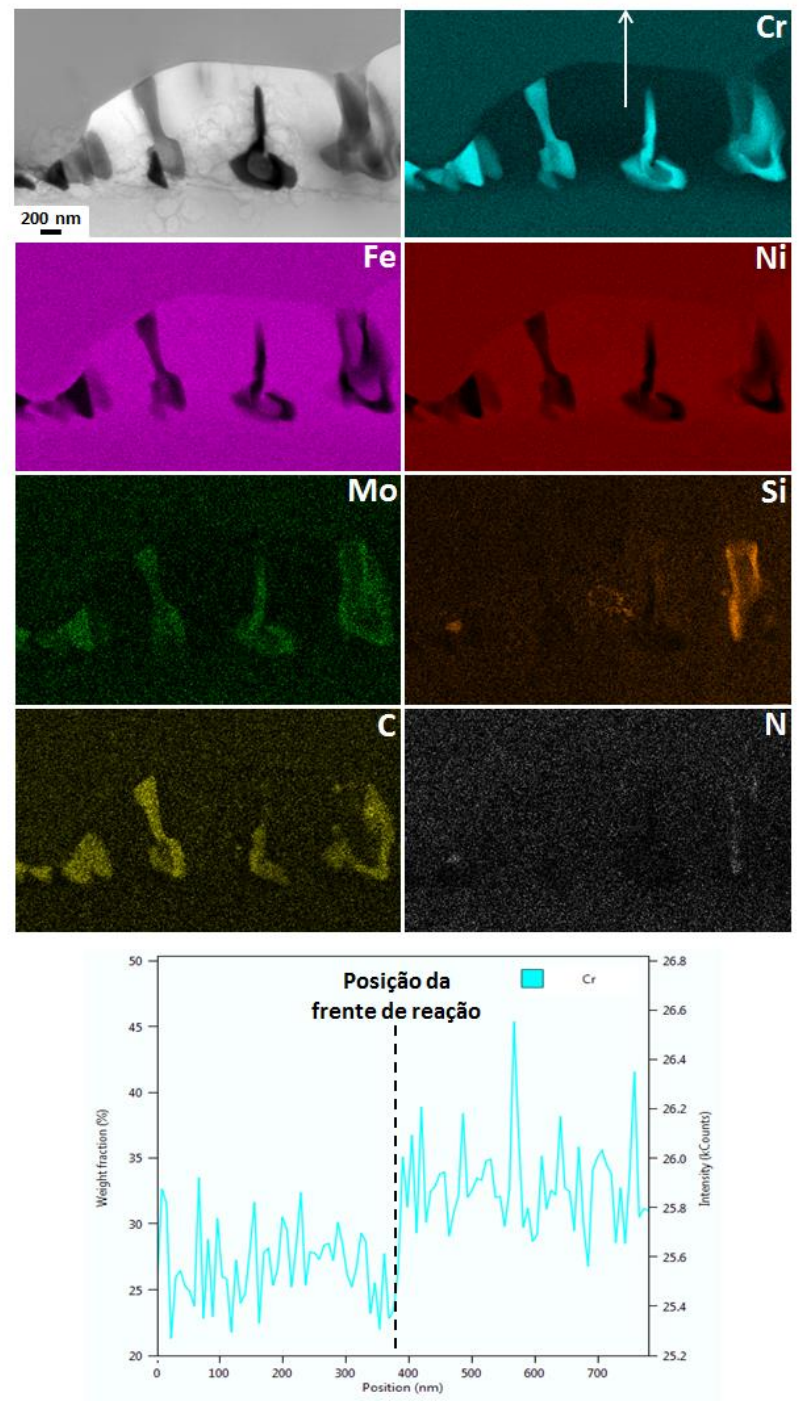

Figura 4.46 - Imagem de STEM-BF obtida da região indicada pelo retângulo amarelo na Figura 4.45 e os correspondentes mapas elementares obtido por STEM/XEDS do $\mathrm{Cr}$, Fe, $\mathrm{Ni}, \mathrm{Mo}, \mathrm{Si}, \mathrm{C}$ e N. O resultado da análise de XEDS em linha, obtida na região indicada pela seta, mostra uma acentuada descontinuidade na composição do $\mathrm{Cr}$ através da frente de reação da PD. 
Na Figura 4.47 é apresentada uma imagem de STEM-BF da Liga 33 envelhecida a $800{ }^{\circ} \mathrm{C}$ por $5 \mathrm{~h}$. Nesta figura vários precipitados na posição original do contorno são observados. Enquanto dois destes precipitados, apontados com as setas, permaneceram na posição original do contorno fixando sua migração, outros dois cresceram para dentro da matriz empobrecida em soluto. É importante observar o precipitado na forma de plaqueta na frente de reação da PD. A fim de identificar a natureza dos precipitados mencionados acima, a região indicada pelo retângulo vermelho na Figura 4.47 foi analisada em mais detalhes por meio de análises de STEM/XEDS como mostrado na Figura 4.48. Nesta figura, é mostrada uma imagem de STEM-HAADF e o mapeamento elementar por STEM-XEDS do $\mathrm{Cr}, \mathrm{Fe}, \mathrm{Ni}, \mathrm{Mo}, \mathrm{Si}, \mathrm{N}$ e $\mathrm{C}$ obtido nesta região revela a existência de três diferentes precipitados, como segue: (1) precipitado rico em $\mathrm{Cr}$ na região varrida pelo contorno, o qual foi identificado por difração de elétrons como a fase $\alpha$-Cr com estrutura $\mathrm{CCC}$; (2) precipitado enriquecido em $\mathrm{Cr}$, Mo e $\mathrm{C}$ (carbeto- $\mathrm{M}_{23} \mathrm{C}_{6}$ ) no ponto triplo e (3) precipitado enriquecido em $\mathrm{Si}, \mathrm{Mo}, \mathrm{Ni}, \mathrm{N}$ e $\mathrm{Cr}$ também no ponto triplo. Como observado anteriormente, a fase enriquecida em $\mathrm{Si}$ formou associada com o carbeto- $\mathrm{M}_{23} \mathrm{C}_{6}$.

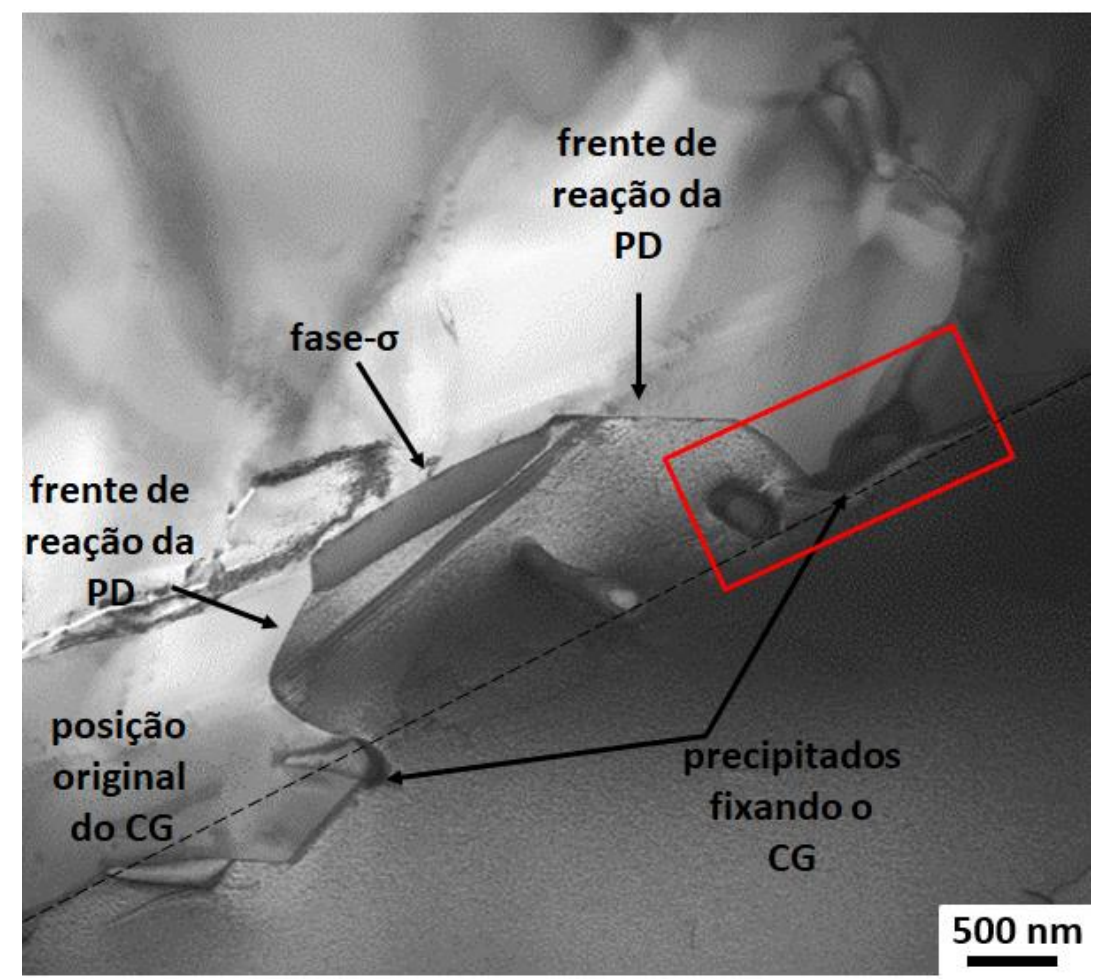

Figura 4.47 - Imagem de STEM-BF da Liga 33 envelhecida a $800{ }^{\circ} \mathrm{C}$ por 5 horas mostrando a precipitação concomitante com a migração no CG. $O$ retângulo vermelho indica a região mostrada na Figura 4.48 . 

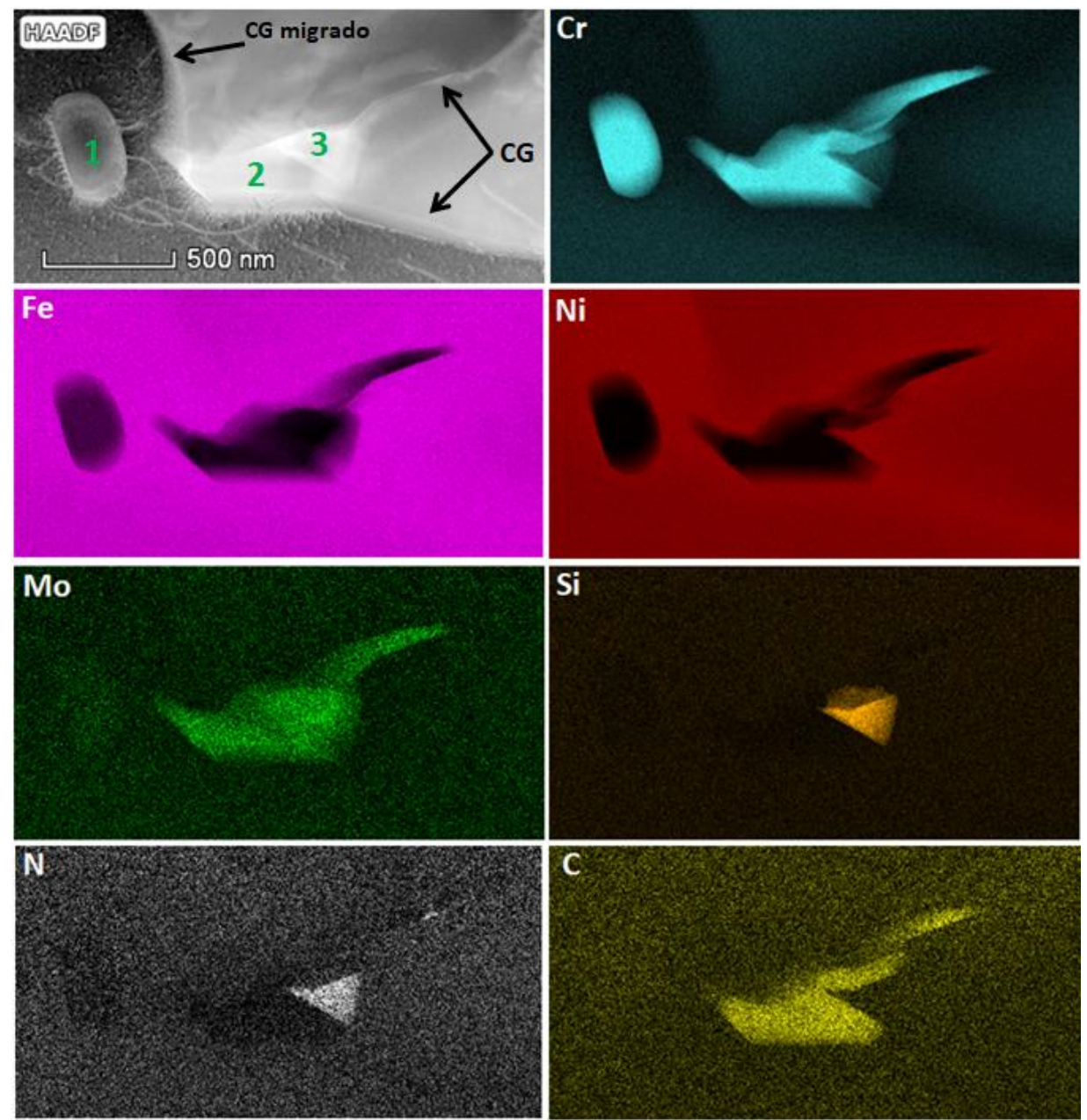

Figura 4.48 - Imagem de STEM-HAADF obtida da região indicada pelo retângulo vermelho na Figura 4.47 e os correspondentes mapas elementares obtidos por $\mathrm{STEM} / \mathrm{XEDS}$ do $\mathrm{Cr}, \mathrm{Fe}, \mathrm{Ni}, \mathrm{Mo}, \mathrm{Si}, \mathrm{N}$ e C. CG: contorno de grão. Precipitado $\mathrm{n}^{\circ} 1$ : fase $\alpha-$ $\mathrm{Cr}$; precipitado $\mathrm{n}^{\circ}$ 2: carbeto- $\mathrm{M}_{23} \mathrm{C}_{6}$; precipitado 3: enriquecido em $\mathrm{Si}, \mathrm{N}$ e $\mathrm{Ni}$.

A Figura 4.49 mostra uma imagem de STEM-HAADF obtida de outra região na Figura 4.47 e os correspondentes mapas elementares por XEDS. Nestas imagens aparece no topo o precipitado em forma de plaqueta na frente de reação da PD, o qual foi encontrado ser enriquecido em $\mathrm{Cr}$ e Mo contendo $\mathrm{Fe}$, Ni e Si. A Figura 4.50 mostra uma imagem de MET-CDF deste precipitado. Baseado no padrão SAED, esta fase foi identificada como a fase intermetálica $\sigma$ com estrutura tetragonal, a qual também já foi observada por outros autores ocorrer na frente de reação de colônias PD em aços inoxidáveis austeníticos [4][52][148]. Portella et al. [3] reportou a ocorrência da fase intermetálica $\sigma$ no CG da Liga 33 envelhecida a $700{ }^{\circ} \mathrm{C}$ e $900{ }^{\circ} \mathrm{C}$, ambas nestas temperaturas por $100 \mathrm{~h}$. Também nesta figura, são verificados precipitados da fase $\alpha$-Cr na posição original do CG e na região varrida pelo contorno. 
A Figura 4.51 mostra a mesma imagem de STEM-BF da colônia de PD mostrada na Figura 4.47 e os espectros pontuais obtidos por STEM/XEDS obtidos dos precipitados, os quais confirmam a existência de quatro diferentes fases precipitadas nesta região do CG. O espectro 1 foi obtido da fase $\alpha-\mathrm{Cr}$, a qual era rica em $\mathrm{Cr}$ contendo $\mathrm{Fe}$, Mo e Ni. $\mathrm{O}$ espectro 2 foi obtido do carbeto- $\mathrm{M}_{23} \mathrm{C}_{6}$ no ponto triplo, o qual era rico em $\mathrm{Cr}$ contendo $\mathrm{Mo}$, Ni e Fe. O baixo pico do $\mathrm{Si}$ nos espectros 1 e 2 pode ser proveniente da matriz localizada abaixo ou ao redor do precipitado e, assim, o elemento Si não foi considerado como constituinte destas fases precipitadas. $\mathrm{O}$ espetro 3 foi obtido do nitreto, o qual era enriquecido em $\mathrm{Si}$, $\mathrm{Ni}$, Cr, Mo e N, com baixo teor de Fe e V. O espectro 4 foi obtido da fase intermetálica $\sigma$ enriquecida em $\mathrm{Cr}$ e Mo contendo Fe, Si e baixo teor de Ni. Esta específica colônia de PD mostra características diferentes quando comparadas com a maioria das colônias observadas neste trabalho. Em geral, o precipitado identificado no $\mathrm{CG}$ é o carbeto- $\mathrm{M}_{23} \mathrm{C}_{6}$, mas nesta colônia de $\mathrm{PD}$, mostrada nas Figuras 4.47 e 4.51, a fase $\alpha$-Cr foi observada na posição original do contorno. 


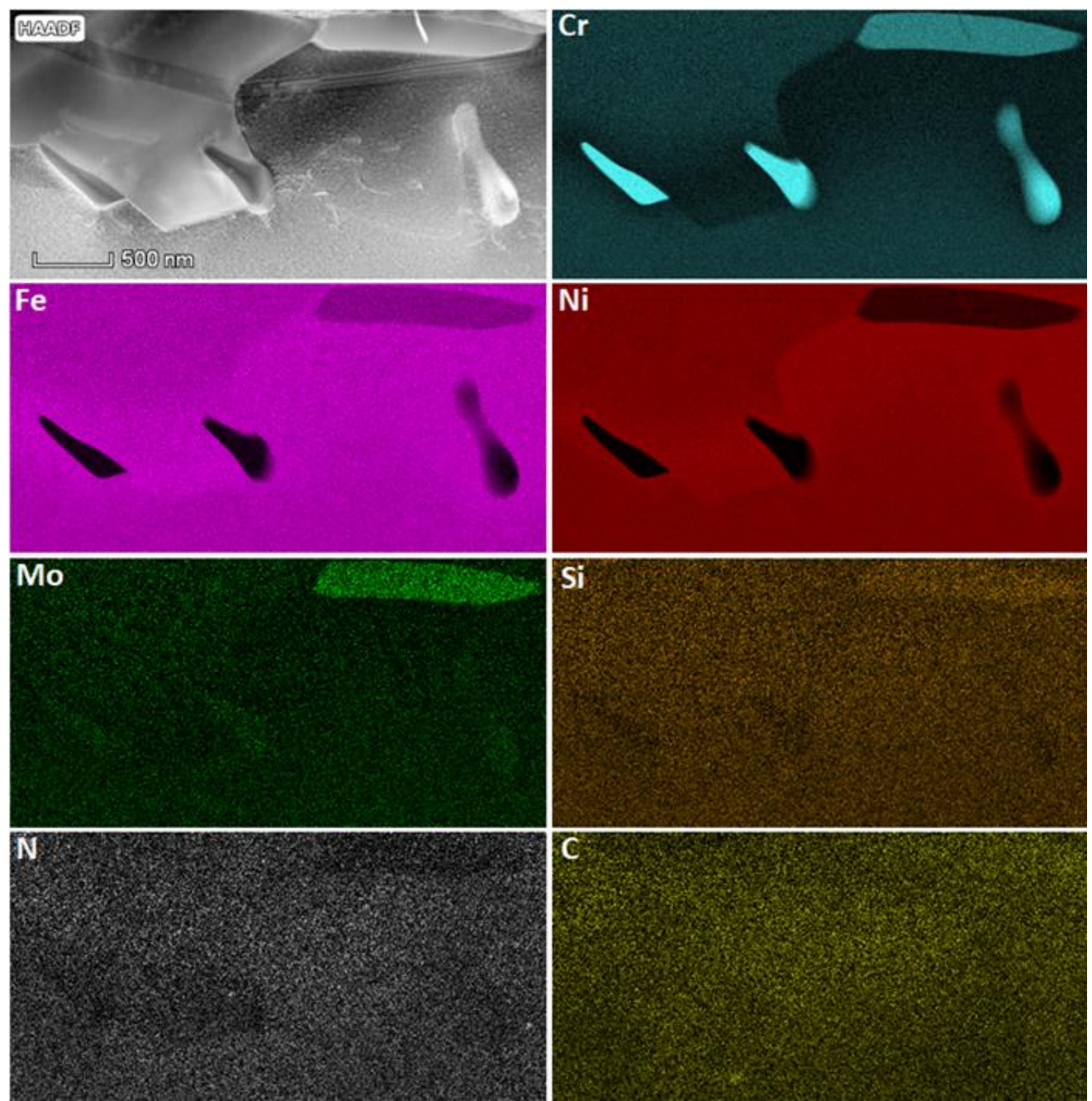

Figura 4.49 - Imagem de STEM-HAADF obtida da imagem mostrada na Figura 4.47 e os correspondentes mapas elementares obtidos por STEM/XEDS do $\mathrm{Cr}$, Fe, Ni, Mo, Si, $\mathrm{N}$ e C.

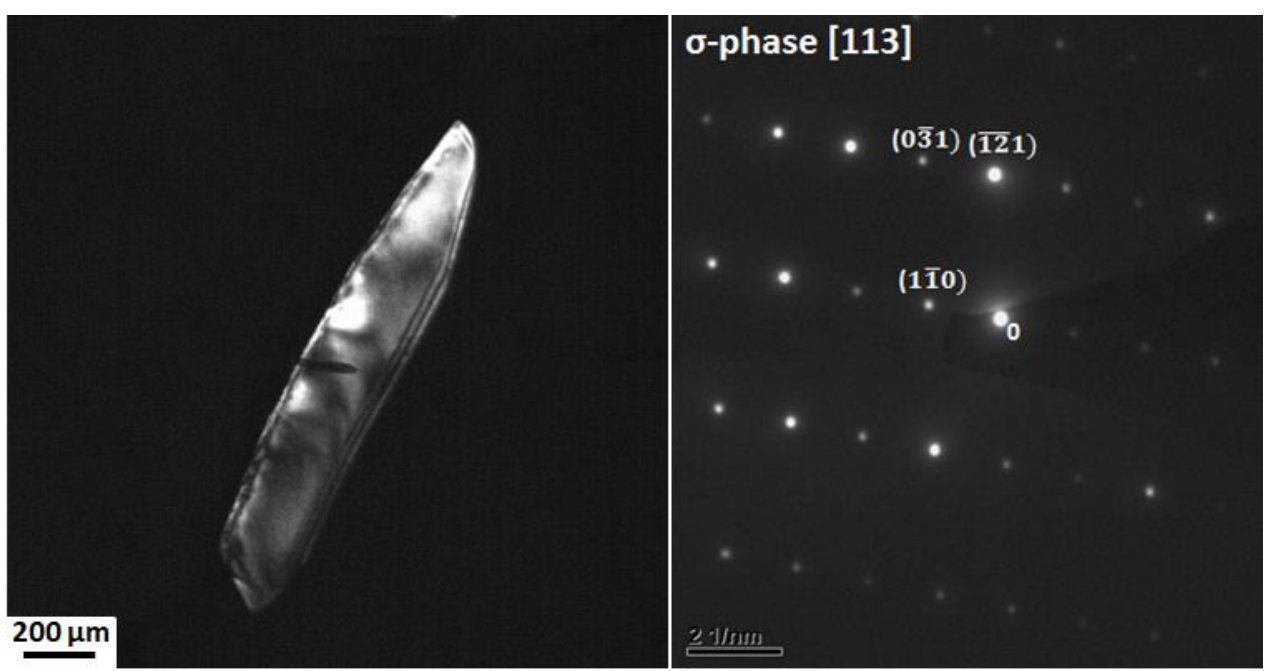

Figura 4.50 - Imagem de MET-CDF da fase intermetálica $\sigma$ com estrutura tetragonal formada na frente de reação da PD e o respectivo padrão SAED no eixo de zona [ $\left.\begin{array}{ll}1 & 1\end{array}\right]$. 

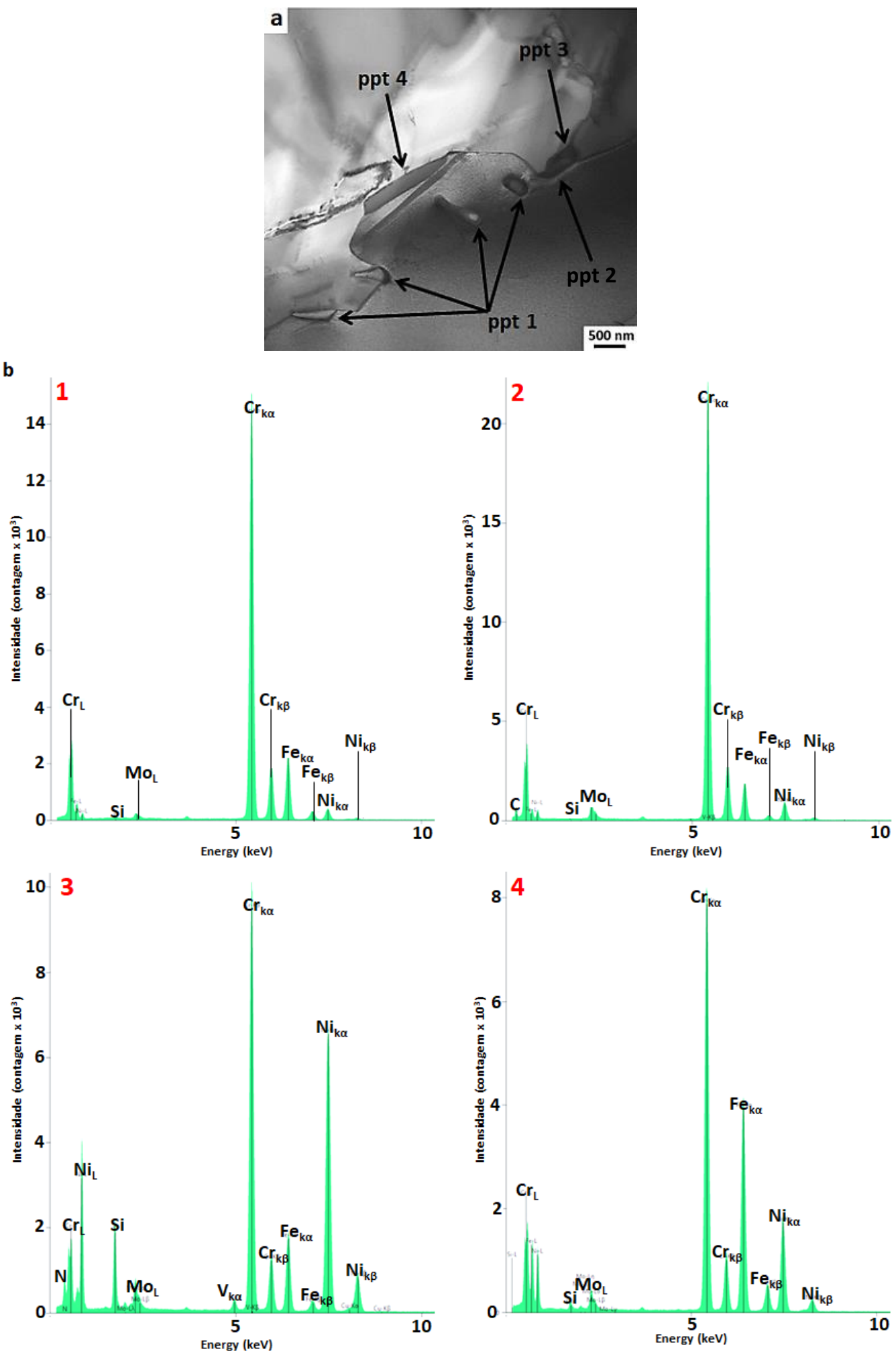

Figura 4.51 - (a) Imagem de STEM-BF da colônia de PD mostrada na Figura 4.47 e (b) espectros pontuais obtidos por STEM/XEDS dos precipitados indicados pelos números 1,2 , 3 e 4 em (a). (1) fase $\alpha-\mathrm{Cr}$ (estrutura $C C C$ ); (2) carbeto- $\mathrm{M}_{23} \mathrm{C}_{6}$ (estrutura $\mathrm{CCC}$ ); (3) fase precipitada enriquecida em $\mathrm{Si}$; (4) fase intermetálica $\sigma$ (estrutura tetragonal). 
A Figura 4.52 mostra uma imagem de STEM-HAADF de um típico exemplo de colônia de PD observada na Liga 33 envelhecida a $800{ }^{\circ} \mathrm{C}$ por $10 \mathrm{~h}$. Esta colônia contém uma cadeia de precipitados na posição original do CG e precipitados lamelares crescendo para dentro da matriz CFC, como também observado por Portela et al. [3] na Liga 33 envelhecida a $700{ }^{\circ} \mathrm{C}$ por $100 \mathrm{~h}$. Os mapas elementares obtidos por STEM/XEDS desta colônia de PD confirmaram que todos os precipitados eram enriquecidos em $\mathrm{Cr}$, além da existência das zonas empobrecida em $\mathrm{Cr}$ e enriquecida em $\mathrm{Fe}$ e Ni na região varrida pelo contorno. É também verificada a existência de, pelo menos, três diferentes precipitados constituindo esta colônia de PD: (1) carbetos- $\mathrm{M}_{23} \mathrm{C}_{6}$ ricos em $\mathrm{Cr}$ na posição original do CG; (2) precipitados lamelares da fase- $\alpha$ rica em Cr; e (3) precipitados enriquecidos em $\mathrm{Si}, \mathrm{Mo}, \mathrm{Cr}$ e Ni formados tanto na posição original do contorno como dentro da colônia de PD.

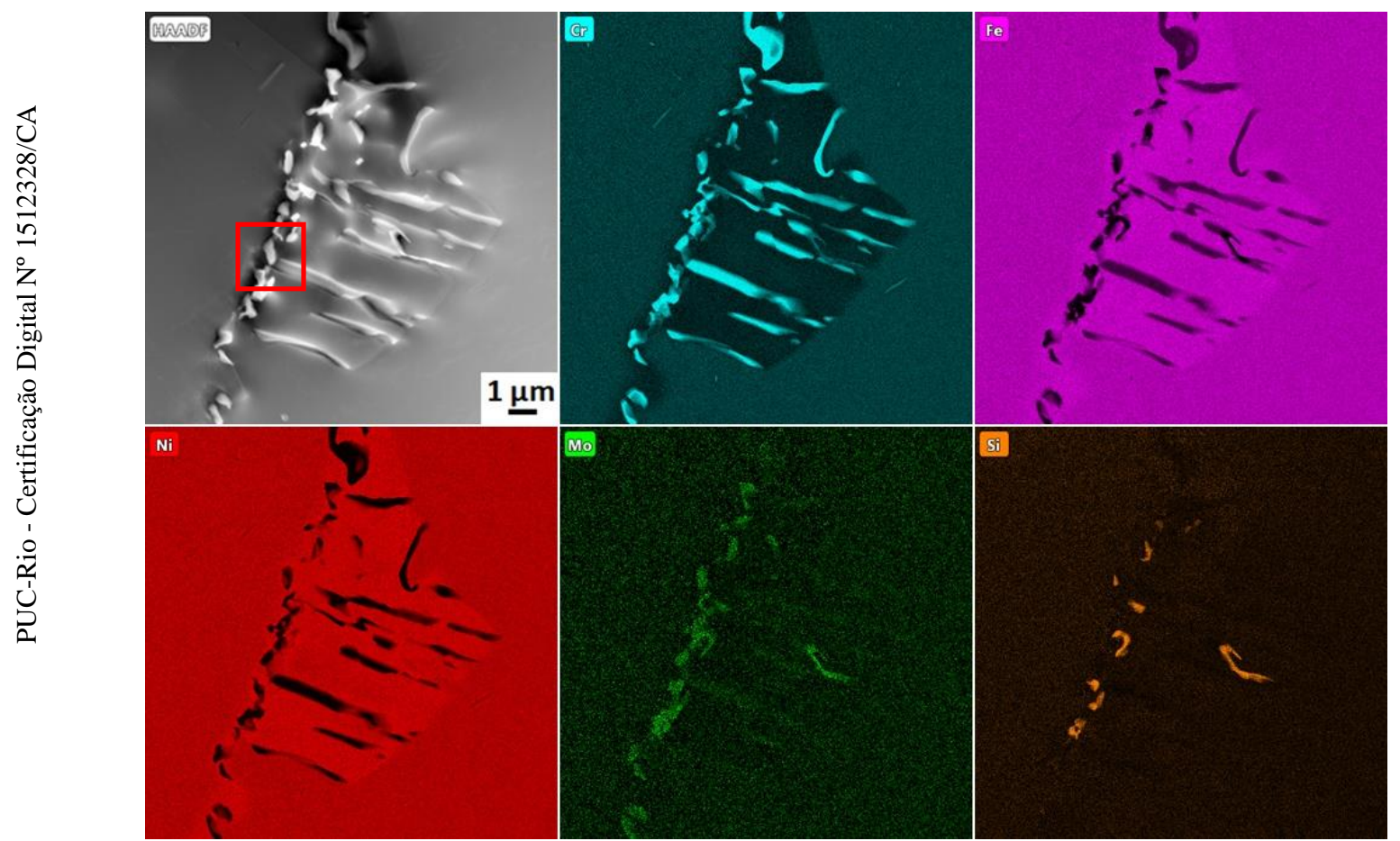

Figura 4.52 - Imagem de STEM-HAADF de uma colônia de PD na Liga 33 envelhecida a $800{ }^{\circ} \mathrm{C}$ por $10 \mathrm{~h}$ e os correspondentes mapas elementares obtidos por STEM/XEDS do $\mathrm{Cr}, \mathrm{Fe}, \mathrm{Ni}, \mathrm{Mo}$ e Si. O quadrado indica a região mostrada na Figura 4.53.

Como mostrado no decorrer deste trabalho, uma fase enriquecida em Si foi observada precipitar após o envelhecimento a $800{ }^{\circ} \mathrm{C}$ por $30 \mathrm{~min}$. Precipitados enriquecidos em Si, tais como fase-G [72][73][91][102][103][105][107-109], fase-H [110][111] e fase- $\eta$ [6][7][60][70][72][73][105][112-117][119] já foram reportados em vários tipos de ligas estruturais multicomponentes. Entretanto, Maziasz [118] afirmou que a fase-H deveria ser referida como fase- $\eta$. Neste 
sentido, os argumentos que serão apresentados a seguir são pertinentes para a discussão na tentativa de identificar a fase enriquecida em Si encontrada na Liga 33 no presente trabalho.

A fase-G enriquecida em Si com estrutura CFC (grupo espacial Fm3m) e parâmetro de rede $\mathrm{a}=1.09-1.12 \mathrm{~nm}$ foi reportada em diversas ligas, tais como AI austeníticos irradiados [72][73][105][107], AI duplex [102], AI austeníticos envelhecidos isotermicamente [103][109] e ligas à base de Ni [108]. Esta fase tem uma composição ideal $\mathrm{A}_{6} \mathrm{~B}_{16} \mathrm{Si}_{7}$, no qual Ti e Ni são, respectivamente, os mais efetivos elementos A e B [91][73]. Entretanto, outros elementos tais como $\mathrm{Fe}, \mathrm{Cr}$, Mn, Nb, e Mo podem substituir o Ti e Ni [72][91][102-105][107][109]. Como uma consequência dos vários elementos que podem constituir a fase $\mathrm{G}$, a composição química e o parâmetro de rede é flexível [109]. Por exemplo, o teor de Si nesta fase foi reportado variar na faixa de 14 até $41 \%$ at. dependendo da composição química e condições da liga [73][91][102][107][109].

A fase- $\eta$ enriquecida em Si com estrutura cúbica-diamante (grupo espacial Fd3m) e parâmetro de rede de 1.06 - 1.24 nm [6][60][73][105][110][111] também já foi reportada em diversos tipos de materiais estruturais, tais como AI irradiados [6][72][73][105][112], AI austeníticos envelhecidos [6][7][70][112] e ligas à base de Ni [6][114]. Como observado com a fase-G, a composição química da fase- $\eta$ é variável, mas em geral esta última é enriquecida em $\mathrm{Si}$, $\mathrm{Ni}$ e $\mathrm{Cr}$, podendo conter Fe, Mo, Mn, Nb e V [6][7][72][73][105][111-113][117] e, dependendo da composição química da liga, a fase- $\eta$ pode ser formada como carbetos [70][72][73][105][113][114][116], nitretos [60], e carbonitretos [7][117].

Como descrito acima, a composição química dos precipitados enriquecidos em $\mathrm{Si}$ (fases $\mathrm{G}$ e $\eta$ ) reportados na literatura mostra uma significante variação dependendo da composição da liga, o que torna sua identificação uma tarefa não tão simples, baseado somente na composição química da fase precipitada. Neste sentido, para confirmar a natureza da fase enriquecida em $\mathrm{Si}$ encontrada no presente trabalho, análises por difração de elétrons (SAED) foram extensivamente utilizadas. Isso porque dependendo do eixo de zona no qual a fase está orientada em relação ao feixe de elétrons do microscópio, ambas as fases $\mathrm{G}$ (estrutura CFC) e $\eta$ (estrutura cubica-diamante) podem gerar padrões SAED similares, como mencionado ter sido observado na Figura 4.45. Entretanto, padrões de difração da estrutura cúbica-diamante (fase- $\eta$ ) no eixo de zona [001] 
podem ser distinguíveis dos padrões no mesmo eixo de zona da estrutura CFC. Esta diferença entre as estruturas cristalinas cúbica-diamante e CFC ocorre devido ao fator de estrutura da primeira prever ausências sistemáticas das reflexões (200), (420), as quais estão presentes para a estrutura CFC [73][105].

A Figura 4.53 apresenta uma imagem de STEM-HAADF obtida da região indicada pelo quadrado vermelho na Figura 5.52 mostrando precipitados na posição original do contorno e parte do precipitado lamelar. Na mesma figura, também são mostrados padrões SAED obtidos respectivamente da matriz CFC, do carbeto- $\mathrm{M}_{23} \mathrm{C}_{6}$ com estrutura $\mathrm{CFC}$ e da fase enriquecida em Si. Um dos precipitados formados na posição original do CG mostrado na Figura 5.53 foi identificado como o carbeto- $\mathrm{M}_{23} \mathrm{C}_{6}$ com estrutura CFC. Como observado nesta figura, na qual todos os padrões de difração foram obtidos no eixo de zona [001], o carbeto- $\mathrm{M}_{23} \mathrm{C}_{6}$ apresentou um padrão SAED diferente do da fase enriquecida em Si. Neste último, algumas reflexões proibidas foram verificadas confirmando a estrutura cúbica-diamante da fase enriquecida em Si. Também foi verificado que ambas as fases, carbeto- $\mathrm{M}_{23} \mathrm{C}_{6}$ e a fase- $\eta$, têm uma R.O. cubo-a-cubo com a matriz $\mathrm{CFC}, \quad[001]_{M_{23} C_{6}} / /[001]_{\text {matriz }-C F C} / /[001]_{\eta}$. Baseado nestas observações, pode-se concluir que a fase enriquecida em Si formada tanto na posição original do CG como dentro da colônia de PD na Liga 33 envelhecida a $800{ }^{\circ} \mathrm{C}$ é a fase- $\eta$ com estrutura cúbica-diamante. 


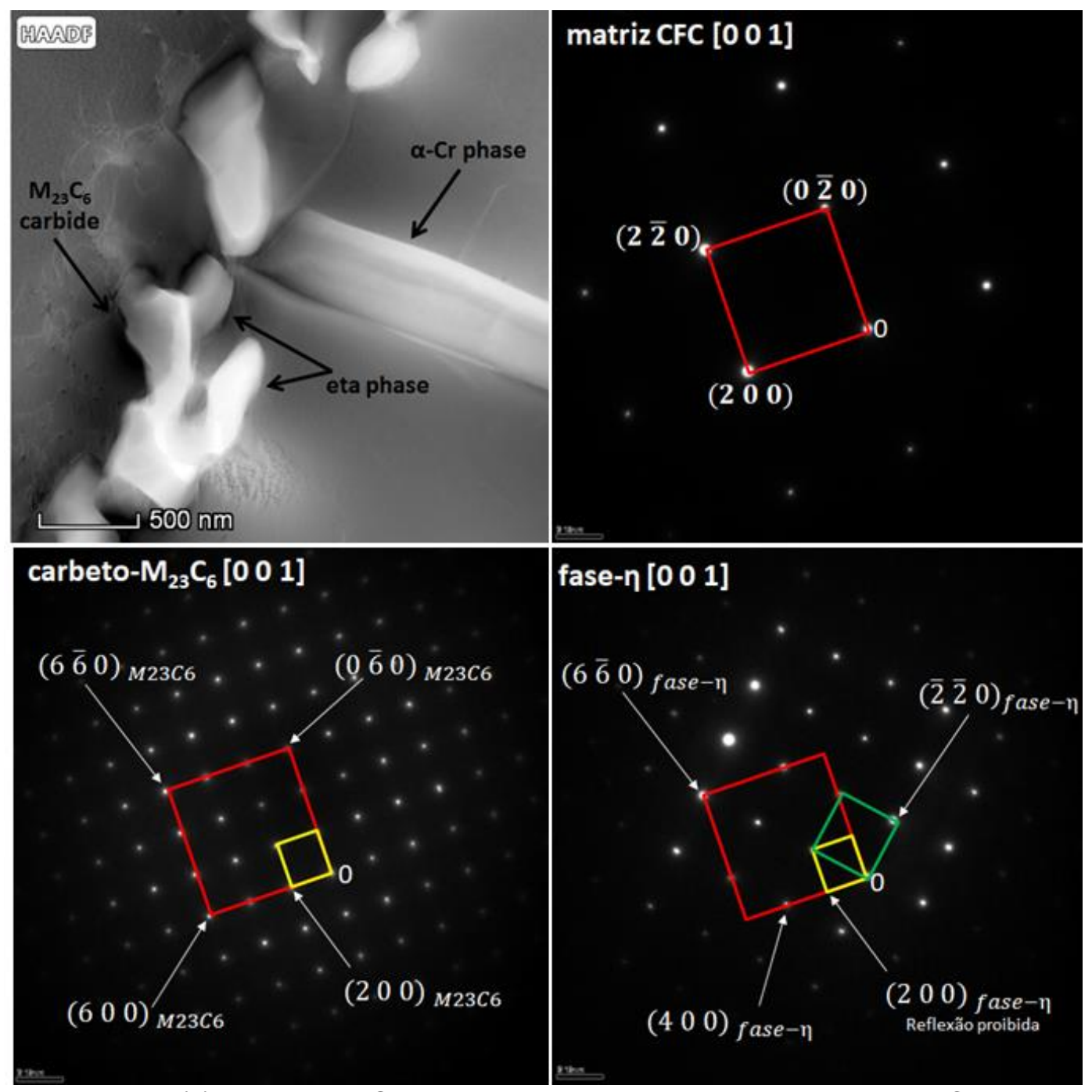

Figura 4.53 - (a) Imagem de STEM-HAADF da Liga 33 envelhecida a $800{ }^{\circ} \mathrm{C}$ por $10 \mathrm{~h}$ obtida da região indicada pelo quadrado vermelho na Figura 4.52 e os padrões SAED obtidos no eixo de zona [001] da matriz CFC, carbeto- $\mathrm{M}_{23} \mathrm{C}_{6}$ e fase- $\eta$, respectivamente. $\mathrm{O}$ quadrado vermelho é referente à matriz-CFC, o quadrado amarelo é referente ao carbeto- $\mathrm{M}_{23} \mathrm{C}_{6}$ e o quadrado verde é referente à fase-n.

Baseado nos resultados encontrados neste trabalho, pode-se afirmar que a fase- $\eta$ sempre precipitou associada ao carbeto- $\mathrm{M}_{23} \mathrm{C}_{6}$ na posição original do $\mathrm{CG}$, como visto na Figura $4.52 \mathrm{e}$ em outras figuras mostradas anteriormente. Entretanto, a precipitação da fase- $\eta$ dentro da colônia (Figura 4.52) contradiz a sugestão feita anteriormente neste trabalho que a fase- $\eta$ somente precipita associada ao carbeto- $\mathrm{M}_{23} \mathrm{C}_{6}$, já que não foi encontrado tal carbeto dentro das colônias de PD. Porém, uma análise mais cuidadosa da Figura 4.52 mostra que a precipitação da fase- $\eta$ dentro da colônia ocorreu associada ao precipitado lamelar da fase- $\alpha$ rica em Cr. Assim, pode ser sugerido que a fase- $\eta$ precipitou na Liga 33 sempre associada ou com o carbeto- $\mathrm{M}_{23} \mathrm{C}_{6}$ ou com a fase $\alpha-\mathrm{Cr}$ (como será mostrada em outros resultados no decorrer deste trabalho) devido ao 
enriquecimento de elementos, nas regiões adjacentes a estes precipitados, que tem pouca solubilidade tanto no carbeto- $\mathrm{M}_{23} \mathrm{C}_{6}$ como na fase $\alpha-\mathrm{Cr}$, mas que constituem a fase- $\eta$, tais como Si, Ni e N [70][72][73][84][87][93][94][242].

A seguir são feitas algumas considerações em relação ao desenvolvimento da reação de PD na Liga 33 em comparação com a literatura existente. Estudos sobre PD tiveram inicialmente foco em ligas binárias contendo apenas átomos de solutos substitucionais. Em tais sistemas, existem contribuições bem estabelecidas na literatura em relação aos mecanismos propostos para iniciação [177-179][181] e modelos de crescimento cinético [182-187]. Entretanto, em sistemas multicomponentes contendo átomos substitucional e intersticial (como a Liga 33), os quais têm diferenças de ordens de magnitude nas difusividades atômicas entre os diferentes solutos, existem também inúmeras diferenças nas características cinética e estrutural. Em particular, a diferença na composição química tem um importante papel na reação descontínua global [8][53][148][168][195-198]. Neste sentido, enquanto em sistemas binários, o crescimento da reação de PD no estado estacionário pode ser modelado [24][23], a mesma condição não se aplica para sistemas multicomponentes devido à adicional complexidade que surge quando os átomos de solutos são substitucionais e intersticiais [4][148]. Entretanto, uma característica é comum em todos os sistemas onde ocorrem PD, tanto em sistemas binários como multicomponentes reportados na literatura: a fase precipitada na posição original do CG cresce junto com a migração do contorno tornando-se a principal fase precipitada dentro da colônia de PD, i.e. os precipitados lamelares descontínuos. Neste contexto, uma complexidade adicional na ocorrência da reação de PD em ligas multicomponentes foi confirmada no presente trabalho, onde qual a primeira fase precipitada formada no $\mathrm{CG}$ foi o carbeto- $\mathrm{M}_{23} \mathrm{C}_{6}$ com estrutura CFC. Entretanto, baseado na teoria clássica de PD, a fase precipitada no CG deveria crescer e tornar-se a principal fase precipitada constituindo a colônia de PD, i.e. os precipitados descontínuos lamelares. Então, era esperado que o carbeto- $\mathrm{M}_{23} \mathrm{C}_{6}$ formado no $\mathrm{CG}$ cresceria junto com a migração do $\mathrm{CG}$, mas na Liga 33 envelhecida a $800{ }^{\circ} \mathrm{C}$ os precipitados lamelares é uma diferente fase: a fase $\alpha$-Cr com estrutura CCC, a qual nucleou na região adjacente ao CG e cresceu em direção a matriz supersaturada.

Outra observação constantemente verificada na Liga 33 envelhecida a 800 ${ }^{\circ} \mathrm{C}$ que merece destaque é a ocorrência de colônias de PD com mais de uma fase 
precipitada constituindo a mesma colônia. Embora, uma forma não-usual de colônias de PD em sistemas multicomponentes tenha sido reportado em ligas à base de Ni com uma matriz supersaturada bifásica, na qual a colônia de PD continha 3 diferentes fases [10][210][213], a ocorrência de colônias de PD contendo mais de uma fase precipitada dentro da colônia gerada a partir da uma matriz monofásica não é normalmente reportada na literatura.

Baseados nas observações morfológicas/microestruturais por MET, resultados analíticos obtidos por STEM/XEDS e difração de elétrons (SAED) da Liga 33 envelhecida a $800{ }^{\circ} \mathrm{C}$ por $1 \mathrm{~h}$ até $10 \mathrm{~h}$, pode ser afirmado que:

- O fenômeno DIGM parece ter um importante papel, não só na iniciação da reação de PD (como discutido no item 4.2), mas também no processo de crescimento e consequente desenvolvimento das colônias de PD.

- Carbetos- $\mathrm{M}_{23} \mathrm{C}_{6}$ com estrutura $\mathrm{CFC}$ e fase- $\eta$ com estrutura cúbica-diamante têm uma R.O. cubo-a-cubo, (100) $)_{M_{23} C_{6}} \|(100)_{\text {matriz-CFC }}$; $[100]_{M_{23} C_{6}} \|[100]_{\text {matriz-CFC }}$, com a matriz CFC. Foi verificado também uma R.O. K-S entre o precipitado lamelar $\alpha-\mathrm{Cr}$ e a matriz CFC, $(-110)_{\alpha-\mathrm{Cr}} \|$ $(-111)_{\text {matriz }},[111]_{\alpha-C r} \|[101]_{\text {matriz. }}$

- Colônias de PD são geradas pelo particionamento de soluto dentro da colônia resultando na formação de três diferentes fases precipitadas na mesma colônia: (1) carbetos- $\mathrm{M}_{23} \mathrm{C}_{6}$ com estrutura $\mathrm{CFC}$ formados na posição original do CG; (2) fase- $\eta$ enriquecida em Si com estrutura cúbica-diamante formada tanto no CG original como dentro da colônia; e (3) precipitados lamelares da fase- $\alpha$ rica em Cr.

- A evolução microestrutural durante o envelhecimento a $800{ }^{\circ} \mathrm{C}$ indica que a natureza da reação de PD na Liga 33 difere da teoria clássica da PD. A teoria prevê que o precipitado inicialmente formado no $\mathrm{CG}$ (carbeto- $\mathrm{M}_{23} \mathrm{C}_{6}$ no presente trabalho) cresce junto com a migração do contorno, mas como mostrado os precipitados lamelares (fase $\alpha-\mathrm{Cr}$ ) começaram a crescer adjacente à posição original do CG e não na posição do CG e com o contorno já migrado. 


\subsubsection{Precipitação no envelhecimento por $20 \mathrm{~h}$}

A seguir são apresentados alguns resultados obtidos a partir de três diferentes colônias de PD observadas nos CG na Liga 33 envelhecida a $800{ }^{\circ} \mathrm{C}$ por $20 \mathrm{~h}$ no que se refere a morfologia das colônias e às diferentes fases precipitadas.

\section{Colônia 1}

A imagem de MEV-BSE na Figura 4.54a foi obtida de uma amostra como lamina fina ("thin-foil") de MET preparada a partir da Liga 33 envelhecida a 800 ${ }^{\circ} \mathrm{C}$ por 20 h. A colônia de PD apresentada na imagem de STEM-BF na Figura 4.54b com características similares àquelas mostradas anteriormente no presente trabalho foi obtida da região indicada pelo retângulo vermelho na Figura 4.54a. Pequenos precipitados na posição original do $\mathrm{CG}$, além de vários precipitados dentro desta colônia com diferentes tamanhos, morfologias e direções de crescimento foram observadas. A imagem de STEM-BF na Figura 4.54c obtida da região indicada pelo retângulo vermelho na Figura 4.54b mostra alguns dos precipitados na posição original do CG, além de outros precipitados maiores na região adjacente ao contorno. Nesta imagem é possível verificar diferenças no contraste entre a maioria dos precipitados e àqueles marcados com o número 3. Os resultados do mapeamento elementar obtido por STEM/XEDS apresentados na Figura 4.54c confirmaram a ocorrência, nesta região da colônia de PD, dos mesmos três tipos de precipitados já identificados após $10 \mathrm{~h}$ de envelhecimento: (1) carbetos- $\mathrm{M}_{23} \mathrm{C}_{6}$ ricos em $\mathrm{Cr}$ com estrutura CFC (Figura 4.57); (2) fase- $\alpha$ rica em $\mathrm{Cr}$ com estrutura CCC e (3) fase- $\eta$ enriquecida em Si com estrutura cúbicadiamante (Figuras 4.57 e 4.58). Mesmo o elemento vanádio não sendo reportado na composição química da Liga 33, o mapeamento deste elemento está apresentado em alguns resultados nesta sessão, como na Figura 4.55c, com a intenção de mostrar que é consistente com observações anteriores de que a fase- $\eta$ absorve tal elemento em sua rede cristalina. A imagem de MET-BF na Figura 4.55a, obtida da região indicada pelo retângulo vermelho na Figura 4.54b, mostra os carbetos- $\mathrm{M}_{23} \mathrm{C}_{6}$ formados na posição original do $\mathrm{CG}$ e o respectivo padrão SAED mostrando uma R.O. cubo-a-cubo, $[001]_{M_{23} C_{6}} / /[001]_{\text {matriz-CFC }}$, entre o 
carbeto e a matriz CFC. Tal padrão de difração foi obtido do precipitado indicado pelo círculo na Figura 4.55b, o qual está apontado pela seta vermelha na Figura $4.54 \mathrm{c}$

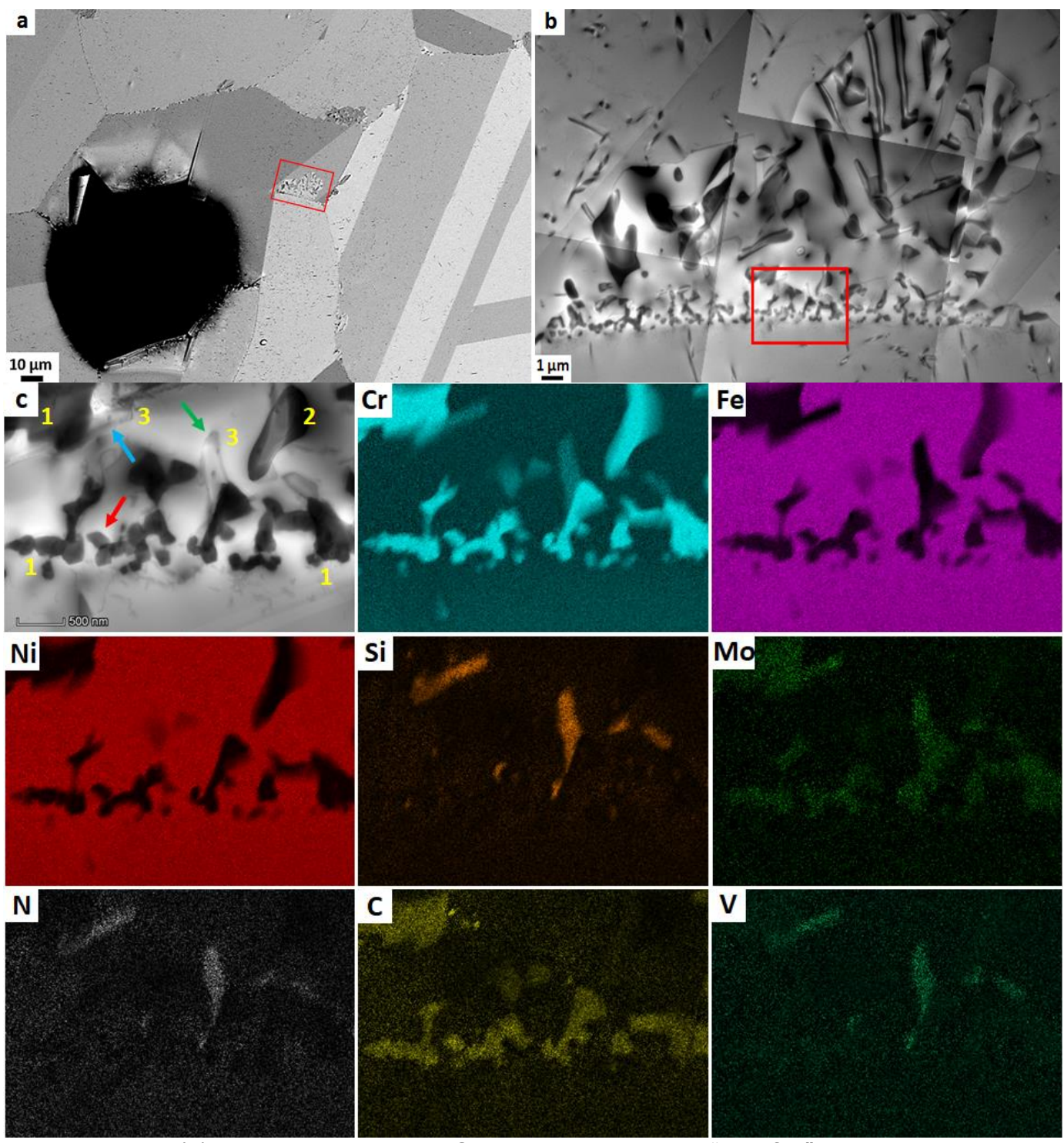

Figura 4.54 - (a) Imagem de MEV-BSE de uma amostra "thin-foil" de MET da Liga 33 envelhecida a $800^{\circ} \mathrm{C}$ por $20 \mathrm{~h}$; (b) Imagem de STEM-BF mostrando uma colônia de PD obtida da região indicada pelo retângulo vermelho em (a); e (c) Imagem de STEM-BF obtida da região indicada pelo retângulo vermelho em (b) e os correspondentes mapas elementares obtidos por STEM/XEDS do $\mathrm{Cr}$, Fe, Ni, Si, Mo, N, C e V. Precipitado $\mathrm{n}^{\circ} 1$ : carbeto- $\mathrm{M}_{23} \mathrm{C}_{6}$; precipitado $\mathrm{n}^{\circ} 2$ : fase $\alpha-\mathrm{Cr}$; precipitado $\mathrm{n}^{\circ} 3$ : fase- $\eta$. 

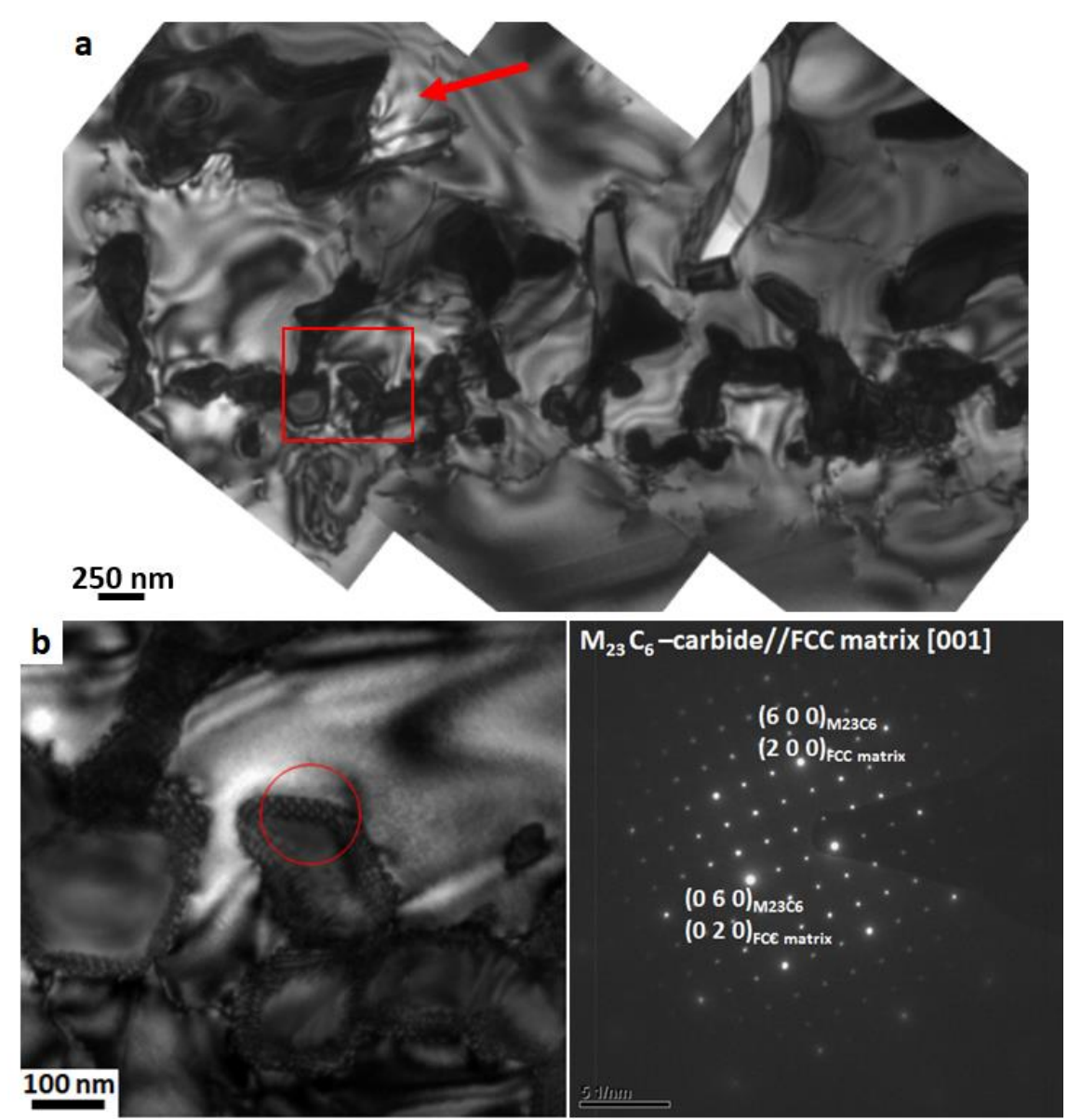

Figura 4.55 - (a) Imagem de MET-BF obtida da mesma região mostrada na Figura 4.54c e (b) imagem de MET-BF obtida da região indicada pelo retângulo vermelho em (a) e o padrão SAED obtido da região indicada pelo círculo em (b) mostrando uma R.O. cubo-acubo, $[001]_{M_{23} C_{6}} / /[001]_{\text {matriz-CFC }}$ entre o carbeto e a matriz CFC. A seta vermelha indica precipitados mostrados na Figura 4.56 e 4.57.

A imagem de MEV-BSE na Figura 4.56a mostra a mesma colônia de PD da Figura 4.54b. Já a Figura 4.56 b obtida da região indicada pelo quadrado vermelho na Figura 4.56a mostra dois precipitados com diferentes morfologias e contrastes (estes precipitados estão indicados pela seta vermelha na Figura 4.55a). Baseado nos resultados dos mapas elementares obtidos por STEM/XEDS na Figura 4.54c, o precipitado com contraste mais escuro mostrado na Figura 4.56b é o carbeto- $\mathrm{M}_{23} \mathrm{C}_{6}$ com estrutura $\mathrm{CFC}$ e o outro precipitado menor (indicado pela seta azul na Figura 4.54c) é a fase- $\eta$ enriquecida em Si com estrutura cúbicadiamante. Os padrões SAED mostrados na Figura 4.56c foram obtidos a partir da região indicada pelos números 1, 2, e 3 na Figura 4.56b. É verificado que ambos os padrões SAED, da matriz CFC e do carbeto- $\mathrm{M}_{23} \mathrm{C}_{6}$, estão no eixo de zona [001], porém o padrão SAED obtido da fase- $\eta$ foi indexado no eixo de zona [122], mostrando uma nova R.O. entre a fase $\eta$ e a matriz CFC, 
$[122]_{\eta} / /[001]_{\text {matriz-CFC }}$. Esta observação é diferente daquela mostrada na Figura 4.53 (item $4.4 .1-800{ }^{\circ} \mathrm{C}$ por $10 \mathrm{~h}$ ), a qual mostrou todos os padrões SAED obtidos da matriz $\mathrm{CFC}$, carbeto- $\mathrm{M}_{23} \mathrm{C}_{6}$ e da fase- $\eta$ no mesmo eixo de zona, [001]. Os pares de imagens de MET-BF/CDF na Figura 4.57 apresentam o carbeto$\mathrm{M}_{23} \mathrm{C}_{6}$, fase- $\eta$ e os respectivos padrões SAED mostrados na Figura 4.56c. A Figura 4.57c confirma a afirmação feita anteriormente neste trabalho que a fase- $\eta$ nucleia associada com o carbeto- $\mathrm{M}_{23} \mathrm{C}_{6}$, além de mostrar discordâncias na interface matriz CFC/fase- $\eta$. Também como verificado anteriormente do presente trabalho, os precipitados lamelares indicados pela seta vermelha na Figura 4.56 foram identificados por difração de elétrons (SAED), como a fase $\alpha$-Cr com estrutura CCC, como mostrado na Figura 4.58.
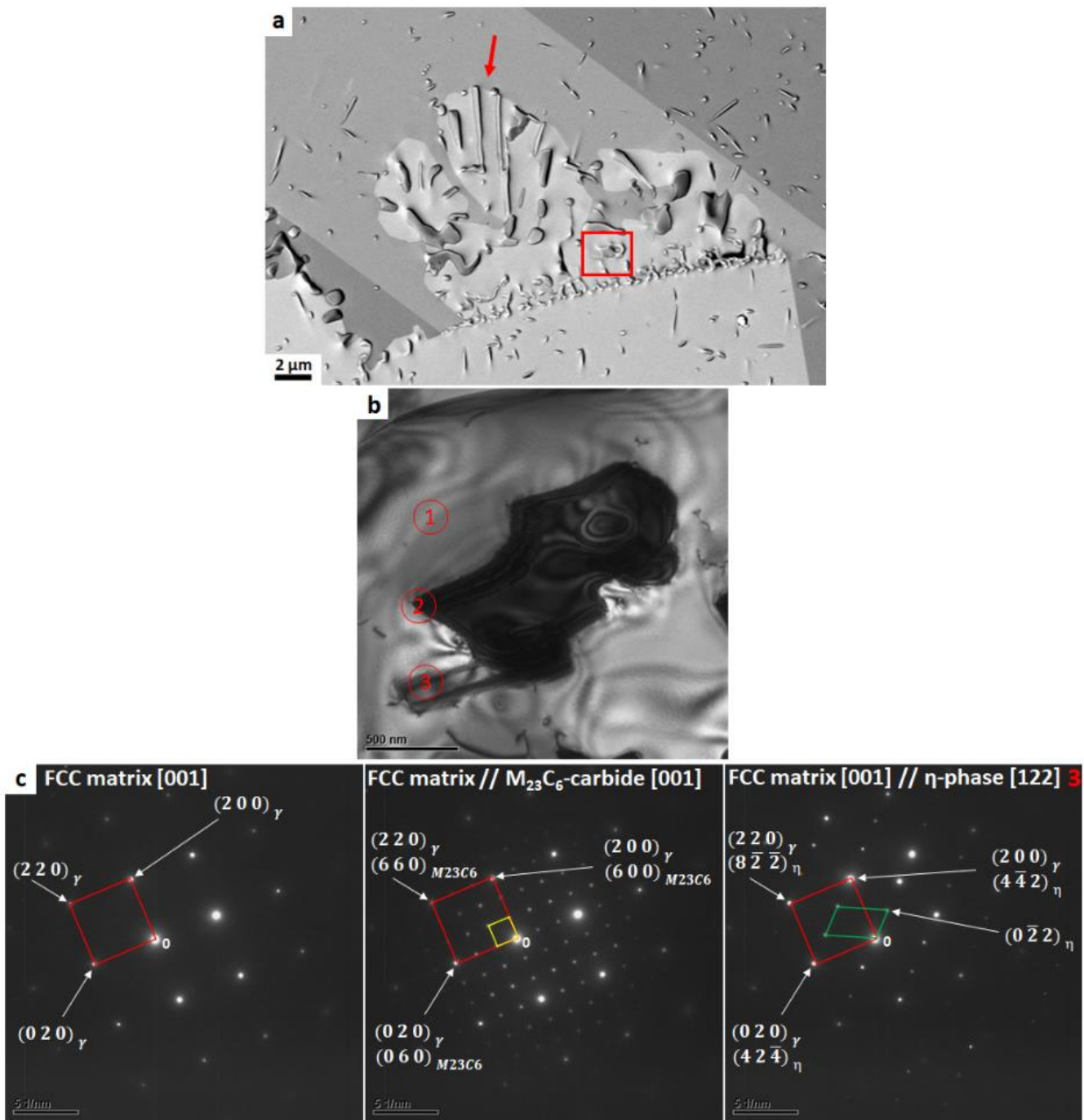

Figura 4.56 - (a) Imagem de MEV-BSE mostrando a mesma colônia de PD da Figura 4.54; (b) imagem de MET-BF obtida da região indicada pelo quadrado vermelho em (a); e (c) padrões SAED obtidos das regiões indicadas pelos números 1, 2 e 3 em (b). A seta indica os precipitados mostrada na Figura 4.58. Nos padrões SAED: o quadrado vermelho é referente à matriz-CFC, o quadrado amarelo é referente ao carbeto- $\mathrm{M}_{23} \mathrm{C}_{6} \mathrm{e}$ o paralelogramo verde é referente à fase-n. 


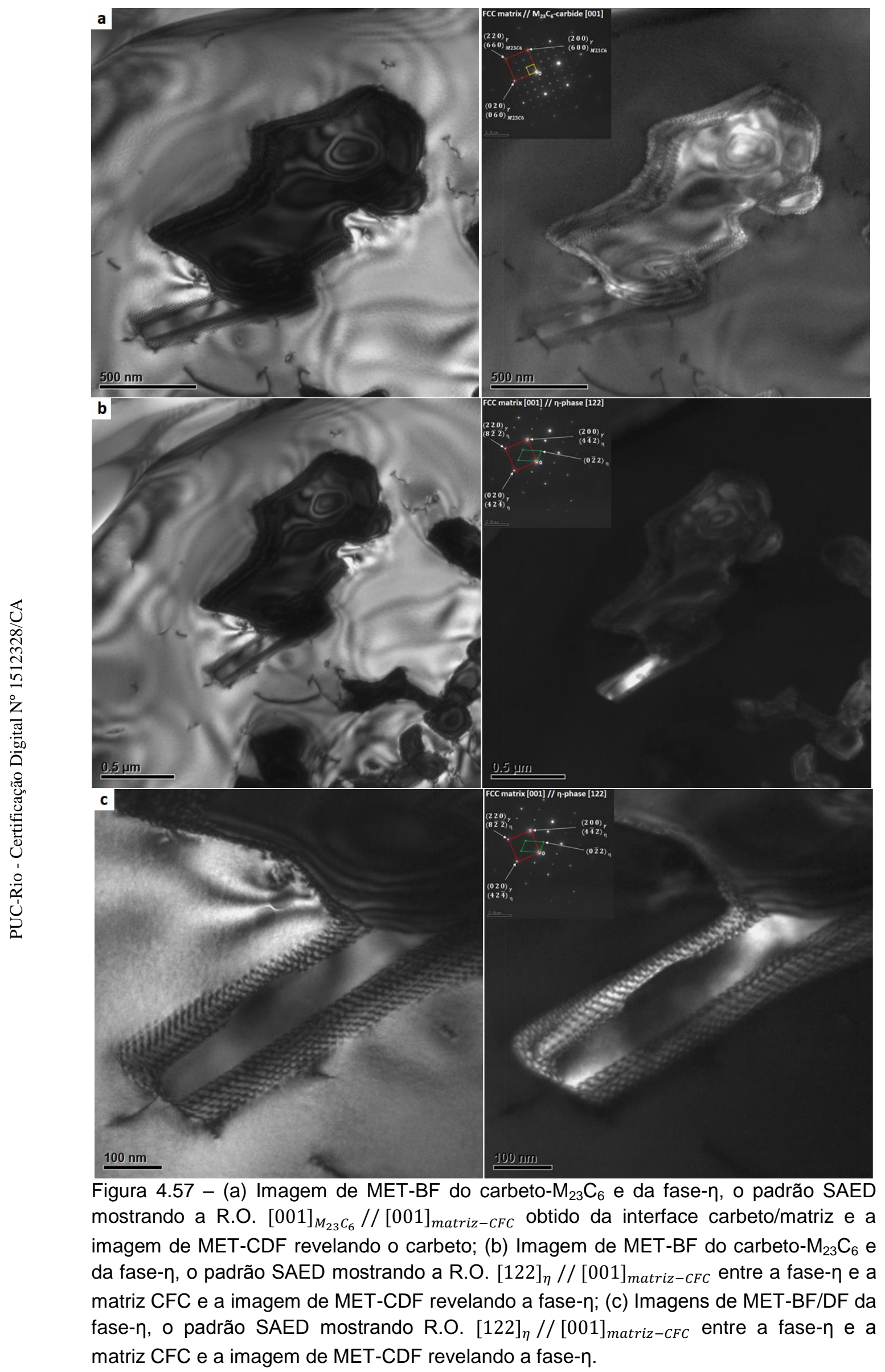




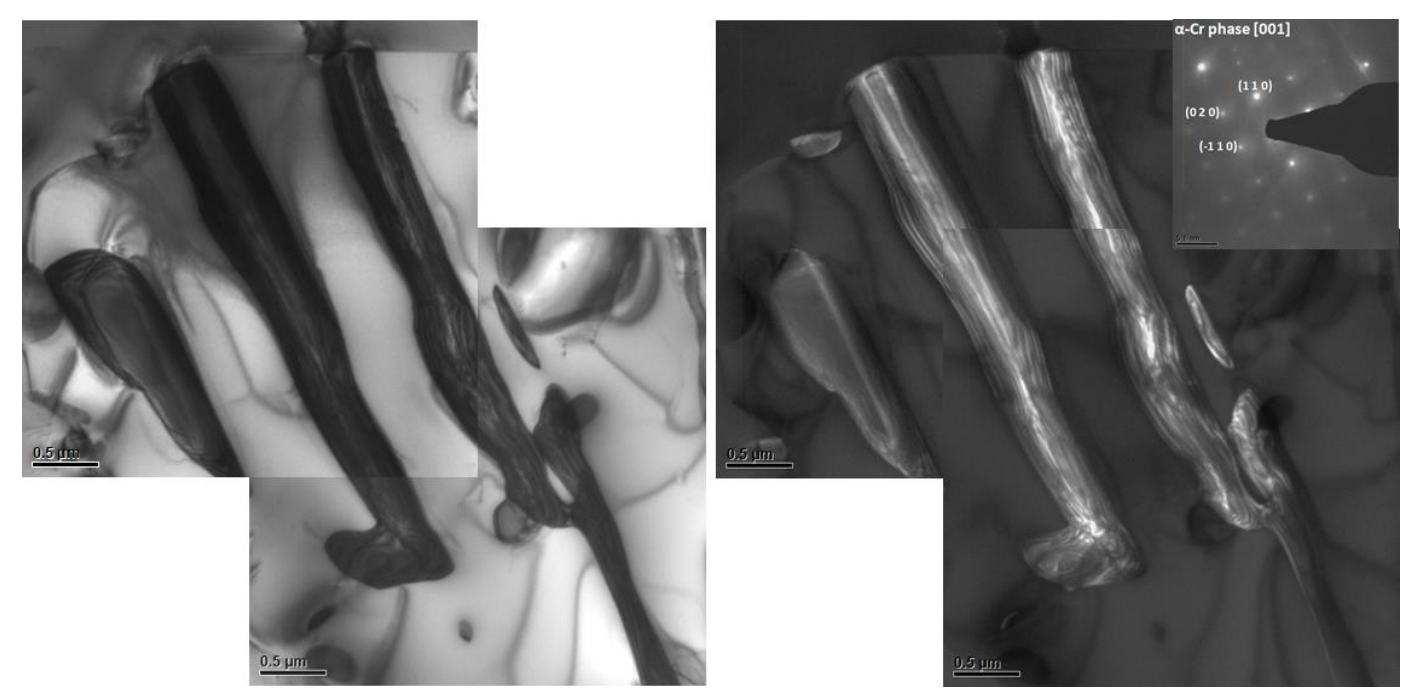

Figura 4.58 - Imagens de MET-BF/CDF dos precipitados lamelares da fase $\alpha-\mathrm{Cr}$ indicados pela seta na Figura 4.57a e o respectivo padrão SAED no eixo de zona [001].

Os resultados obtidos por MET e padrões de difração de elétrons (SAED) juntamente com STEM/XEDS e mostrado nas Figuras 4.54 a 4.58 permitem fazer algumas afirmações em relação a esta específica colônia de PD:

- Uma cadeia de precipitados permaneceram na posição original do CG, na qual carbetos- $\mathrm{M}_{23} \mathrm{C}_{6}$ ricos em $\mathrm{Cr}$ e a fase- $\eta$ enriquecida em Si foram identificadas. Foi verificado uma nova R.O. entre a fase- $\eta$ e a matriz $\mathrm{CFC}[001]_{\text {matriz-CFC }} / /[122]_{\text {fase- }}$.

- A fase- $\eta$ enriquecida em Si foi observada na posição original do CG e também dentro da colônia de PD. Sua formação foi sempre verificada ocorrer associada ao carbeto.

- Precipitados lamelares descontínuos ricos em Cr foram identificados como a fase $\alpha$-Cr com estrutura CCC. Esta fase também foi observada dentro da colônia de PD na forma de partículas. 


\section{Colônia 2}

A imagem de MEV-BSE na Figura 4.59a foi obtida de outra amostra "thin-foil" de MET preparada a partir da Liga 33 envelhecida a $800{ }^{\circ} \mathrm{C}$ por $20 \mathrm{~h}$. A colônia de PD na imagem de MEV-BSE na Figura 4.59b obtida da região indicada pelo retângulo vermelho na Figura 4.59a mostra precipitados heterogêneos em alguns contornos que permaneceram estáticos, precipitados homogêneos distribuídos pela matriz CFC e uma colônia de PD (alguns precipitados homogêneos, identificados por análises de STEM/XEDS e padrões SAED como a fase $\alpha$-Cr, estão ilustrados na Figura 4.62). Tal colônia apresenta algumas características diferentes quando comparadas com a colônia mostrada na Figura 4.54b. Na colônia da Figura 4.59b, não foram observados precipitados lamelares crescendo para dentro da matriz CFC, mas precipitados com diversas morfologias e direção de crescimento, além da ocorrência na frente de reação de uma fase com contraste mais claro na imagem de MEV-BSE. Os resultados mostrados nos mapas elementares por STEM/XEDS na Figura 4.59c confirmaram a formação de carbetos- $\mathrm{M}_{23} \mathrm{C}_{6}$ e a fase- $\eta$ enriquecida em Si na posição original do $\mathrm{CG}$, além da existência de precipitados tanto lamelares como nodulares da fase- $\alpha$ rica em $\mathrm{Cr}$ e precipitados da fase- $\eta$ dentro da colônia. Entretanto, nesta colônia a fase intermetálica $\sigma$ enriquecida em $\mathrm{Cr}$ e Mo foi identificada na frente de reação da PD com morfologia de uma longa plaqueta (como já mostrado nas Figuras 4.49 e 4.50). Na Figura 4.60, é apresentada uma imagem de MEV-BSE e dois padrões SAED obtidos da fase- $\sigma$ indicada pelo ponto vermelho na figura. Em resumo, a existência de quatro diferentes fases precipitadas foi confirmada constituir esta específica colônia: (1) carbetos- $\mathrm{M}_{23} \mathrm{C}_{6}$ ricos em $\mathrm{Cr}$ (estrutura $\mathrm{CFC}$ ); (2) fase- $\eta$ enriquecida em Si (estrutura cúbica-diamante); (3) fase- $\alpha$ rica em $\mathrm{Cr}$ (estrutura $\mathrm{CCC})$; (4) fase intermetálica $\sigma$ enriquecida em $\mathrm{Cr}$ e Mo (estrutura tetragonal).

A Figura 4.61 mostra uma imagem de MET-BF de parte do precipitado lamelar formado dentro da colônia de PD na Figura 4.59c, o qual está indicado pelo quadrado vermelho. A partir do padrão SAED mostrado na Figura 4.61, o precipitado lamelar que cresceu na direção paralela ao contorno original foi identificado como a fase $\alpha$-Cr com estrutura CCC. Foi verificado a R.O. K-S entre a fase $\alpha-C r$ e a matriz CFC, $\left(\begin{array}{lll}-1 & 0 & 1\end{array}\right)_{\alpha} / /\left(\begin{array}{lll}-1 & -1 & 1\end{array}\right)_{\gamma},\left[\begin{array}{lll}1 & 1 & 1\end{array}\right]_{\alpha} / /\left[\begin{array}{lll}1 & 0 & 1\end{array}\right]_{\gamma}$. Como mostrado durante todo esse trabalho, a fase lamelar formada dentro das colônias 
na Liga 33 é a fase- $\alpha$ rica em $\mathrm{Cr}$ com estrutura CCC, porém a ocorrência deste tipo de precipitado constituindo colônias de PD em ligas multicomponentes não é muito reportada na literatura. Tal fase, $\alpha$-Cr, já foi reportada ocorrer em ligas multicomponentes, mas como precipitação convencional [122][124][61][131]. Entretanto, lamelas da fase $\alpha-\mathrm{Cr}$ constituindo colônias de PD foi apenas reportada em ligas binárias Ni-Cr [137][138], na qual também foi observada a R.O. K-S entre a fase $\alpha$-Cr e a matriz CFC [137], como também encontrado no presente trabalho. Porém, uma R.O. do tipo Nishiyama-Wassermann (N-W) também foi verificada entre lamelas da PD da fase $\alpha-\mathrm{Cr}$ e a matriz CFC em ligas binárias NiCr [138].

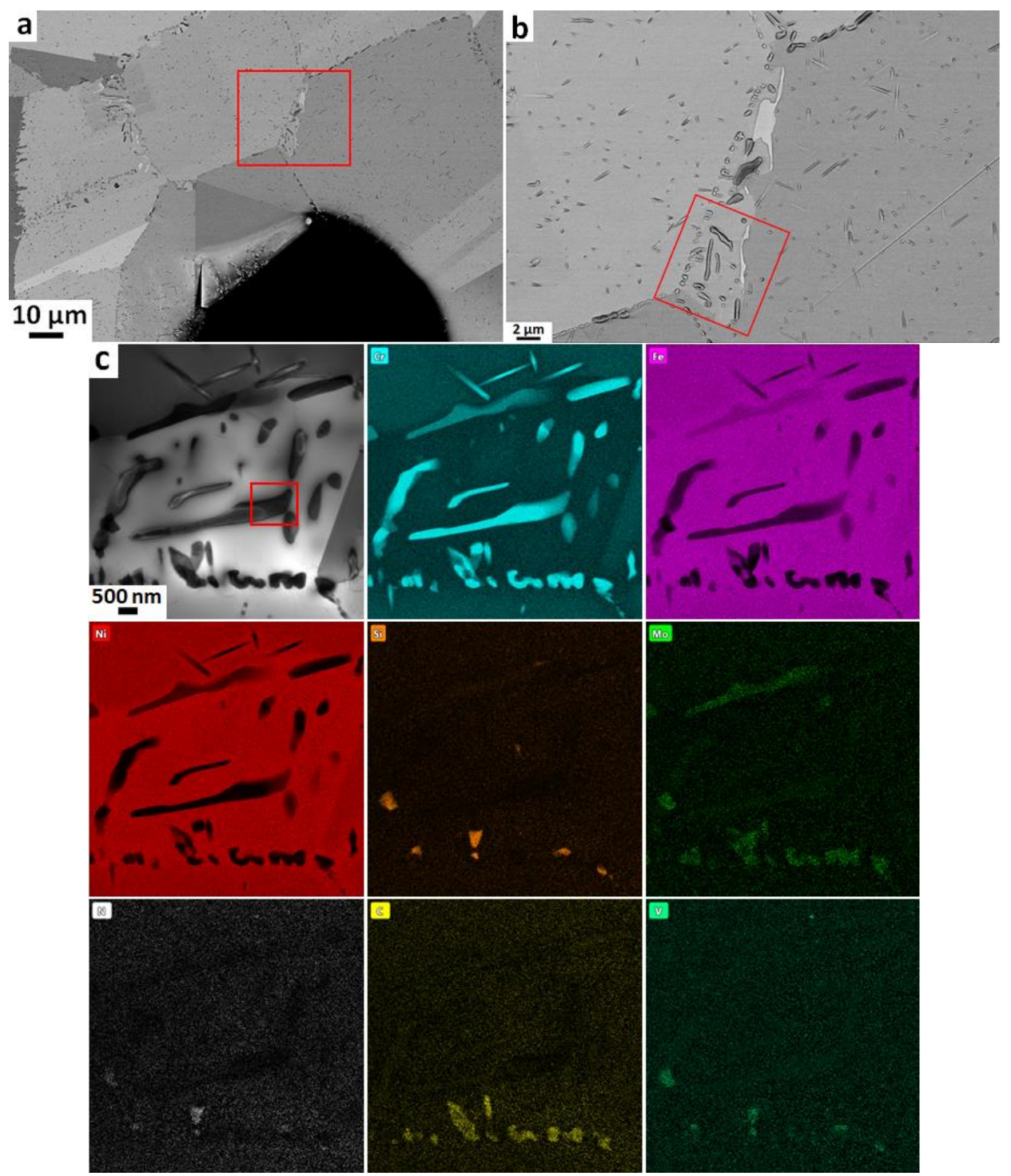

Figura 4.59 - (a) Imagem de MEV-BSE de uma amostra "thin-foil" de MET da Liga 33 envelhecida a $800^{\circ} \mathrm{C}$ por $20 \mathrm{~h}$; (b) Imagem de MEV-BSE mostrando uma colônia de PD obtida da região indicada pelo retângulo vermelho em (a); e (c) Imagem de STEM-BF obtida da região indicada pelo retângulo vermelho em (b) e os correspondentes mapas elementares obtidos por STEM/XEDS do $\mathrm{Cr}$, Fe, Ni, Si, Mo, N, C e V. O retângulo vermelho em (c) indica a região mostrada na Figura 4.61. 

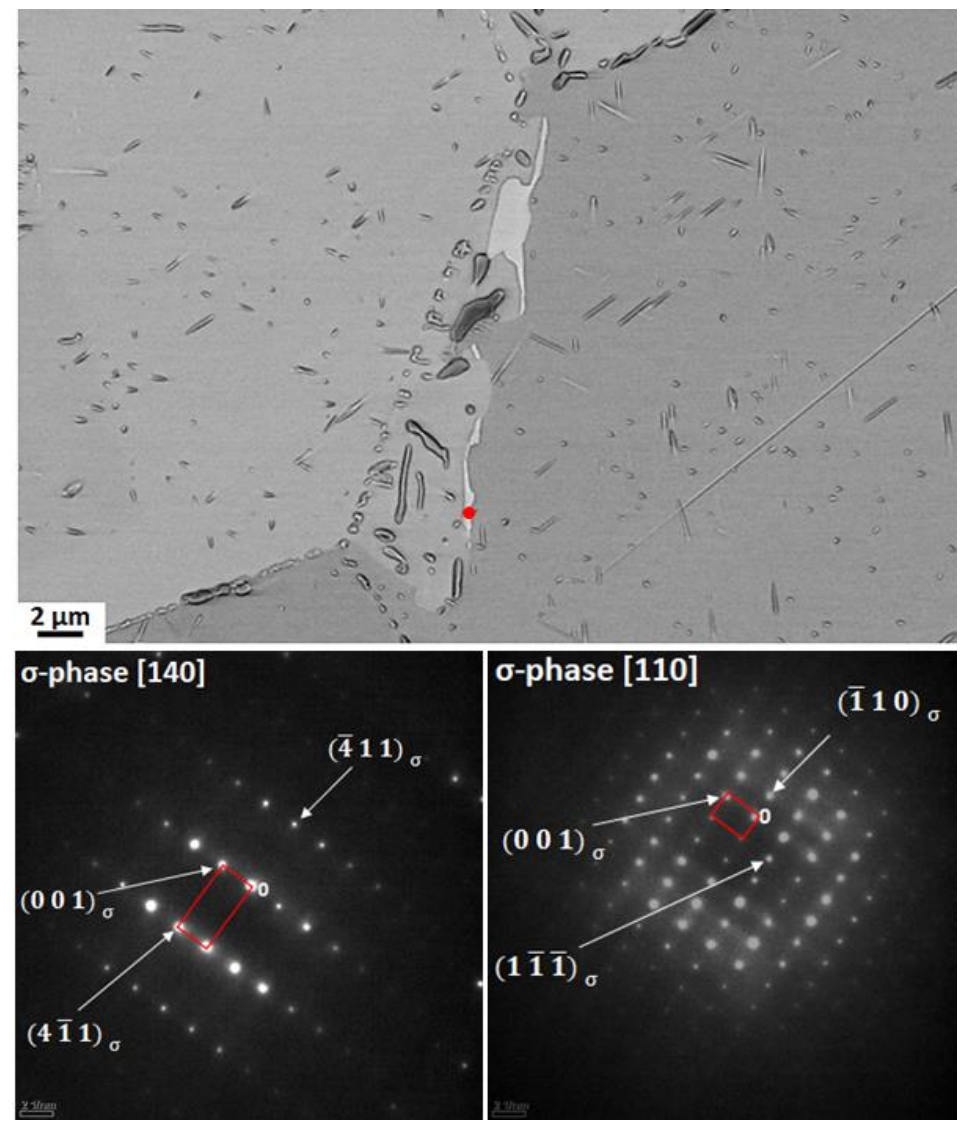

Figura 4.60 - (a) Imagem de MEV-BSE da mesma colônia de PD mostrada na Figura 4.59 e padrões SAED em dois diferentes eixos de zona, [140] e [110], obtidos da fase- $\sigma$ na frente de reação da PD indicada pelo círculo vermelho.
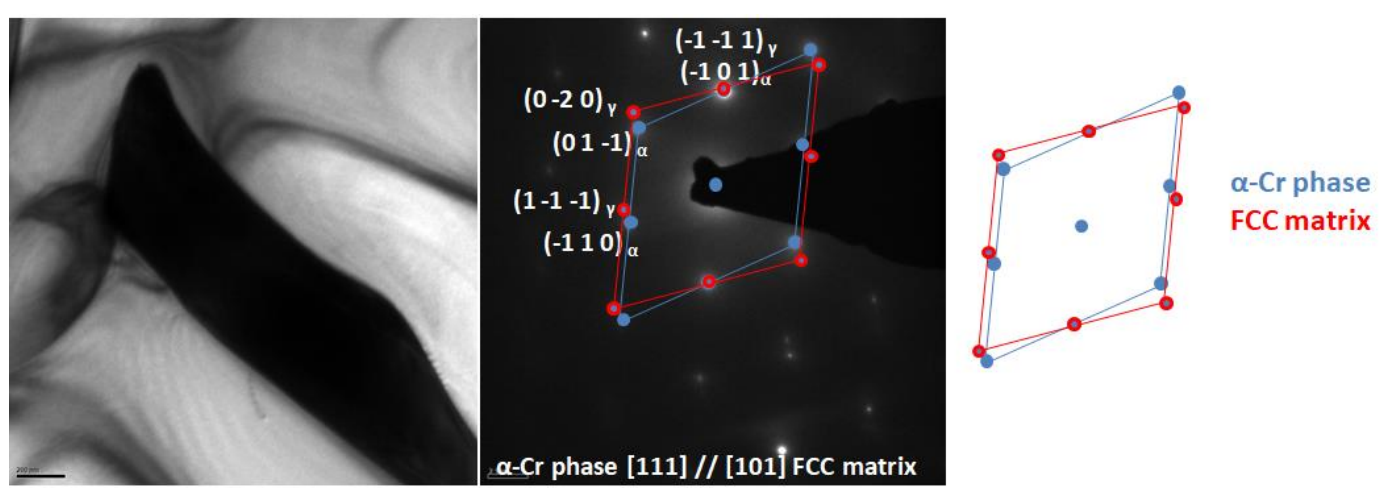

Figura 4.61 - (a) Imagem de MET-BF obtido da região indicada pelo quadrado vermelho na Figura $4.59 \mathrm{c}$ e o respectivo padrão SAED mostrando a R.O. K-S, $(\overline{1} 10)_{\alpha} / /$ $(\overline{1} \overline{1} 1)_{\text {matriz-CFC }} ;[111]_{\alpha} / /[101]_{\text {matriz-CFC }}$ entre a fase $\alpha-C r$ e a matriz CFC. 


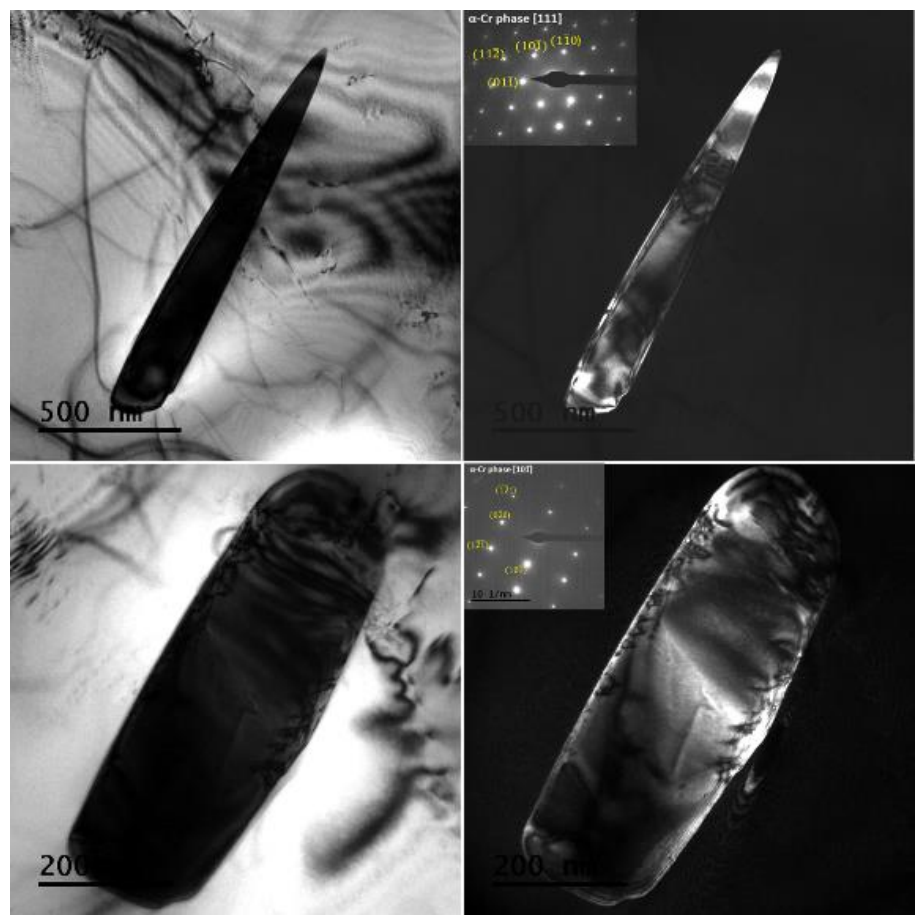

Figura 4.62 - Pares de imagens de MET-BF/CDF mostrando precipitados homogêneos na Liga 33 envelhecida a $800^{\circ} \mathrm{C}$ por $20 \mathrm{~h}$.

Baseado nas observações morfológicas juntamente com os resultados analíticos obtidos por STEM/XEDS e por difração de elétrons (SAED) mostrados nas Figuras 4.59 a 4.61, é possível fazer algumas afirmações em relação a esta específica colônia de PD:

- Como esperado, carbeto- $\mathrm{M}_{23} \mathrm{C}_{6}$ e a fase- $\eta$ foram observados na posição original do CG. A fase- $\eta$ também foi observada dentro da colônia de PD. Sua formação foi sempre verificada ocorrer associada ao carbeto no CG ou a fase $\alpha-\mathrm{Cr}$ dentro da colônia.

- Precipitado lamelar da fase- $\alpha$ rica em Cr foi observado ter a R.O. K-S, $(\overline{1} 10)_{\alpha} / /(\overline{1} \overline{1} 1)_{\text {matriz-CFC }} ;[111]_{\alpha} / /[101]_{\text {matriz-CFC }}$, com a matriz CFC.

- A fase intermetálica $\sigma$ enriquecida em Cr e Mo com estrutura tetragonal foi observada na frente de reação da PD na forma de uma longa plaqueta.

- A existência de quatro diferentes fases precipitadas foi confirmada constituir esta colônia de PD: (1) carbetos- $\mathrm{M}_{23} \mathrm{C}_{6}$ ricos em $\mathrm{Cr}$ (estrutura CFC); (2) fase- $\eta$ enriquecida em Si (estrutura cúbica-diamante); (3) fase- $\alpha$ rica em $\mathrm{Cr}$ (estrutura $\mathrm{CCC}$ ); (4) fase intermetálica $\sigma$ enriquecida em $\mathrm{Cr}$ e Mo (estrutura tetragonal). 


\section{Colônia 3}

A Figura 4.63 apresenta imagens de STEM-BF/HAADF de uma colônia de PD com morfologia lamelar clássica com os precipitados crescendo paralelos entre si. Tal morfologia desenvolvida pelo crescimento da colônia foi raramente observada no presente trabalho. Entretanto, como já mostrado anteriormente, a ocorrência de pequenos precipitados decorando o contorno original e precipitados lamelares que nuclearam adjacente ao CG e cresceram paralelos entre si atrás do contorno avançando foram verificados. Os resultados do mapeamento elementar obtido por STEM/XEDS confirmaram, a existência de quatro diferentes precipitados nesta região da colônia de PD mostrada na Figura 4.63: (1) carbetos$\mathrm{M}_{23} \mathrm{C}_{6}$ no CG original; (2) fase- $\eta$ também no CG original e dentro da colônia; (3) precipitados lamelares da fase $\alpha-C r$; e (4) fase intermetálica $\sigma$ na frente de reação da PD. Vale a pena mencionar que nesta colônia a fase- $\eta$ enriquecida em Si formou-se distribuída por toda a colônia de PD, mas sempre associada com o carbeto- $\mathrm{M}_{23} \mathrm{C}_{6}$ ou a fase $\alpha$ rica em $\mathrm{Cr}$.

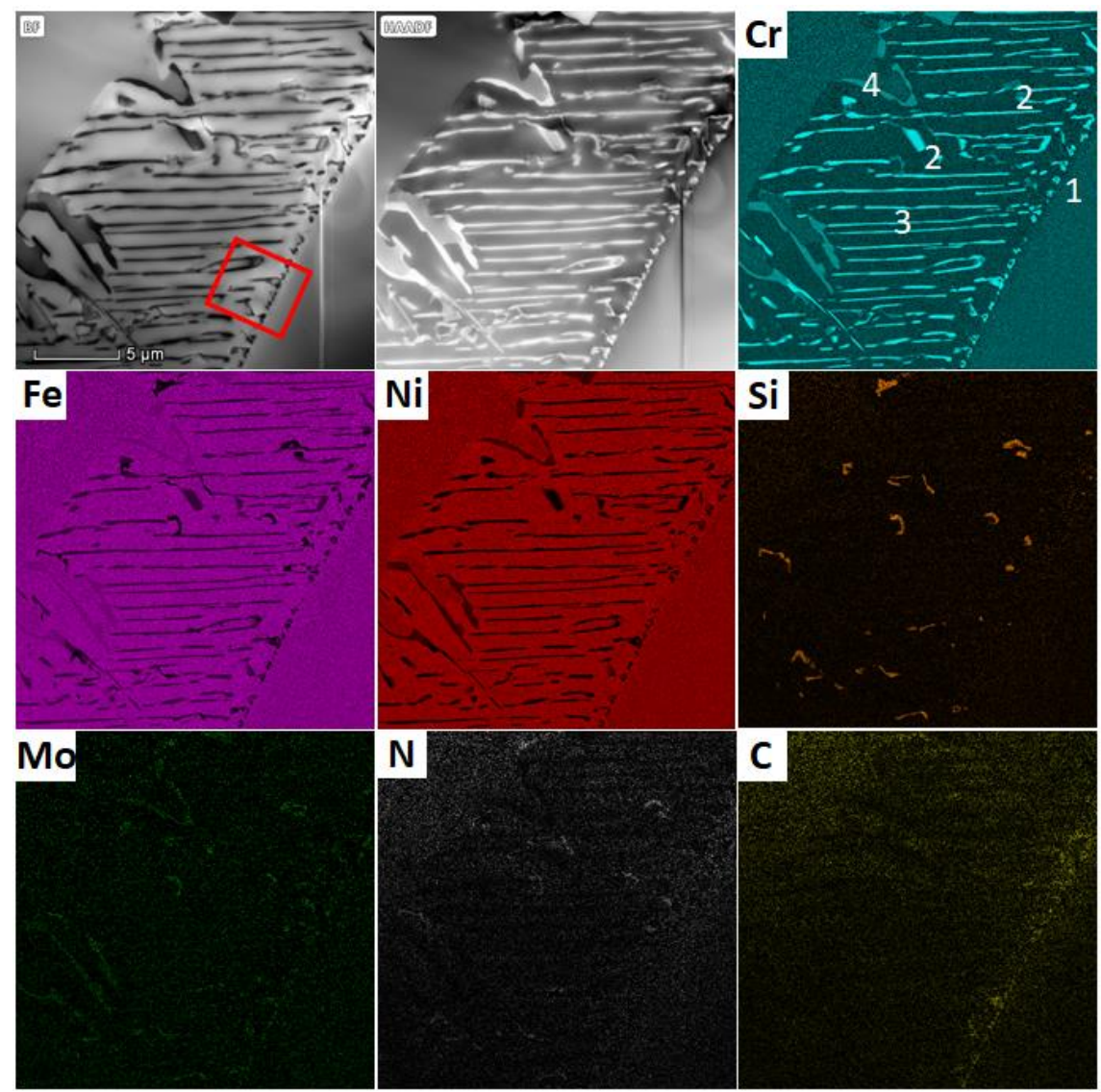

Figura 4.63 - Imagens de STEM-BF/HAADF de uma colônia de PD com morfologia clássica na Liga 33 envelhecida a $800{ }^{\circ} \mathrm{C}$ por $20 \mathrm{~h}$ e os correspondentes mapas elementares obtidos por STEM/XEDS do $\mathrm{Cr}, \mathrm{Fe}, \mathrm{Ni}, \mathrm{Si}, \mathrm{Mo}, \mathrm{N}$ e C. O retângulo vermelho indica a região mostrada na Figura 4.64. 
A Figura 4.64 mostra imagens de STEM-BF/HAADF obtidas da região indicada pelo quadrado vermelho na Figura 4.63. Nesta figura, pequenos precipitados na posição original do CG da colônia de PD foram observados, além de precipitados lamelares que nuclearam adjacentes ao CG. Os mapas elementares de STEM/XEDS mostrados nesta figura confirmaram a existência de três precipitados nesta região: carbetos- $\mathrm{M}_{23} \mathrm{C}_{6}$ e fase- $\eta$ na posição original do $\mathrm{CG}$, e lamelas da fase $\alpha$-Cr na região varrida pela frente de reação. Como verificado ao longo deste trabalho, e confirmado na Figura 4.64, a fase lamelar descontínua $\alpha$ Cr nucleou adjacente ao CG e cresceu atrás do contorno migrando. Outra confirmação realizada a partir da Figura 4.64 é a formação da fase- $\eta$ enriquecida em Si sempre associada ou com o carbeto- $\mathrm{M}_{23} \mathrm{C}_{6}$ na posição original do $\mathrm{CG}$ ou com a fase $\alpha$-Cr dentro da colônia. Na Figura 4.65 são apresentados três espectros obtidos por STEM/XEDS dos precipitados indicados pelos números 1, 2 e 3 na Figura 4.64. O espectro 1 foi obtido da fase- $\eta$, a qual era enriquecida em $\mathrm{Si}, \mathrm{Ni}$, $\mathrm{Cr}$, Mo e N, contendo Fe e V. O espectro 2 foi obtido das lamelas da fase $\alpha-\mathrm{Cr}$, as quais eram ricas em $\mathrm{Cr}$ contendo $\mathrm{Fe}$ e baixos teores de Mo e Ni. O espectro 3 foi obtido do carbeto- $\mathrm{M}_{23} \mathrm{C}_{6}$ no $\mathrm{CG}$, o qual era rico em $\mathrm{Cr}$ contendo $\mathrm{Mo}$, Ni, e Si. No espectro 3, foi observado que o pico de Si era um pouco maior que o observado em outros espectros obtidos a partir do carbeto- $\mathrm{M}_{23} \mathrm{C}_{6}$ em outros tempos de envelhecimento mostrados anteriormente neste trabalho. Mesmo assim, uma afirmação conclusiva sobre o elemento Si constituir o carbeto- $\mathrm{M}_{23} \mathrm{C}_{6}$ na Liga 33 somente pode ser realizada após uma investigação mais aprofundada. 


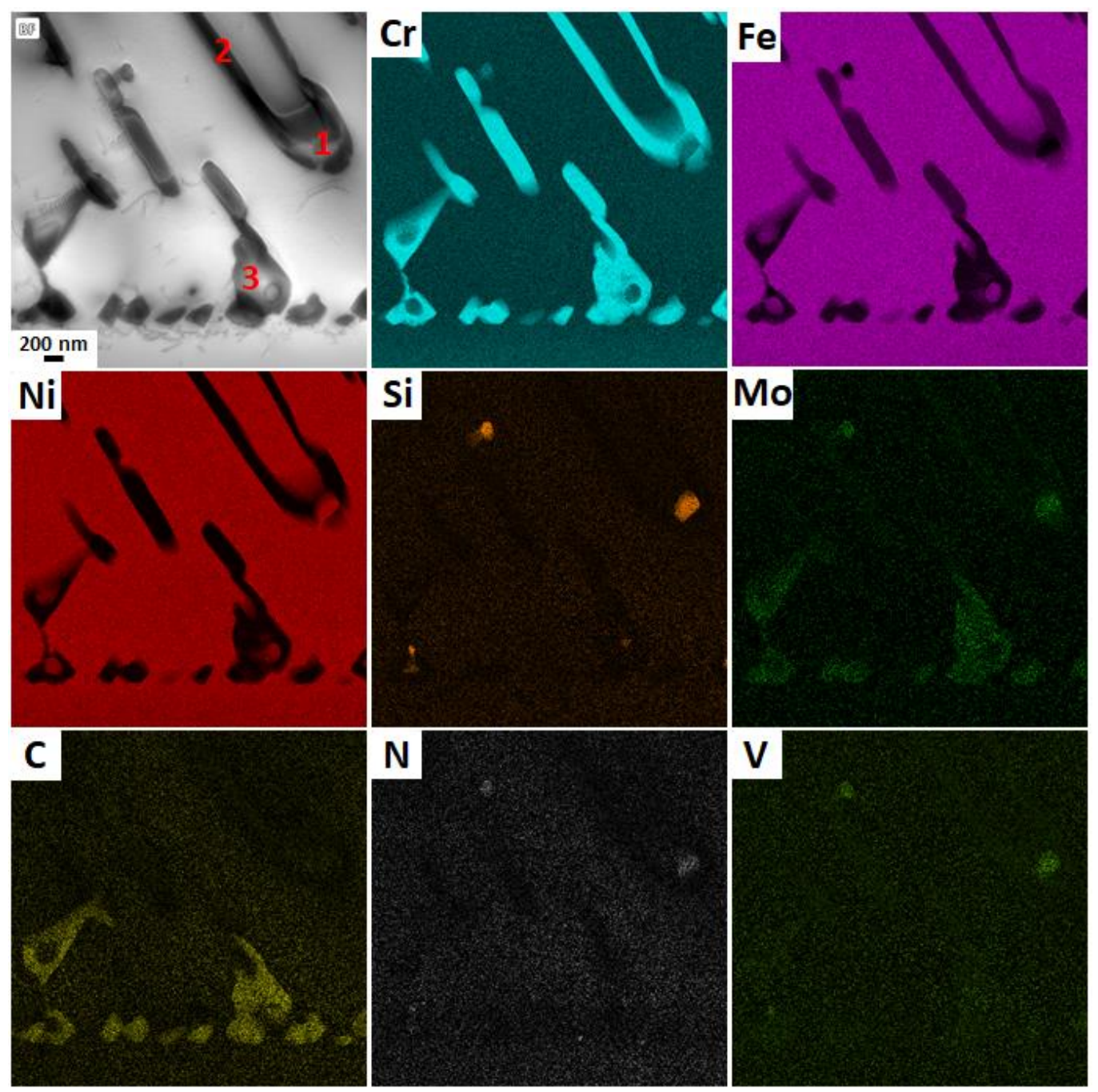

Figura 4.64 - Imagem de STEM-BF obtido da região indicada pelo quadrado vermelho na Figura 4.63 e os correspondentes mapas elementares obtidos por STEM/XEDS do $\mathrm{Cr}, \mathrm{Fe}, \mathrm{Ni}, \mathrm{Si}, \mathrm{Mo}, \mathrm{C}, \mathrm{N}$ e V. 


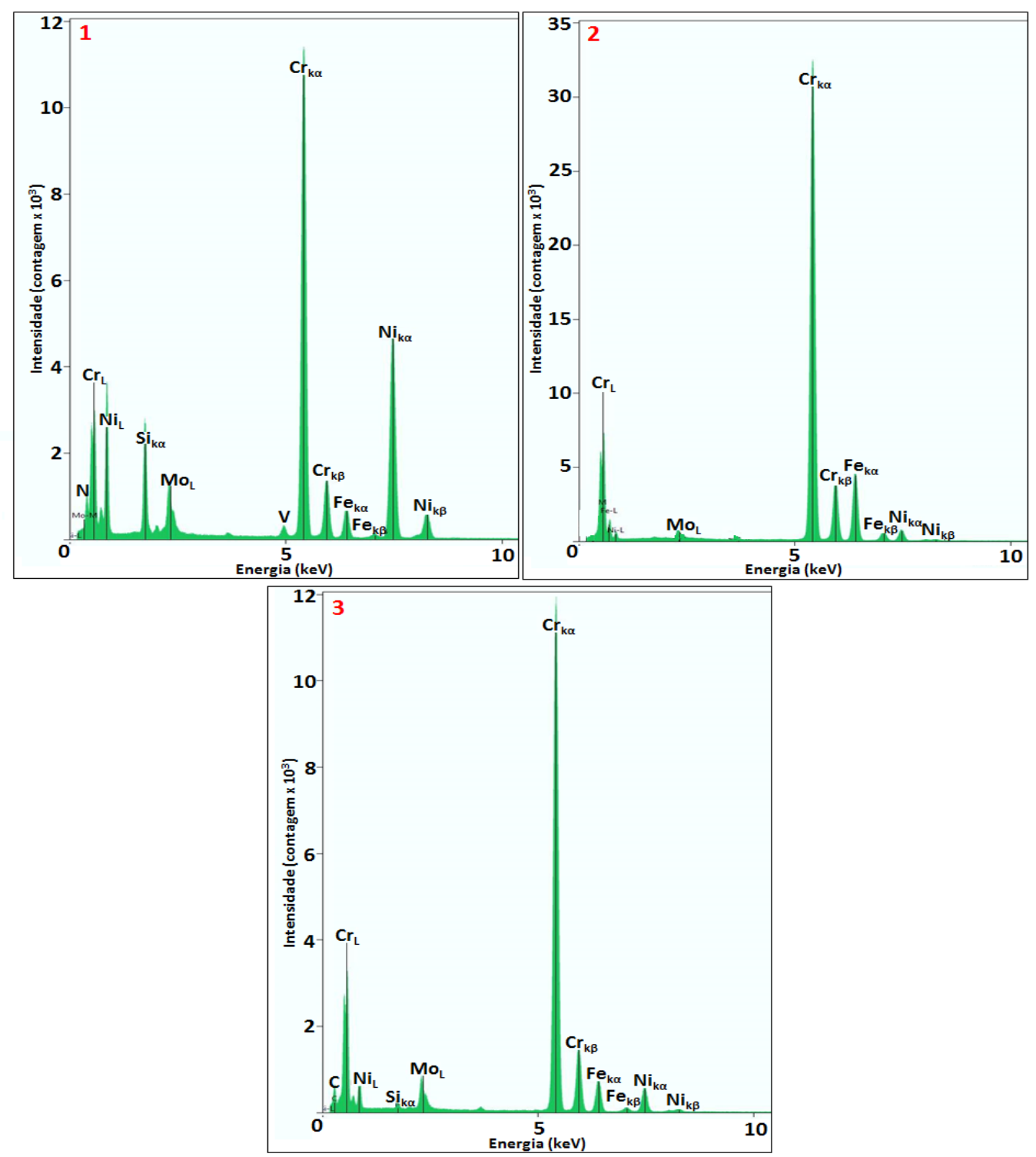

Figura 4.65 - Espectros pontuais obtidos por STEM/XEDS dos precipitados indicados pelos números 1, 2, e 3 na Figura 4.64. Espectro 1: Fase-n; Espectro 2: Fase $\alpha-\mathrm{Cr}$; Espectro 3: carbeto- $\mathrm{M}_{23} \mathrm{C}_{6}$.

A imagem de STEM-BF na Figura 4.66 ilustra outra região da mesma colônia de PD mostrada na Figura 4.63. Nesta figura, lamelas grosseiras da fase intermetálica $\sigma$ são observadas dentro da colônia, as quais estão conectadas com a frente de reação da PD. Pode ser sugerido que essa morfologia da fase- $\sigma$ ocorreu devido à sua nucleação na frente de reação e, com a continuação do movimento de migração do contorno, a fase- $\sigma$ cresceu acompanhando a frente de reação, desenvolvendo uma morfologia lamelar grosseira. A precipitação da fase intermetálica $\sigma$ já foi reportada por vários autores em $\mathrm{AI}$ austeníticos $\mathrm{CrMnN}$ em na frente de reação de colônias de PD constituídas tanto de nitretos- $\mathrm{M}_{2} \mathrm{~N}$ 
[4][9][144][148] como carbetos- $\mathrm{M}_{23} \mathrm{C}_{6}$ [52], além da observação próxima à colônias de nitretos- $\mathrm{M}_{2} \mathrm{~N}$ também em aços duplex [5].

A formação da fase intermetálica $\sigma$ foi explicada, por outros autores, devido à formação de zonas empobrecidas em $\mathrm{N}$ próximos aos nitretos- $\mathrm{M}_{2} \mathrm{~N}$, isso porque o $\mathrm{N}$ não tem solubilidade na fase intermetálica $\sigma$ [4]. Entretanto, a fase- $\sigma$ também foi observada nuclear em zonas empobrecidas em $\mathrm{C}$ formadas próximo a carbetos [4][86]. Esta última ideia foi suportada por Weiss e Stickler [70] que afirmaram que a formação da fase- $\sigma$ foi atrasada com o aumento no teor de $\mathrm{C}$ em solução sólida em um AI austenítico tipo-316. Assim, se um alto teor de C e N inibe a precipitação da fase intermetálica $\sigma$, a nucleação de carbetos e nitretos, a qual tende a criar zonas empobrecidas de $\mathrm{C}$ ou $\mathrm{N}$ ao redor da fase nucleada (carbeto ou nitreto), pode levar a posterior nucleação da fase- $\sigma$, contanto que o teor de Cr seja mantido alto suficiente para sua formação [243]. Além do papel dos elementos intersticiais mencionados acima ( $\mathrm{N}$ e $\mathrm{C}$ ), a difusão do $\mathrm{Cr}$ é vista como um dos fatores que controlam a precipitação da fase intermetálica $\sigma$, já que a mesma é enriquecida em Cr [59][243]. Além do elemento $\mathrm{Cr}$, os elementos Mo [70][244] e Si [142][152] são considerados desempenhar um importante papel para promover a nucleação da fase- $\sigma$.

Os mapas elementares obtidos por STEM/XEDS mostrados na Figura 4.66 confirmaram a existência de zonas empobrecidas em $\mathrm{Cr}$ e enriquecidas em Fe e $\mathrm{Ni}$ na região varrida pelo contorno, além da existência de quatro diferentes fases precipitadas nesta região da colônia de PD: (1) precipitados lamelares e nodulares da fase- $\alpha$ rica em Cr; (2) fase intermetálica $\sigma$; (3) fase- $\eta$ tanto dentro da colônia como na frente de reação; e (4) uma outra fase precipitada enriquecida em $\mathrm{Cr}, \mathrm{N}$ e $\mathrm{V}$ tanto na frente de reação como dentro da colônia de PD (indicadas pelas setas no mapa do elemento $\mathrm{N}$ na Figura 4.66), sugerindo a formação de outro tipo de nitreto dentro da colônia de PD na Liga 33 envelhecida a $800{ }^{\circ} \mathrm{C}$. A Figura 4.65 b apresenta dois espectros obtidos por STEM/XEDS dos precipitados indicados pelos número 1 e 2 na Figura 4.65a. $\mathrm{O}$ espectro 1 foi obtido da fase precipitada indicada pelo número 1 na Figura 4.65a, a qual era rica em $\mathrm{Cr}$ contendo N, Fe, Ni e baixos teores de V e Mo, confirmando a formação de um nitreto de cromo dentro da colônia de PD. O espectro 2 foi obtido da fase intermetálica $\sigma$ indicada pelo número 2, a qual era enriquecida em $\mathrm{Cr}$, Mo e Fe contendo Ni e Si. 

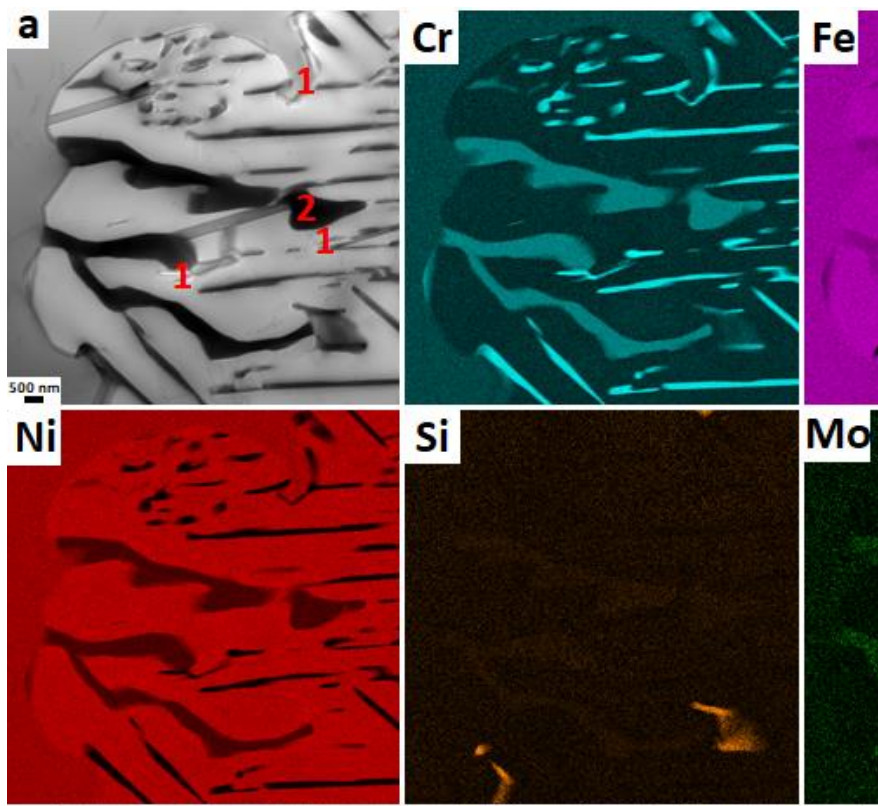

$\mathrm{Si}$

Mo

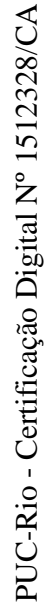
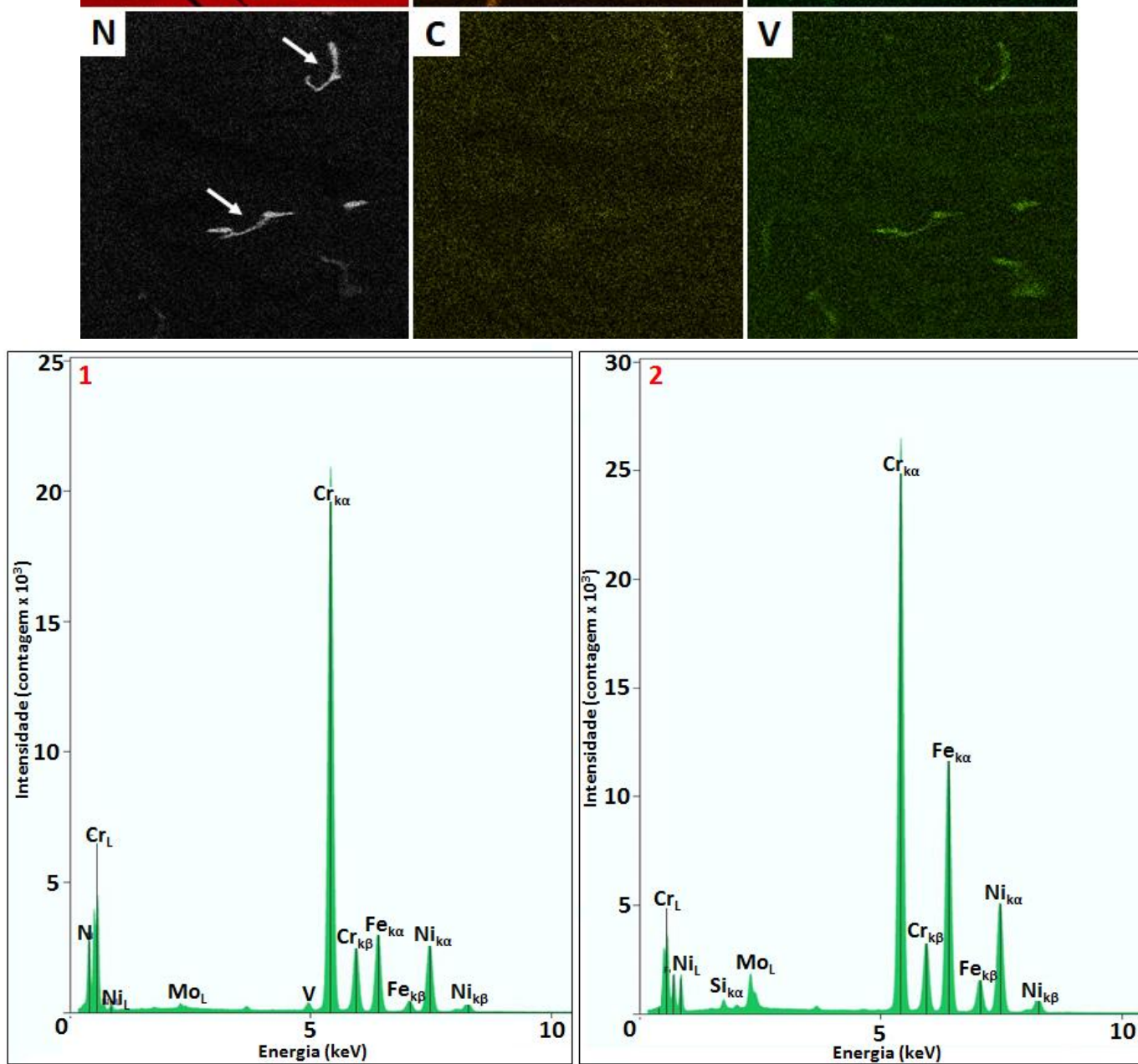

Figura 4.66 - (a) Imagem de STEM-BF obtida da mesma colônia de PD mostrada na Figura 4.63 e os correspondentes mapas elementares de STEM/XEDS do $\mathrm{Cr}, \mathrm{Fe}, \mathrm{Ni}, \mathrm{Si}$, Mo, $\mathrm{C}, \mathrm{N}$ e $\mathrm{V}$ e (b) Espectros pontuais obtidos por STEM/XEDS dos precipitados indicados pelos números 1 e 2 em (a). As setas indicam nitretos ricos em $\mathrm{Cr}$ formados dentro da colônia de PD. 
Como mostrado na Figura 4.66, um outro tipo de nitreto (além da fase- $\eta$ ) foi observado precipitar próximo à fase intermetálica $\sigma$. Zhang et al. [55] observaram a formação de nitretos- $\mathrm{M}_{2} \mathrm{~N}$ na frente de reação da $\mathrm{PD}$ constituída da fase- $\sigma$ e também nas interfaces $\sigma /$ matriz CFC após 6 horas de envelhecimento a $900{ }^{\circ} \mathrm{C}$. Foi sugerido pelos autores que devido a um enriquecimento em $\mathrm{N}$ nas regiões adjacentes à fase- $\sigma$ juntamente com a difusão de $\mathrm{Cr}$, a nucleação do nitreto- $\mathrm{M}_{2} \mathrm{~N}$ foi favorecida. Devido à região da amostra analisada para a obtenção dos resultados apresentados nas Figuras 4.63 até 4.66 não estar fina suficiente para a obtenção de padrões SAED, a identificação completa do nitreto formado também dentro desta colônia de PD não foi realizada. Entretanto, como será apresentado nos resultados obtidos na Liga 33 envelhecida a $800{ }^{\circ} \mathrm{C}$ por $100 \mathrm{~h}$ (item 4.4.3), o nitreto observado dentro da colônia de PD após o envelhecimento da Liga 33 a $800{ }^{\circ} \mathrm{C}$ por $20 \mathrm{~h}$ foi identificado por padrões SAED como o nitreto$\mathrm{M}_{2} \mathrm{~N}$ rico em $\mathrm{Cr}$.

$\mathrm{Na}$ Figura 4.67a, é apresentada uma imagem de MET-BF de uma fase intermetálica $\sigma$ observada na mesma colônia de PD mostrada na Figura 4.63 e os respectivos padrões de difração obtidos da matriz CFC (Figura 4.67b), fase intermetálica $\sigma$ com estrutura tetragonal (Figura 4.67c) no eixo de zona [110] e da interface matriz/fase- $\sigma$ (Figura 4.67d) mostrando a R.O. $[101]_{\gamma} / /[110]_{\sigma}$ entre a matriz CFC e a fase- $\sigma$, a qual também foi reportada por outros autores [54] [55][160]. 
a

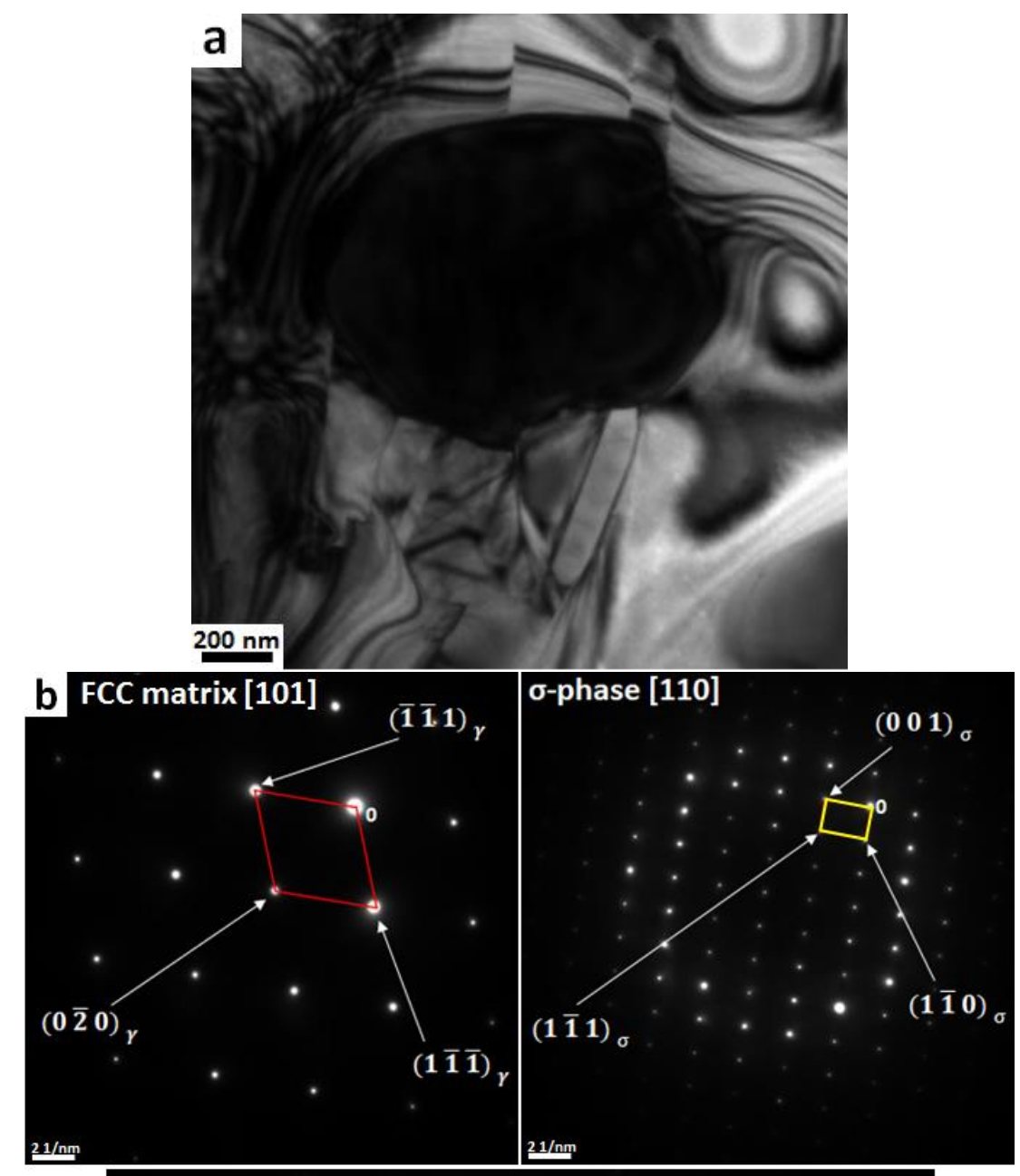

FCC matrix [101] // $\sigma$-phase [110]

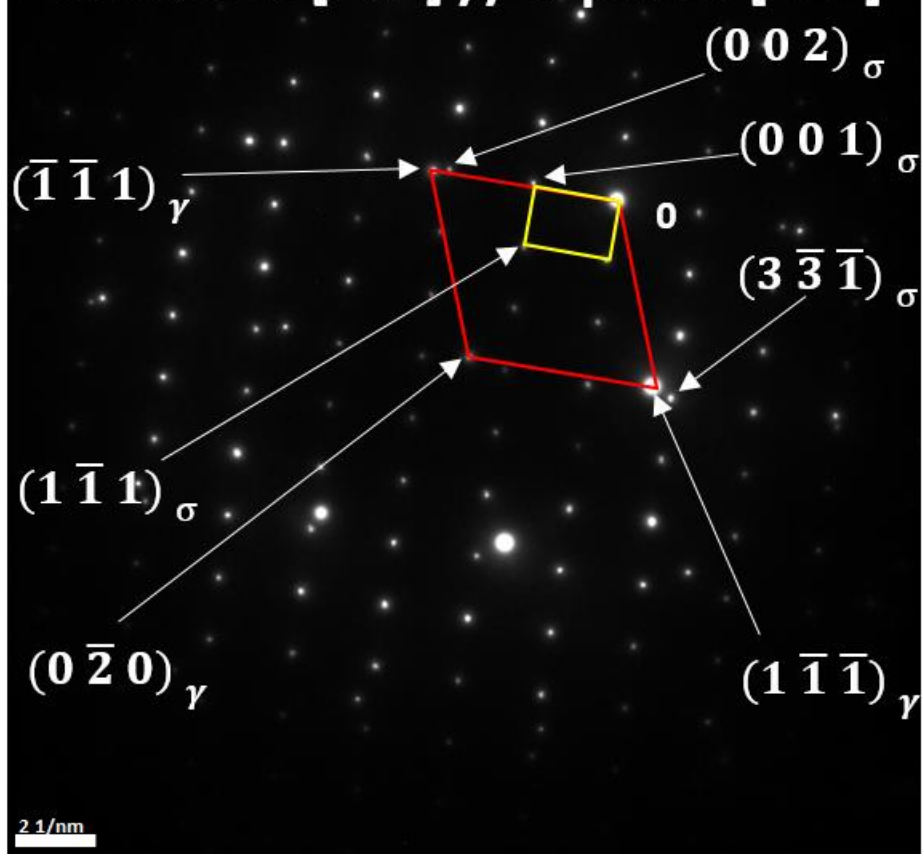

Figura 4.67 - (a) Imagem de MET-BF da fase intermetálica $\sigma$ na Liga 33 envelhecida a $800^{\circ} \mathrm{C}$ por $20 \mathrm{~h}$ e (b) padrões SAED obtidos, respectivamente, da matriz CFC, fase- $\sigma$ com estrutura tetragonal e da interface matriz CFC/fase- $\sigma$ mostrando a R.O. [101] $/ /$ $[110]_{\sigma}$. O losango vermelho é referente à matriz-CFC e o retângulo amarelo é referente à fase- $\sigma$. 
Os resultados obtidos por MET e STEM/XEDS permitem fazer algumas afirmações em relação a colônia de PD número 3:

- Carbetos- $\mathrm{M}_{23} \mathrm{C}_{6}$ e fase- $\eta$ enriquecida em $\mathrm{Si}$ foram observadas no CG original da colônia. Na região do contorno, a fase- $\eta$ nucleou associada ao carbeto e dentro da colônia associada à fase lamelar $\alpha-\mathrm{Cr}$, além da observação também da fase- $\eta$ na frente de reação da PD.

- Precipitados lamelares grosseiros da fase intermetálica $\sigma$ com estrutura tetragonal foram observados na frente de reação e também dentro da colônia. Foi verificado a R.O. [101] $]_{\text {matriz-CFC }} / /[110]_{\sigma}$ entre a fase- $\sigma$ e a matriz CFC.

- Um tipo de nitreto rico em Cr foi verificado tanto dentro da colônia como na frente de reação da PD.

- Em resumo, cinco diferentes fases precipitadas foram confirmadas constituir a mesma colônia de PD nesta condição de envelhecimento: (1) carbetos- $\mathrm{M}_{23} \mathrm{C}_{6}$ (estrutura $\mathrm{CFC}$ ); (2) fase- $\eta$ enriquecida em Si (estrutura cúbica-diamante); (3) precipitados lamelares da fase $\alpha-\mathrm{Cr}$ (estrutura CCC); (4) fase intermetálica $\sigma$ (estrutura tetragonal); e (5) nitreto rico em $\mathrm{Cr}$.

A Figura 4.68 mostra o produto da precipitação resultante do envelhecimento a $800{ }^{\circ} \mathrm{C}$ por $20 \mathrm{~h}$ em uma macla (confirmada pelos padrões SAED na Figura 4.68) na Liga 33. Nesta figura é verificada a existência de precipitados em forma de plaquetas nos contornos incoerentes desta macla. $\mathrm{O}$ resultado do mapeamento obtido por STEM/XEDS da região indicada pelo quadrado vermelho na Figura 4.68a confirma a existência de dois diferentes tipos de precipitados, já identificados em CG no presente trabalho, carbetos- $\mathrm{M}_{23} \mathrm{C}_{6}$ ricos em $\mathrm{Cr}$ e a fase- $\eta$ enriquecida em $\mathrm{Si}$. A formação de carbetos- $\mathrm{M}_{23} \mathrm{C}_{6} \mathrm{com}$ morfologia de plaquetas já foi extensivamente reportada ocorrer em contornos incoerentes de macla [1][2][53][65][66][70][74][76][80][90], entretanto a ocorrência da fase- $\eta$ em tais contornos tem sido pouco reportada. Os resultados mostrados na Figura 4.68 confirmam que a fase- $\eta$ enriquecida em Si precipita associada ao carbeto- $\mathrm{M}_{23} \mathrm{C}_{6}$, também em contornos incoerentes de macla na Liga 33 envelhecida a $800{ }^{\circ} \mathrm{C}$ por $20 \mathrm{~h}$. 


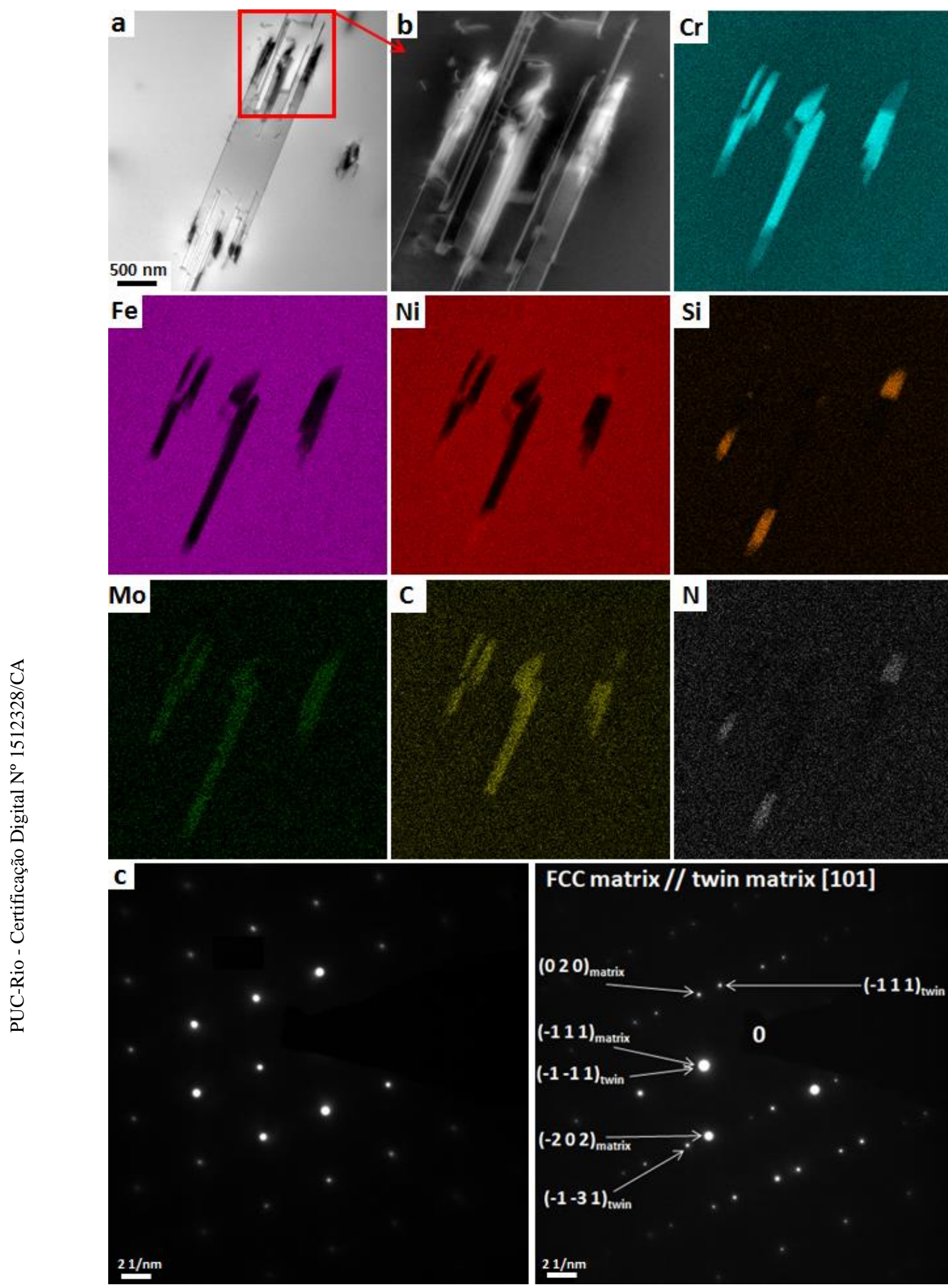

Figura 4.68 - (a) Imagem de STEM-BF mostrando precipitados com morfologia de plaquetas nos contornos incoerentes de macla na Liga 33 envelhecida a $800^{\circ} \mathrm{C}$ por $20 \mathrm{~h}$; (b) imagem de STEM-HAADF obtida da região indicada pelo quadrado em (a) e os correspondentes mapeamentos elementares do $\mathrm{Cr}, \mathrm{Fe}, \mathrm{Ni}, \mathrm{Si}, \mathrm{Mo}, \mathrm{C}$ e N confirmando a existência de carbetos $-\mathrm{M}_{23} \mathrm{C}_{6}$ e fase- $\eta$ e (c) os padrões de difração SAED da matriz e da interface matriz/macla. 


\subsubsection{Precipitação no envelhecimento por $50 \mathrm{~h}$ e $100 \mathrm{~h}$}

Como já mencionado anteriormente (item 4.3), os resultados encontrados por MEV na Liga 33 envelhecida a $800{ }^{\circ} \mathrm{C}$ por $50 \mathrm{~h}$ não mostraram diferenças em relação às fases que constituem a colônia de PD resultante do envelhecimento a $800{ }^{\circ} \mathrm{C}$ por $20 \mathrm{~h}$. Quando amostras envelhecidas a $800{ }^{\circ} \mathrm{C}$ por $50 \mathrm{~h}$ foram analisadas no MET, os resultados mostraram as mesmas fases identificadas após $20 \mathrm{~h}$ de envelhecimento: carbeto- $\mathrm{M}_{23} \mathrm{C}_{6}$, fase- $\eta$, fase $\alpha-\mathrm{Cr}$ e fase- $\sigma$. Assim, os resultados obtidos das amostras da Liga 33 envelhecida a $800{ }^{\circ} \mathrm{C}$ por 50 h não são mostrados neste trabalho.

Quando o tempo de envelhecimento da Liga 33 foi aumentado de 50 para $100 \mathrm{~h}$, foi confirmada a formação de outro tipo de nitreto, além da fase- $\eta$, como já mostrado na Figura 4.66. A Figura 4.69a apresenta uma imagem de STEM-BF da Liga 33 envelhecida a $800{ }^{\circ} \mathrm{C}$ por $100 \mathrm{~h}$ mostrando parte de uma colônia de PD constituída de precipitados com diferentes morfologias e direções de crescimento. Nesta colônia, a frente de reação é bastante irregular (característica frequentemente observada neste trabalho). Além da colônia de PD, precipitados com morfologias de plaquetas e partículas foram observados dentro da matriz CFC não-transformada. As imagens STEM-BF/HAADF da Figura 4.69b juntamente com os mapas elementares de STEM/XEDS foram obtidas da região indicada pelo quadrado vermelho na Figura 4.69a. Tais mapas confirmaram a existência de três diferentes precipitados nesta região da colônia de PD: (1) fase intermetálica $\sigma$ enriquecida em $\mathrm{Cr}$ e Mo; (2) nitreto- $\mathrm{M}_{2} \mathrm{~N}$ rico em $\mathrm{Cr}$ com estrutura hexagonal, o qual foi identificado por padrões SAED (Figura 4.70); e (3) precipitados da fase- $\alpha$ ricos em Cr. A Figura 4.71 mostra a mesma imagem da Figura $4.69 \mathrm{~b}$ e três espectros pontuais obtidos por STEM/XEDS dos precipitados indicados pelos números 1,2 e 3 . O espectro 1 foi obtido da fase intermetálica $\sigma$ enriquecida em $\mathrm{Cr}$, Fe e Mo contendo Ni e baixos níveis de Si. O espectro 2 foi obtido do nitreto- $\mathrm{M}_{2} \mathrm{~N}$ rico em $\mathrm{Cr}$ contendo $\mathrm{N}$ e baixos níveis de Mo. Neste espectro é verificado que os picos dos elementos Fe e Mo são muito pequenos, podendo ser provenientes da matriz ao redor do precipitado. O espectro 3 foi obtido da fase- $\alpha$ rica em $\mathrm{Cr}$ contendo Fe e baixos níveis de Mo e Ni. Os resultados obtidos pelas análises pontuais de XEDS corroboram os resultados do mapeamento elementar mostrado na Figura 4.69b. 

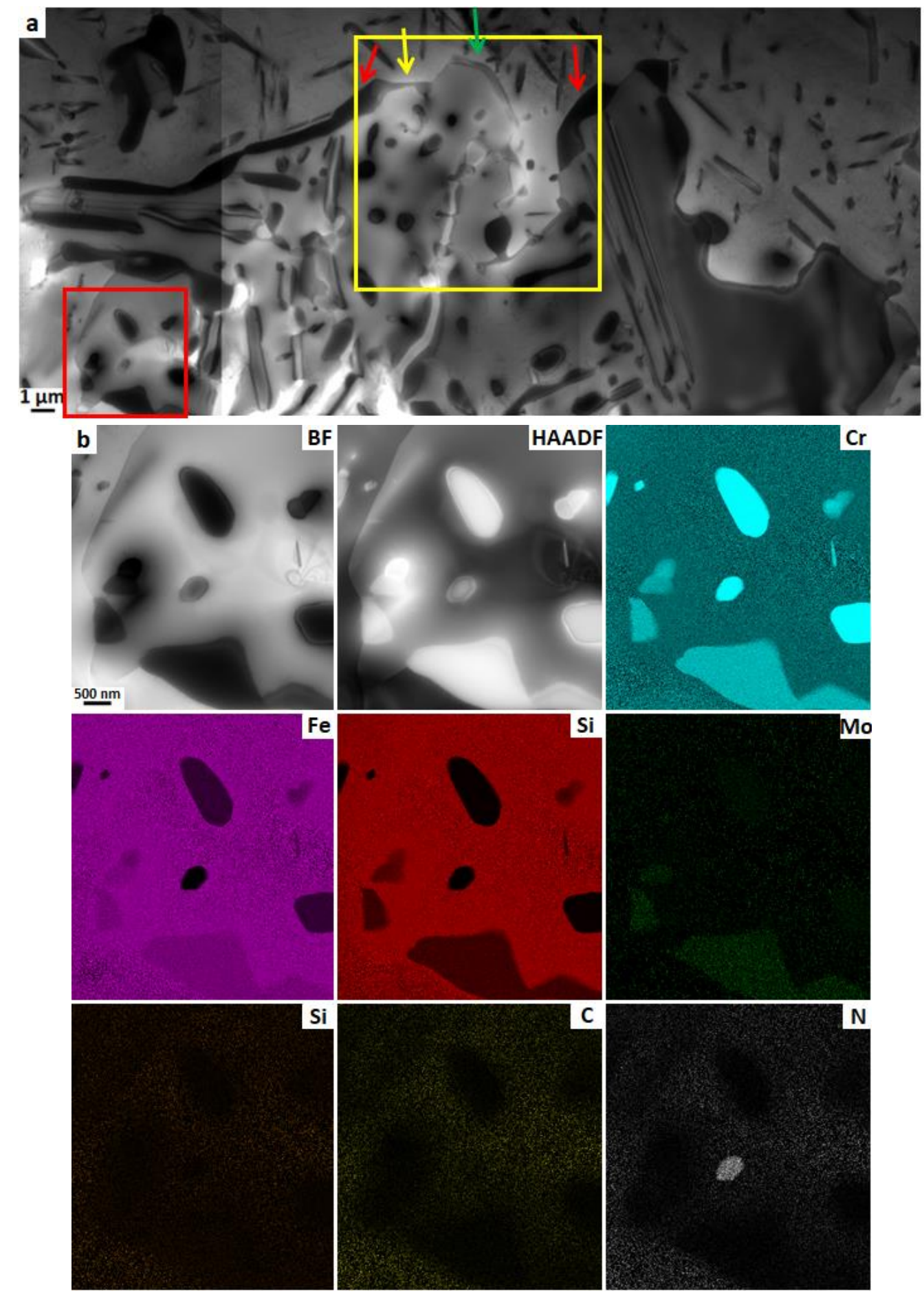

Figura 4.69 - (a) Imagem de STEM-BF de uma colônia de PD na Liga 33 envelhecida a $800{ }^{\circ} \mathrm{C}$ por $100 \mathrm{~h}$ e (b) imagens de STEM-BF/HAADF obtidas da região indicada pelo quadrado vermelho em (a) e os correspondentes mapas elementares de STEM/XEDS do $\mathrm{Cr}, \mathrm{Fe}, \mathrm{Ni}, \mathrm{Mo}, \mathrm{Si}, \mathrm{N}$ e C. As setas indicam três diferentes fases precipitadas na frente de reação da PD. O quadrado amarelo indica a região mostrada na Figura 4.72 

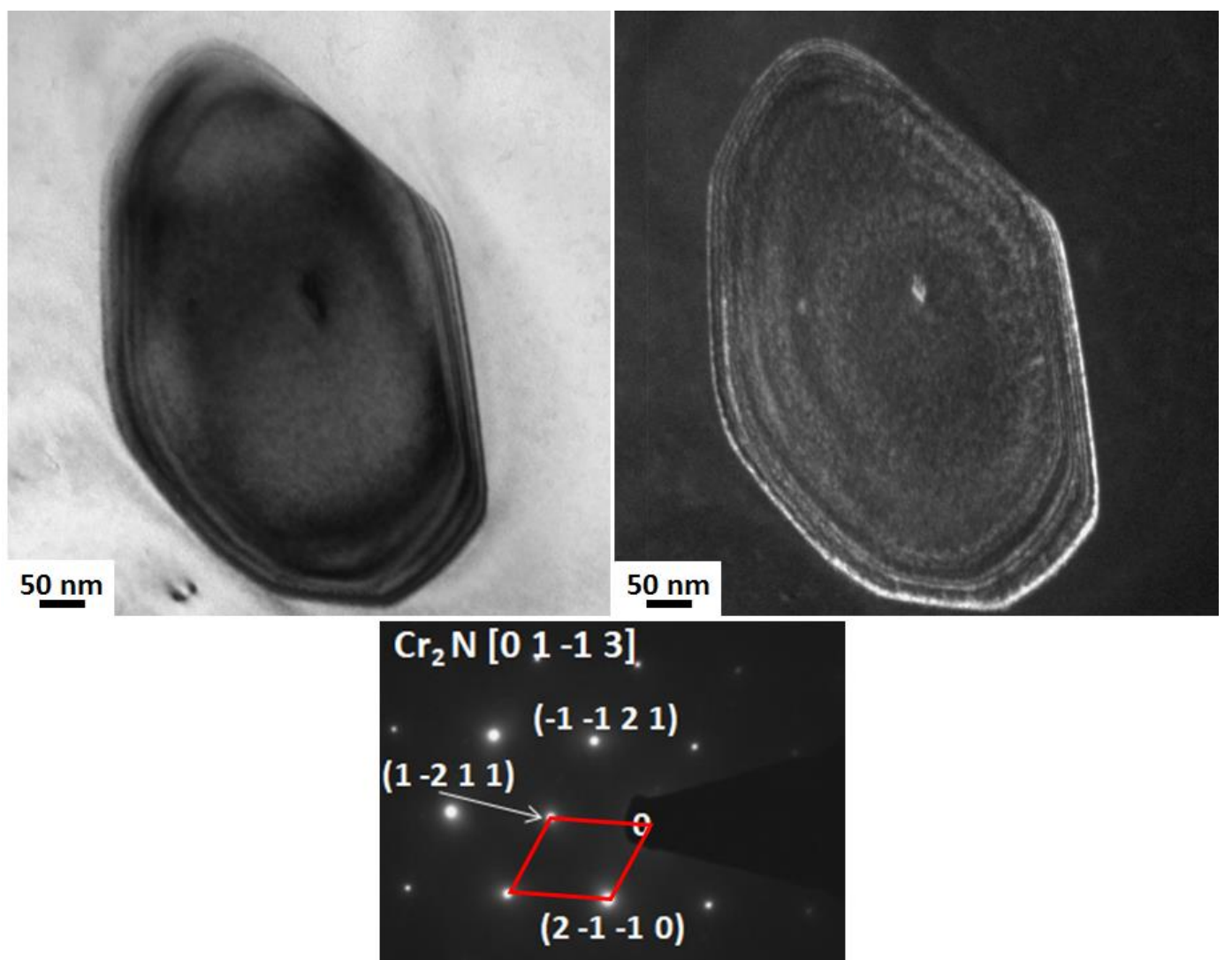

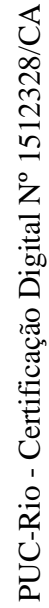

Figura 4.70 - Imagens de MET-BF/CDF do nitreto- $\mathrm{M}_{2} \mathrm{~N}$ rico em $\mathrm{Cr}$ mostrado na Figura $4.69 \mathrm{~b}$ e o respectivo padrão SAED no eixo de zona [ $\left[\begin{array}{lll}0 & 1 & \overline{1}\end{array}\right]$. 


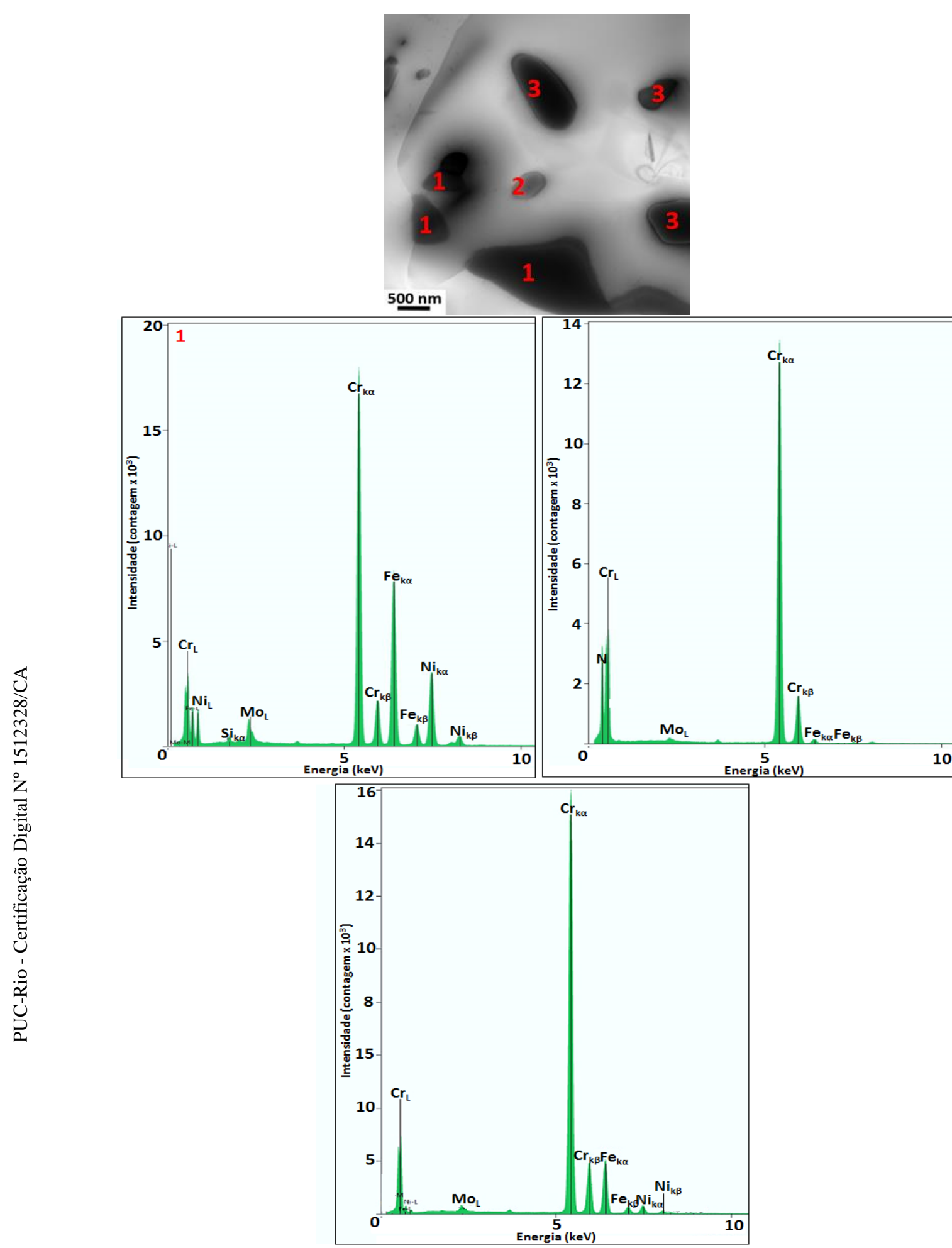

Figura 4.71 - Imagem de STEM-BF da mesma região mostrada na Figura 4.69b e três espectros pontuais obtidos por STEM/XEDS dos precipitados indicados pelos números 1 , 2, e 3. Precipitado $n^{\circ} 1$ : fase- $\sigma$; precipitado $n^{\circ} 2$ : nitreto- $-M_{2} N$; precipitado $n^{\circ} 3$ : fase $\alpha-$ Cr. 
A imagem de STEM-BF na Figura 4.73 foi obtida de região indicada pelo quadrado amarelo na colônia mostrada na Figura 4.69a. Os resultados obtidos pelo mapeamento por STEM/XEDS confirma quatro diferentes fases precipitadas nesta região da colônia de PD: (1) fase intermetálica $\sigma$ enriquecida em $\mathrm{Cr}$ e Mo (indicadas pelas setas vermelhas nas Figuras 4.69 e 4.72); (2) nitreto- $\mathrm{M}_{2} \mathrm{~N}$ rico em $\mathrm{Cr}$ (indicado pelas setas verdes nas Figuras 4.69 e 4.72); (3) precipitado da fase- $\alpha$ rico em Cr (indicado pelas setas brancas na Figura 4.72); e (4) fase- $\eta$ enriquecida em Si (indicadas pelas setas amarelas nas Figuras 4.69 e 4.72). Interessante notar que nesta colônia de PD, três diferentes fases nuclearam e cresceram como plaquetas na frente de reação da PD, estas fases estão indicadas pelas setas na Figura 4.69: fase intermetálica $\sigma$ (seta vermelha), nitreto- $\mathrm{M}_{2} \mathrm{~N}$ (seta verde) e fase$\eta$ (seta amarela). Algumas destas fases parecem terem nucleado em associação com outra fase formada também na frente de reação, como pode ser verificado na Figura 4.77 que mostra a fase- $\eta$, indicada pela seta amarela na Figura 4.72, associada com a fase intermetálica $\sigma$, ambas na frente de reação da PD. É verificado que as três fases nucleadas na frente de reação cresceram tornando-se plaquetas, podendo ser sugerido que esse tipo de morfologia ocorre pois ao nuclear na frente de reação, o precipitado provavelmente forma uma interface coerente/semi-coerente tanto com a matriz supersaturada à frente do contorno migrando como com a matriz empobrecida. Tal interface dificulta o crescimento do precipitado como uma lamela crescendo em direção da matriz nãotransformada. Este tipo de precipitação pode prejudicar a migração da frente de reação devido a fixação do contorno pelo precipitado. Porém, com a continuação do processo de envelhecimento, o precipitado tende a crescer formando uma lamela na frente de reação. Esse comportamento observado na Figura 4.70a no que se refere ao crescimento das fases formadas na frente de reação é diferente daquele observado na Figura $4.66 \mathrm{com}$ a fase intermetálica $\sigma$, a qual cresceu como uma lamela acompanhando a migração do contorno.

Como mostrado anteriormente neste trabalho e também na colônia da Figura 4.69, o nitreto- $\mathrm{M}_{2} \mathrm{~N}$ nucleou e cresceu tanto na frente de reação da PD como dentro da colônia. Foi observado também nos mapas elementares obtidos por STEM/XEDS da Figura 4.72 que ambos os nitretos encontrados neste trabalho, fase- $\eta$ e nitreto- $\mathrm{M}_{2} \mathrm{~N}$, continham o elemento $\mathrm{V}$ em suas composições químicas. Porém, como observado na Figura 4.72, parece que o elemento V está 
presente em maior concentração na fase- $\eta$ quando comparado com o nitreto- $\mathrm{M}_{2} \mathrm{~N}$. A Figura 4.73 mostra um par de imagens de MET-BF/CDF obtidas do nitreto$\mathrm{M}_{2} \mathrm{~N}$ indicado pela seta azul no mapa elementar do $\mathrm{N}$ na Figura 4.72 e o respectivo padrão SAED no eixo de zona [ $\left[\begin{array}{llll}0 & 1 & \overline{1} & 0\end{array}\right]$.

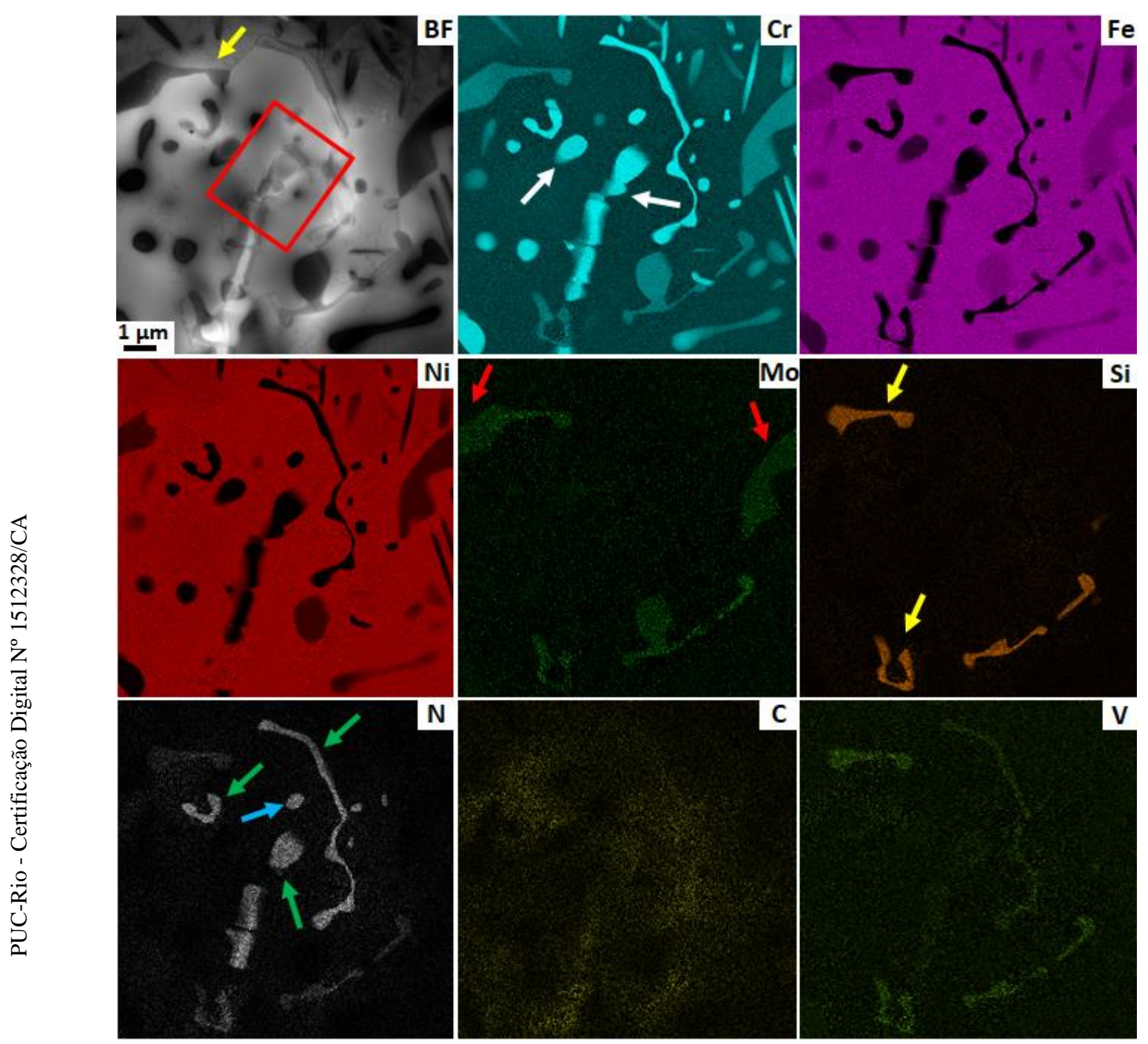

Figura 4.72 - Imagens de STEM-BF/HAADF obtidas da região indicada pelo quadrado amarelo na Figura 4.69 e os correspondentes mapas elementares obtidos por STEM/XEDS do Cr, Fe, Ni, Mo, Si, N e C. Seta amarela: fase- $\eta$; seta branca: fase $\alpha-\mathrm{Cr}$; seta vermelha: fase- $\sigma$; setas verde e azul: nitreto- $\mathrm{M}_{2} \mathrm{~N}$. O retângulo indica a região mostrada na Figura 4.74. 


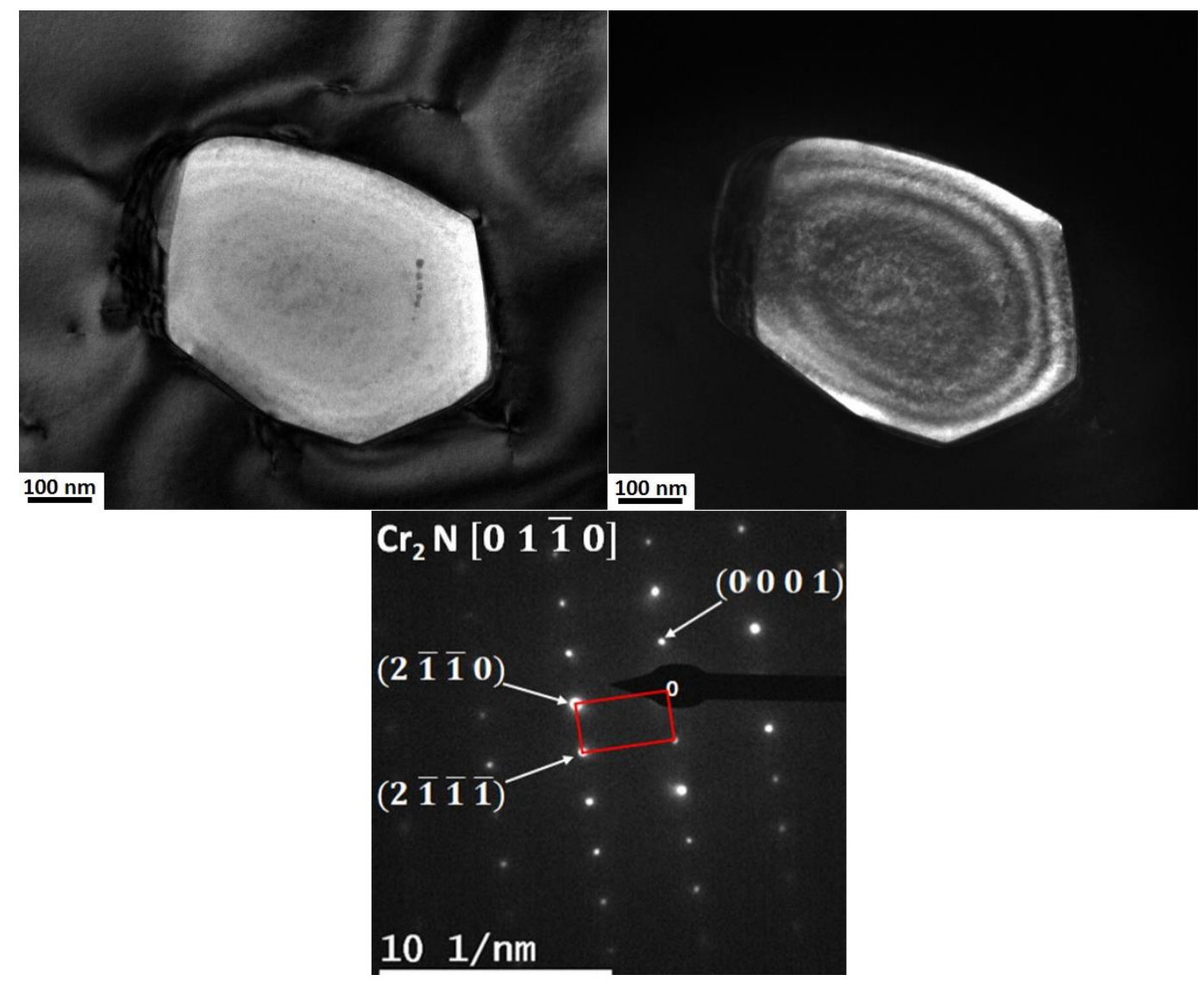

Figura 4.73 - Imagens de MET-BF/CDF mostrando o nitreto- $\mathrm{M}_{2} \mathrm{~N}$ indicado pela seta azul no mapa do $\mathrm{N}$ na Figura 4.72 e o respectivo padrão SAED do nitreto no eixo de zona $\left[\begin{array}{llll}0 & 1 & \overline{1} & 0\end{array}\right]$.

A Figura 4.74 obtida da região indicada pelo retângulo vermelho na Figura 4.72, mostra vários precipitados formados em sequência na região varrida pelo CG avançando. Os mapas elementares obtidos por STEM/XEDS nesta figura indicam a ocorrência do nitreto- $\mathrm{M}_{2} \mathrm{~N}$ rico em $\mathrm{Cr}$ em associação da fase- $\alpha$ rica em Cr. Na Figura 4.72, são apresentadas um par de imagens de MET-BF/CDF e padrões SAED obtidos, respectivamente, da matriz $\mathrm{CFC}$, do nitreto- $\mathrm{M}_{2} \mathrm{~N}$, e da interface nitreto- $\mathrm{M}_{2} \mathrm{~N} /$ matriz $\mathrm{CFC}$ do precipitado indicado pela seta na Figura 4.74. Foi verificado que o nitreto- $\mathrm{M}_{2} \mathrm{~N}$ localizado dentro da colônia de PD tem a seguinte R.O. com a matriz CFC, $\left[\begin{array}{lll}1 & 0 & 1\end{array}\right]_{\text {matriz } C F C} / /\left[\begin{array}{llll}0 & 1 & 1 & 0\end{array}\right]_{M 2 N}$, o que já foi encontrado por outros autores [168], mas diferente do reportado por outros autores [54][169][8][75]. Vale a pena mencionar que Portella et al. [3] reportaram a ocorrência de um carbonitreto- $\mathrm{M}_{2}(\mathrm{CN})$ com estrutura ortorrômbica no $\mathrm{CG}$ da Liga 33 envelhecida a $700{ }^{\circ} \mathrm{C}$ por $100 \mathrm{~h}$, mas não encontrou o nitreto- $\mathrm{M}_{2} \mathrm{~N}$ constituindo a colônia de PD. 


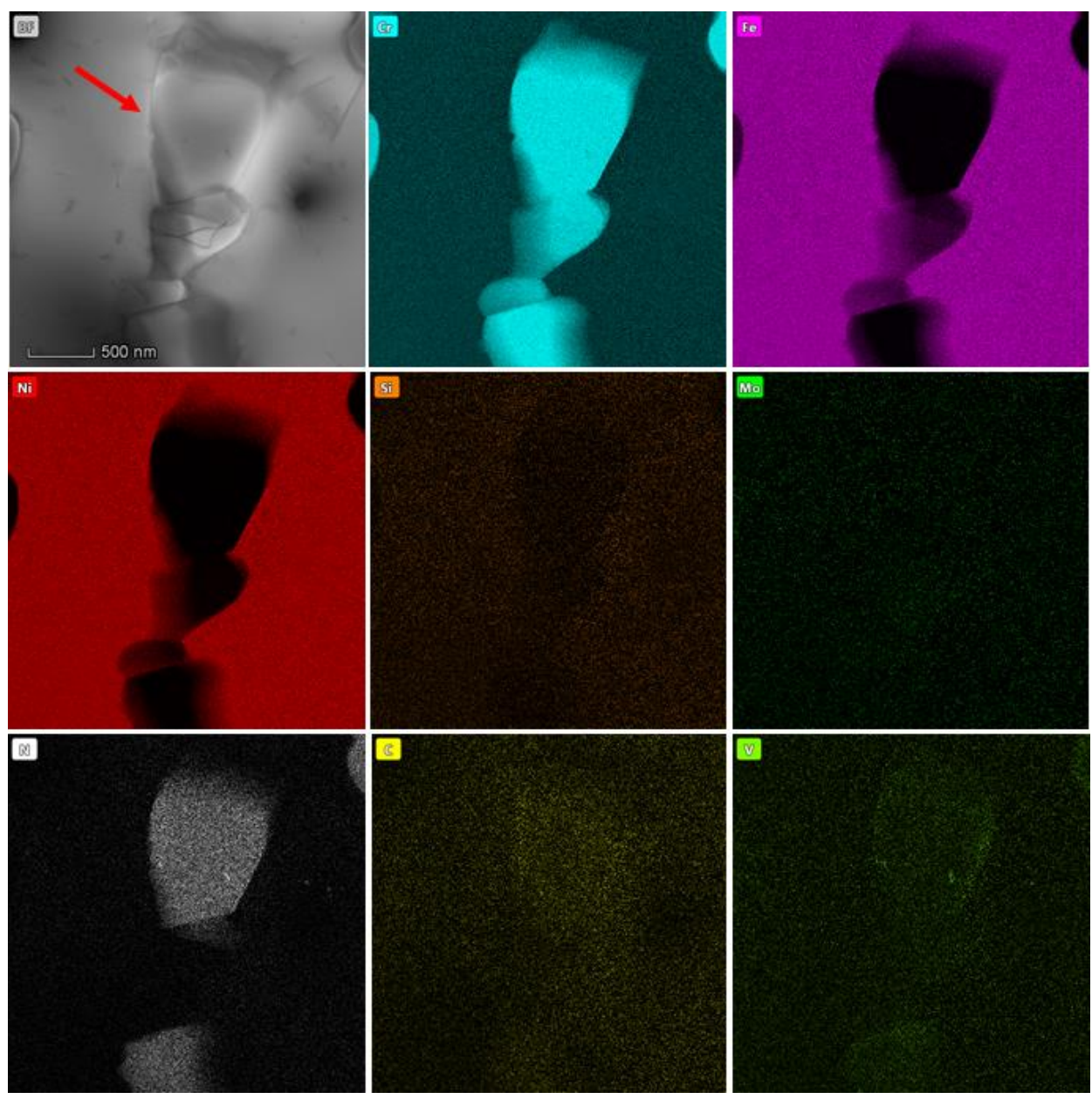

Figura 4.74 - Imagem de STEM/BF obtida da região indicada pelo retângulo vermelho na Figura 4.72 e os correspondentes mapas elementares obtidos por STEM/XEDS do $\mathrm{Cr}$, $\mathrm{Fe}, \mathrm{Ni}, \mathrm{Mo}, \mathrm{Si}, \mathrm{N}, \mathrm{C}$ e V. A seta indica o nitreto rico em $\mathrm{Cr}$ identificado via SAED na Figura 4.75 . 

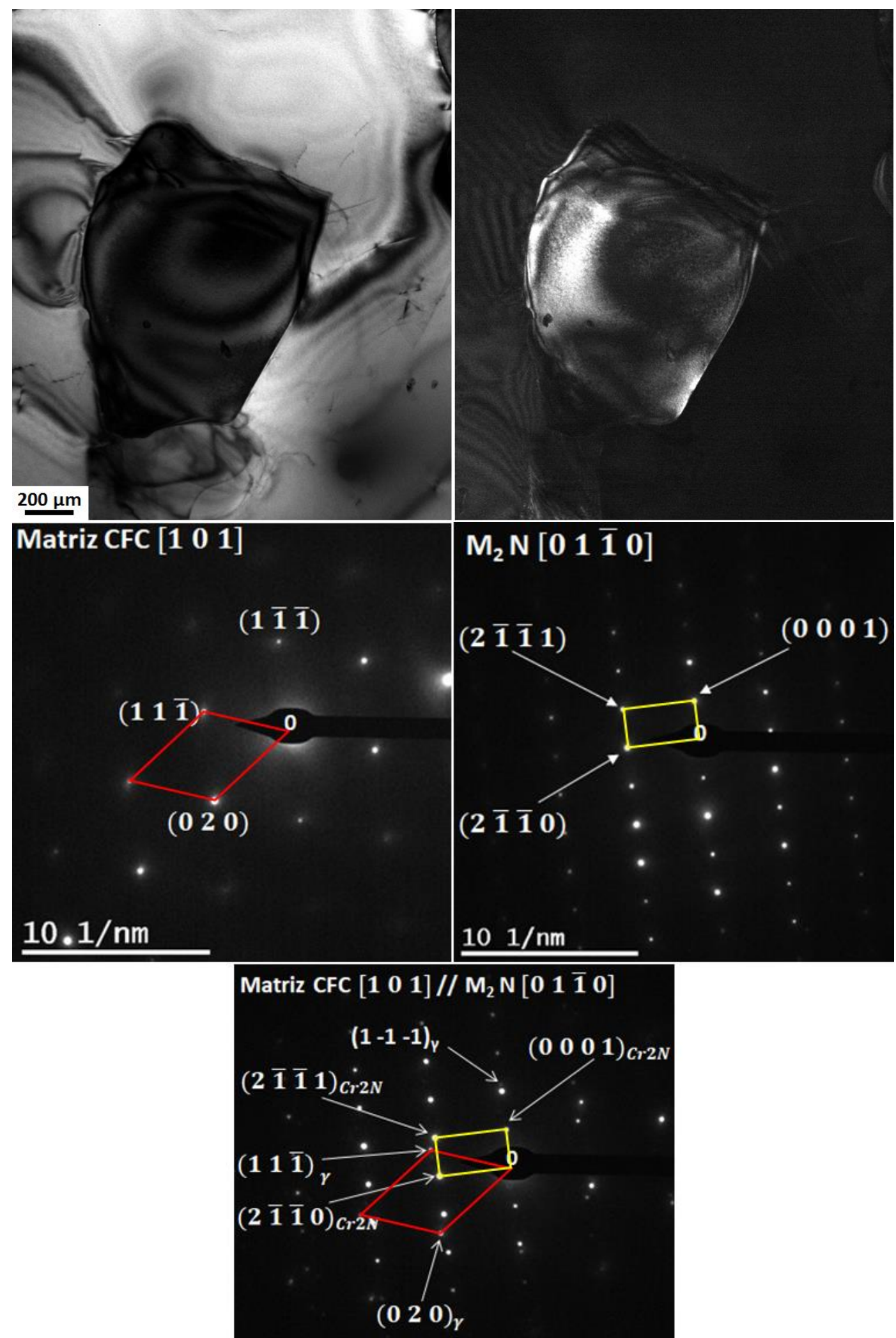

\section{$10.1 / \mathrm{nm}$}

Figura 4.75 - Imagens de MET-BF/CDF mostrando o nitreto- $\mathrm{M}_{2} \mathrm{~N}$ indicado pela seta na Figura 4.74 e padrões SAED, respectivamente, da matriz CFC, nitreto- $\mathrm{M}_{2} \mathrm{~N}$ e interface matriz CFC/nitreto-M $\mathrm{M}_{2} \mathrm{~N}$, mostrando uma R.O. $\left[\begin{array}{lll}1 & 0 & 1\end{array}\right]_{\text {matriz } C F C} / /\left[\begin{array}{llll}0 & 1 & 1 & 0\end{array}\right]_{M 2 N}$ entre o nitreto e a matriz $\mathrm{CFC}$. O losango é vermelho é referente à matriz-CFC e o retângulo amarelo é referente ao nitreto- $\mathrm{M}_{2} \mathrm{~N}$. 


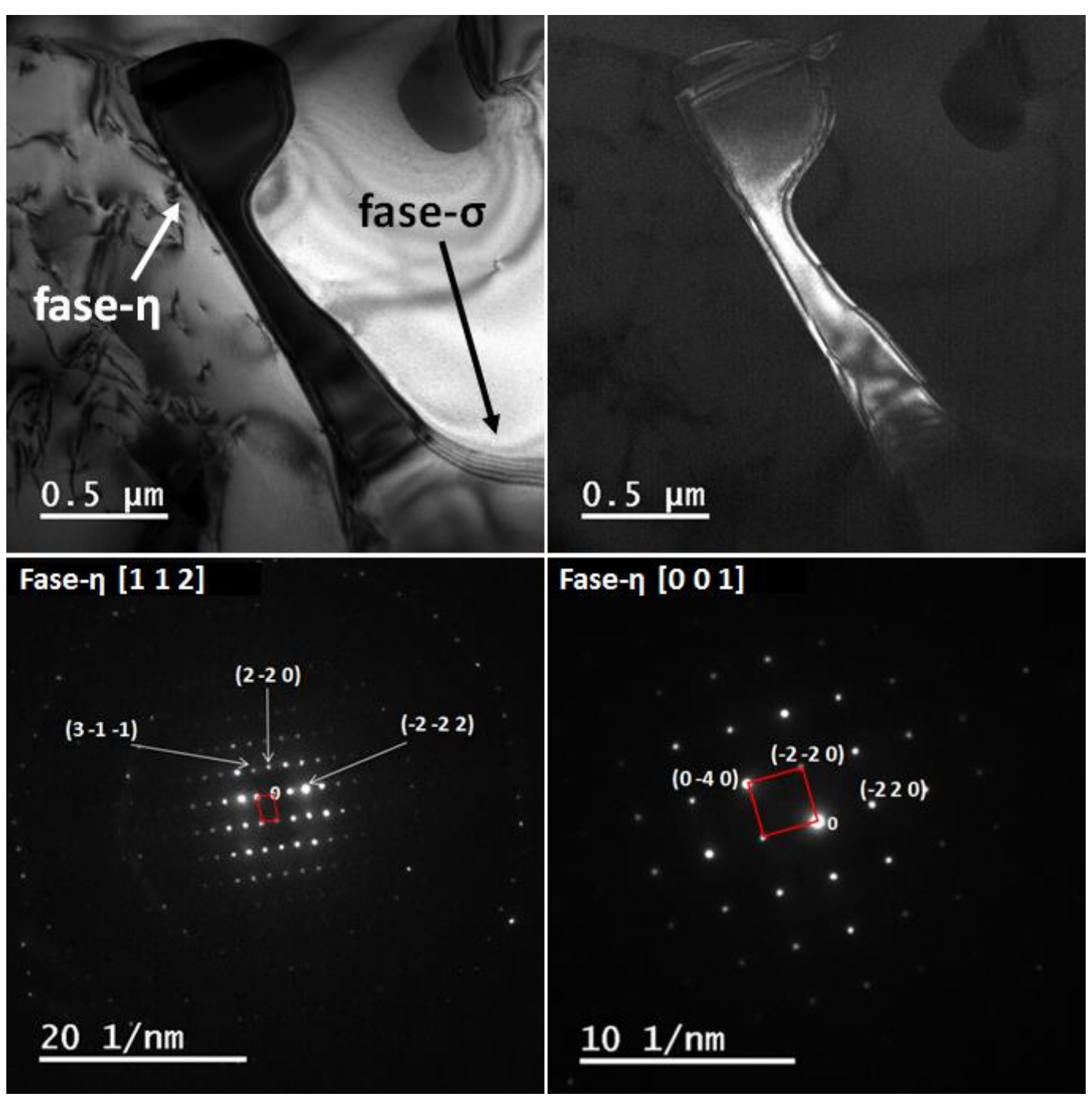

Figura 4.76 - Imagens de MET-BF/CDF da fase-n enriquecida em Si localizada na frente de reação da PD e dois padrões SAED em diferentes eixos de zona, [112] e [001]. Este precipitado está indicado pela seta amarela na imagem de STEM-BF na Figura 4.72a.

A Figura 4.77 apresenta a mesma imagem mostrada na Figura 4.72 e quatro espectros pontuais obtidos por STEM/XEDS dos precipitados marcados pelos números 1, 2, 3 e 4 constituindo a colônia de PD. O espectro ${ }^{\circ} 1$ foi obtido da fase intermetálica $\sigma$ na frente de reação da $\mathrm{PD}$, a qual era enriquecida em $\mathrm{Cr}$, Fe e Mo contendo Ni e baixos níveis de Si. O espectro 2 foi obtido das fases- $\eta$ enriquecidas em $\mathrm{Si}, \mathrm{Ni}, \mathrm{Cr}, \mathrm{N}$ e Mo contendo Fe e V. O espectro $\mathrm{n}^{\circ} 3$ foi obtido dos nitretos- $\mathrm{M}_{2} \mathrm{~N}$ ricos em $\mathrm{Cr}$ contendo $\mathrm{N}$ e baixos níveis de Mo. Neste espectro é verificado que o pico do elementos Fe é muito pequeno, podendo ser proveniente da matriz ao redor do precipitado. $\mathrm{O}$ espectro $\mathrm{n}^{\circ} 4$ foi obtido da fase- $\alpha$ rica em $\mathrm{Cr}$ contendo Fe e baixos níveis de Mo e Ni. 

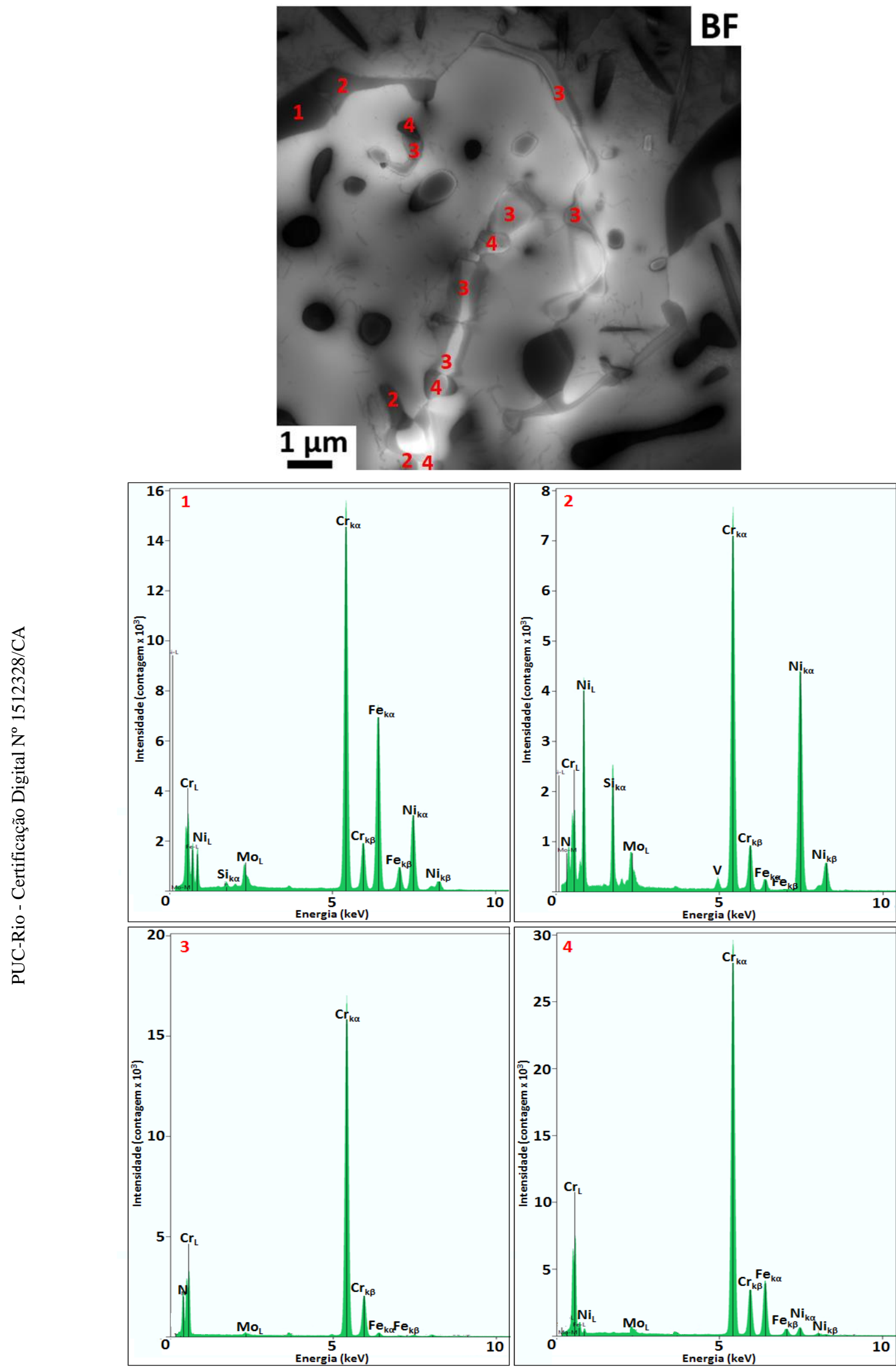

Figura 4.77 - Imagem STEM-BF e quatro espectros obtidos por STEM/XEDS dos precipitados indicados marcados pelos números $1,2,3$ e 4 . Precipitado $n^{\circ} 1$ : fase- $\sigma$; precipitado $n^{\circ} 2$ : fase- $\eta$; precipitado $n^{\circ} 3$ : nitreto- $M_{2} N$; precipitado $n^{\circ} 4$ : fase $\alpha-C r$. 
A partir das observações morfológicas juntamente com os resultados analíticos obtidos por STEM/XEDS e por difração de elétrons (SAED) nas amostras da Liga 33 envelhecida a $800{ }^{\circ} \mathrm{C}$ por $100 \mathrm{~h}$, é possível concluir:

- Nitretos- $\mathrm{M}_{2} \mathrm{~N}$ ricos em $\mathrm{Cr}$ com estrutura hexagonal foram confirmados precipitar dentro da colônia de PD e também na frente de reação. Dentro da colônia foi verificado a R.O. $\left[\begin{array}{lll}1 & 0 & 1\end{array}\right]_{\text {matriz } C F C} / /$ $\left[\begin{array}{llll}0 & 1 & \overline{1} & 0\end{array}\right]_{C r 2 N}$ entre o nitreto e a matriz CFC.

- Três diferentes fases precipitadas foram observadas na forma de longas plaquetas na frente de reação da PD: (1) fase intermetálica $\sigma$; (2) fase- $\eta$ enriquecida em $\mathrm{Si}$; e (3) nitreto- $\mathrm{M}_{2} \mathrm{~N}$.

- Em resumo, cinco diferentes fases precipitadas foram confirmadas constituir a colônia de PD nesta condição de envelhecimento: (1) carbetos- $\mathrm{M}_{23} \mathrm{C}_{6}$ (estrutura $\mathrm{CFC}$ ); (2) fase- $\eta$ enriquecida em Si (estrutura cúbica-diamante); (3) precipitados lamelares da fase $\alpha-\mathrm{Cr}$ (estrutura $\mathrm{CCC}$ ); (4) fase intermetálica $\sigma$ (estrutura tetragonal); e (5) nitreto- $\mathrm{M}_{2} \mathrm{~N}$ rico em $\mathrm{Cr}$ com estrutura hexagonal.

Baseado nos resultados obtidos durante o presente trabalho foi proposto um mecanismo para o processo de desenvolvimento da reação de PD na Liga 33 envelhecida a $800{ }^{\circ} \mathrm{C}$, o qual está ilustrado na Figura 4.78 e descrito a seguir. (1) inicialmente o contorno se encontra estático e livre de precipitados; (2) nos estágios iniciais do tratamento térmico, carbetos- $\mathrm{M}_{23} \mathrm{C}_{6}$ ricos em $\mathrm{Cr}$ nucleiam no CG devido a difusão intergranular do $\mathrm{Cr}$ e $\mathrm{C}$; (3) com o processo de envelhecimento os carbetos crescem e regiões adjacentes ao carbeto inicia o movimento de migração do CG devido ao fenômeno DIGM; (4) precipitados da fase- $\eta$ enriquecidos em Si também nucleiam e crescem na posição original do CG sempre associado ao carbeto- $\mathrm{M}_{23} \mathrm{C}_{6}$; (5) com o aumento do tempo de envelhecimento, o contorno continua a migrar e precipitados da fase- $\alpha$ rica em $\mathrm{Cr}$ nucleiam adjacente ao CG e crescem com morfologia lamelar na direção da matriz CFC. Precipitados da fase $\alpha-\mathrm{Cr}$ na forma de partículas também formam na região varrida pelo contorno em movimento; (6) precipitados da fase $\alpha-\mathrm{Cr}$ crescem na 
forma de lamelas para dentro da matriz $\mathrm{CFC}$, ao mesmo tempo que novos precipitados desta mesma fase nucleiam na região varrida pela frente de reação da PD; (7) com o aumento no tempo de envelhecimento, as lamelas da fase $\alpha-\mathrm{Cr}$ crescem acompanhando a migração do contorno e precipitados da fase- $\eta$ nucleiam dentro da colônia de PD associada à fase- $\alpha$ rica em Cr. Eventualmente ocorre a formação da fase- $\eta$ enriquecida em Si na frente de reação da PD; (8) as lamelas da fase $\alpha-\mathrm{Cr}$ continuam a crescer com o processo de envelhecimento do material e, com isso ocorre a formação de precipitados da fase intermetálica $\sigma$ na frente de reação da $\mathrm{PD}$, a qual cresce na forma de plaquetas permanecendo na frente de reação ou crescendo como lamelas grosseiras acompanhando a migração do contorno; (9) nos estágios finais do processo de envelhecimento, quando a migração do contorno praticamente cessou seu movimento na direção da matriz não-transformada, ocorre a formação do nitreto- $\mathrm{M}_{2} \mathrm{~N}$ tanto na frente de reação como dentro da colônia de PD. Na Tabela 4.1 são apresentados os precipitados identificados neste estudo e algumas de suas características. 


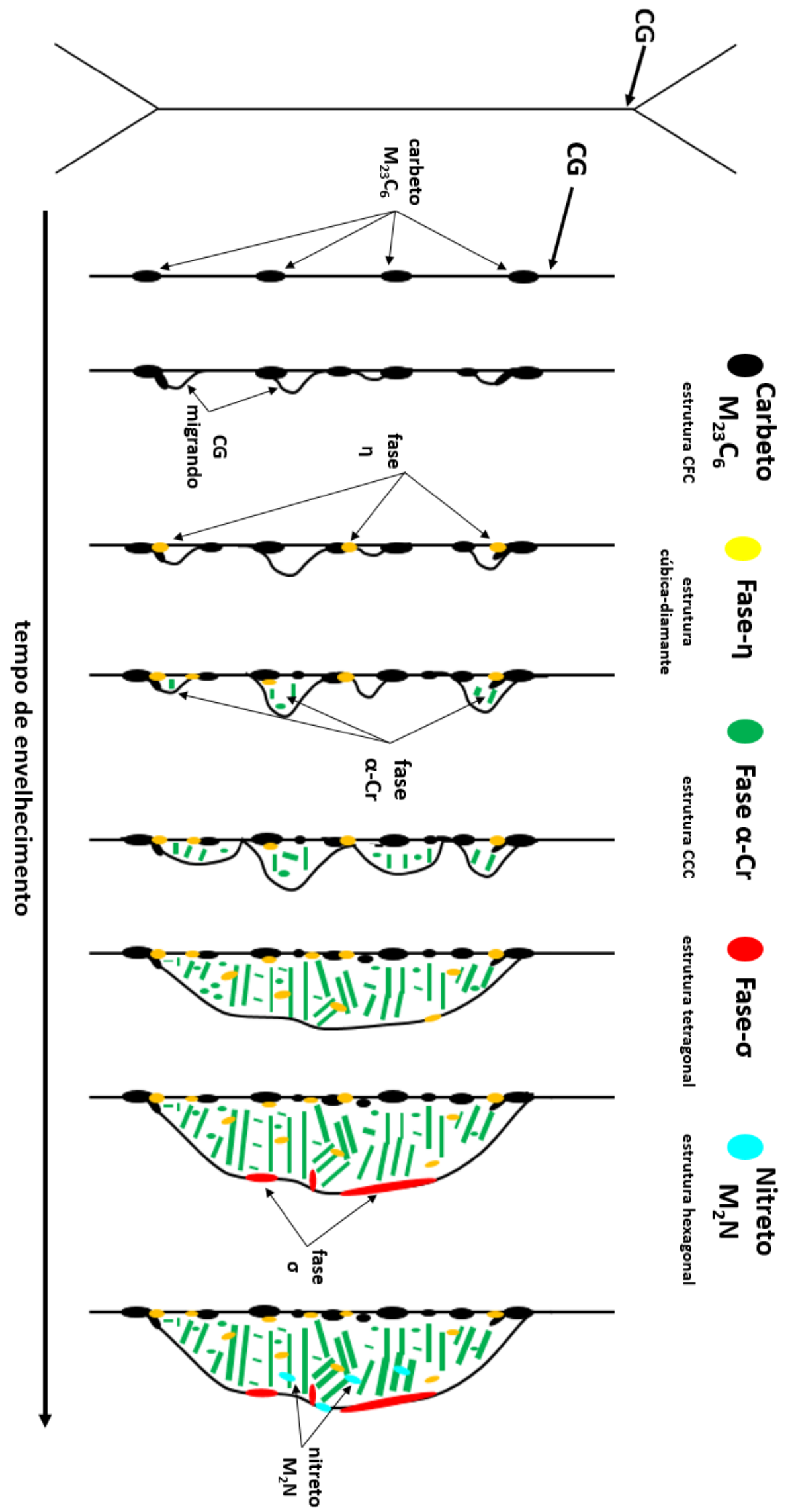

Figura 4.78 - Esquema do mecanismo de crescimento da colônia de PD na Liga 33 envelhecida a $800^{\circ} \mathrm{C}$ até 100 horas. 
Tabela 4.1 - Fases precipitadas identificadas na Liga 33 envelhecida a $800^{\circ} \mathrm{C}$ até $100 \mathrm{~h}$.

\begin{tabular}{|c|c|c|c|}
\hline $\begin{array}{c}\text { Fase } \\
\text { Precipitada }\end{array}$ & $\begin{array}{l}\text { Estrutura } \\
\text { Cristalina }\end{array}$ & $\begin{array}{c}\text { Composição Química } \\
\text { por STEM/XEDS }\end{array}$ & $\begin{array}{l}\text { Relação de Orientação com a } \\
\text { Matriz CFC }\end{array}$ \\
\hline $\begin{array}{c}\text { Carbeto- } \\
\mathrm{M}_{23} \mathrm{C}_{6}\end{array}$ & $\mathrm{CFC}$ & $\begin{array}{c}\text { rico em } \mathrm{Cr} \text { contendo } \\
\mathrm{Mo}, \mathrm{Fe}, \mathrm{Ni} \text { e C }\end{array}$ & {$\left[\begin{array}{lll}0 & 0 & 1\end{array}\right]_{M_{23} C_{6}} / /\left[\begin{array}{lll}0 & 0 & 1\end{array}\right]_{m}$} \\
\hline Fase- $\eta$ & $\begin{array}{l}\text { Cúbica- } \\
\text { diamante }\end{array}$ & $\begin{array}{c}\text { enriquecida em } \mathrm{Si}, \mathrm{Ni} \text {, } \\
\mathrm{Cr}, \text { Mo e } \mathrm{N} \text { contendo } \\
\text { baixos teores de } \mathrm{Fe} \mathrm{e} \mathrm{V}\end{array}$ & $\begin{array}{l}{\left[\begin{array}{lll}0 & 0 & 1\end{array}\right]_{\text {fase }-\eta} / /\left[\begin{array}{lll}0 & 0 & 1\end{array}\right]_{\text {matriz }-C F C}} \\
{\left[\begin{array}{lll}1 & 2 & 2\end{array}\right]_{\text {fase }-\eta} / /\left[\begin{array}{lll}0 & 0 & 1\end{array}\right]_{\text {matriz }-C F C}}\end{array}$ \\
\hline Fase $\alpha-\mathbf{C r}$ & $\mathrm{CCC}$ & $\begin{array}{c}\text { rica em } \mathrm{Cr} \text { contendo } \mathrm{Fe} \\
\text { e baixos teores de } \mathrm{Ni} \mathrm{e} \\
\text { Mo }\end{array}$ & {$\left[\begin{array}{lll}1 & 1 & 1\end{array}\right]_{\text {fase } \alpha-C r} / /\left[\begin{array}{lll}1 & 0 & 1\end{array}\right]_{\text {matriz-CFC }}$} \\
\hline Fase- $\sigma$ & Tetragonal & $\begin{array}{c}\text { enriquecida em } \mathrm{Cr}, \mathrm{Mo} \mathrm{e} \\
\mathrm{Fe} \text { contendo } \mathrm{Ni} \text { e baixo } \\
\text { teor de } \mathrm{Si}\end{array}$ & {$\left[\begin{array}{lll}1 & 1 & 0\end{array}\right]_{\text {fase }-\sigma} / /\left[\begin{array}{lll}1 & 0 & 1\end{array}\right]_{\text {matriz }-C F C}$} \\
\hline Nitreto- $\mathrm{M}_{2} \mathbf{N}$ & Hexagonal & $\begin{array}{c}\text { rico em } \mathrm{Cr} \text { contendo } \mathrm{Ne} \\
\text { baixo teor de Mo }\end{array}$ & {$\left[\begin{array}{lll}1 & 0 & 1\end{array}\right]_{\text {matriz } C F C} / /\left[\begin{array}{llll}0 & 1 & \overline{1} & 0\end{array}\right]_{M 2 N}$} \\
\hline
\end{tabular}

\subsection{Relação entre a Desorientação Angular no CG e a Ocorrência da Reação de PD na Liga 33 envelhecida a $800{ }^{\circ} \mathrm{C}$ (EBSD)}

É bem conhecido que fenômenos que desempenham um importante papel na estabilidade dos materiais metálicos, tais como migração do CG, segregação de soluto e processos de precipitação estão diretamente relacionados com as características individuais dos CG [24][245]. A desorientação entre os grãos do material, a qual refere-se à relação de orientação cristalográfica entre grãos adjacentes da mesma fase, é um dos parâmetros mais importantes governando propriedades intrínsecas - tais como energia, difusividade e mobilidade - além de controlar transformações no estado sólido, como as reações de PD [175][246].

Variando a desorientação entre grãos adjacentes, a energia livre do contorno também é alterada, resultando em diferentes energias que influenciarão de maneira distinta a cinética de formação e crescimento dos precipitados nos CG. Esta diferença energética gerada pela desorientação angular entre grãos tem um efeito chave no comportamento da precipitação em ligas metálicas [62][89][76]. Por exemplo, a formação de carbetos- $\mathrm{M}_{23} \mathrm{C}_{6}$ já foi reportada ser fortemente influenciada pelo tipo CG nos materiais estruturais, tais como AI austenítico e ligas à base de $\mathrm{Ni}$ [1][2][65][74][76-79][227]. Trillo e Murr [76][77] demonstraram a necessidade do CG fornecer uma energia mínima para a nucleação dos carbetos- $\mathrm{M}_{23} \mathrm{C}_{6}$. Além disso, os autores encontraram que, com o aumento no tempo de envelhecimento, os carbetos- $\mathrm{M}_{23} \mathrm{C}_{6}$ precipitaram em $\mathrm{CG}$ com menor desorientação. Lim et al. [2] também observaram que a precipitação 
de carbetos foi retardada em contornos de baixo ângulo quando comparado com CG de alto ângulo.

A influência do tipo dos CG na reação de PD já foi reportada em diversas ligas binárias e ternárias [24][137][175][180][247-250] e também em ligas multicomponentes estruturais [10][210][213][219][251]. Porter e Edington [180] reportaram que a cinética de crescimento da $\mathrm{PD}$ em ligas $\mathrm{Mg}$-Al foi fortemente dependente das características do CG. Hirth e Gottstein [249] mostraram em ligas Al-Pt-Ga que a reação de PD foi preferencialmente iniciada em CG com ângulos de desorientação entre $25^{\circ}$ e $40^{\circ}$. Wirth e Gleiter [250] observaram que a variação na temperatura de envelhecimento em ligas $\mathrm{Cu}-\mathrm{Ag}$ influenciou os tipos de $\mathrm{CG}$ que ocorreu a PD. Os autores verificaram que em temperaturas mais altas, a PD ocorreu apenas em contornos de alta energia, porém em temperaturas mais baixas de envelhecimento foi observado que tanto em contornos de alta energia como de baixa energia a reação de PD foi observada. Recentemente, Keskar et al. [137] reportaram que a nucleação da PD constituída da fase $\alpha-\mathrm{Cr}$ em uma liga binária Cr-Ni teve um pico de ocorrência em contornos com desorientação de $45^{\circ}$.

Desta forma, com o objetivo de estudar a relação entre a desorientação angular dos CG e a ocorrência da reação de PD na Liga 33, análises por EBSD foram realizadas em amostras na condição como recebida e também amostras envelhecidas a $800{ }^{\circ} \mathrm{C}$. Como já mencionado anteriormente, como via de regra da reação de PD, a relação de orientação do grão inicial é estendida para a colônia, resultando que a região varrida pelo contorno avançando terá a mesma orientação cristalina que a matriz na qual a colônia iniciou o crescimento. Isso pode ser verificado em mapeamentos por EBSD, como o apresentado na Figura 4.79, que mostra que a orientação cristalina do grão de cima na Figura 4.79b (representado na figura como o "grão rosa") foi transferida para colônia de PD, a qual está consumindo os grãos de baixo na imagem ("grão vermelho" e "grão azul”). 


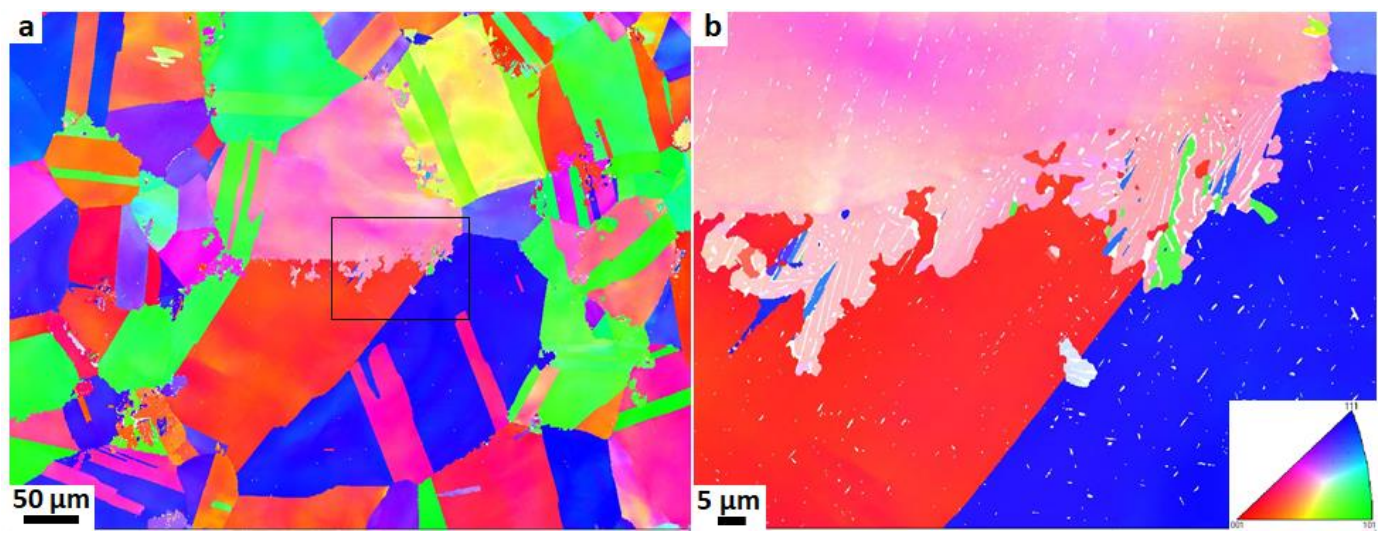

Figura 4.79 - Mapas de EBSD da Liga 33 envelhecida a $800^{\circ} \mathrm{C}$ por $50 \mathrm{~h}$. (b) imagem de EBSD obtida da região indicada pelo retângulo em (a) mostrando que a orientação cristalina do grão de cima ("grão rosa") é transferida para a colônia de PD, a qual consome os grãos de baixo ("grão vermelho" e "grão azul").

A Figura 4.80 mostra os mapas de EBSD da Liga 33 na condição como recebida e envelhecida a $800{ }^{\circ} \mathrm{C}$ por $2 \mathrm{~h}$ e $20 \mathrm{~h}$ e os correspondentes mapas somente com os CG delineados. Na condição como recebida (Figura 4.80a) é possível verificar que os CG estavam retos e não apresentavam precipitação nem migração do contorno (como mostrado anteriormente neste trabalho, item 4.1). Após $2 \mathrm{~h}$ de envelhecimento a $800{ }^{\circ} \mathrm{C}$ é possível verificar no mapa da Figura $4.80 \mathrm{~b}$ que alguns $\mathrm{CG}$ se mostram ondulados (indicado pelas setas na figura), o que indica a ocorrência de migração do contorno. Quando o tempo de envelhecimento foi aumentado de $2 \mathrm{~h}$ para 20 h, as colônias de PD cresceram na direção do grão adjacente o que pode ser verificado pela forma irregular dos contornos na Figura 4.80c. 


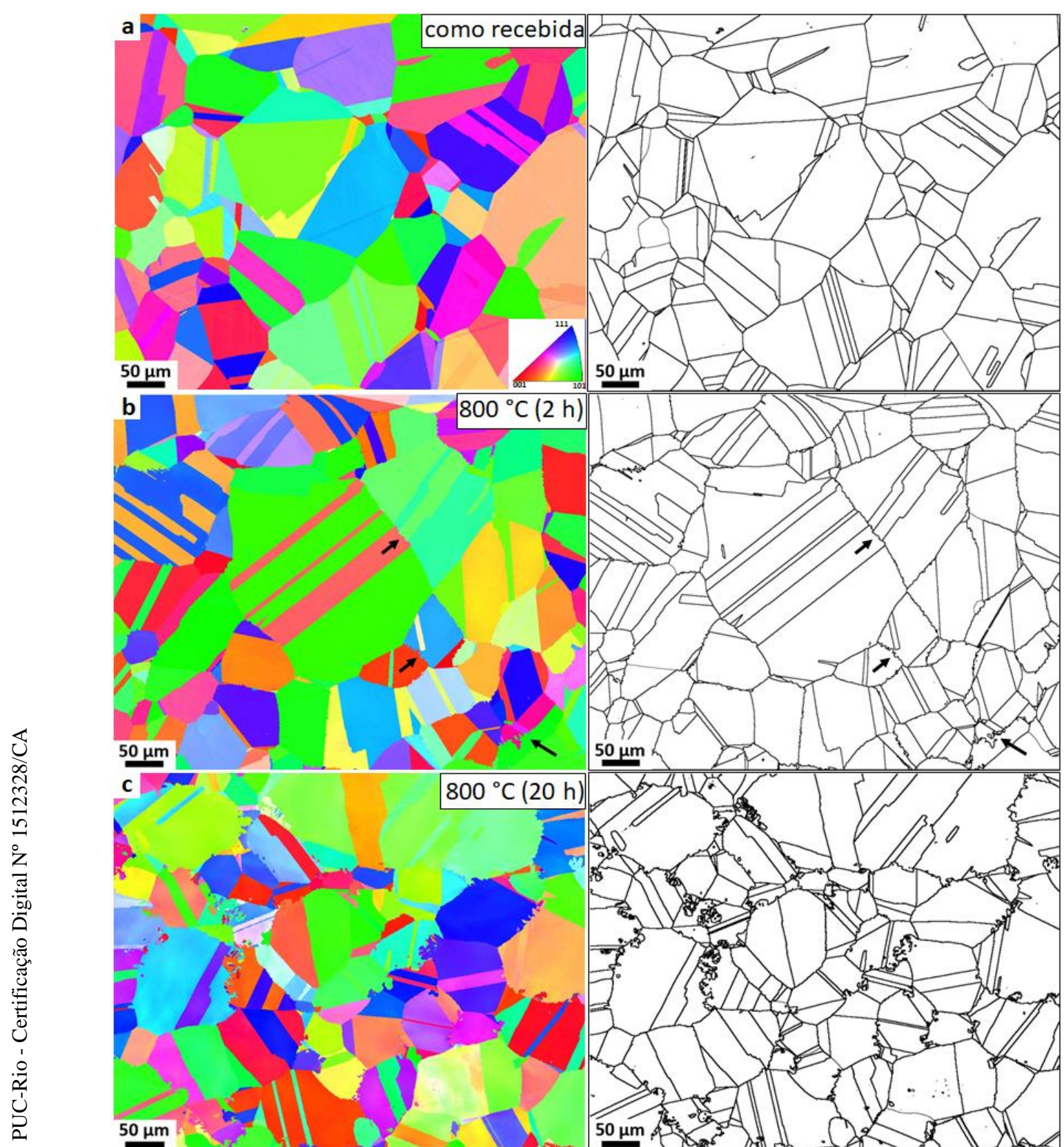

Figura 4.80 - Mapas de EBSD e os respectivos mapas somente com CG delineados da Liga 33 na condição (a) como recebida; e envelhecida a $800^{\circ} \mathrm{C}$ por (b) $2 \mathrm{~h}$; e (c) $20 \mathrm{~h}$.

Como observado na Figura 4.80, a reação de PD não ocorreu em todos os contornos do material, bem como nos contornos de macla, o que é esperado neste último devido à baixa energia destes tipos de contornos. Na tentativa de obter qual a desorientação entre os grãos que favorece a ocorrência da PD na Liga 33 envelhecida a $800{ }^{\circ} \mathrm{C}$ por $2 \mathrm{~h}$ e $20 \mathrm{~h}$ foram realizadas medidas, com o auxílio do software TANGO (Oxford Instruments), da desorientação nos CG que foram observadas a ocorrência da PD e também nos CG em que não foram observadas migração. Foram utilizados dois mapeamentos por ESBD com magnificação de 
500x de cada condição do material para a obtenção dos dados da desorientação entre os grãos. Os resultados obtidos estão apresentados na Figura 4.81.

A imagem na Figura 4.81a mostra a distribuição da ocorrência de PD em relação à desorientação angular dos CG na Liga 33 (representado nos gráficos pelas barras verdes), onde também é possível observar a distribuição do total de CG em relação a desorientação dos CG (barras azuis) obtidos da amostra da Liga 33 envelhecida a $800{ }^{\circ} \mathrm{C}$ por $2 \mathrm{~h}$. Nesta figura, é verificado que a reação de PD ocorre preferencialmente em CG com desorientação na faixa de $30^{\circ}$ a $50^{\circ}$ indicando uma leve tendência a ter um pico em torno de $40^{\circ}$ e $50^{\circ}$. Porém, ao analisar o comportamento no gráfico da Figura $4.81 \mathrm{~b}$, o qual mostra a porcentagem de ocorrência da $\mathrm{PD}$ em relação a desorientação dos CG, é verificado que a reação de PD ocorre com frequência similar ( $50 \%)$ em CG com desorientação entre $25^{\circ}$ e $50^{\circ}$. Quando o tempo de envelhecimento foi aumentado de $2 \mathrm{~h}$ para $20 \mathrm{~h}$, foi observado praticamente o mesmo comportamento da ocorrência da PD em relação à desorientação dos CG verificado após $2 \mathrm{~h}$ de envelhecimento. Mesmo sendo observado um pico de ocorrência da PD entre CG com desorientação próximo a $45^{\circ}$ (barras verdes na Figura 4.81c), a porcentagem de ocorrência da PD é praticamente a mesma em contornos com desorientação entre $20^{\circ}$ e $50^{\circ}$, como mostrado na Figura $4.81 \mathrm{~d}$.

(a)

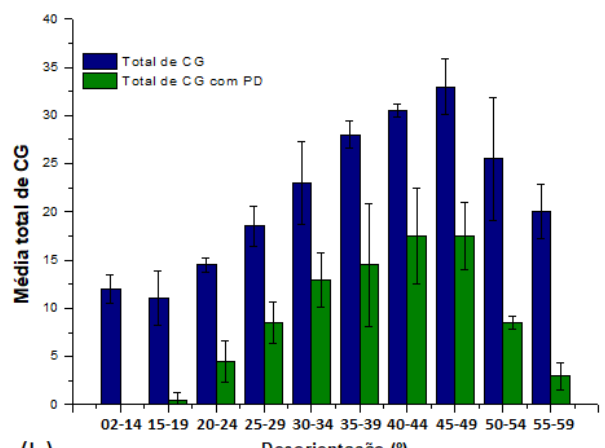

(b)

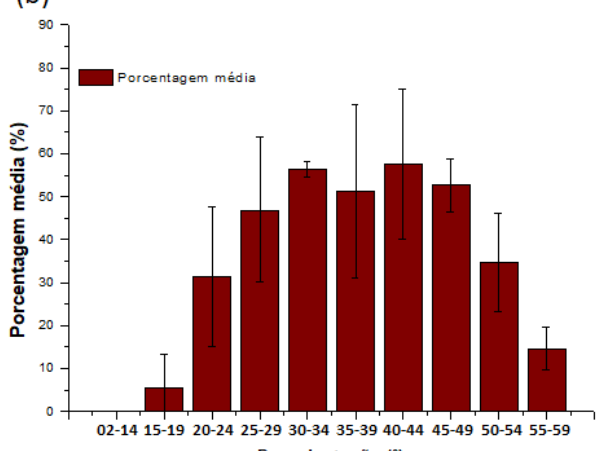

(c)

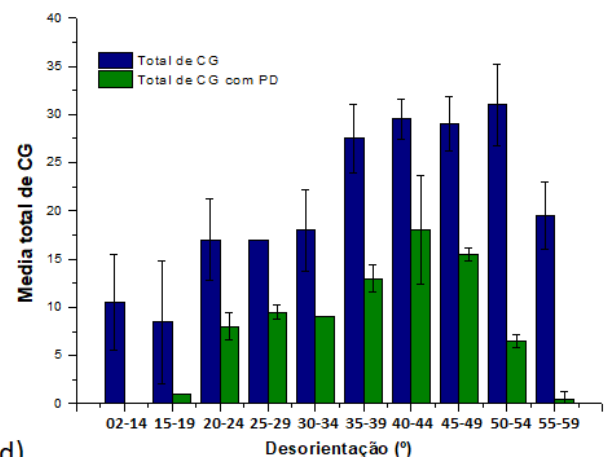

(d)

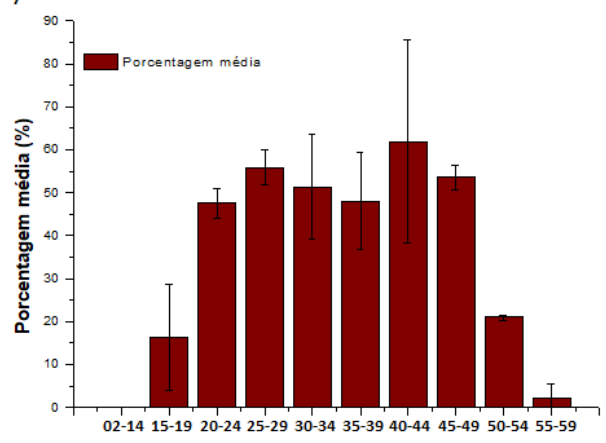

Desorientação $\left({ }^{\circ}\right)$

Figura 4.81 - (a) e (c) Distribuição dos CG em relação à desorientação angular dos CG; (b) e (d) porcentagem de ocorrência da PD em relação à desorientação dos CG. 
Baseado nos resultados apresentados na Figura 4.81, é verificado que a ocorrência da reação de PD na Liga 33 em contornos com desorientação menor que $20^{\circ}$ é muito baixa mesmo após 20 horas de envelhecimento a $800{ }^{\circ} \mathrm{C}$, confirmando a necessidade de contornos de alta energia para o desenvolvimento da reação de PD. Entretanto, com o aumento no tempo de envelhecimento de $2 \mathrm{~h}$ para $20 \mathrm{~h}$, foi verificado que contornos com desorientação acima de $20^{\circ}$ e abaixo de $25^{\circ}$ se tornaram mais susceptíveis à formação da PD (gráficos (b) e (d) da Figura 4.81). Vale a pena mencionar que mesmo sendo necessário uma maior quantidade de análises para melhor entender tal comportamento, a observação verificada no presente trabalho é coerente como reportado por Monzen et al. [247] em bicristais de ligas $\mathrm{Cu}-\mathrm{Be}$, os quais observaram que contornos de baixa energia exibiram um maior período de incubação para a formação da PD em relação aos CG de alto ângulo.

Os resultados encontrados no presente trabalho referentes à dependência da desorientação entre CG para a ocorrência da PD estão de acordo com outros autores. Walston et al. [219] estudando ligas à base de $\mathrm{Ni}$, observaram que a reação de $\mathrm{PD}$ ocorreu em CG com desorientação maior que $10^{\circ}$, mas em geral foram necessárias desorientações maiores para a formação de colônias. Nystrom et al. [210] também estudando bicristais de uma liga à base de $\mathrm{Ni}$ com desorientação entre $7^{\circ}$ e $30^{\circ}$, observaram o desenvolvimento de colônias de PD em CG com desorientação maior que $10^{\circ}$, mas os autores verificaram que a extensão das colônias aumentou com o aumento na desorientação entre os grãos. Heckl et al. [10] também reportaram, em ligas à base de Ni, que a formação de PD ocorreu em CG com desorientação maior que $12^{\circ}-15^{\circ}$. Desta forma, os resultados encontrados no presente trabalho, referentes à dependência da desorientação entre grãos para ocorrer a reação de PD, estão em concordância com o reportado por outros autores e corroboram a premissa que a reação de PD ocorre em CG de alto ângulo. Também é válido mencionar a dependência estrutural de cada CG para que ocorra a PD [175][176], já que diferentes contornos com desorientação angular similar mostraram diferentes comportamentos em relação à ocorrência da PD. Assim, pode ser afirmado que a reação da PD é fortemente dependente da desorientação angular do CG (i.e. da natureza dos contornos), o que pode ser racionalizada pelas diferenças energéticas dos CG. 
Baseado nos resultados obtidos por MEV/EBSD das amostras da Liga 33 envelhecida a $800{ }^{\circ} \mathrm{C}$ por $2 \mathrm{~h}$ e $20 \mathrm{~h}$ pode ser afirmado que:

- A ocorrência da reação de PD é fortemente dependente da desorientação angular entre os grãos austeníticos, confirmando a necessidade de contornos de alto ângulo (alta energia) para a ocorrência desta reação.

- Não foi verificada uma desorientação preferencial entre os grãos para a ocorrência da PD na Liga 33 envelhecida a $800{ }^{\circ} \mathrm{C}$, podendo ser considerado que que CG com desorientação entre $20^{\circ}$ e $50^{\circ}$ são suscetíveis à formação da reação de $\mathrm{PD}$.

\subsection{Características da Cinética de PD na Liga 33 envelhecida a $800^{\circ} \mathrm{C}$}

Como já mencionado anteriormente no presente trabalho, nas ligas estruturais contendo solutos substitucionais e intersticiais, normalmente, as colônias de PD são constituídas de carbetos- $\mathrm{M}_{23} \mathrm{C}_{6}$ ou nitretos- $\mathrm{M}_{2} \mathrm{~N}$ com morfologia lamelar. Entretanto, colônias de PD constituídas de lamelas da fase- $\sigma$, ao invés de carbetos ou nitretos, foram recentemente observadas como a principal fase precipitada dentro da colônia. Estudos sobre o crescimento da reação de PD destes diferentes tipos de precipitados já foram realizados em diversos tipos de materiais estruturais [8][9][53][55][56][148][168][195-198][252][253].

Para o estudo sobre a reação de PD, saber quais fatores controlam seu crescimento é considerado de grande importância. Neste sentido, alguma atenção já foi dada na tentativa de verificar qual mecanismo de difusão controla este fenômeno em ligas multicomponentes, sendo propostos alguns modelos. Hillert e Lagneborg [197] verificaram que a reação de PD de carbetos- $\mathrm{M}_{23} \mathrm{C}_{6}$ em um AI austenítico (Fe-35Ni-20Cr) foi governada pela difusão de CG do Cr e difusão de volume do $\mathrm{C}$ e relacionaram a baixa fração volumétrica transformada pela reação de PD com a gradual diminuição no teor de $\mathrm{C}$ na matriz não-transformada durante o tempo de reação. Já Presser e Silcock [198] afirmaram que o crescimento da reação de $\mathrm{PD}$, também de carbetos, em um AI austenítico (Fe-18Mn-18Cr-0.6N) foi governado pela difusão de volume do Cr. Por outro lado, Voice e Faulkner 
[195] verificaram que o crescimento da $P D$ de carbetos- $M_{23} C_{6}$ na Liga Nimonic 80A (Ni-18-21Cr-3Fe) foi controlado pela difusão de CG do Cr e difusão parcial de volume do $\mathrm{C}$.

Modelos para o crescimento da PD de nitretos $-\mathrm{M}_{2} \mathrm{~N}$ também já foram propostos. Kajihara et al. [254] propôs um modelo computacional em um AI austenítico $(25 \mathrm{Cr}-20 \mathrm{Ni}-(0.4-0.6) \mathrm{N})$ para explicar a desaceleração da taxa de migração da frente de reação da PD. Em seguida, Kikuchi et al. [8][25] por meio de análises experimentais por STEM/XEDS confirmaram que o crescimento da PD de nitretos- $\mathrm{M}_{2} \mathrm{~N}$ em um AI austenítico (25Cr-20Ni-0.4N) ocorreu no estado não-estacionário, corroborando o mecanismo proposto por Kajihara et al. Os autores mostraram que a reação de PD foi governada inicialmente pela difusão de contorno do $\mathrm{Cr}$ e pela difusão de volume do $\mathrm{N}$ e, posteriormente, a difusão de volume do $\mathrm{Cr}$ também desempenhou um importante papel no crescimento da reação. Vandershaeve et al. [9] reportaram em um AI austenítico (Fe-19Mn-18Cr$0.9 \mathrm{~N}$ ) que a reação de $\mathrm{PD}$ de nitreto- $\mathrm{M}_{2} \mathrm{~N}$ também envolveu dois mecanismos de difusão, difusão intersticial de $\mathrm{N}$ e difusão substitucional de $\mathrm{Cr}$ e que a reação ocorreu no estado não-estacionário. Mas diferentemente de Kikuchi et al. [8][25], Vandershaeve et al. [9] afirmaram que a cinética de crescimento da PD foi governado primeiramente pela difusão de $\mathrm{CG}$ do $\mathrm{Cr}$, e depois pela difusão de volume do $\mathrm{Cr}$.

Para a reação de PD da fase- $\sigma$, Zhang et al. [56] reportaram que o processo de crescimento da reação de PD em um AI duplex (Fe-27Cr-7Ni-5Mo-0.4N) foi sucessivamente controlado pela difusão intergranular e, então pela difusão volumétrica do $\mathrm{Cr}$ e Mo, mas não envolveu a difusão de $\mathrm{C}$ nem $\mathrm{N}$ devido à baixa solubilidade destes elementos na fase intermetálica $\sigma$ [54][209], mesmo a liga contendo alto teor de N. A mesma conclusão foi feita por Zhang et al. [55] em um AI austenítico (Fe-25Cr-22Ni-8Mo-0.5N), onde a reação de PD da fase- $\sigma$ foi sucessivamente controlada pela difusão intergranular e, então, pela difusão de volume do Cr e Mo.

Neste sentido, com o objetivo de analisar quais mecanismos de difusão desempenham importante papel no desenvolvimento da reação de PD contendo a fase $\alpha-\mathrm{Cr}$ na Liga 33 durante o processo de envelhecimento a $800{ }^{\circ} \mathrm{C}$, foram obtidos mapas elementares por STEM/XEDS na matriz CFC através do contorno da frente de reação. As imagens de STEM-BF, os mapas elementares do Cr, bem 
como os perfis composicionais obtidos a partir da região indicada pela linha em cada imagem em amostras envelhecidas por 30 min, 10 h, 20 h, 50 h e 100 h estão apresentados na Figura 4.82.

$\mathrm{Na}$ amostra envelhecida por 30 min (Figura 4.82a), a concentração de $\mathrm{Cr}$ na região varrida pelo contorno $(\alpha)$ era menor que na matriz não-transformada $\left(\alpha_{0}\right)$. Nesta condição de tratamento, foi verificado a existência de um degrau na composição do $\mathrm{Cr}$ através da frente de reação da $\mathrm{PD}$, e nenhuma zona de difusão foi detectada à frente do contorno na matriz não-transformada, o que é confirmado no perfil composicional obtido pela análise em linha mostrado na Figura 4.82a). Tal observação indica que não ocorreu difusão de volume (difusão de longo alcance) durante este estágio do envelhecimento. Este gradiente composicional verificado através da frente de reação neste estágio do tratamento térmico é considerado a força motriz do fenômeno DIGM para a migração do CG e, consequentemente, para o desenvolvimento das colônias de PD na Liga 33.

Após 10 h de envelhecimento foi observado o início da formação de uma zona de difusão do $\mathrm{Cr}$ à frente do contorno de célula migrando, como mostrado no perfil composicional na Figura 4.82b. A existência desta zona de difusão indica uma transição no mecanismo de difusão controlando o crescimento da reação de PD, da difusão intergranular no início da reação para a difusão de volume. Ao aumentar o tempo de reação de $10 \mathrm{~h}$ para $20 \mathrm{~h}$, a largura da zona de difusão à frente do contorno migrando também aumentou, como mostrado na Figura 4.82c. Tal observação pode ser verificada tanto no mapeamento elementar do $\mathrm{Cr}$, no qual é possível verificar uma mudança contínua no contraste da imagem e, também pode ser confirmada no perfil composicional extraído da região indicada pela linha na Figura 4.82c. Esse aumento na largura da zona de difusão à frente do contorno migrando indica que a difusão de volume começa a ser a responsável pelo processo de crescimento da reação de PD na Liga 33 durante o processo de envelhecimento.

Quando o tempo de envelhecimento foi aumentado para $50 \mathrm{~h}$, a largura da zona de difusão também aumentou (Figura 4.82d), ao passo que após $100 \mathrm{~h}$ de tratamento, foi verificado que o gradiente composicional, observado nos estágios iniciais da reação através da frente de reação, desapareceu (Figura 4.82e). A partir dos resultados analíticos na escala nanométrica obtidos por STEM/XEDS através da frente de reação migrando, é possível afirmar que o processo de crescimento da 
reação de $\mathrm{PD}$ da fase $\alpha-\mathrm{Cr}$ na Liga 33 é controlado inicialmente pela difusão de $\mathrm{CG}$ do $\mathrm{Cr}$ e, posteriormente, pela difusão de volume do Cr. 

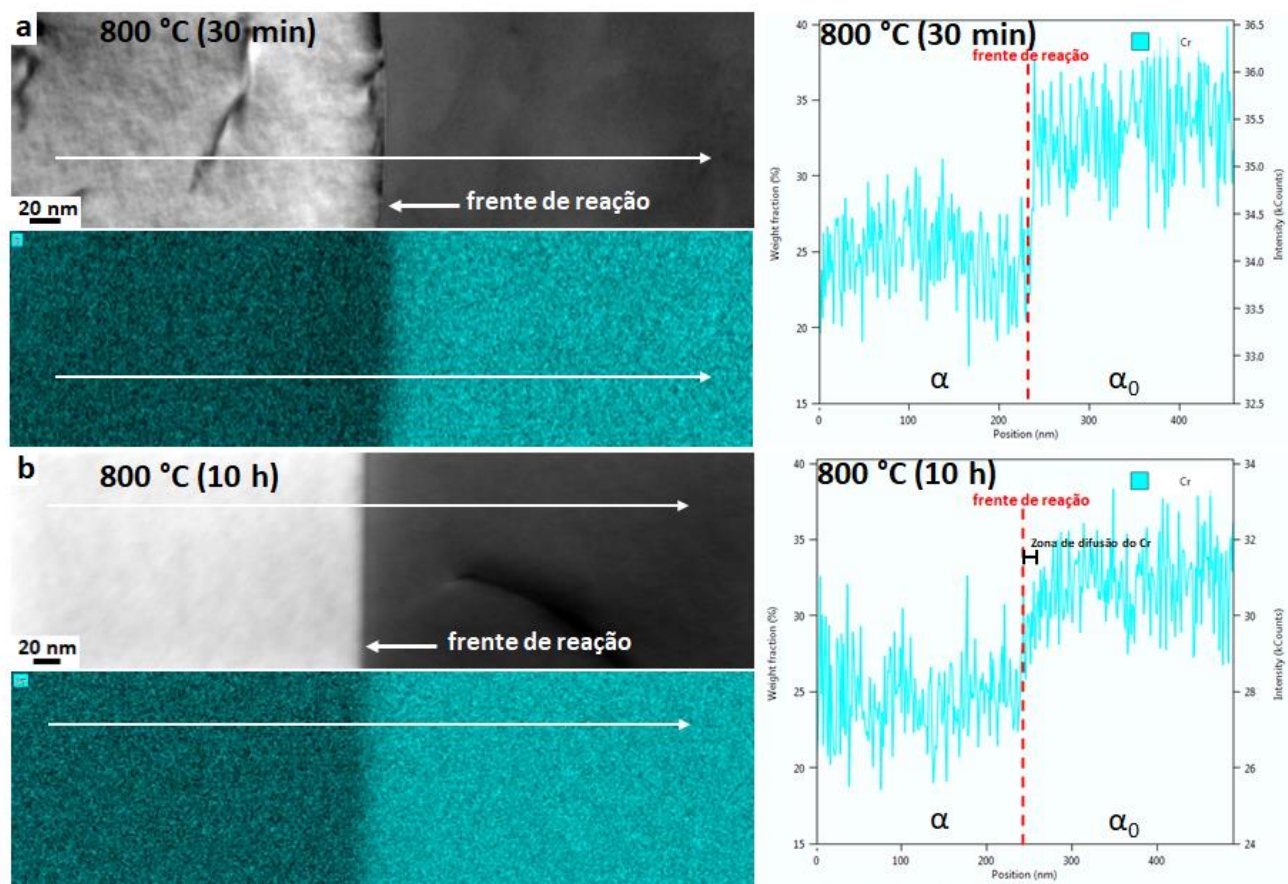

Uू.
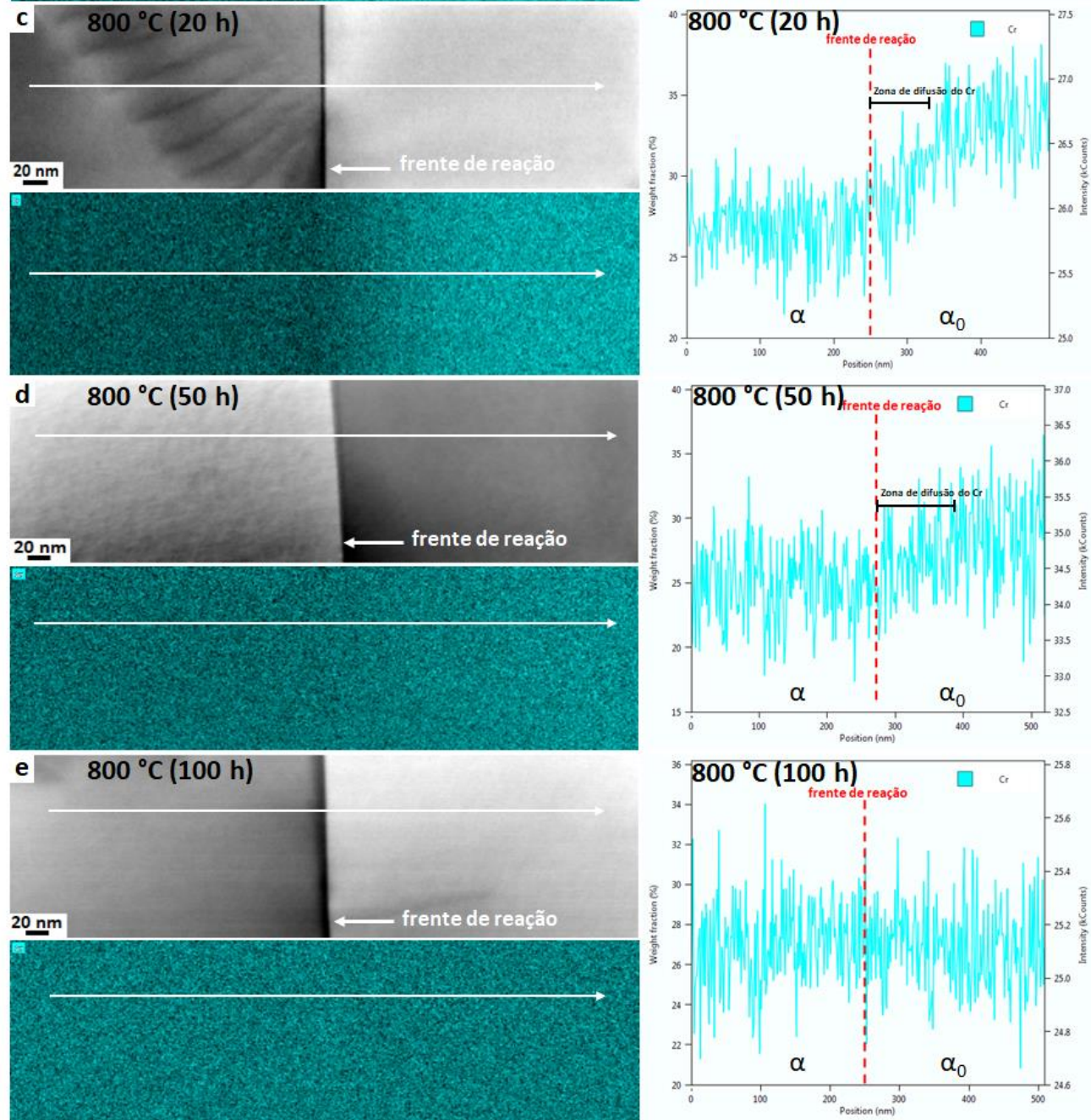

Figura 4.82 - Imagens de STEM-BF da Liga 33 envelhecida a $800{ }^{\circ} \mathrm{C}$, os correspondentes mapas elementares obtidos por STEM/XEDS de uma região através do contorno da frente de reação e os respectivos perfis composicionais extraídos da região indicada pela linha no mapa elementar. (a) $30 \mathrm{~min}$; (b) $10 \mathrm{~h}$; (c) $20 \mathrm{~h}$; d) $50 \mathrm{~h}$; e) $100 \mathrm{~h}$. 
Como verificado na Figura 4.82, a largura da zona de difusão do $\mathrm{Cr}$ aumentou com o tempo de reação. Tal característica pode ser relacionada com a desaceleração na taxa de migração do contorno de célula verificado quando o tempo de reação é aumentado, como mostrado na Figura 4.83. Kikuchi et al. [25] mostrou que o aumento na zona de difusão do $\mathrm{Cr}$ na frente de reação foi a responsável pela diminuição na taxa de migração do contorno, a qual pode ser explicada da seguinte maneira. Se nenhuma difusão de volume ocorre à frente do contorno migrando (Figura 4.82a), a descontinuidade na concentração de soluto continua alta, significando que a força motriz para a migração do contorno também é alta e o movimento do contorno pode continuar. Entretanto, se uma zona de difusão é formada à frente do contorno migrando (Figuras 4.82b, 4.82c e 4.82d), devido à difusão de volume do $\mathrm{Cr}$, a força motriz química é reduzida [255][256], o que resulta na diminuição da taxa de migração da frente de reação da PD, como confirmado na Figura 4.83.

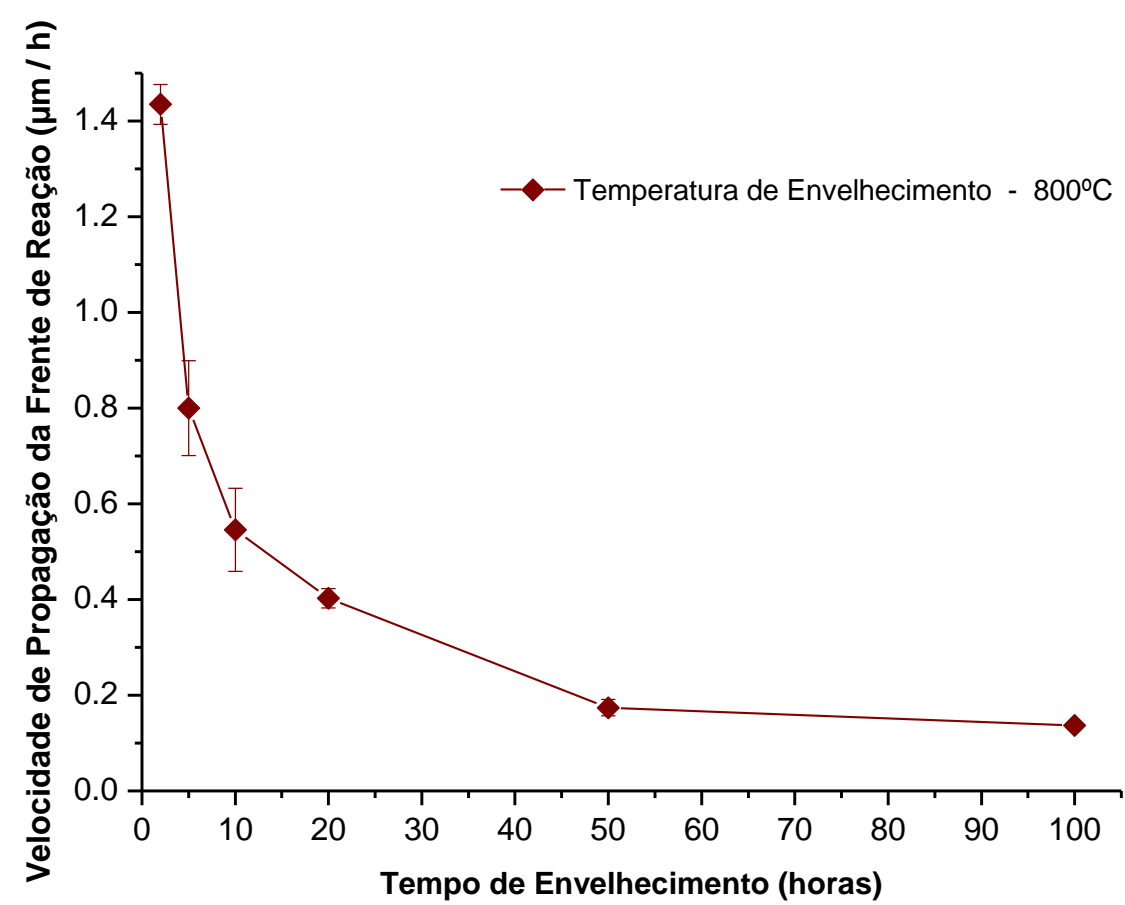

Figura 4.83 - Variação da velocidade de propagação da frente de reação da PD na Liga 33 envelhecida a $800^{\circ} \mathrm{C}$ por $2 \mathrm{~h}$ até $100 \mathrm{~h}$.

A diminuição na taxa de migração do contorno da célula foi confirmada no presente trabalho (Figura 4.83). Nesta figura, são verificados dois diferentes comportamentos durante a reação de PD na Liga 33 envelhecida a $800{ }^{\circ} \mathrm{C}$. Até 10 
$\mathrm{h}$ do processo de envelhecimento, a velocidade de migração do contorno diminuiu a taxas bem maiores quando comparado com tempos mais longos de tratamento, podendo ser considerado que o movimento do contorno praticamente cessa após 100 h. Este comportamento no estado não-estacionário da cinética de crescimento da reação de PD em sistemas multicomponentes já foi evidenciado por outros autores estudando a reação da PD de nitretos- $\mathrm{M}_{2} \mathrm{~N}$ ricos em $\mathrm{Cr}$ [8][9][25], nos quais a desaceleração da frente de reação foi explicada devido à formação de uma zona de difusão de $\mathrm{Cr}$ à frente do contorno migrando resultante da difusão de volume do Cr durante a reação, como também encontrado no presente trabalho.

Entretanto, no presente trabalho deve ser considerado que, concomitante com a diminuição da frente de reação da $\mathrm{PD}$, ocorreu o aumento na fração volumétrica dos precipitados formados dentro dos grãos austeníticos e após $100 \mathrm{~h}$ de envelhecimento, praticamente toda a matriz CFC foi preenchida por precipitados, como mostrado nas Figuras 4.21g e 4.30c. Assim, pode ser inferido que a força motriz para a migração da frente de reação da PD diminuiu por dois fatores: (1) a formação de uma zona de difusão de $\mathrm{Cr}$ à frente do contorno em movimento e (2) a nucleação de novas fases precipitadas dentro da matriz juntamente com o crescimento dos precipitados já existentes também na matriz. Além disso, vale a pena mencionar que devido ao fator (2) mencionado acima, a largura da zona de difusão do Cr à frente do contorno tende a se tornar maior com mais rapidez. 


\section{Conclusões}

Foi realizado um estudo na Liga 33 para investigar os processos de precipitação resultantes de envelhecimentos isotérmicos, principalmente a $800{ }^{\circ} \mathrm{C}$ por tempos de 10 min até 100 h. Este estudo mostra, pela primeira vez, a evolução das reações descontínuas nos CG nesta liga, bem como a identificação das fases precipitadas que constituem as colônias de PD nesta temperatura de envelhecimento. Baseado nas observações microestruturais juntamente com os resultados analíticos obtidos por STEM/XEDS e por difração de elétrons (SAED), é possível chegar as seguintes conclusões:

$1 \mathrm{O}$ primeiro precipitado formado no $\mathrm{CG}$ na Liga 33 foi o carbeto- $\mathrm{M}_{23} \mathrm{C}_{6}$ rico em $\mathrm{Cr}$ com estrutura CFC. Além do carbeto, foi confirmada a formação da fase- $\eta$ enriquecida em Si sempre associada ao carbeto no CG. Os carbetos- $\mathrm{M}_{23} \mathrm{C}_{6}$ com estrutura $\mathrm{CFC}$ e a fase- $\eta$ com estrutura cúbicadiamante têm uma R.O. cubo-a-cubo, $\left[\begin{array}{lll}0 & 0 & 1\end{array}\right]_{M_{23} C_{6}} / /\left[\begin{array}{lll}0 & 0 & 1\end{array}\right]_{\text {matriz } C F C}$ com a matriz CFC.

2 Durante os estágios iniciais do tratamento de envelhecimento, foi verificado que o CG migrou sem conexão com os precipitados formados na posição original do CG, deixando uma região empobrecida em soluto atrás do contorno, o que indica que o fenômeno de migração de CG induzido por difusão, DIGM, desempenha um importante papel como precursor na reação de PD na Liga 33 envelhecida nesta temperatura. Tal fenômeno também foi considerado o responsável pela migração do contorno durante o processo de formação das colônias de PD.

3 A partição de soluto dentro da colônia de PD resultou na formação de cinco diferentes fases precipitadas pertencendo à mesma colônia: (1) carbetos- $\mathrm{M}_{23} \mathrm{C}_{6}$ ricos em $\mathrm{Cr}$ na posição original do $\mathrm{CG}$; (2) fase- $\eta$ enriquecida em Si na posição original do CG e dentro da colônia; (3) precipitados lamelares e nodulares da fase- $\alpha$ rica em $\mathrm{Cr}$; (4) fase intermetálica $\sigma$ na frente de reação da $\mathrm{PD}$; (5) nitreto- $\mathrm{M}_{2} \mathrm{~N}$ rico em $\mathrm{Cr}$ na frente de reação da PD e dentro da colônia. 
4 Os precipitados lamelares da fase $\alpha-\mathrm{Cr}$ com estrutura CCC tem uma $\begin{array}{llll}\text { relação de } & \text { orientação }\end{array}$ $\left(\begin{array}{lll}\overline{1} & 1 & 0\end{array}\right)_{\text {fase } \alpha-C r} / /\left(\begin{array}{lll}\overline{1} & 1 & 1\end{array}\right)_{\text {matriz } C F C} ;\left[\begin{array}{lll}1 & 1 & 1\end{array}\right]_{\text {fase } \alpha-C r} / /$ $\left[\begin{array}{lll}1 & 0 & 1\end{array}\right]_{\text {matriz } C F C}$. Foi verificada outra R.O. entre a fase $\eta$ e a matriz CFC, $\left[\begin{array}{lll}1 & 1 & 2\end{array}\right]_{\text {fase }-\eta} / /\left[\begin{array}{lll}0 & 0 & 1\end{array}\right]_{\text {matriz } C F C}$. A fase intermetálica $\sigma$ tem uma R.O. $\left[\begin{array}{lll}1 & 1 & 0\end{array}\right]_{\text {fase }-\sigma} / /\left[\begin{array}{lll}1 & 0 & 1\end{array}\right]_{\text {matriz-CFC }}$ com a matriz e o nitreto- $\mathrm{M}_{2} \mathrm{~N}$ tem uma R.O. $\left[\begin{array}{llll}0 & 1 & \overline{1} & 0\end{array}\right]_{M 2 N} / /\left[\begin{array}{lll}1 & 0 & 1\end{array}\right]_{\text {matriz } C F C}$ com a matriz CFC.

5 Inicialmente, o crescimento cinético da reação de PD na Liga 33 foi controlado pela difusão intergranular do $\mathrm{Cr}$ e, progressivamente controlada pela difusão de volume do $\mathrm{Cr}$ até os estágios finais do processo de envelhecimento. Resultados de EBSD mostraram a dependência energética para o desenvolvimento da reação de PD, confirmando a necessidade de CG de alto ângulo para a reação ocorrer.

6 A evolução microestrutural durante o envelhecimento a $800{ }^{\circ} \mathrm{C}$ indica que a natureza da reação de PD na Liga 33 difere da teoria de PD clássica. A teoria prevê que o precipitado inicialmente formado no CG (carbeto$\mathrm{M}_{23} \mathrm{C}_{6}$ rico em $\mathrm{Cr}$ ) cresce juntamente com a migração do contorno, mas como mostrado neste trabalho, os precipitados lamelares da PD (fase- $\alpha$ rica em $\mathrm{Cr}$ ) nuclearam e começaram a crescer adjacentes ao $\mathrm{CG}$, e não na posição original do CG. 


\section{6 . Sugestões para Trabalhos Futuros}

No decorrer deste trabalho foi confirmada a complexidade dos fenômenos de precipitação da Liga 33 após ser submetida a tratamentos isotérmicos de envelhecimento. Com base nas observações e conclusões realizadas na presente tese sugerem-se os seguintes estudos complementares:

1 Através da técnica de espectroscopia de perda de energia de elétrons EELS, avaliar qualitativa e quantitativamente os elementos intersticiais, $\mathrm{N}$ e $\mathrm{C}$, nos precipitados formados dentro da colônia de $\mathrm{PD}$, bem como os precipitados convencionais.

2 Explorar o modo de contraste de fase, microscopia em alta resolução, no MET para identificar a natureza das interfaces precipitado/matriz nas diferentes fases, bem como medir o grau de desajuste atômico e, consequentemente, estimar o campo de deformação (strain fields) locais gerados nos processos de precipitação.

3 Estudar a evolução microestrutural no que se refere à identificação das fases precipitadas nos modos convencionais e descontínuo na faixa de temperatura de $600{ }^{\circ} \mathrm{C}$ a $1000{ }^{\circ} \mathrm{C}$ e construir a curva TTT para os diversos precipitados formados na Liga 33.

4 Utilizando a técnica de feixe de íons focalizado (FIB, "focused ion beam") no MEV estudar a formação e crescimento das colônias de PD em três dimensões (3D) afim de avaliar a interação entre os diferentes tipos de precipitados formados dentro da colônia e esclarecer efeitos de corte eventual em fases precipitadas.

5 Avaliar o efeito dos processos de precipitação resultantes do envelhecimento isotérmico na faixa de temperatura de $600{ }^{\circ} \mathrm{C}$ a 1000 ${ }^{\circ} \mathrm{C}$ no desempenho mecânico e na resistência contra a corrosão da Liga 33.

6 Realizar o refino de grão da Liga 33 utilizando tanto a rota termomecânica como a rota térmica. A última consistindo em promover a formação de colônias de PD seguido de dissolução contínua dos precipitados formados na colônia. 
7 Com o produto do refino de grão obtido, como descrito no item anterior, submeter a Liga 33 a tratamentos térmicos de envelhecimento para promover processos de precipitação e comparar com os resultados obtidos após a liga ser somente envelhecida. 


\section{Referências bibliográficas}

[1] T. M. Angeliu and G. S. Was, "Behavior of grain boundary chemistry and precipitates upon thermal treatment of controlled purity alloy 690," Metall. Trans. A, vol. 21, no. 8, pp. 2097-2107, 1990.

[2] Y. S. Lim, D. J. Kim, S. S. Hwang, H. P. Kim, and S. W. Kim, "M23C6 precipitation behavior and grain boundary serration in Ni-based Alloy 690," Mater. Charact., vol. 96, pp. 28-39, 2014.

[3] P. D. Portella, M. Köhler, and M. Renner, "Investigation of Microstructure and Properties of a Chromium-Rich Austenitic Material with High Nitrogen Content," Mater. Sci. Forum, vol. 318-320, pp. 201-208, 1999.

[4] T.-H. Lee, C.-S. Oh, C. G. Lee, S.-J. Kim, and S. Takaki, "Precipitation of $\sigma$-phase in high-nitrogen austenitic $18 \mathrm{Cr}-18 \mathrm{Mn}-2 \mathrm{Mo}-0.9 \mathrm{~N}$ stainless steel during isothermal aging," Scr. Mater., vol. 50, no. 10, pp. 1325-1328, 2004.

[5] I. F. Machado and A. F. Padilha, "Aging Behaviour of $25 \mathrm{Cr}-17 \mathrm{Mn}$ High Nitrogen Duplex Stainless Steel.," ISIJ Int., vol. 40, no. 7, pp. 719-724, 2000.

[6] P. J. Maziasz, "The formation diamond-cubic eta ( $\eta$ ) phase in type 316 stainless steel exposed to thermal aging or irradiation environments," Scr. Metall., vol. 13, no. 7, pp. 621-626, 1979.

[7] R. F. A. Jargelius-Pettersson, "Precipitation in a nitrogen-alloyed stainless steel at $850^{\circ} \mathrm{C}, "$ S Scr. Metall. Mater., vol. 28, no. 11, pp. 1399-1403, 1993.

[8] M. Kikuchi, M. Kajihara, and S.-K. Choi, "Cellular precipitation involving both substitutional and interstitial solutes: cellular precipitation of $\mathrm{Cr} 2 \mathrm{~N}$ in $\mathrm{Cr}-\mathrm{Ni}$ austenitic steels," Mater. Sci. Eng. A, vol. 146, pp. 131-150, 1991.

[9] F. Vanderschaeve, R. Taillard, and J. Foct, "Discontinuous precipitation of $\mathrm{Cr} 2 \mathrm{~N}$ in a high nitrogen, chromium-manganese austenitic stainless steel," J. Mater. Sci., vol. 30, pp. 6035-6046, 1995.

[10] A. Heckl, S. Cenanovic, M. Göken, and R. F. Singer, "Discontinuous Precipitation and Phase Stability in Re- and Ru-Containing Nickel-Base Superalloys," Metallurgical and Materials Transactions A, vol. 43A. pp. 10-19, 2012.

[11] H. F. Merrick, H. W. Hayden, and R. C. Gibson, "The effect of carbon and titanium on the hot workability of $25 \mathrm{Cr}-6 \mathrm{Ni}$ stainless steels," Metall. Trans., vol. 4, no. March, pp. 827-832, 1973.

[12] A. A. Tavassoli and G. Colombe, "On the Creep Ductility decline of Alloy 800," Scr. Metall., vol. 11, pp. 191-192, 1977.

[13] A. A. Tavassoli and G. Colombe, "Mechanical and microstructural properties of alloy 800," Metall. Trans. A, vol. 9, no. 9, pp. 1203-1211, 1978.

[14] J. W. Simmons, D. G. Atteridge, and J. C. Rawers, "Sensitization of High-Nitrogen Austenitic Stainless Steels by Dichromium Nitride Precipitation," Corros. Sci., vol. 50, no. 7, p. 491, 1994. 
[15] J. W. Simmons, "Influence of Nitride (Cr2N) Precipitation on the plasstic Flow Behavior of High-Nirogen Austenitic Stainless Steel," Scr. Metall. Mater., vol. 32, no. 9, pp. 265-270, 1995.

[16] J. W. Simmons, "Mechanical properties of isothermally aged high-nitrogen stainless steel," Metall. Mater. Trans. A, vol. 26, no. October, pp. 2579-2595, 1995.

[17] W. S. Walston, J. C. Schaeffer, and W. H. Murphy, "A new type of microstructural instability in superalloys - SRZ," Superalloys 1996, pp. 9-18, 1996.

[18] T. Lee, S. Kim, and S. Takaki, "Time-temperature-precipitation characteristics of high nitrogen austenitic Fe-18Cr-18Mn-2Mo-0.9N steel," Metall. Mater. Trans. A, vol. 37, no. December, pp. 3445-3454, 2006.

[19] L. Zheng, X. Hu, X. Kang, and D. Li, "Precipitation of M23C6 and its Effect on TensilePproperties of 0.3C-20Cr-11Mn-1Mo-0.35N Steel," Mater. Des., vol. 78, pp. 42-50, 2015.

[20] E. L. Raymond, "Mechanisms of Sensitization and Stabilization of INCOLOY NickelIron-Chromium Alloy 825," Corrosion, vol. 24, no. 6, pp. 180-188, 1968.

[21] I. Chattoraj, S. K. Das, S. Jana, S. P. Chakraborty, and A. K. Bhattamishra, "Passivity breakdown due to discontinuous precipitation during ageing of $21 \mathrm{Cr}$ 10Mn-5Ni stainless steel," J. Mater. Sci., vol. 30, no. 20, pp. 5313-5320, 1995.

[22] $\mathrm{H}$. Ha and $\mathrm{H}$. Kwon, "Effects of $\mathrm{Cr} 2 \mathrm{~N}$ on the pitting corrosion of high nitrogen stainless steels," Electrochim. Acta, vol. 52, no. 5, pp. 2175-2180, 2007.

[23] I. Manna, S. K. Pabi, and W. Gust, "Discontinuous reactions in solids," Int. Mater. Rev., vol. 46, no. 2, pp. 53-91, 2001.

[24] D. B. Williams and E. P. Butler, "Grain boundary discontinuous precipitation reactions," International Materials Reviews, vol. 26, no. 1. pp. 153-183, 1981.

[25] M. Kikuchi, T. Urabe, G. Cliff, and G. W. Lorimer, "The loss of driving force due to volume diffusion ahead of a migrating boundary in a cellular precipitation reaction," Acta Metall. Mater., vol. 38, no. 6, pp. 1115-1120, 1990.

[26] M. Köhler, U. Heubner, K.-W. Eichenhofer, and M. Renner, "Nicrofer 3033 - alloy 33: A new corrosion-resistant austenitic material for many applications," VDM Rep., no. 24, 1998.

[27] “Nicrofer 3033 - Alloy 33 - Material Data Sheet," no. 4042, 2000.

[28] M. S. Elbakhshwan et al., "High-temperature oxidation of advanced FeCrNi alloy in steam environments," Appl. Surf. Sci., vol. 426, pp. 562-571, 2017.

[29] J. Klöwer, I. Rommerskirchen, A. Kolb-Telieps, and M. Köhler, "Alloy 33 - A New High Strength Austenitic Alloy for Marine Applications," Corros. 2000, no. 636, 2000.

[30] J. C. Spadotto, J. Dille, M. Watanabe, and I. G. Solórzano, "Grain boundary precipitation phenomena in an alloy $33(\mathrm{Cr}-\mathrm{Fe}-\mathrm{Ni}-\mathrm{N})$ subjected to direct-aging treatments $\left(700^{\circ} \mathrm{C}\right.$ and $\left.900^{\circ} \mathrm{C}\right), "$ Mater. Charact., vol. 140, no. April, pp. 113- 
121, 2018.

[31] M. Köhler, U. Heubner, K.-W. Eichenhofer, and M. Renner, "Progress with Alloy 33 (UNS R20033), A New Corrosion Resistant Chromium-Based Austenitic Material," Corros. 1996, no. 428, 1996.

[32] S. Nagarajan and N. Rajendran, "Crevice corrosion behaviour of superaustenitic stainless steels: Dynamic electrochemical impedance spectroscopy and atomic force microscopy studies," Corros. Sci., vol. 51, no. 2, pp. 217-224, 2009.

[33] M. Köhler, U. Heubner, K.-W. Eichenhofer, and M. Renner, "Alloy 33 - A New Chromium-Based Corrosion Resistant Austenitic Material," Chem. Pet. Eng., vol. 32, no. 6, pp. 615-621, 1996.

[34] D. C. Agarwal and M. Köhler, "Alloy 33, A New Material Resisting Marine Corrosion," Corros. 97, no. 424, pp. 1-17, 1997.

[35] A. Gildenpfennig, U. Gramberg, and G. Hohlneicher, "Passivation and corrosion of the metallic high performance materials Alloy 33 and MC-Alloy in different environments," Corros. Sci., vol. 45, no. 3, pp. 575-595, 2003.

[36] M. Köhler, U. Heubner, K.-W. Eichenhofer, and M. Renner, "Alloy 33: A New Material for the Handling of HNO3/HF Media in Reprocessing of Nuclear Fuel," Corros. 1997, no. 115, 1997.

[37] L. Paul and G. Clark, "Coal Ash Corrosion Resistance of New High Chromium and Chromium-Silicon Alloys," Corros. 2005, NACE Int., no. 05453, pp. 1-11, 2005.

[38] R. M. Deacon, J. N. DuPont, and A. R. Marder, "High Temperature Corrosion Resistance of Candidate Nickel-based Weld Overlay Alloys in a Low NOx Environment," Mater. Sci. Eng. A, vol. 460-461, pp. 392-402, 2007.

[39] L. Paul, G. Clark, and M. Eckhardt, "Laboratory and Field Corrosion Performance of a High Chromium Alloy for Protection of Waterwall Tubes from Corrosion in Low NOx Coal Fired Boilers," Corros. 2006, no. 06473, pp. 1-14, 2006.

[40] L. Paul, "Weld Overlay Materials for Extending the Life of Boiler Tubes in Coal Fired Power Plants," Corros. 2008, no. 08442, pp. 1-17, 2008.

[41] S. Bsat, B. Xiao, X. Huang, and S. Penttilä, "Oxidation Behaviour of Alloys $800 \mathrm{H}$, 3033 and 304 in High-Temperature Supercritical Water," Oxid. Met., vol. 89, no. 1-2, pp. 151-163, 2018.

[42] S. Mahboubi, G. A. Botton, and J. R. Kish, "Corrosion Resistance of Alloy 33 (Fe33Cr-32Ni) in Supercritical Water," Corrosion, vol. 71, no. 9, pp. 1064-1070, 2015.

[43] V. Kain, P. Sengupta, P. K. De, and S. Banerjee, "Case reviews on the effect of microstructure on the corrosion behavior of austenitic alloys for processing and storage of nuclear waste," Metall. Mater. Trans. A Phys. Metall. Mater. Sci., vol. 36, no. 5, pp. 1075-1084, 2005.

[44] R. B. Rebak, "Alloy Selection for Accident Tolerant Fuel Cladding in Commercial Light Water Reactors," Metall. Mater. Trans. E, vol. 2, no. 4, pp. 197-207, 2015. 
[45] I. Younker and M. Fratoni, "Neutronic evaluation of coating and cladding materials for accident tolerant fuels," Prog. Nucl. Energy, vol. 88, pp. 10-18, 2016.

[46] L. Paul and H. Alves, "Alloy 33: A Versatile Alloy for Concentrated Mineral Acid and Others Applications," Corros. 2004, no. 04226, pp. 1-13, 2004.

[47] B. A. Pint, K. A. Terrani, M. P. Brady, T. Cheng, and J. R. Keiser, "High temperature oxidation of fuel cladding candidate materials in steam-hydrogen environments," J. Nucl. Mater., vol. 440, no. 1-3, pp. 420-427, 2013.

[48] M. Fulger, M. Mihalache, D. Ohai, S. Fulger, and S. C. Valeca, "Analyses of oxide films grown on AISI 304L stainless steel and Incoloy 800HT exposed to supercritical water environment," J. Nucl. Mater., vol. 415, no. 2, pp. 147-157, 2011.

[49] L. Tan, T. R. Allen, and Y. Yang, "Corrosion behavior of alloy $800 \mathrm{H}$ (Fe-21Cr-32Ni) in supercritical water," Corros. Sci., vol. 53, no. 2, pp. 703-711, 2011.

[50] J. Li, W. Zheng, S. Penttilä, P. Liu, O. T. Woo, and D. Guzonas, "Microstructure stability of candidate stainless steels for Gen-IV SCWR fuel cladding application," J. Nucl. Mater., vol. 454, no. 1-3, pp. 7-11, 2014.

[51] E. J. Dolley, P. L. Andresen, M. M. Morra, X. Lou, and R. B. Rebak, "Cracking Resistance of Chromium Rich Alloys in High Temperature Water," Corros. 2014, no. 4293, pp. 1-20, 2014.

[52] T.-H. Lee, H.-Y. Ha, and S.-J. Kim, "Precipitation of Second Phases in HighInterstitial-Alloyed Austenitic Steel," Metall. Mater. Trans. A, vol. 42, no. 12, pp. 3543-3548, 2011.

[53] L. Zheng, X. Hu, X. Kang, and D. Li, "Precipitation of M23C6 and its effect on tensile properties of $0.3 \mathrm{C}-20 \mathrm{Cr}-11 \mathrm{Mn}-1 \mathrm{Mo}-0.35 \mathrm{~N}$ steel," Mater. Des., vol. 78, pp. 42-50, 2015.

[54] T. Lee, S. Kim, and Y. Jung, "Crystallographic details of precipitates in Fe-22Cr21Ni-6Mo-(N) superaustenitic stainless steels aged at $900{ }^{\circ} \mathrm{C}, "$ Metall. Mater. Trans. A, vol. 31, pp. 1713-1723, 2000.

[55] S. Zhang et al., "Precipitation behavior and phase transformation mechanism of super austenitic stainless steel S32654 during isothermal aging," Mater. Charact., vol. 137, no. November 2017, pp. 244-255, 2018.

[56] B. Zhang, Z. Jiang, H. Li, S. Zhang, H. Feng, and H. Li, "Precipitation behavior and phase transformation of hyper duplex stainless steel UNS S32707 at nose temperature," Mater. Charact., vol. 129, no. September 2016, pp. 31-39, 2017.

[57] H. I. Aaronson, M. Enomoto, and J. K. Lee, Mechanisms of Diffusion Phase Transformations in Metals and Alloys. 2010.

[58] R. Abbaschian, L. Abbaschian, and R. E. Reed-Hill, Physical Metallurgy Principles. 2009.

[59] K. H. Lo, C. H. Shek, and J. K. L. Lai, "Recent developments in stainless steels," Mater. Sci. Eng. R Reports, vol. 65, no. 4-6, pp. 39-104, 2009. 
[60] T. Sourmail and H. K. D. H. Bhadeshia, "Microstructural evolution in two variants of NF709 at 1023 and 1073 K," Metall. Mater. Trans. A, vol. 36, no. 1, pp. 23-34, 2005.

[61] F. Sun, Y. F. Gu, J. B. Yan, Z. H. Zhong, and M. Yuyama, "Phenomenological and microstructural analysis of intermediate temperatures creep in a Ni-Fe-based alloy for advanced ultra-supercritical fossil power plants," Acta Mater., vol. 102, pp. 70-78, 2016.

[62] D. A. Porter, K. E. Easterling, and Y. Sherif, Phase Transformations in Metals and Alloys. 2009.

[63] L. Priester, "Precipitation at Grain Boundaries," in Grain Boundaries, vol. 172, 2013, pp. 217-240.

[64] G. R. Purdy and Y. J. M. Brechet, "Transformations Involving Interfacial Diffusion," in Phase Transformations in Materials, 2001, pp. 482-516.

[65] M. H. Lewis and B. Hattersley, "Precipitation of M23C6 in austenitic steels," Acta Metall., vol. 13, no. 11, pp. 1159-1168, 1965.

[66] L. K. Singhal and J. W. Martin, "The growth of M23C6 carbide on incoherent twin boundaries in austinite," Acta Metall., vol. 15, no. October, pp. 1603-1610, 1967.

[67] F. R. Beckitt and B. R. Clark, "The shape and mechanism of formation of M23C6 carbide in austenite," Acta Metall., vol. 15, no. 1, pp. 113-129, 1967.

[68] L. K. Singhal and J. W. Martin, "The nucleation and growth of widmannstätten M23C6 precipitation in an austenitic stainless steel," Acta Metall., vol. 16, no. 9, pp. 1159-1165, 1968.

[69] J. P. Adamson and J. W. Martin, "The nucleation of M23C6 carbide particles in the grain boundaries of an austenitic stainless steel," Acta Metall., vol. 19, no. 10, pp. 1015-1018, 1971.

[70] B. Weiss and R. Stickler, "Phase instabilities during high temperature exposure of 316 austenitic stainless steel," Metall. Trans., vol. 3, no. 4, pp. 851-866, 1972.

[71] H. Tanaka, M. Murata, F. Abe, and H. Irie, "Microstructural evolution and change in hardness in type $304 \mathrm{H}$ stainless steel during long-term creep," Mater. Sci. Eng. A, vol. 319, no. 321, pp. 788-791, 2001.

[72] T. M. Williams, J. M. Titchmarsh, and D. R. Arkell, "Void-swelling and precipitation in a neutron-irradiated, niobium-stabilised austenitic stainless steel," J. Nucl. Mater., vol. 107, no. 2-3, pp. 222-244, 1982.

[73] R. M. Boothby, D. R. Harries, and T. M. Williams, "Precipitation and void-swelling in nickel-manganese austenitic stainless steels," J. Nucl. Mater., vol. 115, no. 1, pp. 16-24, 1983.

[74] Y. S. Lim, J. S. Kim, H. P. Kim, and H. D. Cho, "The effect of grain boundary misorientation on the intergranular $\mathrm{M} 23 \mathrm{C} 6$ carbide precipitation in thermally treated Alloy 690," J. Nucl. Mater., vol. 335, no. 1, pp. 108-114, 2004.

[75] T.-H. Lee and S.-J. Kim, "Phase identification in an isothermally aged austenitic 
22Cr-21Ni-6Mo-N stainless steel," Scr. Mater., vol. 39, no. 7, pp. 951-956, 1998.

[76] E. A. Trillo and L. E. Murr, "A TEM investigation of M23C6 carbide precipitation behaviour on varying grain boundary misorientations in 304 stainless steels," J. Mater. Sci., vol. 33, no. 5, pp. 1263-1271, 1998.

[77] E. A. Trillo and L. E. Murr, "Effects of carbon content, deformation, and interfacial energetics on carbide precipitation and corrosion sensitization in 304 stainless steel," Acta Mater., vol. 47, no. 1, pp. 235-245, 1998.

[78] H. Liu, M. Gao, D. G. Harlow, and R. P. Wei, "Grain boundary character, and carbide size and spatial distribution in a ternary nickel alloy," Scr. Metall. Mater., vol. 32, no. 11, pp. 1807-1812, 1995.

[79] H. Li, S. Xia, B. Zhou, and J. Peng, "The growth mechanism of grain boundary carbide in Alloy 690," Mater. Charact., vol. 81, pp. 1-6, 2013.

[80] N. Terao and B. Sasmal, "Precipitation of M23C6 Type Carbide on Twin Boundaries in Austenitic Stainless Steels," Metallography, vol. 13, pp. 117-133, 1980.

[81] J. K. L. Lai, "A Rewiew of Precipitation Behavior in AISI Type 316 Stainless Steel," Mater. Sci. Eng., vol. 61, pp. 101-109, 1983.

[82] J. E. Spruiell, J. A. Scott, C. S. Ary, and R. L. Hardin, "Microstructural Stability of Thermal-Mechanically Pretreated Type 316 Austenitic Stainless Steel," Metall. Trans., vol. 4, pp. 1533-1544, 1973.

[83] L. Jiang, R. Hu, H. Kou, J. Li, G. Bai, and H. Fu, "The effect of M $23 \mathrm{C} 6$ carbides on the formation of grain boundary serrations in a wrought Ni-based superalloy," Mater. Sci. Eng. A, vol. 536, pp. 37-44, 2012.

[84] T. M. Williams and J. M. Titchmarsh, "Silicon-Rich Phases in Austenitic Alloys," J. Nucl. Mater., vol. 98, pp. 223-226, 1981.

[85] N. Evans, P. Maziasz, and J. Truhan, "Phase Transformations During Service Aging of Nickel Based Superalloy Pyromet 31V," Solid-Solid Phase Transform. ..., 2005.

[86] M. Vach et al., "Evolution of secondary phases in austenitic stainless steels during long-term exposures at 600,650 and $800^{\circ}$ C," Mater. Charact., vol. 59, pp. 1792-1798, 2008.

[87] L. J. Wang, L. Y. Sheng, and C. M. Hong, "Influence of grain boundary carbides on mechanical properties of high nitrogen austenitic stainless steel," Mater. Des., vol. 37, pp. 349-355, 2012.

[88] S. M. Bruemmer and C. H. Henager Jr, "High Voltage Electron Microscopy Observations of Microdeformation in Alloy 600 Tubing," Scr. Metall., vol. 20, no. c, pp. 909-914, 1986.

[89] G. C. Hasson and C. Goux, "Interfacial energies of tilt boundaries in aluminium. Experimental and Theoretical Determination," Scr. Metall., vol. 5, pp. 889-894, 1971.

[90] L. E. Murr, R. J. Hoeylev, and W. N. Lin, "Configurational equilibrium at twin-grain 
boundary intersections in F.C.C metals and alloys, and the measurement of relative interfacial torque," Philos. Mag., vol. 20, no. 168, pp. 1245-1264, 1969.

[91] H. J. Goldschmidt, Interstitial Alloys. 1967.

[92] A. L. Bowman, G. P. Arnold, E. K. Storms, and N. G. Nereson, "The crystal structure of Cr23C6," Acta Crystallogr. B, vol. 28, no. 10, pp. 3102-3103, 1972.

[93] M. Ou, X. Hao, Y. Ma, R. Liu, L. Zhang, and K. Liu, "Effect of carbon on the microstructure and stress rupture properties of a new Ni-Cr-W-Fe alloy for advanced ultra-supercritical power plants," J. Alloys Compd., vol. 732, pp. 107115, 2018.

[94] M. Ou et al., "Microstructure evolution and mechanical properties of a new cast Ni-base superalloy with various Ti contents," J. Alloys Compd., vol. 735, pp. 193201, 2018.

[95] Y. B. Kuz'ma and T. F. Fedorov, "Phase Equilibria in the System MolybdenumChromium-Carbon," Powder Metall. Met. Ceram., vol. 4, pp. 920-922, 1965.

[96] W. B. Pearson, A handbook of lattice spacings and structures of metals and alloys. 1958.

[97] X. P. Tan et al., "Carbide precipitation characteristics in additive manufacturing of Co-Cr-Mo alloy via selective election beam melting," Scr. Mater., vol. 143, pp. 117-121, 2018.

[98] C. M. Hong, J. Shi, L. Y. Sheng, W. C. Cao, W. J. Hui, and H. Dong, "Effects of hotworking parameters on microstructural evolution of high nitrogen austenitic stainless steel," Mater. Des., vol. 32, no. 7, pp. 3711-3717, 2011.

[99] S. M. Bruemmer, L. A. Charlot, and C. H. Henager, "Microstructure and microdeformation effects on IGSCC of Alloy 600 steam generator tubing," Corrosion, vol. 44, no. 11, pp. 782-788, 1988.

[100] P. K. De and S. K. Ghosal, "A Comparative Study of Stress Corrosion Cracking Of Steam Generator Tube Materials in Water at $315 \mathrm{C}^{*}$," Corrosion-Nace, vol. 37, no. 6, pp. 341-349, 1981.

[101] G. P. Airey, "Effect of Carbon Content and Thermal Treatment on the SCC Behavior of Inconel Alloy 600 Steam Generator Tubing.," Corrosion, vol. 35, no. 3, pp. 129-136, 1979.

[102] M. Vrinat, R. Cozar, and Y. Meyzaud, "Precipitated Phases in the Ferrite of Aged Cast Duplex Stainless Steels," Scr. Metall., vol. 20, pp. 1101-1106, 1986.

[103] D. J. Powell, R. Pilkington, and D. A. Miller, "The precipitation characteristics of $20 \% \mathrm{Cr} / 25 \%$ NiNb stabilised stainless steel," Acta Metall., vol. 36, no. 3, pp. $713-$ 724, 1988.

[104] R. C. Ecob, R. C. Lobb, and V. L. Kohler, "The formation of G-phase in 20/25 Nb stainless steel AGR fuel cladding alloy and its effect on creep properties," J. Mater. Sci., vol. 22, no. 8, pp. 2867-2880, 1987.

[105] T. M. Williams and J. M. Titchmarsh, "The occurrence of a silicon-rich phase of 
the M6C type in neutron-irradiated FV548 steel," J. Nucl. Mater., vol. 87, no. 2-3, pp. 398-400, 1979.

[106] J. K. L. Lai, "Precipitate phases in type 321 steel," Mater. Sci. Technol., vol. 1, no. 2, pp. 97-100, 1985.

[107] T. M. Williams, J. M. Titchmarsh, and D. R. Arkell, "A nickel-and silicon-rich phase in irradiated FV548 steel," J. Nucl. Mater., vol. 82, no. 1, pp. 199-201, 1979.

[108] J. P. Shingledecker and G. M. Pharr, "The role of eta phase formation on the creep strength and ductility of inconel alloy 740 at $1023 \mathrm{~K}\left(750^{\circ} \mathrm{C}\right), "$ Metall. Mater. Trans. A, vol. 43, no. 6, pp. 1902-1910, 2012.

[109] M. K. Miller, J. Bentley, S. S. Brenner, and J. A. Spitznagel, "Long Term Thermal Aging of Type Cf 8 Stainless Steel," Le J. Phys. Colloq., vol. 45, no. C9, p. 6, 1984.

[110] H. Hughes, "A New Silicide in a 12 per cent Chromium Steel," Nature, vol. 183, p. 1543, 1959.

[111] S. J. Tither and B. R. Clark, "Precipitation of H Phase in a High-Silicon Austenitic Stainless Steel," Met. Sci., vol. 4, no. June, pp. 118-120, 1970.

[112] H. R. Brager and F. A. Garner, "Swelling as a consequence of gamma prime $\left(\gamma^{\prime}\right)$ and M23(C, Si)6 formation in neutron irradiated 316 stainless steel," J. Nucl. Mater., vol. 73, no. 1, pp. 9-19, 1978.

[113] J. M. Leitnaker, G. A. Potter, D. J. Bradley, J. C. Franklin, and W. R. Laing, "The Composition of Eta Carbide in Hastelloy N After Aging 10,000 h at $815{ }^{\circ} \mathrm{C}$," Metall. Trans. A, vol. 9, no. March, pp. 397-400, 1978.

[114] X. M. Guan and H. Q. Ye, "Intergranular embrittlement caused by the precipitation of M6C carbide containing silicon," J. Mater. Sci., vol. 15, pp. 29352937, 1980.

[115] J. P. Shingledecker, N. D. Evans, and G. M. Pharr, "Influences of composition and grain size on creep-rupture behavior of Inconel ${ }^{\circledR}$ alloy 740," Mater. Sci. Eng. A, vol. 578, pp. 277-286, 2013.

[116] J. M. Leitnaker, R. L. Klueh, and W. R. Laing, "The composition of eta carbide phase in 2 1/4 Cr-1 Mo Steel," Metall. Trans. A, vol. 6, no. 11, pp. 1949-1955, 1975.

[117] Z. Zhu, C. Cheng, C. Liu, and J. Zhao, "Microstructure evolution and nitridation in an as-cast $25 \mathrm{Cr}$-35Ni-1Mo radiant tube after long-term service," Metall. Mater. Trans. A, vol. 43, no. 12, pp. 4525-4531, 2012.

[118] P. J. Maziasz, "The Precipitation Response of 20\%-Cold Worked Type 316 Stainless Steel to Simulated Fusion Irradiation," J. Nucl. Mater., vol. 85 \& 86, pp. 713-717, 1979.

[119] H. H. Stadelmaier, Developments in the Structural Chemistry of Alloy Phases. 1969.

[120] E. H. Lee, A. F. Rowcliffe, and E. A. Kenik, "Effects of Si and Ti on the phase stability and swelling behavior of AISI 316 stainless steel," J. Nucl. Mater., vol. 83, 
no. 1, pp. 79-89, 1979.

[121] K. W. Andrews, D. J. Dyson, and S. R. Keown, Interpretation of Electron Diffraction Patterns. 1967.

[122] W. Gailian et al., "The microstructural changes and their effect on CCGR after long time thermal exposure in DA718 and STD718," Mater. Sci. Eng. A, vol. 358, no. 1-2, pp. 71-75, 2003.

[123] J. F. Radavich, "Effect of Alpha Chromium on Long Time Behavior of Alloy 718," Superalloys 718, 625, 706 Var. Deriv., pp. 409-415, 1997.

[124] S. Khan, J. B. Singh, A. Verma, and M. Karri, "Precipitation of a chromium-rich $\alpha$ phase in Alloy 693 and its effect on tensile properties," Mater. Sci. Eng. A, vol. 686, no. October 2016, pp. 176-183, 2017.

[125] H. Semba, "Development of Boiler Tubes and Pipes for Advanced USC Power Plants," Tech. Rep., no. 107, pp. 71-77, 2015.

[126] T. Tokairin, K. V. Dahl, H. K. Danielsen, F. B. Grumsen, T. Sato, and J. Hald, "Investigation on long-term creep rupture properties and microstructure stability of Fe-Ni based alloy Ni-23Cr-7W at $700^{\circ}$ C," Mater. Sci. Eng. A, vol. 565, pp. 285291, 2013.

[127] J. F. Radavich and A. Fort, "Effects of Long Time Exposure in Alloy 625 at $1200^{\circ} \mathrm{F}$, $1400^{\circ} \mathrm{F}$ and $1600^{\circ} \mathrm{F}, "$ Superalloys 718,625 Var. Deriv., pp. 635-47, 1994.

[128] X. Xie et al., "Alpha chromium formation in Alloy 718 and its effect on creep crack propagation," Superalloys 718, 625, 706 Var. Deriv., pp. 399-410, 2001.

[129] G. Shen, J. Radavich, X. Xie, and B. Lindsley, "The Effects of Processing on Stability of Alloy 718," Superalloys 2000 (Ninth Int. Symp.), pp. 445-448, 2000.

[130] J. P. Shingledecker and N. D. Evans, "Creep-rupture performance of 0.07C-23Cr45Ni-6W-Ti,Nb austenitic alloy (HR6W) tubes," Int. J. Press. Vessel. Pip., vol. 87, no. 6, pp. 345-350, 2010.

[131] Z. Bi, J. Dong, L. Zheng, and X. Xie, "Phenomenon and Mechanism of High Temperature Low Plasticity in High-Cr Nickel-based Superalloy," J. Mater. Sci. Technol., vol. 29, no. 2, pp. 187-192, 2013.

[132] L. Zheng, C. Xiao, G. Zhang, B. Han, and D. Tang, "Primary $\alpha$ phase and its effect on the impact ductility of a high $\mathrm{Cr}$ content cast Ni-base superalloy," J. Alloys Compd., vol. 527, pp. 176-183, 2012.

[133] J. Dong, B. Zhongnan, N. Wang, X. Xie, and Z. Wang, "Structure control of a newtype high-Cr superalloy," Superalloys 2008, pp. 41-50, 2008.

[134] D. Wu, D. Li, and S. Lu, "Effect of Cr content on the microstructural stability and impact- toughness evolution of a Ni-Fe-based weld metal," J. Alloys Compd., vol. 749, pp. 465-472, 2018.

[135] D. Wu, D. Li, and S. Lu, "Microstructural evolution and mechanical property of a $\mathrm{Ni}$-Fe-based weld metal during long-term exposure at $650^{\circ} \mathrm{C}$ and $700^{\circ} \mathrm{C}, "$ Mater. Sci. Eng. A, 2018. 
[136] C. P. Luo and G. C. Weatherly, "The crystallography of heterogeneous nucleation in a Ni-45 wt\% Cr alloy," Acta Metall., vol. 37, no. 3, pp. 791-801, 1989.

[137] N. Keskar, A. K. Pattanaik, K. V. Mani Krishna, D. Srivastava, and G. K. Dey, "Kinetics and Grain Boundary Selectivity of Discontinuous Precipitation in Binary Ni-Cr Alloy," Metall. Mater. Trans. A, 2017.

[138] C. Miller, R. Field, and M. Kaufman, "Phase stability of $\gamma^{\prime}-\mathrm{Ni2} \mathrm{Cr}$ and $\alpha-\mathrm{Cr}$ in the NiCr binary," Acta Mater., vol. 157, 2018.

[139] Y. Koyanagi, H. Takabayashi, and H. Y. Yasuda, "Influence of $\mathrm{Cr}$ Content on Cellular Precipitation Behaviour of Ni-38Cr-3.8Al Alloy with Lamellar Structure," Mater. Sci. Forum, vol. 941, pp. 1203-1209, 2018.

[140] S. Ueta, M. Hida, and M. Kajihara, "Effects of Fe, W and Mo on Kinetics of Discontinuous Precipitaion in the Ni-Cr System," Mater. Trans., vol. 53, pp. 17441752, 2012.

[141] A. Marucco, "Atomic ordering and $\alpha^{\prime}$-Cr phase precipitation in long-term aged $\mathrm{Ni3Cr}$ and Ni2Cr alloys," J. Mater. Sci., vol. 30, no. 16, pp. 4188-4194, 1995.

[142] E. O. Hall and S. H. Algie, "The Sigma Phase," Metall. Reviws, vol. 11, pp. 61-88, 1966.

[143] A. J. Sedriks, "Corrosion resistance of austenitic Fe-Cr-Ni-Mo alloys in marine environments," Int. Met. Rev., vol. 27, no. 1, pp. 321-353, 1982.

[144] J. Bakajová, M. Dománková, R. Čička, S. Eglsäer, and J. Janovec, "Influence of annealing conditions on microstructure and phase occurrence in high-alloy CrMnN steels," Mater. Charact., vol. 61, no. 10, pp. 969-974, 2010.

[145] J. Källqvist and H.-O. Andrén, "Microanalysis of a stabilised austenitic stainless steel after long term ageing," Mater. Sci. Eng. A, vol. 270, no. 1, pp. 27-32, 1999.

[146] G. Bergman and D. P. Shoemaker, "The determination of the crystal structure of the $\sigma$ phase in the iron-chromium and iron-molybdenum systems," Acta Crystallogr., vol. 7, no. 12, pp. 857-865, 1954.

[147] J. Barcik, "Mechanism of $\sigma$-phase precipitation in $\mathrm{Cr}$-Ni austenitic steels," Mater. Sci. Tech, vol. 4, pp. 5-15, 1988.

[148] R. D. Knutsen, C. I. Lang, and J. A. Basson, "Discontinuous cellular precipitation in a Cr-Mn-N steel with niobium and vanadium additions," Acta Mater., vol. 52, no. 8, pp. 2407-2417, 2004.

[149] M. H. Lewis, "Precipitation of ( $\mathrm{Fe}, \mathrm{Cr}$ ) sigma phase from austenite," Acta Metall., vol. 14, no. 001, pp. 1421-1428, 1966.

[150] T. Koutsoukis, A. Redjaïmia, and G. Fourlaris, "Characterization of Precipitation Sequences in Superaustenitic Stainless Steels," Solid State Phenom., vol. 172174, pp. 493-498, 2011.

[151] L. K. Singhal and J. W. Martin, "The formation of ferrite and sigma-phase in some austenitic stainless steels," Acta Metall., vol. 16, no. 12, pp. 1441-1451, 1968.

[152] T. Sourmail, "Precipitation in creep resistant austenitic stainless steels," Mater. 
Sci. Technol., vol. 17, no. January, pp. 1-14, 2001.

[153] J. K. L. Lai and A. Wickens, "Effect of intergranular particle size and spacing on creep ductility of type 316 stainless steel," Scr. Metall., vol. 13, no. 12, pp. 11971198, 1979.

[154] J. K. Lai and A. Wickens, "Microstructural Changes and Variations on Creep Ductility of 3 Casts of Type 316 Stainless Steel," Acta Metal., vol. 27, pp. 217230, 1979.

[155] D. J. Li, Y. Gao, J. L. Tan, F. G. Wang, and J. S. Zhang, "Effect of $\sigma$-phase on the creep properties of Cr25Ni20 Stainless Steel," Scr. Metall., vol. 23, pp. 13191322, 1989.

[156] C. M. F. Rae and R. C. Reed, "The precipitation of topologically close-packed phases in rhenium-containing superalloys," Acta Mater., vol. 49, no. 19, pp. 4113-4125, 2001.

[157] T. H. Lee, H. Y. Ha, B. Hwang, and S. J. Kim, "Isothermal Decomposition of Ferrite in a High-Nitrogen, Nickel-Free Duplex Stainless Steel," Metall. Mater. Trans. A Phys. Metall. Mater. Sci., vol. 43, no. 3, pp. 822-832, 2012.

[158] C. H. Shek, D. J. Li, K. W. Wong, and J. K. L. Lai, "Creep properties of aged duplex stainless steels containing $\sigma$ phase," Mater. Sci. Eng. A, vol. 266, no. 1-2, pp. 3036, 1999.

[159] C. H. Shek, K. W. Wong, J. K. . Lai, and D. J. Li, "Hot tensile properties of $25 \mathrm{Cr}-8 \mathrm{Ni}$ duplex stainless steel containing cellular $(\sigma+\gamma 2)$ structure after various thermal treatments," Mater. Sci. Eng. A, vol. 231, no. 1-2, pp. 42-47, 2002.

[160] S. Nenno, M. Tagaya, and Z. Nishiyama, "Orientation Relationships between Gamma (f.c.c.) and Sigma Phases in an Iron-Chromium-Nickel Alloy," Trans. JIM, vol. 3, no. 2, pp. 82-93, 1962.

[161] J. S. Kasper, "the Ordering of Atoms in the Chi-Phase of the Iron-ChromiumMolybdenum System," Acta Metall., vol. 2, pp. 456-461, 1954.

[162] C. J. McMahon Jr, "ON THE MECHANISMS OF CREEP DAMAGE IN TYPE 316 STAINLESS STEEL," Scr. Metall., vol. 19, pp. 733-737, 1985.

[163] F. Sun, J. Zhang, P. Liu, Q. Feng, X. Han, and S. Mao, "High resolution transmission electron microscopy studies of $\sigma$ phase in Ni-based single crystal superalloys," J. Alloys Compd., vol. 536, pp. 80-84, 2012.

[164] Y. S. Han and S. H. Hong, "The effects of thermo-mechanical treatments on superplasticity of Fe-24Cr-7Ni-3Mo-0.14N duplex stainless steel," Scr. Mater., vol. 36, no. 5, pp. 557-563, 1997.

[165] J. H. Westbrook, Crystal structures of intermetallic compounds. 2000.

[166] M. J. Marcinkowski and D. S. Miller, A study of defect sub-structures in the Fe-Cr sigma phase by means of transmission electron microscopy, vol. 7, no. 78. 1962.

[167] Z. Z. Yuan, Q. X. Dai, X. N. Cheng, and K. M. Chen, "Microstructural thermostability of high nitrogen austenitic stainless steel," Mater. Charact., vol. 
58, no. 1, pp. 87-91, 2007.

[168] D. B. Rayaprolu and A. Hendry, "Cellular precipitation in a nitrogen alloyed stainless steel," Mater. Sci. Technol., vol. 5, no. 4, pp. 328-332, 1989.

[169] D. Sundararaman, P. Shankar, and V. S. Raghunathan, "Electron microscopic study of Cr2N formation in thermally aged 316LN austenitic stainless steels," Metall. Mater. Trans. A Phys. Metall. Mater. Sci., vol. 27, no. 5, pp. 1175-1186, 1996.

[170] J. W. Simmons, "Overview: High-nitrogen alloying of stainless steels," Mater. Sci. Eng. A, vol. 207, pp. 159-169, 1996.

[171] A. Toro, W. Z. Misiolek, and A. P. Tschiptschin, "Correlations between microstructure and surface properties in a high nitrogen martensitic stainless steel," Acta Mater., vol. 51, no. 12, pp. 3363-3374, 2003.

[172] P. A. Carvalho, I. F. Machado, G. Solorzano, and A. F. Padilha, "On Cr2N Precipitation Mechanisms in High Nitrogen Austenite," Philos. Mag., pp. 1-30, 2007.

[173] M. Tałach-dumanska, P. Zieba, A. Pawłowski, J. Wojewoda, and W. Gust, "Practical aspects of discontinuous precipitation and dissolution," Mater. Chem. Phys., vol. 80, pp. 476-481, 2003.

[174] I. G. Solorzano, G. R. Purdy, and G. C. Weatherly, "Studies of the initiation, growth and dissolution of the discontinuous precipitation product in aluminumzinc alloys," Acta Metall., vol. 32, no. 10, pp. 1709-1717, 1984.

[175] H. Azzeddine, S. Abdessameud, B. Alili, Z. Boumerzoug, and D. Bradai, "Effect of grain boundary misorientation on discontinuous precipitation in an AZ91 alloy," Bull. Mater. Sci., vol. 34, no. 7, pp. 1471-1476, 2011.

[176] M. H. Ainsley, G. J. Cocks, and D. R. Miller, "Influence of grain boundary structure on discontinuous precipitation in austenitic steel.pdf," Met. Sci., vol. 13, pp. 2024, 1979.

[177] K. N. Tu and D. Turnbull, "Morphology of Celullar Precipitation of Tin From LeadTin Bicrystals," Acta Metall., vol. 15, no. February, pp. 369-376, 1967.

[178] K. N. Tu and D. Turnbull, "Morphology of Cellular Precipitation of Tin from LeadTin Bicrystals-II," Acta Metall., vol. 15, pp. 1317-1323, 1967.

[179] I. G. Solorzano and M. F. S. Lopes, "Diffusion-induced grain boundary migration as precursor of discontinuous precipitation in Al-Zn alloys," Phase Transform. 87, pp. 242-245, 1988.

[180] D. A. Porter and J. W. Edington, "Microanalysis and cell boundary velocity measurements for the cellular reaction in a Mg-9 \% Al alloy," Proc. R. Soc. London, vol. 358, no. 1694, pp. 335-350, 1977.

[181] R. Fournelle and J. Clark, "The Genesis of the Cellular Precipitation Reaction," Metall. Trans., vol. 3, pp. 2757-2767, 1972.

[182] J. M. Shapiro and J. S. Kirkaldy, "The kinetics of discontinuous precipitation in 
copper-indium alloys," Acta Metall., vol. 16, no. 10, pp. 1239-1252, 1968.

[183] R. A. Fournelle, "Discontinuous coarsening of lamellar cellular precipitate in an austenitic Fe-30 wt\%Ni-6wt.\%Ti alloy-I. Morphology," Acta Metall., vol. 27, no. 7, pp. 1135-1145, 1979.

[184] J. W. Cahn, "The kinetics of cellular segregation reactions," Acta Metall., vol. 7, no. 1 , pp. 18-28, 1959.

[185] D. Turnbull, "Theory of cellular precipitation," Acta Metall., vol. 3, no. 1, pp. 5563, 1955.

[186] H. I. Aaronson and Y. C. Liu, "On the Turnbull and the Cahn Theories of the cellular reaction," Scr. Metall., vol. 2, pp. 1-8, 1968.

[187] B. E. Sundquist, "Cellular precipitation," Metall. Trans., vol. 4, no. 8, pp. 19191934, 1973.

[188] G. R. Purdy and N. Lange, On The Initial Stages of Discontinuous Precipitation Reactions, vol. In: Haasen. .

[189] J. . Clark, "Age hardening in a Mg-9 wt.\% Al alloy," Acta Metallurgica, vol. 16, no. 2. pp. 141-152, 1968.

[190] M. Hillert, "The Role of Interfaces in Phase Transformations," in The mechanism of phase transformations in crystalline solids, 1969, pp. 231-247.

[191] F. Baumann, J. Michael, and D. B. Williams, "Initiation and Growth of the Grain Boundary Discontinuous Precipitation Reaction," Acta Metall., vol. 29, pp. 13431355, 1981.

[192] W. Gust, T. H. Chuang, and B. Predel, Early Stages of Discontinuous Decomposition, no. Dd. Acta Metallurgica Inc., 1984.

[193] R. A. Fournelle, "Discontinuous coarsening of lamellar cellular precipitate in an austenitic Fe-30 wt. \%Ni - 6 wt. \% Ti alloy - II: Growth kinetics," Acta Metall., vol. 27, pp. 1147-1155, 1979.

[194] D. B. Williams and J. W. Edington, "The Discontinuous Precipitation Reaction in Dilute Al-Li Alloys," Acta Metall., vol. 24, no. 4, pp. 323-332, 1976.

[195] W. E. Voice and R. G. Faulkner, "The discontinuous precipitation of M23C6 in Nimonic 80A," J. Mater. Sci., vol. 22, no. 12, pp. 4221-4232, 1987.

[196] A. Carosi et al., "Heating modification of an austenitic steel with high-nitrogen content," Surf. Interface Anal., vol. 42, no. 6-7, pp. 726-729, 2010.

[197] M. Hillert and L. Lagneborg, "Discontinuous Precipitation of M23C6 in Austenitic Steels," J. Mater. Sci., vol. 6, pp. 208-212, 1971.

[198] R. Presser and J. M. Silcock, "Aging behaviour of $18 \mathrm{Mn}-18 \mathrm{Cr}$ high nitrogen austenitic steel for end rings," Met. Sci., vol. 17, no. May, p. 241, 1983.

[199] M. A. Shaikh, M. Iqbal, M. Ahmad, J. I. Akhtar, and K. A. Shoaib, "Precipitation study of heat-treated Incoloy 825 by scanning electron microscopy," J. Mater. Sci. Lett., vol. 11, no. 14, pp. 1009-1011, 1992. 
[200] N. C. S. Srinivas and V. V. Kutumbarao, "Growth mechanism for discontinuous precipitation in a multi-component (Fe-Cr-Mn-N) system," Scr. Mater., vol. 51, no. 11, pp. 1105-1109, 2004.

[201] H. P. Qu, H. T. Chen, C. X. Cao, Y. P. Lang, S. X. Zhang, and Y. Cui, "Mechanism research on accelerated embrittlement phenomenon of a warm-deformed $\mathrm{Cr}$ Mn-Ni-Mo-N austenitic stainless steel," Mater. Sci. Eng. A, vol. 680, no. August 2016, pp. 1-12, 2017.

[202] Q. Shi, N. An, J. Huo, Y. Zheng, and Q. Feng, "Effect of Co on Discontinuous Precipitation Transformation with TCP Phase in Ni-based Alloy Containing Re," Metall. Mater. Trans. A, 2017.

[203] S. M. Payne and P. McIntyre, "Influence of grain boundary microstructure on the susceptibility of alloy 600 to intergranular attack and stress corrosion cracking," Corrosion, vol. 44, May 1, no. 5, pp. 314-319, 1987.

[204] M. H. Ainsley, G. J. Cocks, and D. R. Miller, "The Ageing Characteristics of an Austenitic Fe-13Mn-2V-0.8C alloy," Scr. Metall., vol. 14, pp. 539-543, 1980.

[205] H. Chandra Holm, P. J. Uggowitzer, and M. O. Speidel, "Influence of annealing temperature on the microstructure and mechanical properties of a high nitrogen containing austenitic stainless steel," Scr. Metall., vol. 21, pp. 513-518, 1987.

[206] N. C. S. Srinivas and V. V Kutumbarao, "On The Discontinuous Precipitation of Cr2N in Cr-Mn-N Austenitic Stainless Steels," Scr. Mater., vol. 37, no. 3, pp. 285291, 1997.

[207] E. Ruedl and T. Sasaki, "Phase Instability of Thermally Aged Cr-Mn Austenitic Steels," J. Nucl. Mater., vol. 123, pp. 794-798, 1984.

[208] P. Shankar, D. Sundararaman, and S. Ranganathan, "Cr2N precipitation stages in 316LN austenitic stainless steels," Scr. Metall. Mater., vol. 31, no. 5, pp. 589593, 1994.

[209] N. S. L. Phillips, L. Scott Chumbley, and B. Gleeson, "Phase transformations in cast superaustenitic stainless steels," J. Mater. Eng. Perform., vol. 18, no. 9, pp. 1285-1293, 2009.

[210] J. D. Nystrom, T. M. Pollock, W. H. Murphy, and A. Garg, "Discontinuous cellular precipitation in a high-refractory nickel-base superalloy," Metall. Mater. Trans. $A$, vol. 28, no. 12, pp. 2443-2452, 1997.

[211] A. W. Funkenbusch, "Discontinuous $\gamma^{\prime}$ Coarsening in a Ni-Al-Mo Base Superalloy," Metallurgical Trans., vol. 14A, pp. 1283-1292, 1983.

[212] A. W. Funkenbusch, T. A. Stephenson, G. Mccarthy, and H. Fraser, "Driving Force for Discontinuous Coarsening in a Ni-Al-Mo Base Superalloy," Metall. Trans. A, vol. 16A, pp. 11-16, 1985.

[213] T. M. Pollock, "The growth and elevated temperature stability of high refractory nickel-base single crystals," Mater. Sci. Eng. B, vol. 32, no. 3, pp. 255-266, 1995.

[214] S. Tin and T. M. Pollock, "Phase instabilities and carbon additions in single-crystal nickel-base superalloys," Mater. Sci. Eng. A, vol. 348, no. 1-2, pp. 111-121, 2003. 
[215] L. Zhuo, M. Huang, F. Wang, J. Xiong, J. Li, and J. Zhu, "Kinetics of cellular discontinuous precipitation in a Re-containing single crystal superalloy," Mater. Lett., vol. 139, pp. 232-236, 2015.

[216] N. D. Souza et al., "Microstructure Instability of Ni-Base Single Crystal Superalloys During Solution Heat Treatment," Superalloys 2016 Proc. ofthe 13th Int. Symp. Superalloys, pp. 267-277, 2016.

[217] A. Heckl, S. Neumeier, S. Cenanovic, M. Göken, and R. F. Singer, "Reasons for the enhanced phase stability of Ru-containing nickel-based superalloys," Acta Mater., vol. 59, no. 17, pp. 6563-6573, 2011.

[218] R. B. Scarlin, "Discontinuous precipitation in a directionally solidified nickel base alloy," Scr. Metall., vol. 10, pp. 711-715, 1976.

[219] W. Walston, J. Schaeffer, and W. Murphy, "A new type of microstructural instability in superalloys - SRZ," Superalloys 1996, pp. 9-18, 1996.

[220] D. B. Williams and C. B. Carter, Transmission Electron Microscopy - A Textbook for Materials Science, $2^{\mathrm{a}}$ ed. New York: Springer, 2009.

[221] R. Haynes, Optical Microscopy of Materials. 2013.

[222] J. I. Goldstein et al., Scanning Electron Microscopy and X-Ray Microanalysis, $2^{\mathrm{a}}$ ed. New York: Plenum Press, 1992.

[223] T. B. Britton et al., "Tutorial: Crystal orientations and EBSD - Or which way is up?," Mater. Charact., vol. 117, pp. 113-126, 2016.

[224] A. J. Wilkinson and T. Ben Britton, "Strains, planes, and EBSD in materials science," Mater. Today, vol. 15, no. 9, pp. 366-376, 2012.

[225] V. Randle, "Electron backscatter diffraction: Strategies for reliable data acquisition and processing," Mater. Charact., vol. 60, no. 9, pp. 913-922, 2009.

[226] S. J. Pennycook et al., "Scanning Transmission Electron Microscopy for Nanostructure Characterization," in Scanning Microscopy for Nanotechnology, 2006, pp. 152-191.

[227] S. Lartigue and L. Priester, "Stability of extrinsic grain boundary dislocations in relation with intergranular segregation and precipitation," Acta Metall., vol. 31, no. 11, pp. 1809-1819, 1983.

[228] K. Kaneko et al., "Formation of M23C6-type precipitates and chromium-depleted zones in austenite stainless steel," Scr. Mater., vol. 65, no. 6, pp. 509-512, 2011.

[229] M. A. Mangan, M. V. Kral, and G. Spanos, "Correlation between the crystallography and morphology of proeutectoid Widmanstätten cementite precipitates," Acta Mater., vol. 47, no. 17, pp. 4263-4274, 1999.

[230] M. G. Burke, G. Bertali, E. Prestat, F. Scenini, and S. J. Haigh, "The application of in situ analytical transmission electron microscopy to the study of preferential intergranular oxidation in Alloy 600," Ultramicroscopy, vol. 176, no. November, pp. 46-51, 2017.

[231] B. Langelier, S. Y. Persaud, A. Korinek, T. Casagrande, R. C. Newman, and G. A. 
Botton, "Effects of boundary migration and pinning particles on intergranular oxidation revealed by 2D and 3D analytical electron microscopy," Acta Mater., vol. 131, pp. 280-295, 2017.

[232] G. Bertali, F. Scenini, and M. G. Burke, "The effect of residual stress on the Preferential Intergranular Oxidation of Alloy 600," Corros. Sci., vol. 111, 2016.

[233] Z. Shen, M. Meisnar, K. Arioka, and S. Lozano-Perez, "Mechanistic understanding of the temperature dependence of crack growth rate in alloy 600 and 316 stainless steel through high-resolution characterization," Acta Mater., vol. 165, pp. 73-86, 2019.

[234] G. Bertali, F. Scenini, and M. G. Burke, "Advanced microstructural characterization of the intergranular oxidation of Alloy 600," Corros. Sci., vol. 100, pp. 474-483, 2015.

[235] D. N. Yoon, M. F. Henry, and M. R. Jackson, "Precipitation induced grain boundary migration in austenitic alloys," Int. Congr. Intergranular Interphase Boundaries Mater., no. 1, pp. 721-726, 1990.

[236] F. J. A. Den Broeder, "Interface reaction and a special form of grain boundary diffusion in the Cr-W system," Acta Metall., vol. 20, no. 3, pp. 319-332, 1972.

[237] R. W. Balluffi and J. W. Cahn, "Mechanism for diffusion induced grain boundary migration," Acta Metall., vol. 29, no. 3, pp. 493-500, 1981.

[238] Mats Hillert and Gary R. Purdy, "Chemically Induced Grain Boundary Migration," Acta Metall., vol. 26, pp. 333-340, 1978.

[239] J. W. Cahn, J. D. Pan, and R. W. Balluffi, "Diffusion Induced Grain Boundary Migration," Scr. Metall., vol. 13, pp. 503-509, 1979.

[240] L. Volpe, M. G. Burke, and F. Scenini, "Understanding the Role of Diffusion Induced Grain Boundary Migration on the Preferential Intergranular Oxidation Behaviour of Alloy 600 via Advanced Characterization," Acta Mater., vol. 175, pp. 238-249, 2019.

[241] S. Y. Persaud, B. Langelier, A. Korinek, R. C. Newman, and G. A. Botton, "Characterization of Initial Intergranular Oxidation Processes in Alloy 600 at a Sub-nanometer Scale," Manuscr. Submitt. Publ., no. April 2017, pp. 0-1, 2016.

[242] V. G. . Gavriljuk and H. Berns, High Nitrogen Steels Structure, Properties, Manufacture, Applications.pdf. 1999.

[243] E. Folkhard, G. Rabensteiner, E. Perteneder, H. Schabereiter, and J. Tosch, Welding Metallurgy of Stainless Steels In collaboration with. 1988.

[244] G. Sasikala, S. K. Ray, and S. L. Mannan, "Kinetics of transformation of delta ferrite during creep in a type 316(N) stainless steel weld metal," Mater. Sci. Eng. A, vol. 359, no. 1-2, pp. 86-90, 2003.

[245] V. Randle, "The Measurement of Grain Boundary Geometry," Aust. J. Entomol., 1994.

[246] V. Randle, H. Davies, and I. Cross, "Grain boundary misorientation distributions," 
Curr. Opin. Solid State Mater. Sci., vol. 5, no. 1, pp. 3-8, 2001.

[247] R. Monzen, C. Watanabe, D. Mino, and S. Saida, "Initiation and growth of the discontinuous precipitation reaction at [ $\left[\begin{array}{lll}0 & 1 & 1\end{array}\right]$ symmetric tilt boundaries in $\mathrm{Cu}-\mathrm{Be}$ alloy bicrystals," Acta Mater., vol. 53, no. 4, pp. 1253-1261, 2005.

[248] N. Boonyachut and D. E. Laughlin, "Influence of boundary structure on cellular nucleation in Cu-3 w/oTi age-hardening alloys," J. Mater. Sci., vol. 44, no. 2, pp. 449-456, 2009.

[249] S. Hirth and G. Gottstein, "Misorientation effects on discontinuous precipitation in Al-Ag-Ga," Acta Mater., vol. 46, no. 11, pp. 3975-3984, 1998.

[250] R. Wirth and H. Gleiter, "Is discontinuous (cellular) precipitation an effect of a structural transformation in the migrating phase boundary?," Acta Metall., vol. 29, no. 11, pp. 1825-1830, 1981.

[251] I. Manna, S. K. Pabi, and W. Gust, "Initiation sites for discontinuous precipitation in some Cu-base alloys," J. Mater. Sci., vol. 26, pp. 4888-4892, 1991.

[252] D. Wang, F. Ernst, H. Kahn, and A. H. Heuer, "Cellular precipitation at a 17-7 PH stainless steel interphase interface during low-temperature nitridation," Metall. Mater. Trans. A, vol. 45, pp. 3578-3585, 2014.

[253] F. Shi, Y. Qi, and C. Liu, "Effects of Mo on the Precipitation Behaviors in HighNitrogen Austenitic Stainless Steels," J. Mater. Sci. Technol., vol. 27, no. 12, pp. 1125-1130, 2011.

[254] M. Kajihara, M. Kikuchi, and S. K. Choi, "Cellular precipitation of Cr2N in chromium-nickel austenitic steels," Proc. Int. Conf Phase Transform. 1987, p. 265, 1988.

[255] M. Hillert, "On theories of growth during discontinuous precipitation," Metall. Trans., vol. 3, no. 11, pp. 2729-2741, 1972.

[256] M. Hillert, "An improved Model for Discontinuous Precipitation," Acta Metall., vol. 30, pp. 1689-1696, 1982.

[257] B. A. Dedavid, C. I. Gomes, and G. Machado, "Microscopia Eletrônica de Varredura - Aplicação e preparação de amostras." p. 60, 2007. 


\section{Apêndice}

\subsection{Publicações Geradas a partir da presente tese de doutorado}

1 J.C. Spadotto, M. Watanabe, and I.G. Solórzano, "AEM Study of Grain Boundary Precipitation Phenomena in Alloy 33 (Cr-Fe-Ni-N) Resulting from the Direct-Aging at $700^{\circ} \mathrm{C}$," Proc. of Microscopy and Microanalysis, vol. 22, S3, pp. 2010-2011, 2016.

2 J.C. Spadotto, M. Watanabe, J. Dille, and I. G. Solórzano, "Phase identification of complex grain boundary precipitation in a high $\mathrm{Cr}$ and $\mathrm{Ni}$ superalloy upon direct-aging," Proc. European Microscopy Congress 2016 Proc., pp. 756757, 2016.

3 J.C. Spadotto and I. G. Solorzano, "DIGM Phenomenon as Precursor of DP Reaction in a High Cr-Ni Corrosion-Resistant Alloy," Proc. of Microscopy and Microanalysis, Vol. 24, S1, pp. 2260-2261, 2018.

4 J.C. Spadotto, J. Dille, M. Watanabe, and I. G. Solórzano, "Grain boundary precipitation phenomena in an alloy $33(\mathrm{Cr}-\mathrm{Fe}-\mathrm{Ni}-\mathrm{N})$ subjected to direct-aging treatments $\left(700^{\circ} \mathrm{C}\right.$ and $\left.900^{\circ} \mathrm{C}\right)$ ", Materials Characterization, vol. 140, pp. 113-121, 2018.

5 J.C. Spadotto, M.G. Burke, I.G. Solórzano, "Discontinuous Precipitation of $\alpha$ $\mathrm{Cr}$ Phase in Alloy 33 (Cr-Fe-Ni-N)", Proc. of Microscopy and Microanalysis, Vol. 25, S2, pp. 2650-2651, 2019. 